\title{
LAS ESPECIES DE BURSERA (BURSERACEAE) EN LA CUENCA SUPERIOR DEL RÍO PAPALOAPAN (MÉXICO)*
}

\author{
JeRZY RZEDOWSKI \\ Instituto de Ecología, A.C., Centro Regional del Bajío \\ Apartado postal 386, 61600 Pátzcuaro, Michoacán
}

Rosalinda Medina Lemus

Instituto de Biología, Universidad Nacional Autónoma de México

Apartado postal 70-233, 04510 México, D.F.

Graciela Calderón de Rzedowski

Instituto de Ecología, A.C., Centro Regional del Bajío

Apartado postal 386, 61600 Pátzcuaro, Michoacán

\section{RESUMEN}

La cuenca superior del Papaloapan se define en el presente trabajo como la porción suroccidental de esta región hidrográfica ubicada por encima de la cota altitudinal de $400 \mathrm{~m}$ y abarca un territorio de alrededor de $21,000 \mathrm{~km}^{2}$, repartido entre los estados de Oaxaca, Puebla y Veracruz.

Con base en el estudio de más de 900 ejemplares de Bursera, procedentes de la comarca, se define la existencia de 21 especies, de las que dos (B. graveolens (H.B.K.) Tr. \& Planch. y $B$. hintonii Bullock) no se conocían previamente de la zona, una cambia de nombre ( $B$. linanoe (La Llave) comb. nova, en lugar de $B$. aloexylon (Schiede ex Schltdl.) Engl. y tres ( $B$. altijuga, $B$. esparzae y $B$. pontiveteris, todas pertenecientes a la sección Bullockia) se describen como nuevas. Se designa asimismo el lectotipo de $B$. submoniliformis Engl. y el neotipo de Amiris linanoe La Llave.

Se presenta una clave para la identificación de las especies y se proporcionan sus descripciones, sinonimias, ilustraciones y mapas de distribución, además de la información sobre nombres comunes y usos locales, así como la correspondiente a las afinidades ecológicas. Se discuten también brevemente algunos aspectos fitogeográficos.

Se incluye por otra parte un resumen histórico del desarrollo del conocimiento taxonómico de Bursera y de sus complejidades nomenclaturales.

Palabras clave: Bursera, Burseraceae, cuenca del Papaloapan, México.

\footnotetext{
* Trabajo realizado con apoyo económico del Instituto de Ecología, A.C. (cuenta 902-07), del Consejo Nacional de Ciencia y Tecnología, así como de la Comisión Nacional para el Conocimiento y Estudio de la Biodiversidad.
} 


\section{ABSTRACT}

The upper Papaloapan river basin is defined in this paper as the southwestern part of this hydrologic region situated above the $400 \mathrm{~m}$ contour line, thus embracing an area of approximately $21,000 \mathrm{~km}^{2}$, shared between the Mexican states of Oaxaca, Puebla and Veracruz.

On the basis of a study of more than 900 collections of Bursera from the region, the existence of 21 species is documented. Two of these (B. graveolens (H.B.K.) Tr. \& Planch. and $B$. hintonii Bullock) were previously unreported from the area. For one species the name $B$. linanoe (La Llave) comb. nova is proposed as legitimate for the plant known as $B$. aloexylon (Schiede ex Schltdl.) Engl. Three additional species (B. altijuga, B. esparzae and $B$. pontiveteris, all belonging to the section Bullockia)) are described as new. A lectotype is also designated for $B$. submoniliformis Engl., as well as a neotype for Amiris linanoe La Llave.

An identification key is provided for all the species, as well as descriptions, synonymy, illustrations, distribution maps and information concerning local names, uses and ecological preferences. A brief phytogeographical discussion is also given.

In addition, a summary of the taxonomic history of Bursera, including its nomenclatural complexities, is provided.

Key words: Bursera, Burseraceae, Mexico, Papaloapan river basin.

\section{INTRODUCCIÓN}

La idea de conocer las especies de Bursera de la cuenca del Papaloapan, nació a raíz de varias visitas realizadas a la región en la década de los años setentas, cuando comenzó a construirse la carretera directa de Tehuacán a Oaxaca, estando dos de los autores adscritos a la Escuela Nacional de Ciencias Biológicas del Instituto Politécnico Nacional.

Con tal propósito Héctor Arroyo Frías y Francisco Ventura Aburto, estuvieron acumulando en forma intensiva materiales de herbario del género en 1978 y 1979.

Infortunadamente, la presión de otras tareas más urgentes vino a interrumpir el seguimiento del estudio por más de 20 años. A su vez, en el transcurso de este intervalo el Instituto de Biología de la Universidad Nacional Autónoma de México decidió iniciar la elaboración de la Flora del Valle de Tehuacán - Cuicatlán y en conexión con ello promovió un importante esfuerzo de muestreo botánico a lo largo y ancho de la comarca. En la labor destacaron sobre todo Pedro Tenorio Lezama y Antonio Salinas Tovar, quienes en conjunto contribuyeron con alrededor de 10,000 colectas.

Tomando como base el acervo así totalizado y que junto con los especímenes de otros botánicos, está sumando más de 900 números de Bursera de esta porción de México, en 2002 decidimos dar los pasos necesarios para redondear la integración del estudio.

No se insistió ya en una búsqueda intensiva, pero mediante varias visitas a la región se procuró completar materiales de las especies insuficientemente 
representadas en los herbarios, de resolver al máximo posible las dudas surgidas a raíz de la revisión de los ejemplares, y de definir mejor la fenología, la ubicación ecológica, así como la distribución geográfica de los taxa involucrados.

El examen crítico reveló la presencia de 21 especies de Bursera, cuyos pormenores se dan a conocer en la parte medular de la contribución.

\section{ÁREA DE ESTUDIO}

La cuenca del río Papaloapan corresponde a una porción del territorio de la República, localizada en la vertiente del Golfo de México, en la cercanía y del lado occidental del Istmo de Tehuantepec. Fig.1.

En sentido amplio, incluye también la (sub)cuenca del río Blanco, misma que, al igual que el Papaloapan, desemboca en la laguna costera de Alvarado. Abarca un área aproximada de $46,500 \mathrm{~km}^{2}$, participando su territorio de tres provincias fisiográficas: a) las Sierras Septentrionales de Oaxaca que, junto con el Valle de Tehuacán y las montañas adyacentes, cubren cerca de la tercera parte de la superficie total; b) una pequeña fracción del Eje Volcánico Transversal, ubicada del Pico de Orizaba hacia el sur y compartida entre los estados de Puebla y Veracruz; c) la Planicie Costera del Golfo, que corresponde mayormente al estado de Veracruz, pero incluye áreas vecinas del norte de Oaxaca y se extiende por un poco más de la mitad de la cuenca del Papaloapan.

Para los propósitos de la presente contribución se excluye su parte baja y plana, o sea la correspondiente a la Planicie Costera, fijando el límite oriental del área en la cota de $400 \mathrm{~m}$ s.n.m. De esta manera restringida, la región abarca alrededor de $21,000 \mathrm{~km}^{2}$ con terrenos de topografía en su mayor parte sumamente accidentada. Constituye una faja alargada en dirección NW-SE, de cerca de $280 \mathrm{~km}$ de largo y de $75 \mathrm{~km}$ de ancho en promedio. Sus coordenadas extremas son $16^{\circ} 56^{\prime}$ y $19^{\circ} 03^{\prime} \mathrm{N}, 95^{\circ} 42^{\prime}$ y $97^{\circ} 52^{\prime} \mathrm{W}$.

En su labor erosiva ascendente, uno de los principales afluentes del Papaloapan, el río Santo Domingo socavó la cadena montañosa del norte de Oaxaca y capturó comarcas situadas en el sotavento de la misma, con toda probabilidad anteriormente tributarias de la cuenca del Balsas. Una parte importante de esta franja la constituye el Valle de Tehuacán - Cuicatlán, la zona más seca del sur de México, aislada del gran conjunto de áreas de tierras áridas del norte y centro del país, y que destaca por una flora rica en endemismos y en formas biológicas espectaculares. La porción oaxaqueña de este sector se conoce con frecuencia como la región de La Cañada y en algunos mapas se le denomina Cañón de Tomellín, ambos nombres haciendo alusión a su particular configuración topográfica.

En su conjunto la cuenca superior del Papaloapan es un área montañosa, profundamente disecada por corrientes fluviales, con varias cadenas elevadas a más de 2500 y en algunas partes a más de $5000 \mathrm{~m}$ de altitud, separadas entre sí por depresiones que descienden a menudo a menos de $1000 \mathrm{~m}$ sobre el nivel 


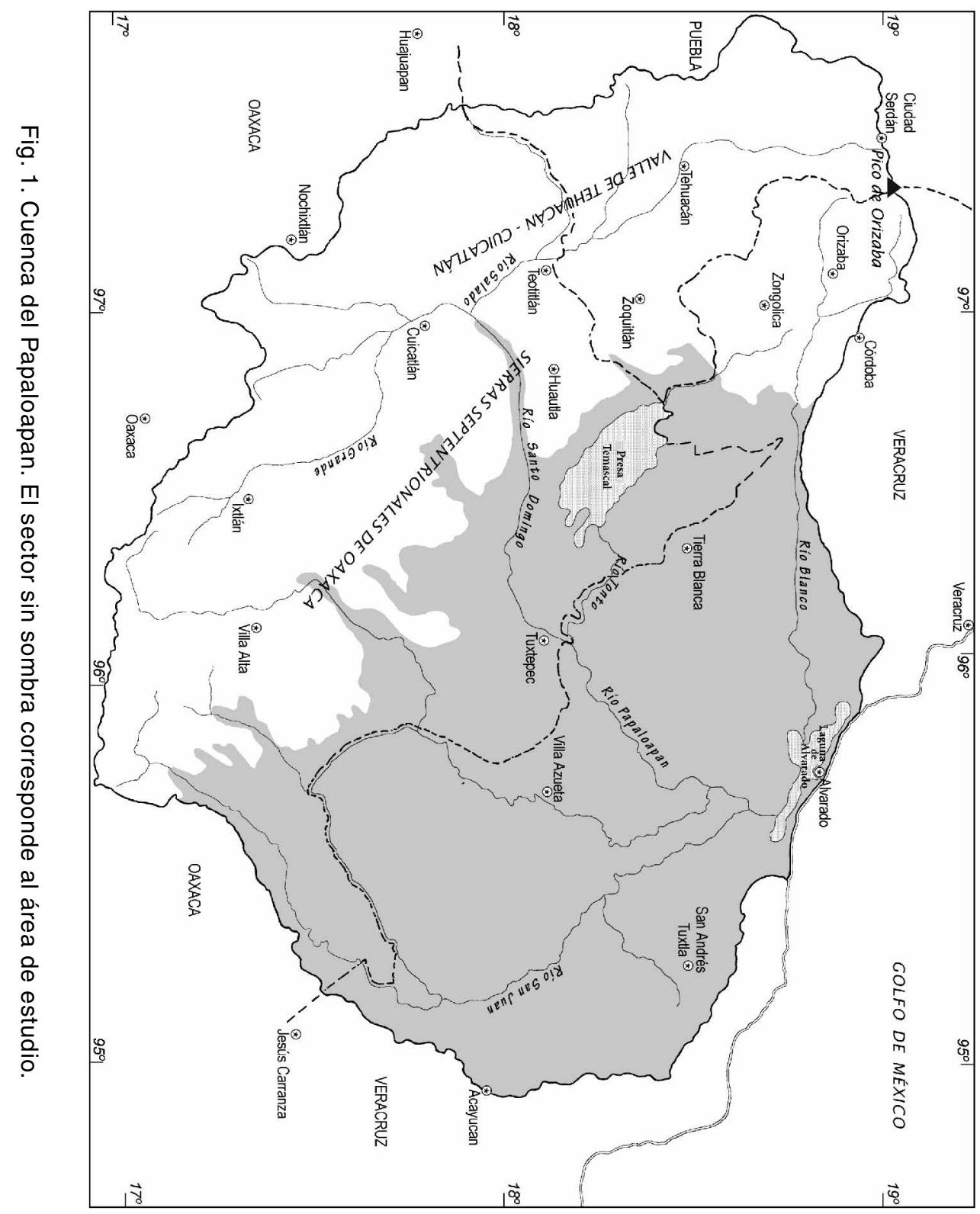


del mar. El sustrato geológico se manifiesta a manera de un complejo mosaico de rocas metamórficas del Precámbrico y Paleozoico (principalmente gneiss y esquistos), sedimentarias marinas del Cretácico (mayormente calizas) y en menor proporción marinas y continentales del Jurásico y Triásico (limonitas y areniscas) así como volcánicas, (preferentemente andesitas) y sedimentarias continentales (areniscas y conglomerados) del Cenozoico.

Dado el escarpado relieve, el clima ofrece también una extraordinaria diversidad. Así, mientras en Cuicatlán (a 500 m s.n.m.) la temperatura media anual es del orden de $26^{\circ} \mathrm{C}$ y la mínima extrema difícilmente desciende de $0^{\circ} \mathrm{C}$, en Cuajimoloyas (a $3200 \mathrm{~m}$ s.n.m.), es de alrededor de $9^{\circ} \mathrm{C}$ y las heladas se presentan en la mayor parte de los meses del año; a su vez las porciones más altas del Pico de Orizaba se mantienen cubiertas de nieve perpetua. En cuanto a la precipitación, el promedio anual en algunas localidades de la región de Tehuacán es de aproximadamente $400 \mathrm{~mm}$ (Lomas, 1998; Ochoa, 2001), concentrada mayormente en 5 meses, mientras que en Huautla de Jiménez excede de $2500 \mathrm{~mm}$, y en algunas otras localidades del barlovento es superior a $5500 \mathrm{~mm}$ con todo el año húmedo. Siguiendo la clasificación de Koeppen, los climas de la región de estudio se ubicarían en las categorías Af, Am, Aw, Cf, Cw, ET, BS y BW.

En correspondencia con lo anterior, la variedad de la cubierta vegetal del área es igualmente impresionante. A continuación se hará referencia a las comunidades mejor representadas y que corresponden sin duda al clímax climático o edáfico.

Del lado húmedo descuellan el bosque tropical perennifolio y el bosque mesófilo de montaña en sus diversas facetas. En los sectores de clima fresco suelen predominar bosques de coníferas y encinares con numerosas variantes florísticas y fisonómicas. En las porciones elevadas del Pico de Orizaba, por encima del límite de la vegetación arbórea, prospera un zacatonal alpino o páramo de altura.

Las laderas inferiores (principalmente entre 500 y 1500 m de altitud) de las depresiones labradas por los cañones de los ríos del lado de sotavento de las sierras, están mayormente cubiertas por el bosque tropical caducifolio, también representado por varias comunidades florísticamente diferentes.

Las zonas más secas de la cuenca superior del Papaloapan se caracterizan principalmente por la presencia de diferentes tipos de matorral xerófilo, de los que algunos son muy notorios debido a la abundancia de grandes cactáceas columnares o candelabriformes. A su vez, la cubierta vegetal original de las zonas con suelos aluviales profundos (abundantes en el Valle de Tehuacán) en la mayor parte de los casos ha sufrido modificaciones drásticas, pero sus vestigios indican que principalmente consistía de un bosque espinoso (mezquital). En cambio, en altitudes superiores a $2000 \mathrm{~m}$ y en los escasos lugares donde el relieve no es muy accidentado, se registra la existencia de pastizales, de los que algunos aparentan representar la vegetación clímax.

El estado de conservación de la cubierta vegetal es igualmente heterogéneo. Las más perturbadas son las áreas en que la población humana es densa, como es el caso de la mayor parte de la fracción veracruzana, así como de las regiones mazateca, mixteca, zapoteca y mixe de Oaxaca, y también de las porciones menos 
escarpadas del Valle de Tehuacán. En otras comarcas la situación es variable, pero por fortuna existen todavía considerables extensiones con vegetación poco modificada en prácticamente todas sus modalidades.

Los datos anteriores indican que la cuenca superior del Papaloapan es el sector ecológicamente más diverso de México y con toda seguridad lo es también desde el punto de vista florístico. Aunque no existe ni siquiera una aproximación al inventario global, una estimación conservadora ubicaría esta riqueza en el orden de 6000 especies de plantas vasculares, o sea cerca de la tercera parte de la cantidad calculada para todo el país.

El área incluye o participa de dos parques nacionales, los correspondientes al Pico de Orizaba y al Cañón del río Blanco, así como de una reserva de la biósfera: la del Valle de Tehuacán - Cuicatlán. Dadas todas sus características especiales, sería deseable, apropiado y oportuno extender la franja de protección definitiva a toda la superficie de la cuenca superior del río Papaloapan.

\section{DATOS GENERALES RELATIVOS AL GÉNERO BURSERA}

Bursera agrupa más de un centenar de especies de plantas leñosas, cuya distribución se restringe al continente americano, en particular a la mitad septentrional de su porción intertropical, pues se extiende desde los extremos suroeste y sureste de los Estados Unidos hasta el norte de Perú y de Brasil, incluyendo las Antillas y las Galápagos.

Su centro de diversidad se localiza en México, de donde hasta la fecha se conocen unas 80 especies más o menos claramente definidas, aunque todavía queda un amplio contingente por descubrir, por estudiar y por describir, de suerte que el total real del grupo en nuestro país posiblemente sobrepase las 100 entidades.

Los representantes de Bursera son mayormente árboles o algunas veces arbustos, de hoja decidua, que constituyen un elemento característico y no pocas veces dominante o codominante de los bosques tropicales caducifolios de México, donde habitan preferentemente en altitudes entre 0 y $1800 \mathrm{~m}$. Solamente una especie, $B$. simaruba, llega a ser componente de ambientes más húmedos y puede prosperar en bosques tropicales subcaducifolios y perennifolios. Varias prosperan en matorrales xerófilos y algunas llegan a ascender a elevaciones cercanas a 2400 m s.n.m., penetrando en ocasiones a áreas transicionales con bosques de encino y de coníferas. Dadas estas afinidades ecológicas, la mayor diversidad de las especies mexicanas de Bursera se establece en la vertiente pacífica de la República, con su máxima concentración en la cuenca del río Balsas (Rzedowski y Kruse, 1979).

A pesar de los esfuerzos de varias generaciones de botánicos, el avance en el conocimiento taxonómico de los componentes de Bursera ha sido lento y dista aún mucho de ser satisfactorio. Tal circunstancia obedece al efecto sumario de varios factores, entre los cuales destacan los siguientes. 
1. Las plantas son casi siempre dioicas o polígamo-dioicas y florecen por lo general antes o al mismo tiempo que van apareciendo las hojas tiernas. Este hecho ha sido la causa de que durante muchos años la representación de las especies de Bursera en los herbarios ha sido en exceso fragmentaria. De ahí resulta que un considerable número de taxa ha sido nombrado y publicado varias veces, pues se carecía de apreciaciones globales y descripciones completas. A su vez, es evidente también que no pocas especies tardaron (y siguen tardando) en darse a conocer, porque no se cuenta con el material suficiente y adecuado para su cabal definición.

2. Una elevada proporción de las especies son plantas de distribución geográfica restringida y sus primeras colectas apenas se están realizando ahora con la exploración más intensa del territorio del país.

3. En muchos casos se carece de buenas características de flores y frutos para separar las especies, por lo que el arreglo taxonómico propuesto descansa fuertemente en la morfología de las hojas. Con frecuencia, sin embargo, el desconocimiento de los alcances de la variación de numerosos rasgos foliares ha sido la causa de una equivocada delimitación de los taxa.

4. Dentro del género se distinguen varios complejos (como por ejemplo, el grupo de $B$. simaruba, el de $B$. fagaroides y el de $B$. excelsa), en los que la separación de las especies mediante caracteres morfológicos de uso tradicional resulta particularmente difícil. Estos conjuntos necesitan de estudios profundos consistentes por una parte de una buena caracterización de las poblaciones naturales, así como también del apoyo quimiotaxonómico fino y molecular, tendiente a apreciar diferencias a nivel del genoma.

5. Todas las especies de Bursera producen aceites escenciales del grupo de los terpenos, que a menudo proporcionan a las plantas intensos y variados aromas al estrujarse. Tales aromas permiten por lo general en el campo separar claramente entre sí las diversas especies que conviven en una determinada localidad. Sin embargo, un amplio estudio llevado a cabo mediante la cromatografía de gases ha mostrado que la presencia y la cuantía de los diferentes terpenos a menudo varía más entre las poblaciones de la misma especie que entre los diferentes taxa del género.

6. Aunque la hibridación entre las especies de Bursera, no parece ser un fenómeno demasiado frecuente, la existencia de individuos con rasgos intermedios, así como los fenómenos de introgresión genética, no pocas veces oscurecen una clara distinción entre los taxa.

\section{BREVE RESEÑA HISTÓRICA DE LA SISTEMÁTICA Y NOMENCLATURA DE BURSERA}

Probablemente la noticia inicial de índole científica sobre una especie de este género corresponde al "tzihuaccopalli", cuyo dibujo aparece en el manuscrito comúnmente conocido como "Códice Badiano", realmente elaborado por el médico 
azteca de la Cruz (1552). Años después, Hernández (1651) proporcionó información e ilustraciones de al menos nueve representantes mexicanos del grupo.

Dentro del contexto del actual sistema de nomenclatura, la primera especie de Bursera se describió en 1753. Sin embargo, el proceso de una apropiada distinción y circunscripción del género dilató cerca de otros 100 años, y aunque en este último lapso la mayor parte de las novedades se describieron como binomios de Elaphrium, otras se dieron a conocer en calidad de miembros de Amyris, Bursera, Fagara, Icica, Pistacia, Schinus, Spondias y Terebinthus.

Kunth (1825, pp. 23-25) estableció y definió las Burseraceae como familia compuesta de 11 géneros, entre los cuales distinguió a Bursera y a Elaphrium. Usando exclusivamente este último nombre, describió seis especies mexicanas y dos sudamericanas, con base en colectas realizadas por A. Humboldt y A. Bonpland.

Se debe a Schlechtendal (1842-1843), el primer trabajo de integración de la información hasta la fecha conocida acerca del conjunto que nos ocupa, determinando su alcance y distribución geográfica. Este autor reconoció 22 especies, todas americanas, de las que ocho describió como nuevas, básicamente a partir de las colectas realizadas por C. J. W. Schiede en México. Siguiendo a Kunth, conservó la distinción de Bursera (como género monotípico) y de Elaphrium (para las restantes especies), vaticinando su futura unión.

Tal conjunción fue planteada por Hooker (1862), quien dentro del inclusivo género Bursera ubicó cuatro subgéneros: Bursera, Elaphrium, Icica y Marignia. Triana y Planchon (1872) confirmaron la situación subgenérica de los dos primeros, pero excluyeron a los restantes, regresando al concepto sugerido por Schlechtendal, mismo que se ha estado siguiendo desde entonces sólo con algunos cambios menores.

El estudio monográfico inicial de Bursera se debe a Engler (1883), quien revisó la sistemática de toda la familia para la obra Monographiae Phanerogamarum de De Candolle. El mencionado autor nunca había visitado América tropical y su trabajo lo basó en el examen del material acumulado en los principales herbarios europeos. Reconoció para México 30 especies del total de 39 distinguidas para entonces.

En el marco de la integración de North American Flora, Rose (1911) se abocó al tratado de las especies de Burseraceae de esta parte del continente, fundamentado escencialmente en acervos existentes de los herbarios estadounidenses. No pudo ver los tipos conservados en Europa, pero tuvo la oportunidad de visitar y colectar en varios sectores de México, incluyendo localidades de la región de este estudio. Reconoció, bajo el nombre genérico de Elaphrium, un total de 77 especies, de las que 23 fueron descritas por él mismo.

Standley (1923), en sus "árboles y arbustos de México" adoptó en términos generales el esquema y los binomios de Rose, aunque redujo algunos de sus nombres a sinonimia y aceptó 42 especies para el país.

De fundamental importancia resultó ser la contribución de Bullock (1936), quien pudo contar con amplios materiales muestreados en diferentes estados fenológicos, incluyendo flores de ambos sexos, colectados en la cuenca del Balsas 
por G. B. Hinton. Tuvo también a su disposición los tipos de la mayor parte de los herbarios europeos y norteamericanos. Bullock reconoció o al menos insinuó la existencia de dos conjuntos discretos en el género: el de las plantas con frutos bivalvados y el de las que desarrollan frutos trivalvados y por primera vez pudo elaborar una clave sencilla y relativamente fácil de usar para 36 de las 41 entidades mexicanas que incluyó en su trabajo. Sin embargo, en gran contraste con Rose, quien exageró en la multiplicación de nombres de especies, Bullock se excedió en su sumisión a la sinonimia.

McVaugh y Rzedowski (1965) confirmaron la trascendencia de la deducción de Bullock, pues en efecto el género es separable en dos grandes grupos naturales, reconocidos por la gente de campo de muchas partes del país, respectivamente bajo los nombres de "cuajiotes" (plantas de ovario trilocular, fruto trivalvado y tronco casi siempre con corteza exfoliante) y de "copales" (plantas con ovario bilocular, fruto bivalvado y tronco por lo general con corteza no exfoliante). Para englobar a estos últimos, los citados autores formalizaron la sección Bullockia, quedando ubicados los primeros en la sección típica Bursera. Definieron asimismo para el occidente de México la existencia de 34 especies del género, acomodándolas tentativamente en 11 grupos informales.

Rzedowski y Kruse (op. cit.) esbozaron algunas tendencias evolutivas en Bursera y al considerar las semejanzas entre la sección Bullockia y el género Commiphora, así como las existentes entre la sección típica y el género Boswellia, plantearon la posibilidad de que Bursera representase un conjunto difilético.

Paralelamente, al evaluar las diferencias entre las secciones Bursera y Bullockia, Gillett (1979) opinó que éstas son suficientemente significativas para considerar los dos grupos como géneros o al menos subgéneros distintos. En ambos casos el nombre Elaphrium tendría preferencia sobre el de Bullockia. El mencionado autor transfirió asimismo la especie sudamericana Bursera leptophloeos al género Commiphora.

Toledo Manzur (1982) inventarió y ubicó ecológicamente a 49 taxa de Bursera en el estado de Guerrero.

Suárez Ramos y Engleman (1982), así como Gómez-Vázquez y Engleman (1984) estudiaron la anatomía de la corteza de $B$. grandifolia, de $B$. longipes (de la sección Bursera) y de B. copallifera (de la sección Bullockia), observando ligeras diferencias entre los dos conjuntos. Así, en la última faltan las fibras en el floema, presentes en las dos primeras.

Palacios Chávez (1984) investigó la morfología del polen de 48 especies mexicanas de Bursera, revelando la existencia de dos patrones esencialmente diferentes, uno correspondiente a 46 de las especies en cuestión (incluyendo representantes tanto de la sección Bursera como de Bullockia) y otro propio solamente de B. sarcopoda P. G. Wilson y de B. tecomaca (DC.) Standl. Consecuentemente Rzedowski y Palacios Chávez (1985) transfirieron a estas últimas al género Commiphora.

Johnson (1992) reconoció 10 especies de Bursera como componentes de la flora del estado de Sonora. 
Daly (1993) proporcionó una clave y definió la distribución geográfica conocida de las siete especies del mismo género que existen en Sudamérica.

Becerra y Venable (1999), así como posteriormente Becerra (2003) se abocaron a investigar las relaciones filogenéticas de los representantes mexicanos de Bursera mediante el análisis de secuencias de nucleótidos de ADN ribosomal de 66 especies y variedades. Sus resultados más significativos señalaron que: a) el género constituye un grupo monofilético, al igual que lo son las secciones Bursera y Bullockia; b) la secuencia en B. tecomaca y en $B$. sarcopoda revela sus cercanas relaciones con otras especies de la sección Bullockia y no con las del género Commiphora; c) los esquemas evolutivos propuestos para muchos de los componentes de la sección Bullockia no necesariamente coinciden bien con las semejanzas y diferencias de orden morfológico.

En contraste, Weeks \& Simpson $(2001,2002)$ anunciaron que los resultados de sus trabajos acerca de las relaciones filogenéticas entre los géneros de Burseraceae revelan que Bursera no constituye un conjunto monofilético. Al parecer, el estudio correspondiente todavía está pendiente de publicarse.

Andrés-Hernández (2001) realizó un análisis cladístico con base en estructuras foliares de 21 especies de Bursera nativas de la cuenca del Balsas. Sus resultados sugieren que el grupo de $B$. simaruba es el más primitivo del género y debe separarse en un taxon equivalente en rango al de la sección Bullockia.

Andrés-Hernández y Espinosa-Organista (2002) estudiaron la morfología de las plántulas de 10 especies mexicanas de Bursera y encontraron que en tal estadío ontogenético también existen caracteres para diferenciar las secciones Bullockia y Bursera y dentro de esta última a dos conjuntos, el de los "mulatos" (grupo de B. simaruba) y el de los "cuajiotes" (las especies restantes).

Además de sus dificultades taxonómicas, Bursera tiene una complicada y embrolladora historia nomenclatural.

Como ya se mencionó, el binomio cronológicamente más antiguo de este conjunto fue establecido en la primera edición de Species Plantarum de Linné (1753), quien optó por llamar la especie como Pistacia simaruba, basándose substancialmente en el dibujo de una planta de Jamaica publicado por Sloane (1696) y dada a conocer como "Terebinthus major betulae cortice, fructu triangulari".

Tres años después P. Browne (1756), en su Civil and Natural History of Jamaica, describió el mismo árbol como "Terebinthus foliis cordato-ovatis pinnatis, cortice levi pubescente, floribus masculinis spicatis". Puesto que el autor no ha utilizado el sistema binario, en sí la descripción carece de valor nomenclatural a nivel de especie, pero de acuerdo con las normas vigentes, es suficiente para validar el nombre genérico Terebinthus.

Por su lado Boehmer, en la tercera edición de Definitiones Generum Plantarum de Ludwig (1760), concibió la denominación genérica Simaruba para la planta en cuestión. Sin embargo, aparentemente esta decisión no la tomó en cuenta ningún autor posterior y en 1775 Aublet definió Simarouba en un contexto taxonómico distinto. 
En la misma época N. J. Jacquin realizó un largo viaje a la región del Caribe y como resultado de sus estudios dio a conocer dos obras importantes: Enumeratio Systematica Plantarum en 1760 y Selectarum Stirpium Americanarum Historia en 1763, en las que describió un gran número de especies vegetales. Enumeratio consiste por lo general de breves diagnosis de plantas que en Historia a menudo se describen e ilustran con detalle. Por esta razón la mayor parte de las posteriores referencias a la obra de Jacquin aluden al libro de 1763, pero para propósitos nomenclaturales son válidos los nombres publicados de 1760, como es el caso del género Elaphrium y de las dos especies E. tomentosum y E. glabrum, designados para plantas provenientes de Curazao y de Colombia respectivamente.

Tocante a Pistacia simaruba, Jacquin inicialmente (1760) la denominó Terebinthus brownii, pero poco tiempo después debe de haber comunicado a Linné que la especie merece ubicarse en un género independiente. De esta manera, en la segunda edición de Species Plantarum, publicada en 1762, la planta fue rebautizada una vez más y situada como miembro de Bursera, nombre nuevo que se dedicó a Joachim Burser (1603-1689), médico y botánico alemán. El binomio que le asignó Linné (o más probablemente Jacquin) fue el de Bursera gummifera, mismo que resulta ilegítimo bajo las actuales reglas de nomenclatura y tuvo que ser reemplazado por B. simaruba (L.) Sarg.

A este respecto cabe agregar la complicación adicional de que ya con anterioridad Loefling (1758) había acuñado y publicado el nombre genérico Burseria en un contexto taxonómico diferente. A pesar de ello o posiblemente en desconocimiento de la obra de Loefling, Jacquin en su contribución de 1763, empleó el binomio Burseria gummifera para la amplia descripción e ilustración de la planta que hacía un año se había dado a conocer como Bursera gummifera.

Las mayores dificultades, sin embargo, comenzaron con la resolución de reunir Bursera con Elaphrium en una sola entidad, pues era necesario prescindir de uno de los nombres. Tanto Hooker (op. cit.) como Triana y Planchon (op. cit.), así como Engler (op. cit.) escogieron a Bursera para denominar al género fusionado y el último autor realizó todas las transferencias necesarias. Tal decisión correspondió a la usanza de aquella época de la botánica europea e indudablemente la razón de mayor peso que la influenció debe haber sido el hecho de no considerarse apropiada la eliminación de Bursera del seno de la familia Burseraceae, que para entonces ya estaba consolidada como un taxon ampliamente reconocido y aceptado.

A su vez, los desacuerdos no tardaron en llegar. En las primeras décadas del siglo XX se produjo una seria escisión entre los botánicos europeos y muchos de los norteamericanos en torno a la aplicación de las reglas de nomenclatura, insistiendo estos últimos, entre otras disconformidades, en la estricta observancia del principio de prioridad cronológica de la publicación de los nombres. Durante un cuarto de siglo rigieron dos códigos de nomenclatura diferentes y esta época coincidió con la de los trabajos de Rose sobre el grupo.

En la primera etapa de sus estudios y bajo la influencia de Wight, Rose (1906) recurrió al término Terebinthus, nombre genérico establecido en tiempos pasados 
por Tournefort, pero no sancionado por Linné, quien se inclinó por incluir sus componentes en Pistacia. Sin embargo, ya en la época de vigencia de la nomenclatura linneana, y como se indicó previamente, P. Browne (op. cit.) había hecho revivir a Terebinthus, ligándolo directa y concretamente con Pistacia simaruba L., años antes de la ubicación de esta última en Bursera. Con tal motivo Rose y Wight transfirieron 43 binomios y el primero describió ocho especies nuevas bajo esta denominación genérica.

En su obra posterior, publicada como parte de North American Flora, el mismo autor (1911) tuvo que recapacitar y desistir del empleo de los binomios publicados en 1906, pues se dio cuenta de que antes de P. Browne, ya P. Miller (1754) había validado el nombre Terebinthus, en contexto taxonómico diferente. Ante tal circunstancia, Rose optó por el uso de Elaphrium, cuya publicación antecede en dos años a la de Bursera, y en conexión con ello realizó 36 nuevas transferencias.

Finalmente procede agregar que Bursera Jacq. ex L. figura en la lista de nombres genéricos conservados, concepto incorporado en 1905 en el Código Internacional de Nomenclatura Botánica y universalmente aceptado en 1930. Como consecuencia, en la actualidad resulta imperativo su empleo en la circunscripción que abarca también a Elaphrium.

\section{PARTE TAXONÓMICA}

BURSERA Jacq. ex L., Sp. Pl. ed. 2. p. 471. 1762, emend. Triana \& Planch., Ann. Sci. Nat. 5 sér. 14: 302. 1872, nom. conserv. Engler, DC. Monogr. Phaner. 4: 36. 1883. Bullock, Bull. Misc. Inform. 1936: 346. 1936. McVaugh \& Rzedowski, Kew Bull. 18: 317. 1965. (Non Burseria Loefl. 1758).

Terebinthus P. Browne, Hist. Jam. p. 345. 1756. Rose, Contr. U.S. Nat. Herb. 10: 117. 1906. (Non Terebinthus Mill. 1754).

Simaruba Boehm. ex Ludwig, Def. Gen. PI. ed. 3. p. 513. 1760. (Non Simarouba Aubl. 1775, nom. conserv.).

Elaphrium Jacq., Enum. PI. Carib. p. 3. 1760. Jacquin, Stirp. Amer. Hist. p. 94. 1763. Schlechtendal, Linnaea 16: 523. 1842. Rose, North Amer. FI. 25: 241. 1911. Standley, Contr. U.S. Nat. Herb. 23: 542. 1923.

Árboles o a veces arbustos caducifolios, resinoso-aromáticos, dioicos o polígamo-dioicos, rara vez hermafroditas; la corteza externa de las partes lignificadas provista de una capa de clorénquima, la del tronco a menudo rojiza o amarillenta y exfoliante, otras veces gris, lisa y sin exfoliarse, las ramillas abreviadas (braquiblastos) comúnmente presentes; hojas sin estípulas, a menudo dispuestas en forma de roseta en los extremos de los braquiblastos, otras veces alternas y esparcidas sobre ramas jóvenes y vigorosas, en la mayor parte de las especies imparipinnadas y con los foliolos opuestos pero a veces (al menos parcialmente) 
bipinnadas, trifolioladas o simples (unifolioladas), el raquis con frecuencia alado, a las hojas normales en muchos casos les anteceden en aparición una o varias rosetas de catafilos más o menos precozmente caedizos, de forma oblonga, lanceolada o triangular, y también es frecuente que las primeras hojas en aparecer sean trifolioladas o con un número de foliolos más reducido que el común para la especie; inflorescencias axilares, originándose por lo general con o antes de las primeras hojas y entonces a menudo se observan como si fueran fasciculadas o aglomeradas sobre los braquiblastos, en forma de panículas, tirsos, (pseudo-) racimos, cimas, glomérulos, o bien, las flores solitarias por reducción, bracteolas por lo general presentes; flores casi siempre unisexuales, rara vez funcionalmente hermafroditas (aunque las femeninas no pocas veces aparentan tener el androceo bien desarrollado), pequeñas, trímeras a pentámeras, rara vez hexámeras; cáliz profundamente dividido, sus lóbulos abiertos en el botón; corola de prefloración valvada, a menudo conduplicado-valvada, los pétalos por lo general más largos que el cáliz, blanquecinos, amarillentos, verdosos o rojizos, con frecuencia cuculados; estambres dos veces más numerosos que los pétalos, dispuestos en dos series iguales o en ocasiones algo desiguales, insertos en la base del disco, anteras dorsifijas, por lo general más pequeñas y estériles en las flores femeninas, disco glandular, anular; ovario sésil, bi- o trilocular, con 2 óvulos péndulos en cada lóculo, estilo por lo general corto o apenas evidente, a veces parcial o totalmente dividido en 2 ramas, estigmas 2 ó 3; fruto en forma de drupa ovoide, obovoide, elipsoide a esférica, biconvenxa o más o menos asimétricamente trígona, exocarpio al principio carnoso pero luego coriáceo y tardíamente dehiscente por medio de 2 ó 3 valvas, hueso parcial o totalmente cubierto por un pseudoarilo que al abrirse el fruto suele ser rojo, anaranjado o amarillento, pero por lo común pronto se torna gris o blanquecino; semilla por lo general una sola en cada fruto.

\section{Tipo del género: Bursera gummifera L. (= B. simaruba (L.) Sarg.)}

En esta aproximación se reconocen 21 especies de Bursera para el área de estudio, de las cuales 15 ya han sido citadas con anterioridad para la región. Tres (B. ariensis, $B$. graveolens y $B$. hintonii), constituyen registros adicionales y tres ( $B$. altijuga, $B$. esparzae y $B$. pontiveteris), se describen como nuevas. La localidad tipo de nueve especies de Bursera se encuentra dentro de la región de estudio.

Siete de las especies (B. aptera, B. biflora, B. fagaroides, B. linanoe, B. morelensis, $B$. schlechtendalii y $B$. submoniliformis) son plantas comunes y por consiguiente componentes importantes de la vegetación de las partes más secas de la cuenca superior del Papaloapan. En contraste, cinco (B. ariensis, B. esparzae, $B$. graveolens, $B$. hintonii y $B$. mirandae) revelan ser elementos de presencia esporádica, en una sola o en unas pocas localidades. Este último hecho indica la posible existencia en la región de otras especies de Bursera, aún no localizadas, pues se trata de un área topográficamente compleja, que dista de estar exhaustivamente explorada. 
A su vez se excluyen las siguientes, que se han mencionado también para la zona de estudio, al parecer en su gran mayoría con base en identificaciones incorrectas: B. copallifera (DC.) Bullock, B. grandifolia (Schltl.) Engl., B. hindsiana (Benth.) Engl., B. laxiflora S. Wats., B. microphylla A. Gray, B. odorata Brandegee y B. suntui C. A. Toledo.

De acuerdo con los datos actuales, únicamente una especie, $B$. pontiveteris, restringe su área a la cuenca del Papaloapan, aunque otras cuatro, $B$. altijuga, $B$. arida, $B$. aspleniifolia y $B$. biflora son casi endémicas, pues fuera de la región sólo se conocen de porciones vecinas del estado de Oaxaca.

1 Ovario trilocular; fruto trivalvado; corteza externa del tronco exfoliante; flores, al menos en su gran mayoría, trímeras o pentámeras.

2 Hojas todas simples; corteza externa del tronco rojiza B. schlechtendalii

2 Hojas, al menos las principales, compuestas de tres a muchos foliolos; corteza externa del tronco rojiza o amarillenta.

3 Foliolos lineares o linear-oblongos, cinco o más veces más largos que anchos; corteza externa del tronco rojiza.

4 Ramas jóvenes, inflorescencias y peciolos glabros .......... B. morelensis

4 Ramas jóvenes, inflorescencias y peciolos pubérulos ......... B. galeottiana

3 Foliolos más anchos que lineares o linear-oblongos, menos de cinco veces más largos que anchos.

5 Foliolos de hojas maduras de más de $3.5 \mathrm{~cm}$ de largo; corteza externa del tronco rojiza.

6 Foliolos (1)3 ó 5; frutos de menos de $10 \mathrm{~mm}$ de largo; árbol hasta de $12 \mathrm{~m}$ de alto, habitante del bosque tropical caducifolio

B. cinerea

6 Foliolos, al menos en algunas hojas, 7 a 13; frutos por lo general de 10 a 15 mm de largo; árbol hasta de $35 \mathrm{~m}$ de alto, habitante preferente del bosque tropical perennifolio y subcaducifolio B. simaruba

5 Foliolos de hojas maduras de menos de $3.5 \mathrm{~cm}$ de largo; corteza externa del tronco amarillenta.

7 Plantas pubescentes, al menos en las ramillas tiernas, en los peciolos y en la inflorescencia.

8 Raquis de la hoja sin alas; foliolos de menos de $1 \mathrm{~cm}$ de largo; flores masculinas trímeras 0 algunas veces tetrámeras ............ B. arida

8 Raquis de la hoja con alas angostas manifiestas; foliolos principales de más de $1 \mathrm{~cm}$ de largo; flores masculinas pentámeras

B. ariensis

7 Plantas glabras o esencialmente glabras.

9 Foliolos (1)5 ó 7(9), de (0.5) 1 a 2(3) cm de largo; planta frecuentemente arbustiva; flores masculinas por lo general pentámeras

B. fagaroides

9 Foliolos (9)11 a 17, de 0.5 a 1(1.6) cm de largo; planta por lo común arborescente; flores masculinas por lo general trímeras ... B. aptera 
1 Ovario bilocular; fruto bivalvado; corteza externa del tronco por lo general no exfoliante; flores en su mayoría tetrámeras, a veces algunas pentámeras.

10 Raquis de las hojas imparipinnadas desprovisto o prácticamente desprovisto de alas (hojas trifolioladas presentes también en algunas especies).

11 Ovario y fruto pubescentes; foliolos de (1.5)2 a 6(8) $\mathrm{cm}$ de largo, por lo común 5 a 11; planta sólo conocida de los alrededores de la estación de ferrocarril El Parián B. esparzae

11 Ovario y fruto glabros.

12 Foliolos acuminados a caudados en el ápice, por lo común 7 ó 9, de

3 a $7(9) \mathrm{cm}$ de largo, glabrescentes; planta cultivada, principalmente en cercas vivas

B. graveolens

12 Foliolos por lo general agudos a redondeados en el ápice, rara vez acuminados, pero entonces en número de 3 a 5 ; plantas silvestres. 13 Fruto obovoide, algo comprimido, de 9 a $11 \mathrm{~mm}$ de largo; foliolos por lo general 5 ó 7; segmentos del cáliz de menos de la mitad del largo de los pétalos; planta colectada por lo general a menos de $1300 \mathrm{~m}$ de altitud B. linanoe

13 Fruto a menudo obovoide pero no comprimido, de 7 a 9 mm de largo; plantas colectadas en altitudes superiores a $1300 \mathrm{~m}$.

14 Foliolos 7 a 13, de (6)9 a 17(21) $\mathrm{mm}$ de largo, de margen tosca e irregularmente crenado-serrado; segmentos del cáliz de menos de la mitad del largo de los pétalos ...... B. mirandae

14 Foliolos 3 ó 5, de margen profunda e irregularmente serrado; segmentos del cáliz al menos de la mitad del largo de los pétalos

B. pontiveteris

10 Raquis de las hojas imparipinnadas alado, o bien, todas las hojas trifolioladas, unifolioladas o bipinnadas.

15 Hojas bipinnadas, al menos en la mayor parte de su extensión

B. bipinnata

15 Hojas imparipinnadas, trifolioladas o unifolioladas.

16 Foliolos de menos de $8 \mathrm{~mm}$ de largo

B. bipinnata

16 Foliolos, al menos los bien desarrollados, de más de $8 \mathrm{~mm}$ de largo.

17 Hojas todas unifolioladas, o bien, trifolioladas y a veces algunas con

5 foliolos; segmentos del cáliz de menos de la mitad del largo de los pétalos

B. biflora

17 Hojas mayormente con 5 o más foliolos, a veces en parte trifolioladas.

18 Ovario y fruto pubescentes; foliolos 9 a 17, densamente velutinos B. submoniliformis

18 Ovario y fruto glabros.

19 Foliolos acuminados a caudados en el ápice, por lo común 7 ó 9, de 3 a 7(9) cm de largo, glabrescentes; planta cultivada, principalmente en cercas vivas

B. graveolens 
19 Foliolos por lo general agudos a redondeados en el ápice, rara vez acuminados, pero entonces tomentosos en el envés; plantas silvestres.

20 Hojas maduras de más de $20 \mathrm{~cm}$ de largo, sus foliolos 11 a 17(21), de más de $5 \mathrm{~cm}$ de largo, velutinotomentosos en el envés; raquis foliar a menudo crenadoserrado B. hintonii

20 Hojas maduras de menos de $20 \mathrm{~cm}$ de largo, sus foliolos de menos de $5 \mathrm{~cm}$ de largo.

21 Hojas, al menos en su mayoría, con 13 o más foliolos sésiles B. aspleniifolia

21 Hojas con 11 o menos foliolos.

22 Frutos obovoides, algo comprimidos; inflorescencia con pelos glandulares pequeños y dispersos, además de pelos desprovistos de glándulas; planta habitante de altitudes inferiores a $1500 \mathrm{~m}$

B. linanoe

22 Frutos obovoides o subesféricos, no comprimidos; inflorescencia sin pelos glandulares; plantas habitantes de altitudes superiores a $1300 \mathrm{~m}$.

23 Margen del foliolo con dientes sencillos, toscos, distribuidos en la mitad o en los 2/3 distales de la lámina; catafilos tomentoso-pubérulos por dentro; fruto elipsoide a orbicular u obovoide, de 9 a $13 \mathrm{~mm}$ de largo

B. glabrifolia

23 Margen del foliolo con dientes finos, a menudo escotados en el ápice, distribuidos desde el ápice hasta cerca de la base de la lámina; catafilos glabros por dentro; fruto ovoide a elipsoide, de 8 a $9 \mathrm{~mm}$ de largo

B. altijuga

1. Bursera altijuga Rzedowski, Calderón \& Medina sp. nov. Tipo: México: Oaxaca: distrito Coixtlahuaca: Puerto Mixteco, $4 \mathrm{~km}$ al N de Tepelmeme, 19.IV.1966, $R$. Cruz 2362 (holotipo IEB, isotipos por distribuirse).

Nombres comunes registrados en la zona: copal, copalillo.

Frutex vel arbor usque 3(8) $\mathrm{m}$ alta dioecia; truncus cortice griseo non exfolianti, ramuli juniores villoso-puberuli; foliorum rosulae juventute cataphyllis exterioribus cinctae, foliola imparipinnata vel trifoliolata, rhachidi alata, foliola (3)59(11) ovata usque elliptica, $0.5-2(2.5) \mathrm{cm}$ longa, $0.4-1.2(1.5) \mathrm{cm}$ lata, foliolum terminale plerumque lateralibus valde majus, apice acuta usque rotundata, basi cuneata usque truncata, marginibus plerumque duplo serratis, supra puberula et 
Rzedowski et al.: Las especies de Bursera de la cuenca del río Papaloapan, México

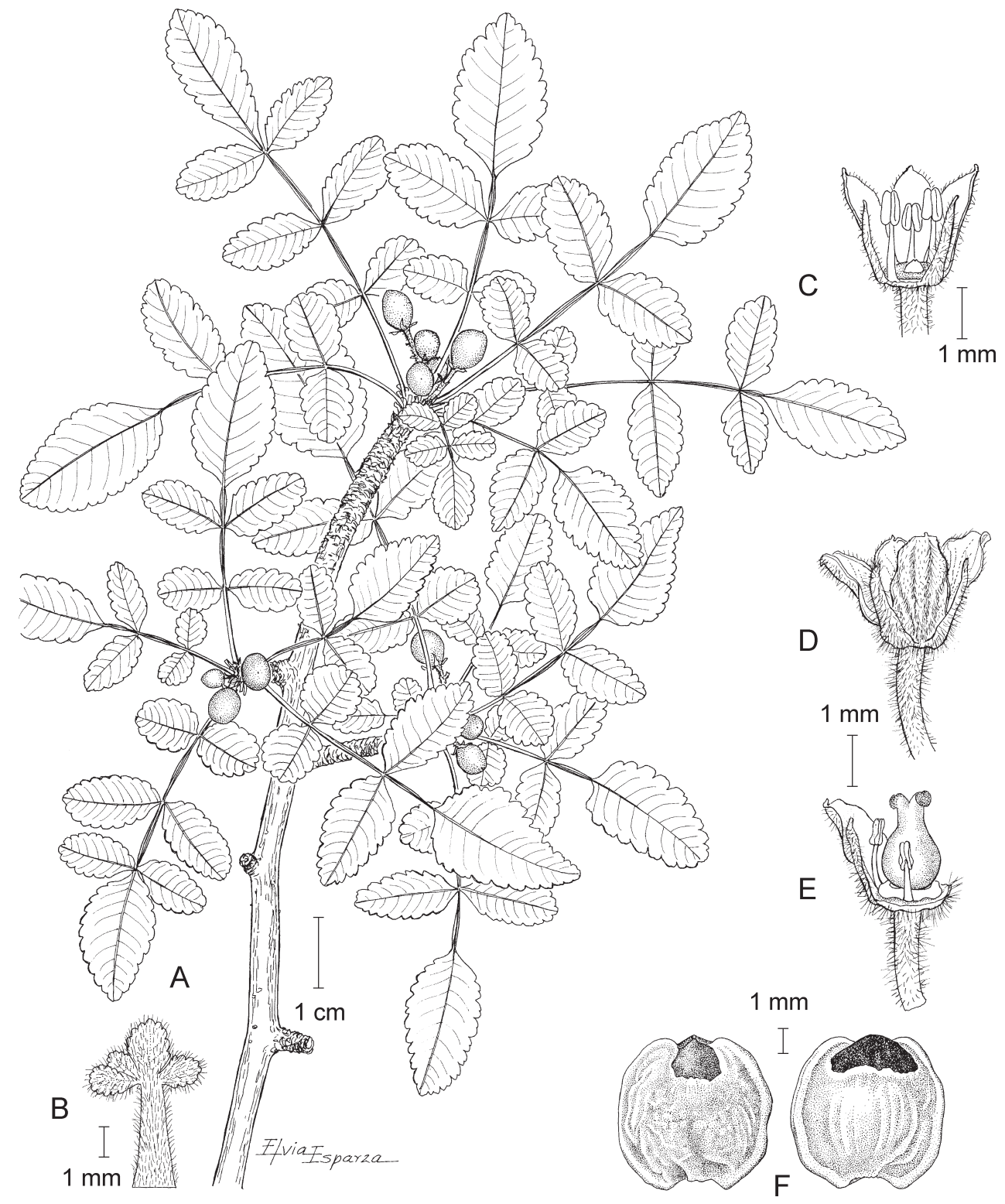

Bursera altijuga Rzed., Calderón \& Medina. A. rama con hojas y frutos; B. catafilo con características similares a las de una hoja; C. flor masculina desprovista de un pétalo y de 5 estambres; D. flor femenina en vista externa; E. flor femenina desprovista de varios segmentos del cáliz, pétalos y estaminodios; F. hueso visto por ambas caras. llustrado por Elvia Esparza. 
mollia, subtus pubescentia varianti e tomentosa usque ad venas restricta; inflorescentiae racemoso-paniculatae ad $4 \mathrm{~cm}$ longae potius compactae; flores masculi tetrameri, calycis lobi lineari-triangulares, ca. $1.5 \mathrm{~mm}$ longi, petala luteoviridula elliptico-oblonga, ca. $2.5 \mathrm{~mm}$ longa, stamina 8; flores feminei masculinorum similes sed calycis lobis ca. $2 \mathrm{~mm}$ longis, ovarium biloculare, stigmata 2; fructus plerumque solitarii, ovoidei vel ellipsoidei, $8-9 \mathrm{~mm}$ longi, pyrenae suborbiculares leviter applanatae, 5-6 mm longae, pseudoarillo aurantiaco per 2/3-3/4 partibus inferis indutae.

Arbusto o árbol dioico, hasta de 3(8) $\mathrm{m}$ de alto, aromático al estrujarse; tronco hasta de $20 \mathrm{~cm}$ de diámetro, corteza externa gris, no exfoliante, ramillas rojizas, glabrescentes, las jóvenes viloso-pubérulas; hojas mayormente agrupadas en rosetas en los ápices de las ramillas cortas, otras veces alternas sobre ramillas de crecimiento nuevo, precedidas en su aparición por un conjunto de catafilos triangulares a linear-triangulares, hasta de $5 \mathrm{~mm}$ de longitud, rojizos, cinéreotomentulosos por fuera, glabros por dentro, peciolo hasta de $1.5(2) \mathrm{cm}$ de largo, lámina ovada u obovada en contorno general, de 2 a $6 \mathrm{~cm}$ de largo y 1.5 a $4 \mathrm{~cm}$ de ancho, por lo general imparipinnada, raquis con alas hasta de $1 \mathrm{~mm}$ de ancho de cada lado, de margen entero, peciólulos de 0 a $1 \mathrm{~mm}$ de largo, foliolos (3) 5 a $7(11)$, ovados a elípticos, de 0.5 a 2(2.5) cm de largo y 0.4 a $1.2(1.5) \mathrm{cm}$ de ancho, el terminal a veces subrómbico, con frecuencia mucho más largo que los laterales, agudos a redondeados en el ápice, cuneados a truncados y a menudo oblicuos en la base, de margen conspicua y regular a irregularmente crenado-serrado desde el ápice hasta cerca de la base de la lámina, con frecuencia doblemente crenadoserrado (con escotadura en el ápice de muchos de los dientes), de textura membranácea a cartácea, pubérulos y suaves al tacto en el haz, en el envés con pubescencia que varía de tomentosa a prácticamente restringida a las nervaduras; inflorescencias racimoso-paniculadas, pero más bien compactas, hasta de $4 \mathrm{~cm}$ de largo, densamente piloso-vilosas, bracteolas subuladas, de ca. $1 \mathrm{~mm}$ de largo, pedicelos de 0.5 a $2 \mathrm{~mm}$ de largo; flores masculinas tetrámeras, lóbulos del cáliz linear-triangulares, de ca. $1.7 \mathrm{~mm}$ de largo, densamente vilosos por fuera, pétalos amarillo-verdosos, elíptico-oblongos, de ca. $2.5 \mathrm{~mm}$ de largo, vilosos por fuera, filamentos de ca. $1 \mathrm{~mm}$ de largo, anteras oblongas, de ca. $0.7 \mathrm{~mm}$ de largo, gineceo vestigial; flores femeninas similares a las masculinas, pero con los lóbulos del cáliz de ca. $2 \mathrm{~mm}$ de largo, anteras de los estaminodios de ca. $0.4 \mathrm{~mm}$ de largo, ovario bilocular, glabro, estigmas 2; frutos por lo general solitarios, sobre pedúnculos hasta de 1 (2) $\mathrm{cm}$ de largo, bivalvados, ovoides o elipsoides, de 8 a $9 \mathrm{~mm}$ de largo y 6 a $7 \mathrm{~mm}$ de diámetro, angulosos en el ápice, glabros, rojizos en la madurez, hueso suborbicular, algo aplanado, de 5 a $6 \mathrm{~mm}$ de largo, rodeado en sus 2/3 ó $3 / 4$ inferiores por un pseudoarilo anaranjado, la porción expuesta negra.

Material adicional examinado de la región de estudio: OAXACA: Distrito Coixtlahuaca: Cerro del Camello, $2 \mathrm{~km}$ al $\mathrm{S}$ de Tepelmeme de Morelos, R. Cruz 2166 (IEB); 9 km al NE de Tejupan, A. García y F. Mérida 2529 (IEB); km 9 del 


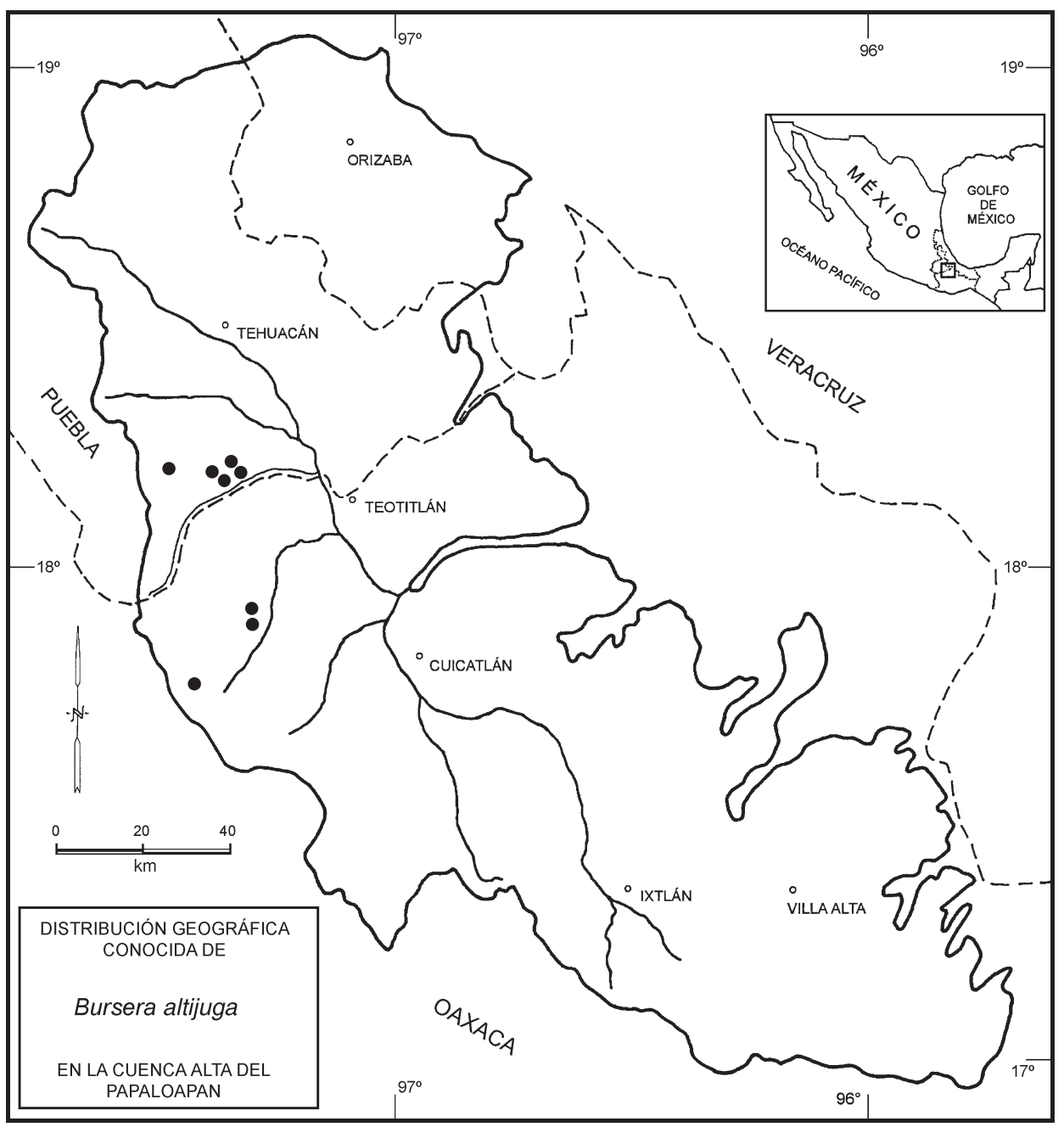

camino de ruta 190 a Coixtlahuaca, D. H. Lorence y A. García 4782 (IEB, MEXU). PUEBLA: Municipio Caltepec: La Cumbre, cerca del cerro El Gavilán, de Caltepec a San Luis Tultitlanapa, 18 $10^{\prime} 4^{\prime \prime}$ N, 97²7'08" W, L. Alvarado et al. 129 (MEXU); $6 \mathrm{~km}$ al E de San Luis Atolotitlán, por la terracería rumbo a Caltepec, $18^{\circ} 11^{\prime} \mathrm{N}$, 97²8' W, F. Chiang et al. F- 2595 (MEXU); abajo del cerro El Gavilán, 18¹0'25" N, 97027'39" W, R. Medina et al. 1164 (IEB, MEXU); La Cumbre, $2 \mathrm{~km}$ al SE de Caltepec, camino a San Luis Atolotitlán, 18¹0'44" N, 97²7'8" W, R. Medina et al. 1174 (IEB, MEXU), 1175 (IEB, MEXU), 1176 (MEXU), 1184 (IEB, MEXU); vicinity of San Luis Tultitlanapa, Puebla, near Oaxaca, C. A. Purpus 3161 (UC); Tlacuiloltepec, C. A. Purpus 4066 (UC); $2 \mathrm{~km}$ al W de San Luis Atolotitlán, al S de Tehuacán, J. Santana et al. 331 (IEB); cerro El Gavilán, al SE de Caltepec, 
1810' N, 97²8' W, P. Tenorio et al. 3723 (IEB, MEXU), 17353 (IEB, MEXU); Cruz Chica, al SW de Caltepec, P. Tenorio et al. 3866 (IEB, MEXU); Planes de San Miguel, F. Ventura 15395 (IEB); Acatepec, F. Ventura 15402 (ENCB, IEB, MEXU).

Material extraterritorial examinado: OAXACA: Distrito Huajuapan: cerro Chicamole, al N de Membrillos, 18²' N, 97³2' W, P. Tenorio 19158 (MEXU). Distrito Teposcolula: $7 \mathrm{~km}$ al NE de Tejupan, carretera a Coixtlahuaca, $18^{\circ} 41^{\prime} \mathrm{N}$, 97³2' W, P. Tenorio 17074 (MEXU).

Planta de distribución restringida a las partes altas de la comarca limítrofe de Puebla y Oaxaca, en la región de Caltepec y Coixtlahuaca, extendiendo ligeramente su área fuera de la cuenca del Papaloapan.

Es habitante de matorrales xerófilos y a veces de encinares, en altitudes entre 1800 y 2350 m, llegando a convivir con B. biflora.

B. altijuga es una especie sumamente variable en cuanto al número de foliolos y a la pubescencia se refiere. La mayor parte de los ejemplares examinados presentan hojas con 5 ó 7 foliolos, pero en algunas poblaciones oaxaqueñas, no son raras las que sólo llevan 3, mientras que del lado de Puebla pueden tener 9 y algunas veces 11. En general las plantas son viloso-pubérulas en la mayoría de las partes verdes, sobre todo en la juventud, pero mientras en algunas las hojas maduras siguen siendo tomentosas en el envés, en otras sólo conservan pelos a lo largo de las nervaduras. Tales diferencias no dejan de plantear una sombra de duda acerca de la correcta ubicación taxonómica de todo el material estudiado y crean serias dificultades para lograr su sencilla separación en la clave de identificación. Sin embargo, la similtud en el aspecto general de los ejemplares y de su afinidad ecológica hacia matorrales xerófilos de altitudes mayormente superiores a $2000 \mathrm{~m}$, se pronuncian por la decisión de considerarlos como pertenecientes a una sola especie.

En virtud de su ovario bilocular y flores tetrámeras, $B$. altijuga se sitúa en la sección Bullockia, donde posiblemente esté relacionada con $B$. heliae Rzed. \& Calderón, conocida de la cuenca del río Tehuantepec de Oaxaca, a la que se parecen sobre todo los individuos con hojas de 3 y 5 foliolos. Sin embargo, esta última planta difiere en sus inflorescencias y flores más grandes, en sus foliolos de mayor tamaño, con más tendencia a volverse ampuloso-rugosos en la madurez, así como en su ubicación ecológica, pues forma parte del bosque tropical caducifolio en altitudes inferiores a $1800 \mathrm{~m}$.

En el número y en el tamaño de los foliolos, así como en la forma de las inflorescencias y de las flores el taxon nuevo guarda semejanza con B. glabrifolia, especie distribuida de Michoacán a Oaxaca y colectada también en el municipio de Caltepec, pero es distinta en sus frutos obovoides, así como en el margen de los foliolos que tiene dientes sencillos, más grandes, en menor número y presentes sólo en la mitad o en los 2/3 distales de la lámina. 
Cabe distinguir asimismo a $B$. altijuga de otras dos especies simpátricas, $B$. biflora y $B$. pontiveteris, con las que en ocasiones podría confundirse. La primera tiene por lo general hojas simples o trifolioladas, aunque en algunas poblaciones se registra la presencia eventual de 5 foliolos de tamaño y forma más o menos similares a los de $B$. altijuga; difiere, sin embargo, en su inflorescencia cimosa abierta, casi siempre triflora, en su cáliz diminuto y en su fruto mucho más largamente pedunculado. La segunda se caracteriza por sus hojas con 3 ó 5 foliolos, de margen profundamente aserrado y por lo general sin o casi sin alas en el raquis.

El nombre de la especie hace alusión a su ubicación ecológica, pues habita a mayores altitudes que la generalidad de los representantes de este género y no forma parte del bosque tropical caducifolio, tipo de vegetación característico del grueso de los miembros de Bursera.

2. Bursera aptera Ramírez, Dat. Mat. Med. Mex. 1: 379. 1894. Terebinthus aptera (Ramírez) Rose, Contr. U.S. Nat. Herb. 10: 118. 1906. Elaphrium apterum (Ramírez) Rose, North Amer. Fl. 25: 249. 1911. Tipo: lámina que acompaña la descripción original, basada en una planta procedente de Jojutla, Morelos, México.

Nombres comunes registrados en la zona: copalillo, cuajiote, cuajiote amarillo, cuajiote verde.

Nombres comunes registrados fuera de la zona de estudio: coxinyotl iztac (lengua náhuatl), cuachital, cuajiote blanco.

Árbol o a veces arbusto dioico, hasta de $8 \mathrm{~m}$ de alto, con resina abundante, aromático y glabro; tronco con corteza interna verde mate o verde brillante, la externa amarillenta y exfoliante en láminas papiráceas, ramillas glabras; hojas imparipinnadas, peciolo de ca. $0.5 \mathrm{~cm}$ de largo, glabro, lámina de 1 a $7(8.5) \mathrm{cm}$ de largo y 0.6 a $3 \mathrm{~cm}$ de ancho, raquis sin alas, foliolos 7 a 19, sésiles a subsésiles, elípticos a ovados u obovados, de 4 a 12(15) $\mathrm{mm}$ de largo y 2 a 5(6) $\mathrm{mm}$ de ancho, ápice agudo a redondeado, base cuneada a redondeada, margen generalmente entero, de textura membranácea a cartácea, glabros, nervadura principal oscura y poco evidente en el haz, en el envés amarillenta y prominente, las secundarias inconspicuas; flores por lo general solitarias o a veces dispuestas en grupos de 2 ó 3, glabras, bracteolas triangular-acuminadas, de 1 a $1.2 \mathrm{~mm}$ de largo, de base ensanchada, glabras, pedicelos de 1 a $1.2 \mathrm{~mm}$ de largo, glabros; flores masculinas trímeras o a veces tetrámeras, hasta de $8 \mathrm{~mm}$ de largo (incluyendo el pedicelo), lóbulos del cáliz triangulares, desiguales, de 1.5 a $3 \mathrm{~mm}$ de largo, glabros, borde al secar con escasos tricomas cortos, pétalos de color amarillo, rojizo o blanquecino, elíptico-oblongos, de ca. $5 \mathrm{~mm}$ de largo y 1 a $1.5 \mathrm{~mm}$ de ancho, cuculados, coriáceos, ápice encorvado, glabros, estambres 6 , filamentos de ca. $1.5 \mathrm{~mm}$ de largo, anteras oblongas, de ca. $2 \mathrm{~mm}$ de largo; flores femeninas trímeras, hasta de $6 \mathrm{~mm}$ de largo (incluyendo el pedicelo), lóbulos del cáliz iguales, cuculado- 


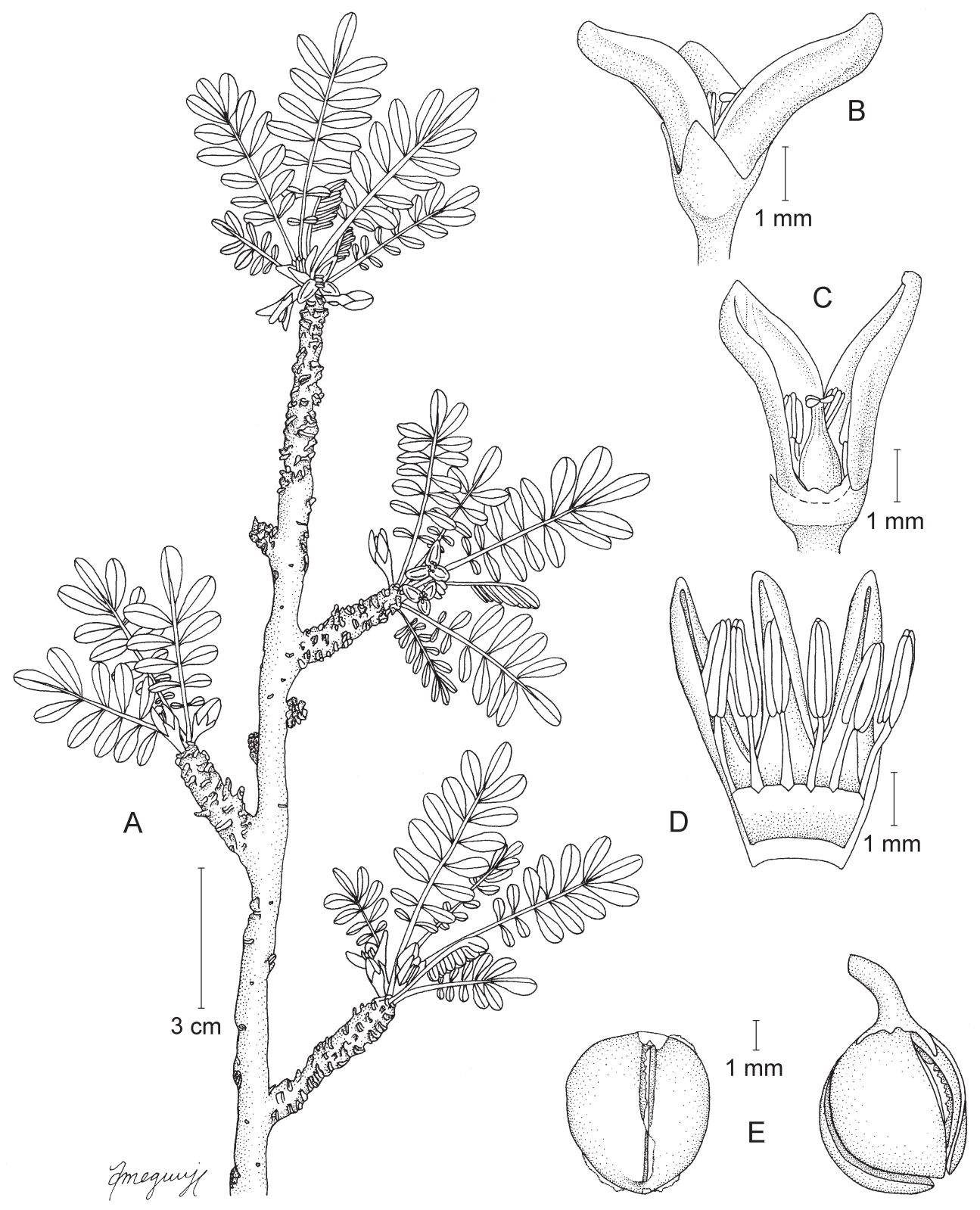

Bursera aptera Ramírez. A. rama con hojas y flores masculinas; B. flor femenina en vista externa; C. flor femenina desprovista de un pétalo y 3 estaminodios; D. flor masculina disecada; E. frutos. Ilustrado por Megumi Andrade. 
deltoides, de 1.2 a $1.6 \mathrm{~mm}$ de largo, reflexos en la madurez, pétalos cuculadoaquillados, de 4 a $5 \mathrm{~mm}$ de largo, estaminodios con anteras de ca. $1 \mathrm{~mm}$ de largo, ovario trilocular, estilo de menos de $1 \mathrm{~mm}$ de largo, estigmas 3; frutos solitarios o agrupados por varios en los ápices de ramillas cortas, trivalvados, globosos a ovoides, apiculados, escasamente triquetros, de 6 a $7 \mathrm{~mm}$ de largo y de 5 a $6 \mathrm{~mm}$ de ancho, rojizos a pardos en la madurez, glabros, hueso de 5 a $6 \mathrm{~mm}$ de diámetro, totalmente cubierto por un pseudoarilo amarillo o blanquecino.

Habita en el bosque tropical caducifolio y en el matorral xerófilo, preferentemente en suelos de origen calizo, en altitudes entre 550 y $1950 \mathrm{~m}$. En la cuenca se encuentra compartiendo el mismo hábitat con $B$. fagaroides, $B$. morelensis y $B$. schlechtendalii. Florece de finales de abril a mediados de julio. Sin follaje de noviembre a mayo.

Especie endémica de México, se distribuye en los estados de Guerrero, Morelos, Oaxaca y Puebla.

Material examinado: OAXACA: Distrito Coixtlahuaca: La Huerta, $20 \mathrm{~km}$ al NE de Tepelmeme de Morelos, R. Cruz 2621 (ENCB). Distrito Cuicatlán: $3.8 \mathrm{~km}$ al S de San José del Chilar, $17^{\circ} 41^{\prime} 11^{\prime \prime} \mathrm{N}, 96^{\circ} 57^{\prime} 31^{\prime \prime} \mathrm{W}, \mathrm{J}$. P. Abascal et al. 186 (IEB, MEXU); $8 \mathrm{~km}$ al NE de Santiago Quiotepec, camino a San Isidro Buenos Aires, $17^{\circ} 54^{\prime} 9^{\prime \prime} \mathrm{N}, 96^{\circ} 58^{\prime} 6^{\prime \prime} \mathrm{W}, \mathrm{L}$. Alvarado et al. 873 (MEXU); $35 \mathrm{mi}$ by road north of Telixtlahuaca on road to Cuicatlan, W. R. Anderson y C. Anderson 5402 (ENCB, MEXU); $2 \mathrm{~km}$ al $W$ de Dominguillo, $H$. Arroyo 49 (ENCB, MEXU); $3 \mathrm{~km}$ al $\mathrm{N}$ de Cuicatlán, camino a Concepción Pápalo, H. Arroyo 52 (ENCB); $5 \mathrm{~km}$ al NE de Cuicatlán, camino a Concepción Pápalo, H. Arroyo 55 (ENCB); $7 \mathrm{~km}$ al NE de Cuicatlán, camino a Concepción Pápalo, H. Arroyo 57 (ENCB, IEB); $15 \mathrm{~km}$ al S de Dominguillo, municipio Cuicatlán, H. Arroyo 60 (ENCB, MEXU); $5 \mathrm{~km}$ al NW de Cuicatlán, camino a Quiotepec, H. Arroyo 64 (ENCB); 9 km al NE de Cuicatlán, camino a Concepción Pápalo, H. Arroyo 69 (ENCB); cerro del Ciruelo, San José del Chilar, C. A. Cruz y E. San Pedro 904 (MEXU); cerro Peña Blanca, San José del Chilar, C. A. Cruz y E. San Pedro 963 (MEXU); La Mantecosera, San José del Chilar, C. A. Cruz y E. San Pedro 1041 (MEXU); cerro El Zacatal, a 4 km al S de San José del Chilar, 1740'59" N, 9657'23" W, C. A. Cruz et al. 1157 (MEXU); cerro La

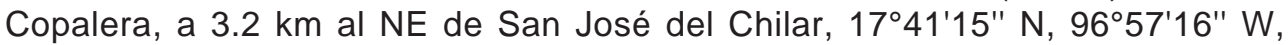
C. A. Cruz et al. 1446 bis (MEXU); $9 \mathrm{~km}$ al NE de Cuicatlán rumbo a Concepción Pápalo, F. González Medrano et al. F-1620 (ENCB, MEXU); terracería de Tomellín hacia Santa María Texcatitlán, R. Medina et al. 1059 (MEXU); 5 km de San Pedro Jaltepetongo, cañada W, R. Medina et al. 1100 (MEXU), 1101 (MEXU); terracería de Santiago Quiotepec a Cuicatlán, 17²47' N, 9657' W, R. Medina et al. 1261 (IEB, MEXU), 1272 (IEB, MEXU); laderas al SE de Cuicatlán, F. Miranda 4548 (MEXU); $3.2 \mathrm{~km}$ al S de Valerio Trujano, S. Ramírez 366 (OAX); $12 \mathrm{~km}$ al SE de Dominguillo, sobre la carretera a Oaxaca, J. Rzedowski 35465 (ENCB); 9 km al S de Dominguillo, 
sobre la carretera a Oaxaca, J. Rzedowski 36522 (ENCB); $6 \mathrm{~km}$ al N de Cuicatlán, carretera $131,2.5 \mathrm{~km}$ al W por la terracería que va rumbo a San Pedro Jocotipac, A. Salinas et al. 4251 (MEXU); 6.2 km de Cuicatlán hacia Jocotipac, municipio Cuicatlán, L. Schibli 109 (OAX); $6 \mathrm{~km}$ al entronque de la brecha a San Pedro Jocotipac, carretera Tehuacán - Cuicatlán, P. Tenorio 17908 (MEXU); 3 km al NE de Cuicatlán, I. Trejo 1586 (MEXU), 1660 (MEXU); San Pedro, municipio Cuicatlán, F. Ventura 15295 (ENCB, MEXU); El Mirador, municipio Santiago Nacaltepec, F. Ventura 15311 (ENCB), 15314 (ENCB); Dominguillo, F. Ventura 15317 (ENCB, IEB), 16434 (ENCB, MEXU), 16435 (ENCB, MEXU); Quiotepec, cerca del F.F.C.C. antes de pasar el río, F. Ventura 15343 (ENCB), 15344 (ENCB); San José del Chilar, F. Ventura 16438 (ENCB, MEXU). Distrito Etla: $4.5 \mathrm{~km}$ al W de Anonas, $H$. Arroyo 134 (ENCB). Distrito Teotitlán: $1.5 \mathrm{~km}$ al NE de Teotitlán del Camino, municipio Teotitlán del Camino, H. Arroyo 15 (ENCB), 17 (ENCB); 3 km al N de San Martín Toxpalan, municipio Teotitlán del Camino, H. Arroyo 22 (ENCB, MEXU); $2 \mathrm{~km}$ al NW de San Juan de Los Cues, municipio San Juan de Los Cues, $H$. Arroyo 39 (MEXU); $3 \mathrm{~km}$ al NW de Teotitlán del Camino, F. Chiang et al. F154 (MEXU); $3 \mathrm{~km}$ al NE de Teotitlán, sobre el camino a Huautla de Jiménez, $A$. García et al. 3372 (IEB, MEXU); San Antonio, H. S. Gentry 22419 (MEXU); 9 km al NE de Teotitlán del Camino, rumbo a Huautla, F. González Medrano et al. F1463 (MEXU); $5 \mathrm{~km}$ al N de Tecomavaca, sobre la carretera a Teotitlán del Camino, J. Rzedowski 28169 (ENCB, MEXU), 32866 (ENCB); 2 km al NW de San Antonio Nanahuatipam, por la terracería rumbo a la estación de tren San Antonio, A. Salinas y O. Dorado F-2660 (MEXU); 3 km adelante de Teotitlán del Camino, por la carretera a Huautla de Jiménez, A. Salinas et al. 4091 (IEB, MEXU); $4 \mathrm{~km}$ adelante de Teotitlán, por la carretera a Huautla de Jiménez, A. Salinas et al. 4227 (IEB, MEXU); $3 \mathrm{~km}$ adelante de Quiotepec, sobre la carretera rumbo a Tehuacán, $A$. Salinas 4872 (MEXU); río Seco a río Santiago, municipio Santa María Ixcatlán, A. Salinas et al. 6749 (MEXU); $5.5 \mathrm{~km}$ de Tecomavaca hacia Ixcatlán, L. Schibli 85 (OAX); puente del río Salado, municipio Tecomavaca, F. Ventura 15323 (ENCB, MEXU); Santiago Viejo, municipio Tecomavaca, F. Ventura 15326 (ENCB, IEB); camino a Telixtlahuaca, cerca de San Martín Toxpalan, municipio San Martín Toxpalan, F. Ventura 15336 (ENCB, IEB); cerro al oriente de San Juan de Los Cues, municipio San Juan de Los Cues, F. Ventura 15341 (ENCB); camino a Huautla de Jiménez, municipio Teotitlán del Camino, F. Ventura 15357 (ENCB, MEXU), 15359 (ENCB); Ignacio Mejía, municipio Teotitlán del Camino, F. Ventura 15369 (ENCB, MEXU). PUEBLA: Municipio Ajalpan, Come Callo, arroyo seco al NE de Ajalpan, $P$. Tenorio 12048 (MEXU). Municipio Coxcatlán: 1.5 km al NE de Coxcatlán, H. Arroyo 10 (ENCB, MEXU); antes de Coxcatlán, M. Cházaro et al. 653 (ENCB); $5 \mathrm{~km}$ adelante de Coxcatlán, M. Cházaro et al. 686 (ENCB, MEXU), 687 (ENCB, MEXU); brecha Coxcatlán a Coyomeapan, Sierra Negra, M. Cházaro y B. L. Mostul 7689 (MEXU); $3 \mathrm{~km}$ al NE de Teotitlán, P. Dávila 62 (ENCB); $45 \mathrm{~km}$ al SE de Tehuacán, $3.5 \mathrm{~km}$ al SE de Coxcatlán, camino a Teotitlán del Camino, A. C. Gibson 3443 (ENCB); $3 \mathrm{mi} \mathrm{N}$ of Teotitlán along hwy 131, C. T. Mason et al. 3020 (ENCB, UC); $3 \mathrm{~km}$ al S de Coxcatlán, J. Rzedowski 53867 (IEB, MEXU); rancho El Aguaje, aproximada- 
mente $4 \mathrm{~km}$ al $\mathrm{S}$ de la cabecera municipal, A. Valiente 154 (MEXU); Tilapa, $F$. Ventura 15350 (ENCB, IEB, MEXU), 15353 (ENCB); San Rafael, F. Ventura 15363 (ENCB, MEXU), 15364 (ENCB, MEXU); Pueblo Nuevo, F. Ventura 15379 (ENCB, MEXU), 15380 (ENCB, MEXU, UAMIZ). Municipio San José Miahuatlán: $10 \mathrm{~km}$ al SW del pueblo de Axusco, cerro Petlanco, F. Chiang et al. F-2483 (MEXU), F2485 (MEXU); $2 \mathrm{~km}$ al NE de cerro Petlanco, por la terracería rumbo a Axusco, F. Chiang et al. F-2486 (MEXU); alrededores de cerro Petlanco, A. Salinas y $P$. Solís F-3290 (MEXU); $8 \mathrm{~km}$ al SE de Axusco, cerro Petlanco, A. Salinas y C. $H$. Ramos F-3844 (MEXU); 6-7 km al SW de Axusco, A. Salinas et al. 4790 (MEXU). Municipio Tehuacán: $3 \mathrm{~km}$ al E de San Diego, H. Arroyo 7 (ENCB, MEXU); $4.4 \mathrm{~km}$ al E de San Pablo Tepetzingo, F. Chiang et al. F-108 (MEXU), F-116 (MEXU), F122 (MEXU); $5 \mathrm{mi}$ SW of Tehuacan along road to Huajuapan de Leon, C. T. Mason et al. 3022 (ENCB), 3024 (ENCB); barranca Nopale, Santa Ana Teloxtoc, D. Robles 16 (MEXU); $8 \mathrm{~km}$ al SW de Tehuacán, sobre la carretera a Huajuapan, J. Rzedowski 35628 (ENCB, IEB, MEXU); 8 km al SW de Tehuacán, J. Rzedowski 19124 (ENCB); Tula, F. Ventura 15268 (ENCB, MEXU); San José Tochapa, F. Ventura 15273 (ENCB), 15277 (ENCB, MEXU), 15278 (ENCB); cerro Colorado, cerca de San Pablo, F. Ventura 15385 (ENCB), 15388 (ENCB, MEXU). Municipio Zapotitlán: a $3 \mathrm{~km}$ del poblado de San Juan Raya, por la brecha, 18 $8^{\circ} 19^{\prime} 12^{\prime \prime} \mathrm{N}, 97^{\circ} 36^{\prime} 18^{\prime \prime} \mathrm{W}$, L. Alvarado et al. 148 (MEXU); $5 \mathrm{~km}$ después de Acatepec, carretera Huajuapan de León a Tehuacán, J. Chavelas y C. Zamora ES-4840 (MEXU); hills and river valley on E side of hwy 125, Tehuacan - Huajuapan de Leon road, $3.7 \mathrm{~km} \mathrm{~S}$ of San Antonio Texcala, $13 \mathrm{~km} \mathrm{~S}$ of Tehuacan, T. S. Cochrane et al. 8512 (ENCB, MEXU); $12 \mathrm{~km}$ al NE de Acatepec, F. Chiang et al. F-1910 (MEXU); $25 \mathrm{mi}$ SW of Tehuacan, $3 \mathrm{mi}$ of road to Huajuapan, H. S. Gentry et al. 20237 (ENCB); $20 \mathrm{~km}$ al SW de Tehuacán, A. C. Gibson 3452 (ENCB); terracería a San Juan Raya, $18^{\circ} 19^{\prime}$ N, 97³6' W, R. Medina et al. 1200 (IEB, MEXU); 4 km al NE de Zapotitlán Salinas, sobre la carretera a Tehuacán, J. Rzedowski 33234 (ENCB, MEXU); hwy 125, km 24, S of Tehuacan, E. H. Sallee ES-72 (MEXU); hwy 125, km $33 \mathrm{~S}$ of Tehuacan, E. H. Sallee ES-97 (MEXU); 4 km al NW de Los Reyes Mezontla, brecha a Zapotitlán Salinas, P. Tenorio 17365 (MEXU); 2 km del poblado de San Juan Raya, A. Valiente et al. 371 (MEXU); Los Reyes Mezontla, $1 \mathrm{~km}$ al NW del poblado, A. Valiente et al. 500 (MEXU); San Antonio Texcala, F. Ventura 15257 (ENCB, IEB), 15261 (ENCB, IEB); minas de cantera de San Antonio Texcala, F. Ventura 15266 (ENCB, MEXU); cerro de La Colmena, F. Ventura 15280 (ENCB, MEXU); cerro El Sanjuanero, F. Ventura 15286 (ENCB, MEXU), 15288 (ENCB, IEB), 15289 (ENCB, MEXU). Municipio Zinacatepec: Mazatepec, F. Ventura 15372 (ENCB, MEXU), 15376 (ENCB).

En la descripción original de $B$. aptera no hay referencia a ejemplares preservados y en ningún herbario mexicano se localizaron tales especímenes, por lo que procede aceptar como tipo al dibujo que forma parte del protólogo y que ilustra de manera apropiada a la planta en cuestión. 


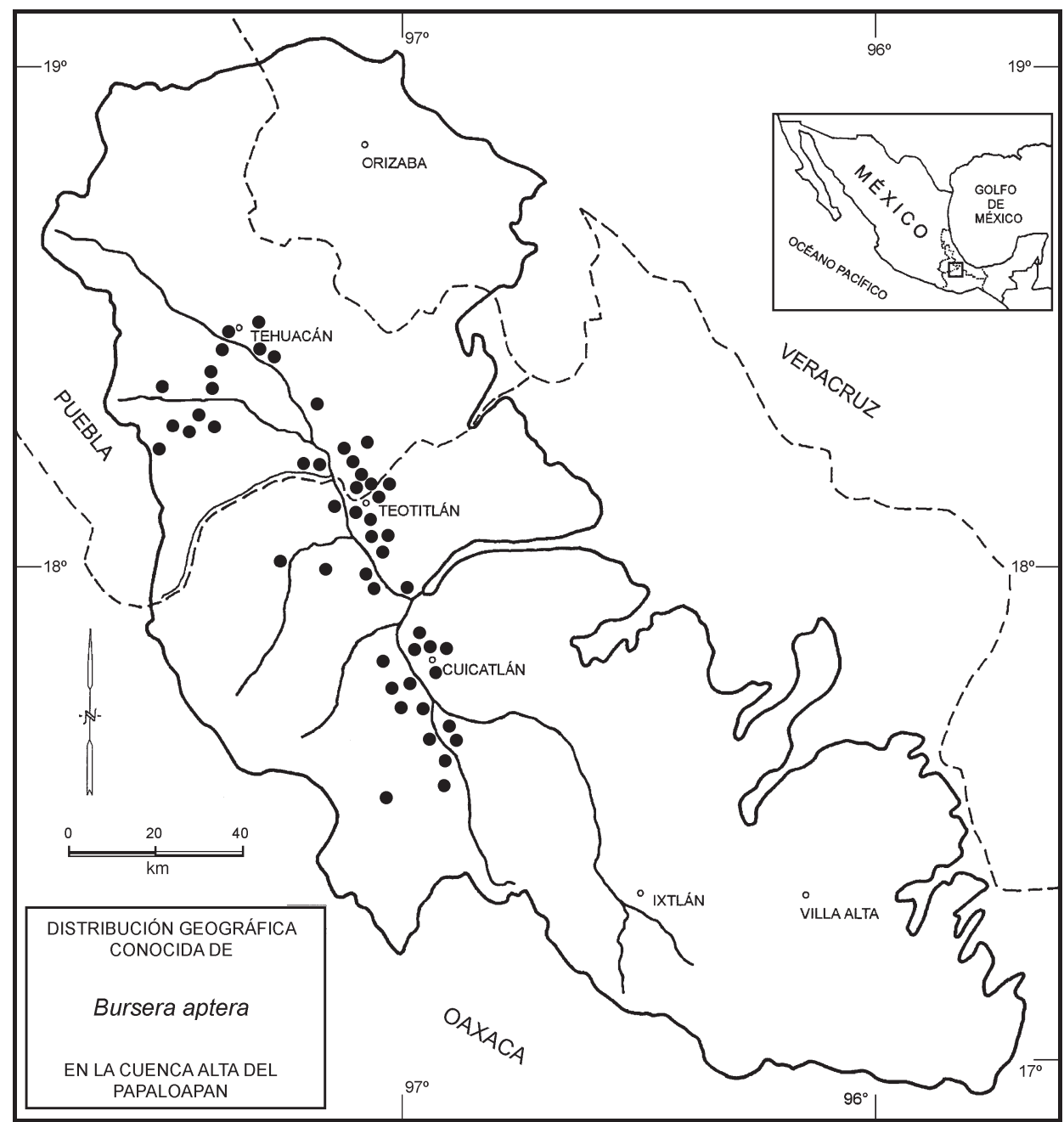

Bursera aptera a menudo se confunde con $B$. fagaroides, sobre todo cuando las plantas no tienen hojas plenamente desarrolladas, debido a que las dos especies presentan la corteza amarillenta exfoliante en láminas grandes y a que sus foliolos se parecen en las primeras etapas de desarrollo. Cuando hay hojas maduras, se les reconoce fácilmente porque $B$. aptera carece de raquis alado, tiene mayor número de foliolos y su fruto es marcadamente apiculado.

Esta similitud llevó a Bullock (op. cit., p. 361) a considerar a B. aptera como sinónimo taxonómico de $B$. fagaroides, pero autores posteriores reivindicaron a la primera como especie independiente. 
3. Bursera arida (Rose) Standl., Publ. Field Mus. Nat. Hist. Chicago, Bot. Ser. 4: 217. 1929. Terebinthus arida Rose, Contr. U.S. Nat. Herb. 10: 118, t. 36.1906. Elaphrium aridum (Rose) Rose, North Amer. Fl. 25: 249. 1911. Tipo: México: Puebla: hills east of Tehuacan, 31.VIII.1905, J. N. Rose, J. H. Painter y J. S. Rose 9985 (holotipo US, isotipo MEXU!).

Nombre común registrado en la zona de estudio: cabrestillo, zapotillo.

Arbusto o a veces árbol bajo, dioico, de (0.8)2 a 3(4) $\mathrm{m}$ de alto, resinoso, aromático; tronco hasta de $20 \mathrm{~cm}$ de diámetro, su corteza externa rojiza, amarillenta o pardo-amarillenta, exfoliando en tiras grandes, ramas maduras de color gris oscuro, glabras, las ramillas jóvenes densamente hirsútulas; hojas aglomeradas en el ápice de las ramillas cortas, con menos frecuencia alternas en ramillas de crecimiento nuevo, imparipinnadas, de (0.8)1.3 a 2(2.5) $\mathrm{cm}$ de largo y de hasta $1 \mathrm{~cm}$ de ancho, peciolos de 3 a 5(6) $\mathrm{mm}$ de largo, densa a escasamente hirsútulos, ligeramente alados, foliolos (3)5 a 9(11), raquis estrechamente alado, hirsútulo, peciólulos laterales de ca. $1 \mathrm{~mm}$ de largo, generalmente presentes en los foliolos proximales, el terminal de 0 a $3 \mathrm{~mm}$ de largo, foliolos oblongos a obovados, de $4 \mathrm{a}$ 6(9) $\mathrm{mm}$ de largo y de 1.3 a $2 \mathrm{~mm}$ de ancho, ápice agudo a obtuso, base cuneada, margen entero, de textura cartácea, haz y envés glabros, sólo la nervadura central evidente; flores solitarias, subsésiles, las masculinas trímeras o algunas veces tetrámeras, de 2 a $2.5 \mathrm{~mm}$ de largo, lóbulos del cáliz triangulares, de ca. $1.5 \mathrm{~mm}$ de largo, pilósulos por fuera, pétalos rojizos, cuculados, de ca. $2 \mathrm{~mm}$ de largo, pilósulos por fuera, estambres 6(8), filamentos de $0.4 \mathrm{~mm}$ de largo, anteras oblongas, de 0.7 a $0.8 \mathrm{~mm}$ de largo, gineceo vestigial; las femeninas trímeras, similares a las masculinas, pero de $1.5 \mathrm{a} 2 \mathrm{~mm}$ de largo, sobre pedicelos de 0.5 a $1 \mathrm{~mm}$ de largo, pilosos, anteras de los estaminodios de $0.3 \mathrm{~mm}$ de largo, ovario trilocular, estigmas 3; frutos solitarios o en pares en los ápices de ramillas cortas, sobre pedúnculos de 1 a $2 \mathrm{~mm}$ de largo, engrosados y pilosos, trivalvados, trígonos u ovoides, de 4 a $5 \mathrm{~mm}$ de largo, apiculados, oscuros en la madurez y pilósulos o rara vez glabros, hueso ovoide o trígono, de 3 a $4 \mathrm{~mm}$ de largo, totalmente cubierto por un pseudoarilo de color amarillo pálido.

Habita principalmente en el matorral xerófilo, con menos frecuencia en el bosque tropical caducifolio, en altitudes de 950 a $1750 \mathrm{~m}$. Florece en mayo y junio. Se encuentra sin hojas de noviembre a mayo.

Especie endémica de México, sólo conocida de los estados de Puebla y Oaxaca. Vive en las zonas más secas de la cuenca.

Material examinado: OAXACA: Distrito Coixtlahuaca: Agua El Tule, ladera E de Cerro Verde, municipio Tepelmeme Villa de Morelos, P. Tenorio et al. 8876 (MEXU). Distrito Teotitlán: $1 \mathrm{~km}$ después de San Martín Toxpalan, rumbo a Cuicatlán, F. González Medrano et al. F-1157 (MEXU); 6 km SE of Teotitlan on 


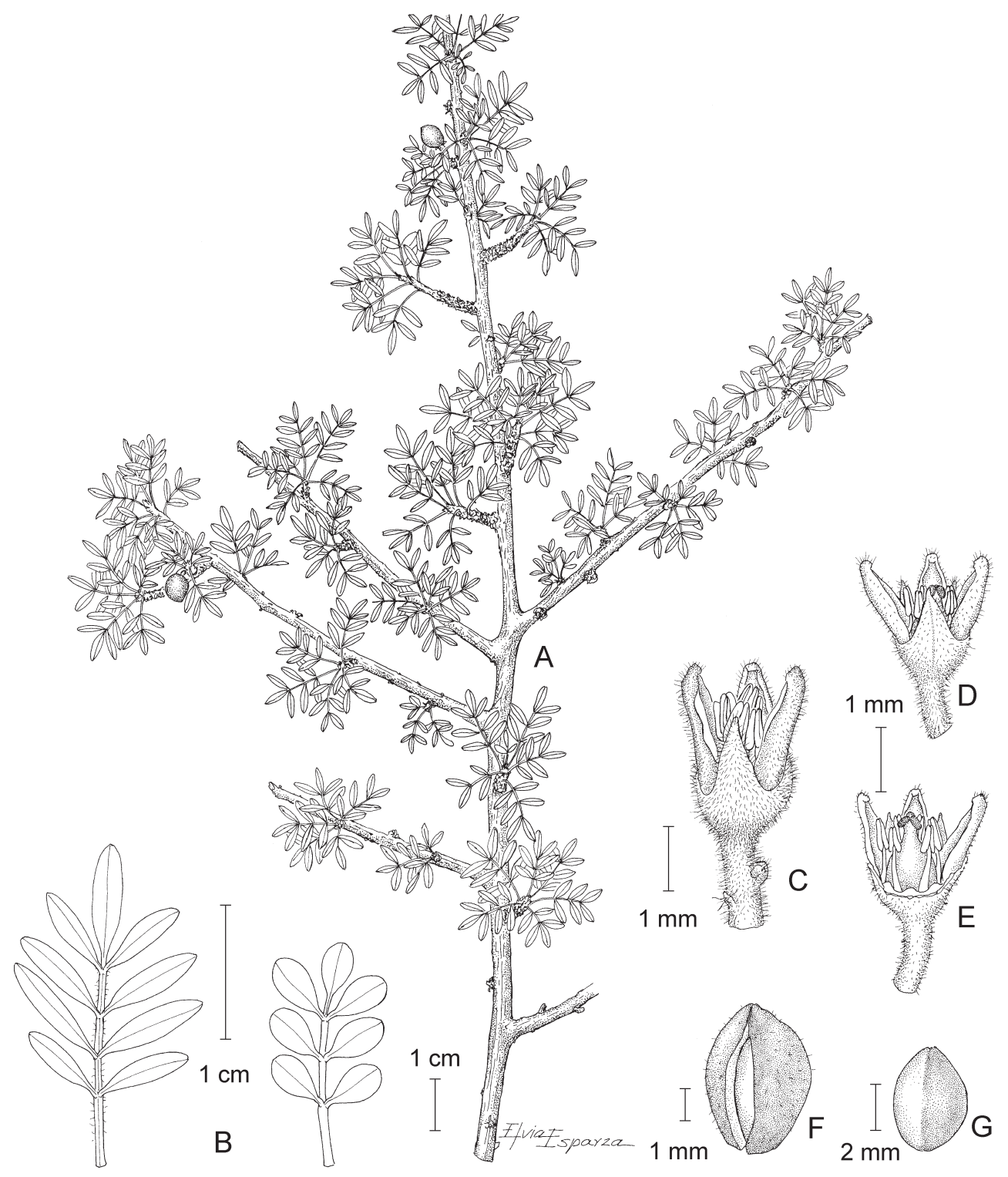

Bursera arida (Rose) Standl. A. rama con hojas y frutos; B. dos variantes de hojas; C. flor masculina; D. flor femenina; E. flor femenina desprovista de un segmento del cáliz; F. fruto; G. hueso. Ilustrado por Elvia Esparza. 
hwy between Tehuacan and Telixtlahuaca, W. D. Stevens y E. Martínez 25209 (IEB, MEXU); camino a Telixtlahuaca, municipio San Martín, F. Ventura 15337 (ENCB, MEXU); cerro al oriente de San Juan de Los Cues, F. Ventura 15338 (ENCB, MEXU). PUEBLA: Municipio Caltepec: Cerro Grande, al SE de Caltepec, $P$. Tenorio y C. Romero de T. 5006 (IEB). Municipio Coxcatlán: Tehuacán - Teotitlán, W. Rauh 24758 (MEXU); 3 km al SE de San Rafael, J. Rzedowski 53871 (IEB, MEXU); near Coxcatlan on Cerro Ajuereado and in the adjacent valley, C. E. Smith Jr. et al. 3555 (MEXU); San Rafael, F. Ventura 15367 (ENCB, MEXU). Municipio San Gabriel Chilac: Barranca al E de La Venta, camino a Chilac, P. Tenorio 17526 (MEXU). Municipio San José Miahuatlán: Cerro Tepetroje, aproximadamente $6 \mathrm{~km}$ al SW de San José Axusco, A. Salinas y P. Solís F-3589 (MEXU); Rincón del Infiernillo, al E de Agua de Los Granados, P. Tenorio et al. 17190 (MEXU). Municipio Tehuacán: $1.5 \mathrm{~km}$ al este de Tehuacán, H. Arroyo 2 (IEB, MEXU), 3 (IEB, MEXU), 4 (IEB, MEXU); $2 \mathrm{~km}$ al W de Tehuacán, F. Chiang et al. F-9a (ENCB, MEXU), F-9b (MEXU); $4.4 \mathrm{~km}$ al E de San Pablo Tepetzingo, F. Chiang et al. F54 (ENCB, MEXU), F-76 (MEXU), F-114 (MEXU); Meseta de San Lorenzo, F. Chiang y M. A. Martínez F-2322 (MEXU); Meseta de San Lorenzo, $8 \mathrm{~km}$ al W de Tehuacán, A. García et al. 3301 (IEB, MEXU); 3 km al W de Tehuacán, F. González Medrano et al. F-1369 (MEXU); 5 mi SW of Tehuacan along road to Huajuapan de Leon, C. T. Mason et al. 2964 (UC), 3026 (ENCB, UC); Tehuacán, F. Miranda 3493 (MEXU); SW de El Riego, F. Miranda 4375 (MEXU); El Riego, C. A. Purpus 1293 (UC); Tehuacán, C. A. Purpus 5708 (UC); 8 km al SW de Tehuacán, sobre el camino a Zapotitlán, L. S. Rodríguez y A. Patiño 1404 (ENCB); cerros al W de Tehuacán, J. Rzedowski 9016 (ENCB, MEXU); $8 \mathrm{~km}$ al W de Tehuacán, J. Rzedowski 19123 (ENCB), 35629 (ENCB, MEXU); El Riego, $3 \mathrm{~km}$ al W de Tehuacán, J. Rzedowski 28179 (ENCB); hwy 125, ca. 4 to 5 mi SW of Tehuacan, L. Spetzman y M. Zapien 1389 (MEXU); cerro Colorado, cerca de San Pablo, F. Ventura 15389 (ENCB, MEXU). Municipio Zapotitlán: camino a Los Reyes Mezontla, $3 \mathrm{~km}$ al E de la carretera Zapotitlán - Huajuapan, H. Arroyo 135 (ENCB, IEB, MEXU); 4 km NW de Los Reyes Mezontla, H. Arroyo 140 (ENCB); $17 \mathrm{~km}$ al SW de Tehuacán, F. Chiang et al. F-347 (MEXU), F-366 (MEXU); $12 \mathrm{~km}$ al NE de Acatepec, F. Chiang et al. F-1916 (MEXU), F-1923 (MEXU); $3 \mathrm{~km}$ al SW de San Antonio Texcala, SW de Tehuacán, A. C. Gibson 3447 (ENCB, MEXU); La Venta, R. Medellín et al. 26 (MEXU); terracería a San Juan Raya, 18¹9' N, 97³4' W, R. Medina et al. 1197 (IEB, MEXU), 1199 (IEB, MEXU), 1202 (IEB, MEXU); km 11 carretera Tehuacán - Zapotitlán Salinas, L. A. Pérez et al. 1421 (MEXU); 1 km al N de Zapotitlán Salinas, sobre la carretera a Tehuacán, J. Rzedowski 28177 (ENCB), 28178 (ENCB); $4 \mathrm{~km}$ al NE de Zapotitlán Salinas, sobre la carretera a Tehuacán, J. Rzedowski 33235 (ENCB); 3 km al S de San Antonio Texcala, sobre la carretera a Zapotitlán, J. Rzedowski 34964 (ENCB, MEXU); 3 km al SW de San Antonio Texcala, sobre el camino a Zapotitlán Salinas, J. Rzedowski 35419 (ENCB, MEXU); $15 \mathrm{~km}$ al SW de Tehuacán, sobre la carretera a Huajuapan, J. Rzedowski 37067 (ENCB, IEB, MEXU); $1 \mathrm{~km}$ al N de Zapotitlán Salinas, frente a los viveros de Cactáceas, A. Salinas y A. Reyes 4892 (MEXU); 4 km al W de Santa Ana 


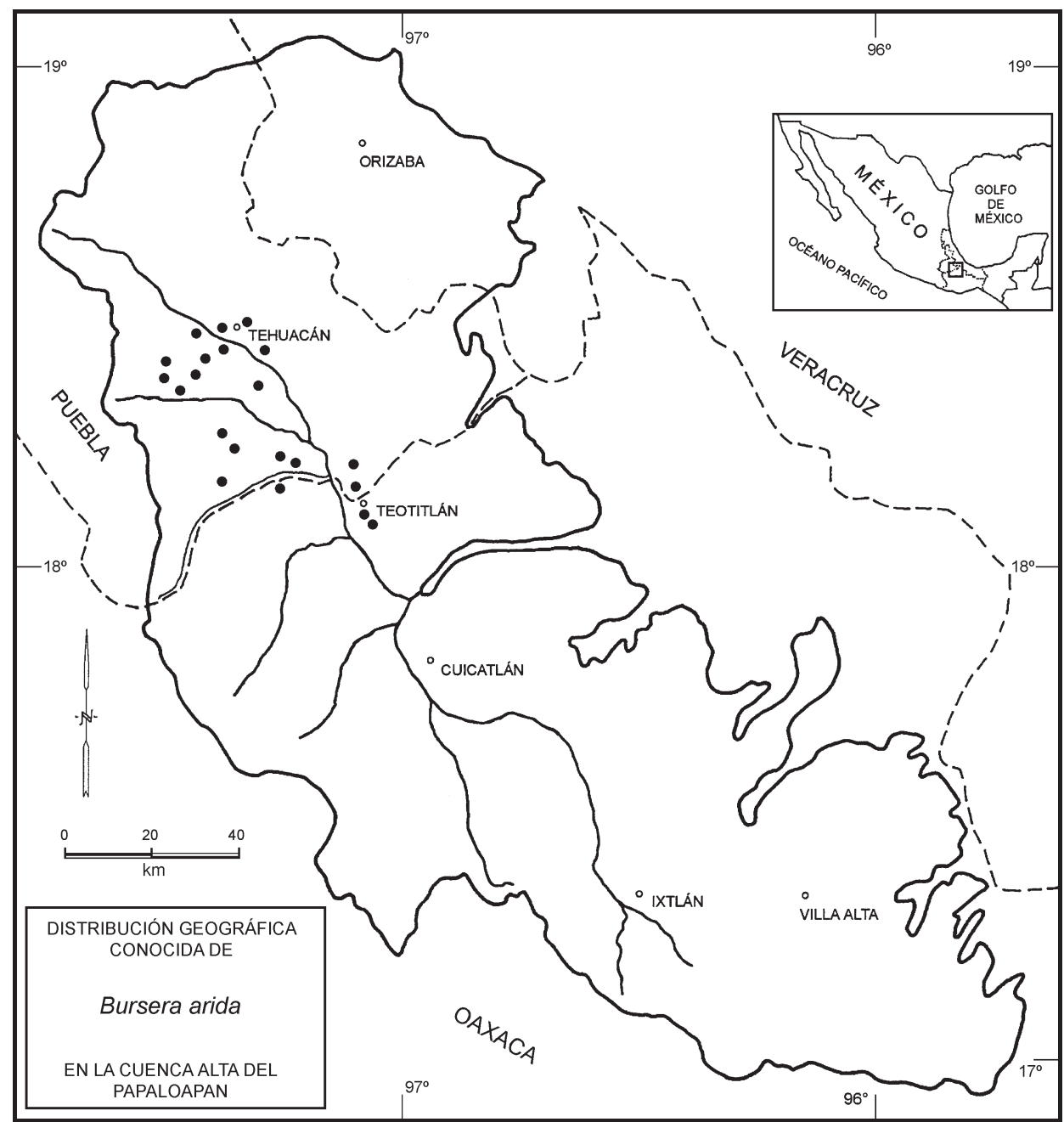

Teloxtoc, P. Tenorio 7269 (MEXU, UAMIZ); San Juan Raya, $2 \mathrm{~km}$ al NE del poblado, A. Valiente et al. 313 (MEXU); Los Reyes Mezontla, $1 \mathrm{~km}$ al NW del poblado, $A$. Valiente et al. 492 (MEXU); Cerro Viejo, A. Valiente et al. 892 (MEXU); cerro de La Colmena, F. Ventura 15283 (IEB, MEXU); cerro Sanjuanero, F. Ventura 15287 (ENCB, MEXU); km 20 carretera Tehuacán - Zapotitlán, Biología de Campo s. $n$. (MEXU).

Los ejemplares H. Arroyo 140 y J. Rzedowski 33235, difieren del resto del material. De entre las especies de Bursera que habitan la región, $B$. arida es la que presenta las hojas y los foliolos más pequeños, por lo que llaman la atención estos especímenes, que poseen hojas de mayor tamaño (hasta de $6 \mathrm{~cm}$ de largo, 
cuando normalmente no rebasan los $2.5 \mathrm{~cm}$ ), los foliolos son más numerosos (casi el doble) y sus pedúnculos fructíferos miden hasta $1 \mathrm{~cm}$ de largo, mientras que en $B$. arida son sólo de 1 ó $2 \mathrm{~mm}$. Estas características señalan una notable similitud con $B$. galeottiana, con la que $B$. arida a menudo convive; sin embargo los ejemplares en cuestión tienen la corteza exfoliante amarilla o algo anaranajada, pero no rojiza, como se observa en $B$. galeottiana. Lo anterior hace suponer que puede tratarse de híbridos con esta última especie.

Referente a posibles híbridos entre $B$. arida y $B$. morelensis, véase la discusión del inciso correspondiente a $B$. morelensis.

Los troncos de esta planta se emplean a manera de horcones.

4. Bursera ariensis (H.B.K.) McVaugh \& Rzed., Kew Bull. 18: 375. 1965. Elaphrium? ariense H.B.K., Nov. Gen. Sp. 7: 31. 1824. Tipo: México: Michoacán: Inter Pazcuaro et montem Jorullo, prope Ario, A. Humboldt y A. Bonpland 4327 (holotipo P!).

Bursera pannosa Engl., DC. Monogr. Phaner. 4: 55. 1883. Terebinthus pannosa (Engl.) Rose, Contr. U. S. Nat. Herb. 10: 121. 1906. Elaphrium pannosum (Engl.) Rose, North Amer. Fl. 25: 254. 1911. Tipo: México: Oaxaca: Mirador, San Felipe, V.1842, F. M. Liebmann 78 (holotipo C, isotipo P!).

Bursera sessiliflora Engl., DC. Monogr. Phaner. 4: 55. 1883. Terebinthus sessiliflora (Engl.) Rose, Contr. U. S. Nat. Herb. 10: 122. 1906. Elaphrium sessiliflorum (Engl.) Rose, North Amer. Fl. 25: 254. 1911. Tipo: México: sin localidad precisa, F. W. Karwinski s. n. (holotipo M).

Elaphrium brachypodum Rose, North Amer. FI. 25: 253. 1911. Bursera brachypoda (Rose) Engl., Nat. Pflanzenfam. ed. 2, 19a: 426. 1931. Tipo: México: Jalisco: near Etzatlán, 2.X.1903, J. N. Rose y J. H. Painter 7534 (holotipo US, isotipos NY, P!).

Bursera sessiliflora var. pubivalvis Bullock, Bull. Misc. Inf. Kew 1937: 451. 1937. Tipo: México: Guerrero: Distrito Mina: Placeres - Puerto, 6.VII.1936, G. B. Hinton et al. 9052 (holotipo K!, isotipos F, MEXU!, NY, US).

Nombres comunes registrados fuera de la zona de estudio: copal, copal amarillo, copal blanco, copal grande, copalillo, cuajiote, cuajiote blanco, guande, guande blanco, mata perro, papelillo.

Árbol o a veces arbusto dioico, de 2 a $8 \mathrm{~m}$ de alto, con abundante resina aromática; tronco hasta de $30 \mathrm{~cm}$ de diámetro, su corteza interna verdosa, con látex blanquecino o de color crema que ennegrece al contacto con el aire, la externa exfoliante, amarilla o amarillo-grisácea, a veces tendiendo a anaranjada, ramas jóvenes velutino-pubérulas o subtomentosas; hojas mayormente agrupadas en forma de rosetas en los ápices de ramillas cortas, otras veces alternas en ramillas 


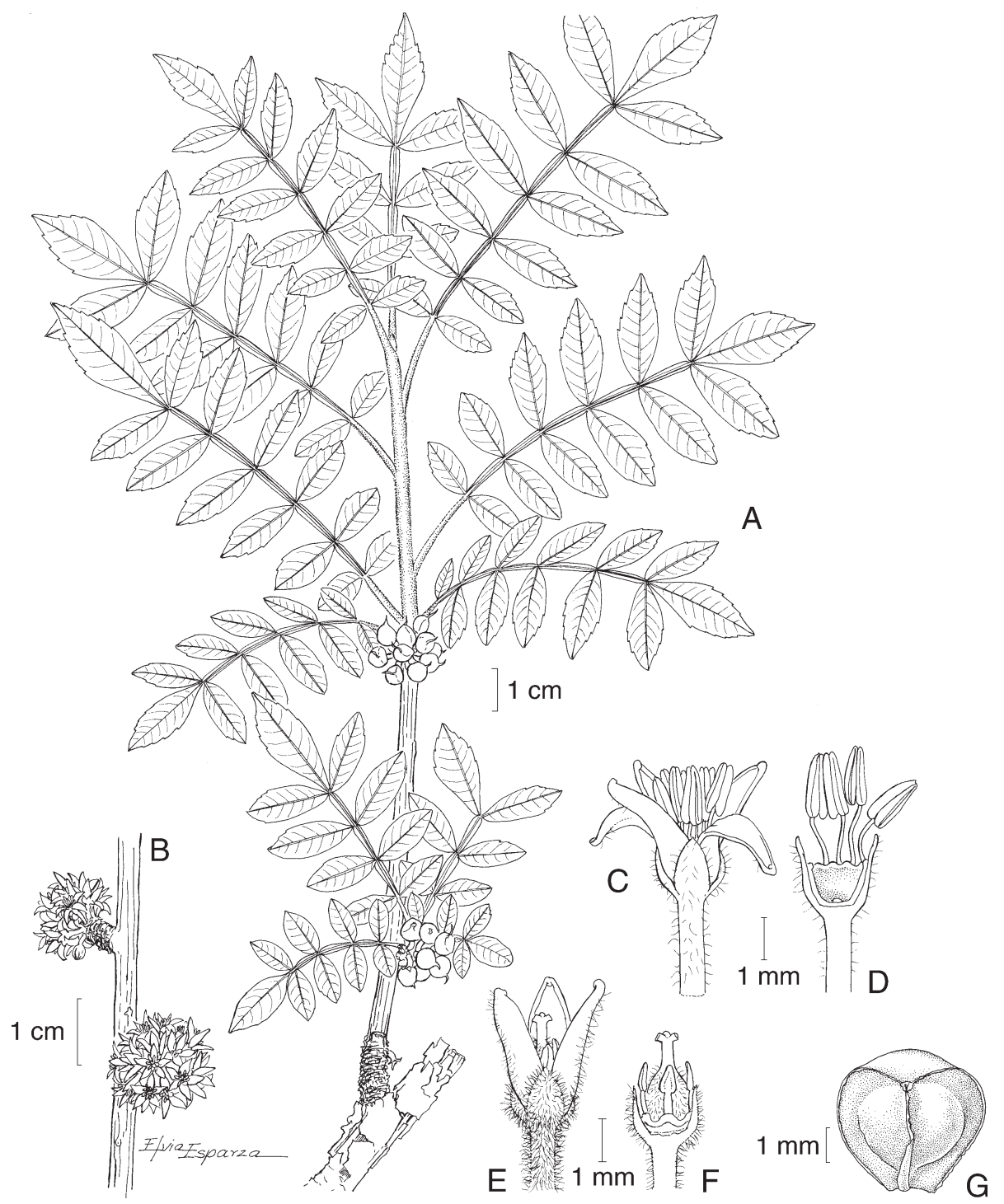

Bursera ariensis (H.B.K.) McVaugh \& Rzed. A. rama con hojas y frutos; B. conjuntos de flores masculinas aglomeradas sobre ramillas cortas; C. flor masculina; D. flor masculina desprovista de una parte del cáliz, de los pétalos y de 6 estambres; E. flor femenina; F. flor femenina desprovista de una parte del cáliz y de los pétalos; G. fruto. Ilustrado por Elvia Esparza. 
de crecimiento nuevo, catafilos ausentes o prácticamente ausentes, hojas imparipinnadas, oblongas en contorno general, de 5 a $22 \mathrm{~cm}$ de largo y 2 a $7 \mathrm{~cm}$ de ancho, peciolo de 0.5 a $3 \mathrm{~cm}$ de largo, raquis con alas hasta de $1 \mathrm{~mm}$ de ancho de cada lado, foliolos (5)9 a 19, sésiles o subsésiles, elípticos a oblongos, lanceolados u oblanceolados, el terminal a menudo subrómbico, de 1 a $3.5 \mathrm{~cm}$ de largo, de 0.4 a $1.8 \mathrm{~cm}$ de ancho, por lo común agudos o acuminados en el ápice, cuneados a redondeados en la base, los laterales comúnmente oblicuos, margen serrado a entero, de textura membranácea a cartácea, nervadura central evidente en ambas caras, densamente pubérulos a subtomentosos en ambas caras en la juventud, con pelos más espaciados en la madurez; flores solitarias, pero a menudo densamente aglomeradas en los ápices de ramillas cortas, sésiles o casi sésiles; las masculinas pentámeras, lóbulos del cáliz triangulares, de 0.7 a $1.7 \mathrm{~mm}$ de largo, amarillo-rojizos, pubérulos por fuera, pétalos oblongos a lanceolados, de 3 a $4 \mathrm{~mm}$ de largo, notablemente involutos, amarillo-anaranjados con tintes rojizos, esparcidamente pubérulos por fuera o totalmente glabros, anteras oblongas, de 1 a $1.3 \mathrm{~mm}$ de largo, gineceo vestigial; flores femeninas trímeras, similares a las masculinas, aunque a menudo más intensamente rojizas, estaminodios de poco menos de $1 \mathrm{~mm}$ de largo; ovario trilocular, estigmas 3; pedúnculo fructífero de $1 \mathrm{a}$ $3 \mathrm{~mm}$ de largo, más bien grueso, frutos a menudo densamente aglomerados, trivalvados, subesféricos a obovoides, por lo general apiculados, rojizos, de 6 a $8 \mathrm{~mm}$ de largo, pubérulos en la juventud pero por lo general glabros en la madurez, hueso ovoide o trígono, de 4 a $5 \mathrm{~mm}$ de largo, cubierto totalmente por el pseudoarilo amarillo o anaranjado.

Especie de presencia esporádica y marginal en la región de estudio, mucho más común en otros sectores de Oaxaca. Habita en el bosque tropical caducifolio, con frecuencia en sitios de transición con el encinar, en altitudes entre 1400 y $1800 \mathrm{~m}$. Florece de abril a principios de junio. Permanece sin follaje de noviembre a mayo.

Se distribuye de Nayarit a Oaxaca.

Material examinado: OAXACA: Distrito Etla: km 215 autopista Oaxaca Tehuacán, S. Acosta 2440 (MEXU). Distrito indefinido (Mixe o Tlacolula): vicinity of Cerro Zempoaltepetl. Along trail from Tlahuitoltepec to Santo Domingo Albarradas, 18-25 kilometers west southwest of summit, B. Hallberg 981 (ENCB).

Bursera ariensis forma parte del complejo de $B$. fagaroides, distinguiéndose por sus hojas pubescentes, de $1 \mathrm{~cm}$ o más de largo, con el raquis notablemente alado. La identidad de esta especie permaneció confundida por mucho tiempo, hasta que Bullock (1936) la reconoció claramente bajo el nombre de B. sessiliflora; posteriormente McVaugh y Rzedowski encontraron que el binomio cronológicamente anterior Elaphrium ariense también se basa en materiales de este taxon, por lo que establecieron la transferencia apropiada. 


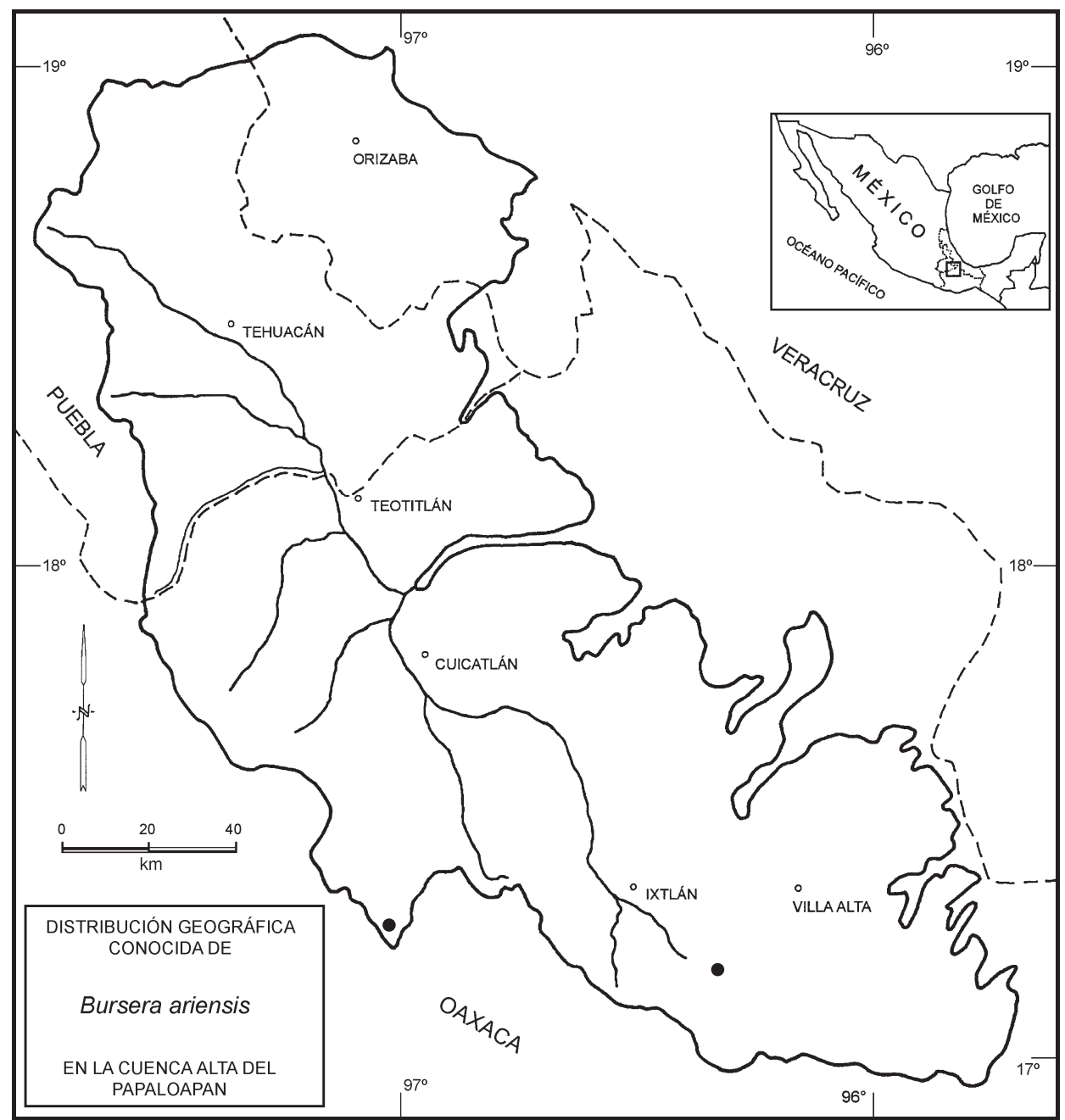

Fuera del área de estudio la especie se emplea para formar cercas vivas, el látex se usa como pegamento y la resina aromática a manera de incienso.

5. Bursera aspleniifolia Brandegee, Univ. Calif. Publ. Bot. 3: 382. 1909. Elaphrium aspleniifolium (Brandegee) Rose, North Amer. Fl. 25: 254. 1911. Tipo: México: Puebla: vicinity of San Luis Tultitlanapa, VI.1908. C. A. Purpus 3162 (holotipo UC!, isotipos NY, US).

Nombres comunes registrados en la zona: copal, copalillo. 
Rzedowski et al.: Las especies de Bursera de la cuenca del río Papaloapan, México

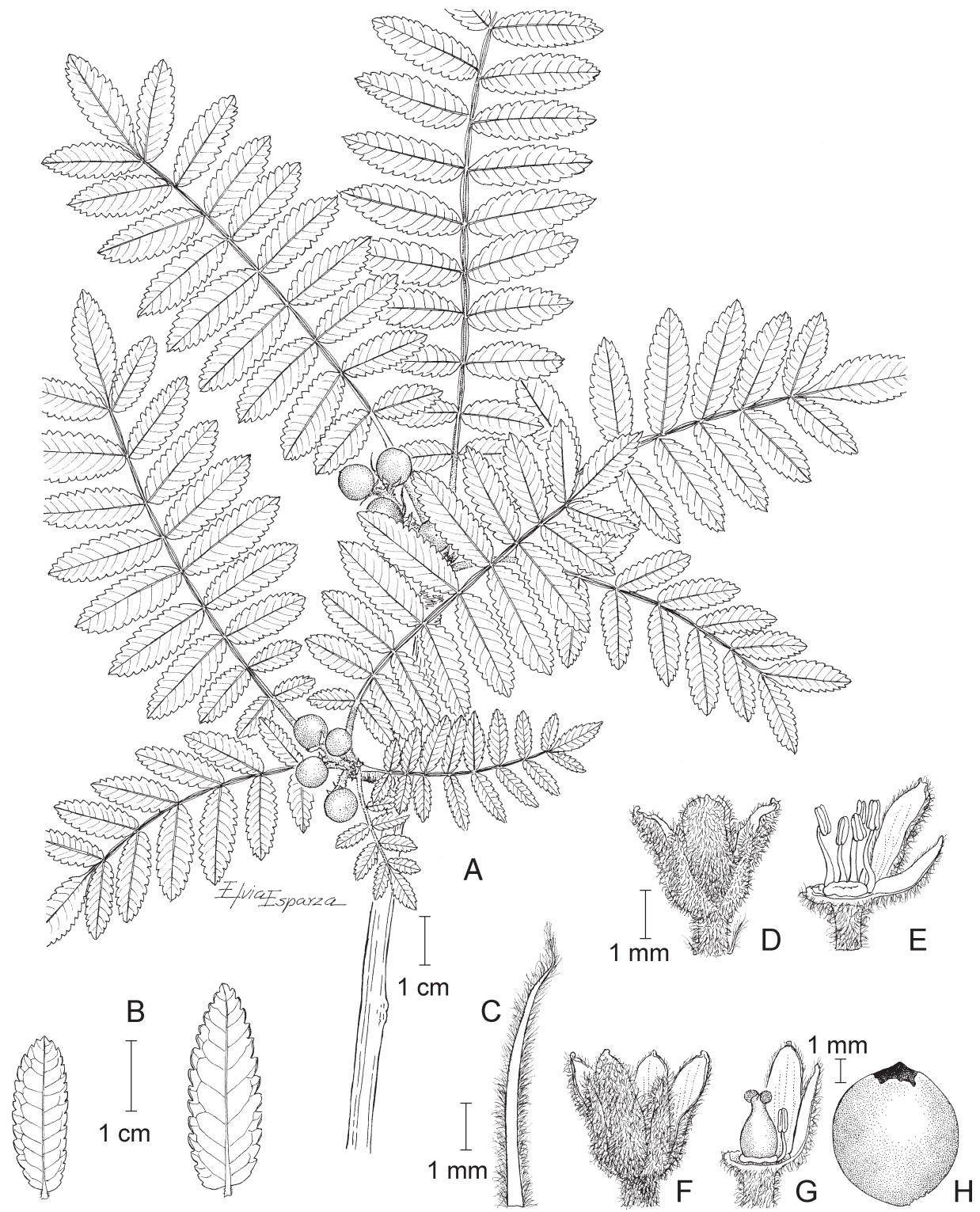

Bursera aspleniifolia Brandegee. A. rama con hojas y frutos; B. foliolos mostrando las nervaduras; C. bracteola; D. flor masculina en vista externa; E. flor masculina desprovista de 3 segmentos del cáliz, de 3 pétalos y de 3 estambres; F. flor femenina en vista externa; G. flor femenina desprovista de 3 segmentos del cáliz, de 3 pétalos y de 7 estaminodios; H. hueso. Ilustrado por Elvia Esparza. 
Árboles o arbustos de 2 a $8 \mathrm{~m}$ alto, dioicos, con resina transparente, aromáticos; tronco de corteza grisácea, no exfoliante, ramas maduras lisas, grisáceas y glabras, ramillas jóvenes lisas, rojizas y ligeramente pilosas, hojas precedidas en su aparición por un conjunto de catafilos triangulares, de 5 a $8 \mathrm{~mm}$ de largo, densamente tomentosos, tempranamente deciduos; hojas aglomeradas en el ápice de ramillas cortas, o bien, alternas en ramillas vigorosas de crecimiento nuevo, peciolos de (0.5)1 a $2.5 \mathrm{~cm}$ de largo, viloso-tomentosos, lámina de 10 a $20.5 \mathrm{~cm}$ de largo y 2 a $7 \mathrm{~cm}$ de ancho, imparipinnada, raquis acanalado, densamente vilosotomentoso, angostamente alado, el ala revoluta (envolviendo prácticamente al raquis), foliolos 13 a 23, sésiles, elíptico-oblongos, de 1 a $3.5 \mathrm{~cm}$ de largo y 0.8 a $1(1.5) \mathrm{cm}$ de ancho, acuminados a obtusos en el ápice, margen irregularmente crenado-serrado, ligeramente revoluto, nervadura principal y secundarias prominentes, las secundarias paralelas, no ramificadas o en ocasiones ramificadas muy cerca del margen, sin nervaduras terciarias evidentes y sin formación de retículo, haz pubescente, verde oscuro, envés cinéreo-tomentoso, verde-amarillento o verderojizo; inflorescencias en forma de panículas tirsiformes compactas aunque a menudo algo interruptas, de 2 a $4(7.5) \mathrm{cm}$ de largo, flores numerosas, densamente tomentosas, bracteolas lineares a triangulares, de 2 a $6 \mathrm{~mm}$ de largo, densamente vilosas por fuera, internamente glabras, pedicelos hasta de $2 \mathrm{~mm}$ de largo, con frecuencia mucho más cortos; flores masculinas tetrámeras, lóbulos del cáliz triangular-acuminados, de 1.5 a $2.5 \mathrm{~mm}$ de largo, libres prácticamente hasta la base, glabros por dentro, densamente vilosos por fuera, pétalos blanquecino-verdosos, de 2 a $3 \mathrm{~mm}$ de largo, oblongos a oblanceolados, involutos, ápice inconspicuamente mucronado, vilosos por fuera, estambres 8 , filamentos de 0.8 a $1.2 \mathrm{~mm}$ de largo, linear-triangulares, anteras oblongas, de 0.5 a $0.7 \mathrm{~mm}$ de largo, gineceo vestigial; flores femeninas con perianto similar al de las masculinas, pero con pétalos ligeramente más cortos que los segmentos del cáliz, estaminodios con anteras de menor tamaño, ovario bilocular, estigmas 2; pedúnculos fructíferos de (0.2)0.5 a $3 \mathrm{~cm}$ de largo, tomentoso-amarillentos, pedicelos de 1 a $2 \mathrm{~mm}$ de largo, densamente tomentosos; frutos por lo común numerosos, bivalvados, subglobosos, de ápice apiculado, de 7 a $8 \mathrm{~mm}$ de diámetro, glabros, pardo-rojizos, hueso de 6 a $7 \mathrm{~mm}$ de diámetro, total o casi totalmente cubierto por un pseudoarilo amarillo o anaranjado.

Se encuentra en bosque tropical caducifolio y matorral xerófilo, sobre suelos someros negros y pardos, derivados de caliza, así como en suelos amarillos arenosos y en suelos depauperados derivados de lutitas y conglomerados, en altitudes de 1200 a $2100 \mathrm{~m}$. Florece en mayo y junio.

Especie endémica de México, se conoce de los estados de Oaxaca y Puebla.

Material examinado: OAXACA: Distrito Teotitlán: $3 \mathrm{~km}$ al NE de Teotitlán, sobre el camino a Huautla de Jiménez, A. García et al. 3355 (IEB, MEXU); $10 \mathrm{~km}$ al E de Teotitlán del C., sobre el camino a Huautla de J., L. S. Rodríguez y A. Patiño 


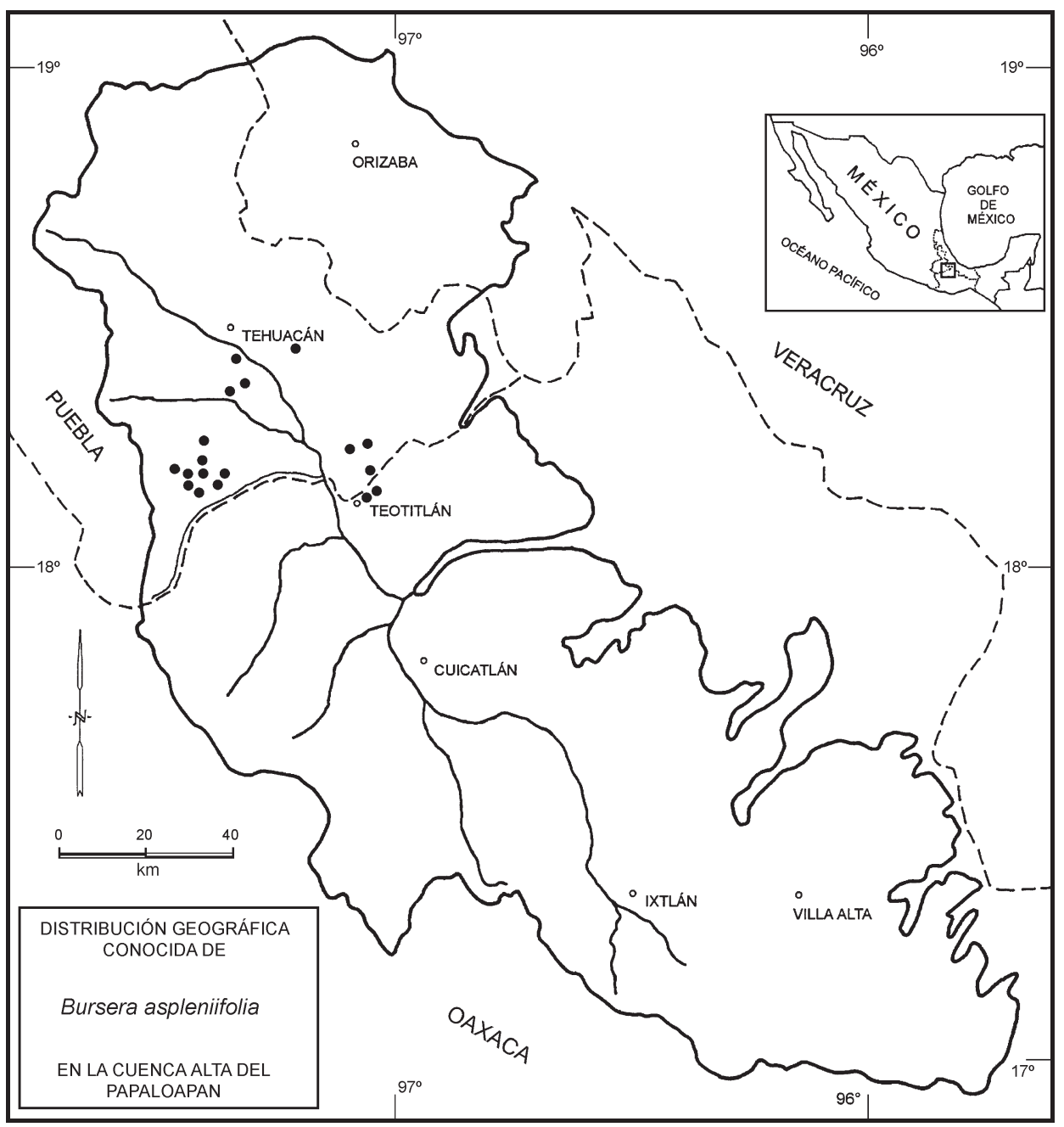

1402 (ENCB); $3 \mathrm{~km}$ al E de Teotitlán del Camino, sobre la carretera a Huautla, J. Rzedowski 28175 (ENCB, IEB, MEXU), 35666 (ENCB, IEB, OAX); 4 km al E de Teotitlán del Camino, sobre la carretera a Huautla, J. Rzedowski 37082a (ENCB, IEB, MEXU), 37082b (MEXU); $3 \mathrm{~km}$ adelante de Teotitlán del Camino, por la carretera a Huautla de Jiménez, A. Salinas et al. 4098 (IEB, MEXU); 4 km adelante de Teotitlán, por la carretera rumbo a Huautla de Jiménez, A. Salinas et al. 4231 (MEXU); 3 km de Teotitlán del Camino, M. Sousa 4648 (ENCB, MEXU); barranca Cruztitla, $6 \mathrm{~km}$ al NE de Teotitlán, carretera a Huautla, P. Tenorio y E. Martínez Correa 17390 (MEXU). PUEBLA: Municipio Ajalpan: brecha a San Luis del Pino, $18^{\circ} 25^{\prime}$ N, 97 $93^{\prime}$ W, P. Tenorio y D. Frame 12076 (IEB). Municipio Caltepec: entrada a Caltepec, ladera W, parte baja, cerca del río, $R$. Medina et al. 1169 (IEB, 
MEXU); Tlacuilotepec, C. A. Purpus 4065 (UC); $7 \mathrm{~km}$ al SE de Atexcoco, sobre el camino a Caltepec, J. Rzedowski 53866 (IEB, MEXU); El Zapote, Barranca de Los Membrillos, P. Tenorio et al. 3840 (IEB, MEXU); La Mesa de Buenavista, al $\mathrm{N}$ de Caltepec, $P$. Tenorio y C. Romero 5937 (MEXU); cerro El Coatepec, al SE de Caltepec, P. Tenorio y C. Romero 6818 (MEXU); Callejón del Carrizal, cerro Grande, P. Tenorio et al. 7803 (MEXU); cerro El Mirador, al W de Caltepec, $P$. Tenorio et al. 17279 (MEXU). Municipio Coxcatlán: km 14.7 carretera Teotitlán - Huautla, L. Abundiz 810 (MEXU); brecha de Coxcatlán a Coyomeapan (Sierra Negra), M. Cházaro y B. L. Mostul 7688 (IEB); near Coxcatlán on Cerro Ajuereado and in the adjacent valley, C. E. Smith Jr. et al. 3622 (F, MEXU). Municipio San

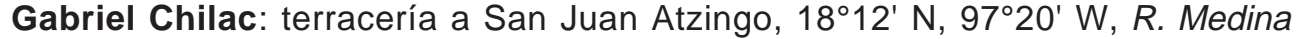
et al. 1204a (IEB; MEXU); San Juan Atzingo, R. Medina et al. 1207b (IEB, MEXU). Municipio Tehuacán: carretera Cuacnopalan - Oaxaca, a $6 \mathrm{~km}$ después de la caseta de Tehuacán, J. D. Hernández B-232 (IEB). Municipio Zapotitlán: 4 km al NW de Los Reyes Mezontla, H. Arroyo 139 (ENCB, MEXU); Los Reyes Mezontla, $1 \mathrm{~km}$ al NW del poblado, A. Valiente et al. 410 (MEXU), 430 (MEXU).

Esta especie es cercana, comparte muchos caracteres y a menudo se confunde en los herbarios con Bursera copallifera (DC.) Bullock. Sin embargo, se les puede distinguir por el patrón que presentan las nervaduras en el envés de los foliolos. En B. copallifera invariablemente se pueden apreciar la nervadura central, las secundarias y las terciarias, todas ellas muy prominentes, las nervaduras terciarias forman un retículo bien definido, y como efecto de éste el haz queda con una superficie de apariencia ampuloso-rugosa. En el caso de B. aspleniifolia se observa la nervadura central y las secundarias también pueden ser prominentes, pero las terciarias están ausentes y las nervaduras secundarias son paralelas entre sí, a veces ramificadas muy cerca del margen y entonces el haz presenta la superficie sin notables rugosidades.

Mientras B. copallifera se extiende desde Durango y Zacatecas hasta Puebla y Oaxaca, $B$. aspleniifolia está restringida a estos últimos dos estados, donde sus áreas llegan a solaparse regionalmente y algunas poblaciones muestran la influencia genética de una en la otra. Las plantas de la región de estudio en general se ajustan bien a las características de $B$. aspleniifolia, salvo el ejemplar Tenorio y Frame 12076, que parece ser francamente intermedio entre esta última y $B$. copallifera.

6. Bursera biflora (Rose) Standl., Publ. Field Mus. Nat. Hist., Bot. Ser. 4:217. 1929. Terebinthus biflora Rose, Contr. U.S. Nat. Herb. 10: 119. 1906. Elaphrium biflorum (Rose) Rose, North Amer. Fl. 25: 253. 1911. Tipo: México: Puebla: Tehuacán, 27.VIII.1897. C. G. Pringle 6686 (holotipo US, isotipos F, K, LE, MEXU!, NY, UC).

Nombres comunes registrados en la zona: copal, copali, mulatillo amarillo.

Árbol o a veces arbusto, dioico, hasta de $8 \mathrm{~m}$ de alto, muy resinoso y de aroma agradable al estrujarse; tronco hasta de $40 \mathrm{~cm}$ de diámetro, por lo general 
Rzedowski et al.: Las especies de Bursera de la cuenca del río Papaloapan, México

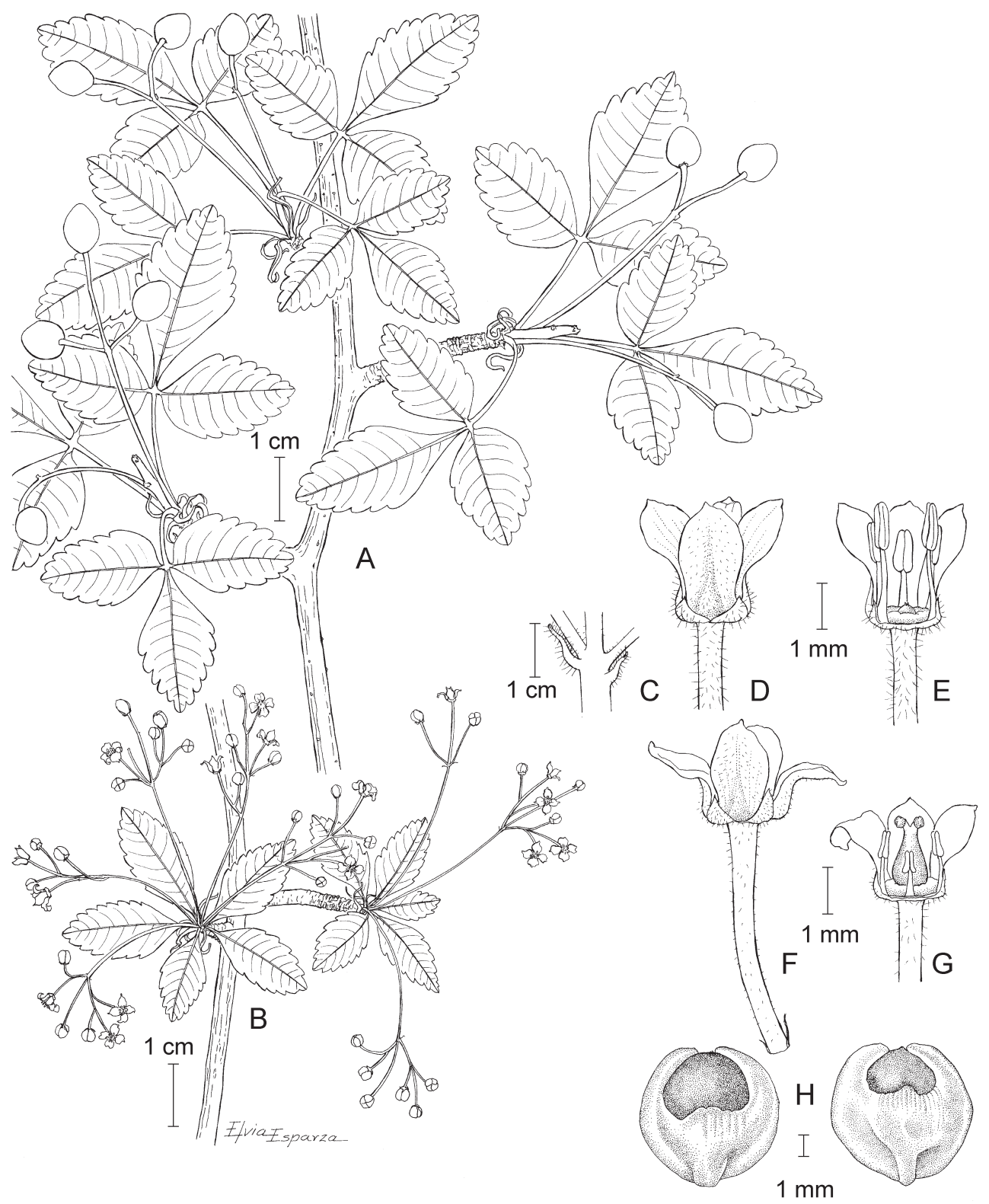

Bursera biflora (Rose) Standl. A. rama con hojas y frutos; B. ramilla con hojas y flores masculinas; C. detalle de la ramificación de la inflorescencia; D. flor masculina en vista externa; E. flor masculina desprovista de 2 segmentos del cáliz, de 2 pétalos y de 3 estambres; F. flor femenina en vista externa; G. flor femenina desprovista de un pétalo y de varios estaminodios; $H$. hueso visto por ambas caras. Ilustrado por Elvia Esparza. 
liso y gris, pero no pocas veces con corteza algo exfoliante y amarillenta, ramillas rojizas a negruzcas, las más jóvenes pubérulas, pronto glabrescentes; hojas con frecuencia aglomeradas en los ápices de ramillas cortas, otras veces alternas en ramillas de crecimiento nuevo, precedidas en su aparición por un conjunto de catafilos lineares a angostamente triangulares, de 3 a $5 \mathrm{~mm}$ de largo, densamente pubérulos por fuera, glabros por dentro, hojas de 1 a $7 \mathrm{~cm}$ de largo y de 0.8 a $6 \mathrm{~cm}$ de ancho, peciolo de $0.3 \mathrm{a} 2 \mathrm{~cm}$ de largo, viloso o pubérulo, foliolos 1 ó 3(5), cuando son cinco, el raquis lleva alas angostas y enteras, hasta de $0.5 \mathrm{~mm}$ de ancho, peciólulo del foliolo terminal hasta de $3 \mathrm{~mm}$ de largo, los de los laterales de 0 a $1.5 \mathrm{~mm}$ de largo, foliolos ovados a elípticos, de 0.9 a 3(5) $\mathrm{cm}$ de largo y de 0.7 a $1.5(2) \mathrm{cm}$ de ancho, el terminal a menudo obovado-subrómbico y por lo general más grande que los laterales, agudos o a veces obtusos en el ápice, cuneados a truncados en la base, toscamente serrados en el margen, de textura cartácea o coriácea en la madurez, con venación prominente en el envés, pubérulos pero con cierta frecuencia glabrescentes en el haz, más o menos densamente vilosos en el envés, pero no pocas veces con la pubescencia restringida a las nervaduras o casi ausente en la madurez; inflorescencia por lo general reducida a una cima triflora, hasta de $3 \mathrm{~cm}$ de largo, pero en algunos individuos masculinos se presenta en forma de panícula hasta de 15 flores, bracteolas linear-subuladas, hasta de $1.5 \mathrm{~mm}$ de largo, aunque con frecuencia mucho más pequeñas, pedicelos filiformes, de 1 a $10 \mathrm{~mm}$ de largo; flores masculinas tetrámeras, lóbulos del cáliz triangulares, de 0.5 a $0.8 \mathrm{~mm}$ de largo, pubérulos o vilosos por fuera, pétalos blanquecinos, elípticos u oblongos, de ca. $2 \mathrm{~mm}$ de largo, pubérulos o vilosos por fuera, estambres 8 , filamentos de 0.6 a $1.3 \mathrm{~mm}$ de largo, anteras oblongas, de 0.6 a $0.9 \mathrm{~mm}$ de largo, gineceo vestigial; flores femeninas similares a las masculinas, estaminodios con anteras de $0.4 \mathrm{~mm}$ de largo, ovario bilocular, estigmas 2; pedúnculos fructíferos filiformes, hasta de 4(5) cm de largo, llevando 1 a 2(3) frutos; éstos elipsoides, ovoides u obovoides, bivalvados, de 7 a $9 \mathrm{~mm}$ de largo, de $5 \mathrm{a}$ $6 \mathrm{~mm}$ de diámetro, rojizos en la madurez, glabros, hueso orbicular a obovoide, de 6 a $7 \mathrm{~mm}$ de largo, cubierto de un lado hasta sus 2/3 inferiores y del otro sólo hasta $1 / 3$ de su longitud por un pseudoarilo anaranjado, la porción expuesta negra.

Habitante frecuente del bosque tropical caducifolio y de diversos matorrales xerófilos, en altitudes de 550 a $2200 \mathrm{~m}$. Florece de mayo a principios de julio. Se encuentra desprovisto de follaje de noviembre a mayo.

Especie endémica de los estados de Puebla y Oaxaca y casi restringida en su distribución al área de estudio, aunque se han visto algunas colectas de las cuencas superiores de los ríos Balsas y Tehuantepec.

Material examinado: OAXACA: Distrito Coixtlahuaca: Concepción Buenavista, base del cerro Pluma, base del cañón del puente Santa Lucía, aproximadamente sobre el km 99-100 de la carretera Tehuacán - Oaxaca (cuota), 1808'24.3" N, 97019'16.8" W, J. L. Panero y J. I. Calzada 4046 (IEB, MEXU); 9 km al N de 
Tepelmeme, sobre la autopista a Tehuacán, municipio Tepelmeme, J. Rzedowski 53891 (IEB), 53892 (IEB), 53893 (IEB), 53894 (IEB); aprox. 2 km al O de El Rodeo, 1754' N, 97²2' W, municipio Tepelmeme, A. Salinas et al. F-3341 (MEXU); faldas del cerro Paraje Ladrón, cerca de Pasto Chino, municipio Tepelmeme, $18^{\circ} 07^{\prime} \mathrm{N}$, 97¹8' W, A. Salinas et al. 7831 (MEXU); arriba de Agua El Guayabo, cerro Paraje Ladrón, km 91-3 carretera Cuacnopalan - Oaxaca, A. Salinas y E. Martínez Correa 7878 (MEXU); cerro entre pueblo de El Rodeo y cerro de la Mesa de Coscomate, $18^{\circ} 01^{\prime} \mathrm{N}, 97^{\circ} 22^{\prime} \mathrm{W}$, municipio Tepelmeme, P. Tenorio y L. M. Kelly 21294 (MEXU). Distrito Cuicatlán: $1 \mathrm{~km}$ al $\mathrm{S}$ de Quiotepec, carretera Tecomavaca - Cuicatlán, municipio Cuicatlán, H. Arroyo 43 (ENCB, IEB, MEXU, OAX); km 100 de la carretera Tecomavaca - Cuicatlán, municipio Cuicatlán, H. Arroyo 44 (ENCB, MEXU, OAX); $43 \mathrm{~km}$ north of Telixtlahuaca, on road to Tehuacan, D. E. Breedlove y F. Almeda 59822 (MEXU); 2 kms camino desviación a Quiotepec, L. M. Cervantes 2271 (MEXU); $5 \mathrm{~km}$ al SE de Cuicatlán, por la desviación a San Pedro Jocotipac, $F$. González Medrano et al. F-1525 (MEXU); 24 km al N de San Sebastián Sedas a Cuicatlán, 17¹9' N, 9655' W, R. Medina et al. 1257 (IEB, MEXU); terracería de Santiago Quiotepec a Cuicatlán, 1747' N, 9657' W, R. Medina et al. 1263 (MEXU), 1267 (IEB, MEXU); $15 \mathrm{~km}$ al S de Dominguillo, sobre la carretera a Oaxaca, J. Rzedowski 34942 (IEB, MEXU); 12 km al SE de Dominguillo, carretera a Oaxaca, municipio Cuicatlán, J. Rzedowski 35468 (ENCB, IEB, MEXU); cerro Virgen de Guadalupe, $6 \mathrm{~km}$ al $\mathrm{N}$ de Cuicatlán, por la carretera 131, y $13 \mathrm{~km}$ al W que va rumbo a Jocotipac, 17016' N, 9702' W, A. Salinas et al. 4293 (MEXU); Vuelta Grande, 9 km al E de Nacaltepec, brecha a La Unión, A. Salinas et al. 6591 (MEXU); $3.5 \mathrm{~km}$ al S de Tonaltepec, carretera Teotitlán - Oaxaca, R. Torres y M. L.Torres 6931 (ENCB, IEB, MEXU); El Puente Viejo, municipio Nacaltepec, F. Ventura 15303 (IEB), 15307 (IEB, MEXU), 15309 (ENCB, IEB, MEXU); El Mirador, municipio Nacaltepec, F. Ventura 15310 (IEB, MEXU) Quiotepec, cerca de la estación de ferrocarril, F. Ventura 15348 (ENCB, IEB, MEXU). Distrito Etla: La Nebrera, municipio Jayacatlán, M. Ambrosio y M. C. León 613 (IEB), 614 (IEB); 2 km al SE de Jayacatlán, municipio Jayacatlán, H. Arroyo 71 (IEB); terracería a San Juan Bautista Jayacatlán, municipio Jayacatlán, R. Medina et al. 1221 (IEB, MEXU); El Progreso, municipio Jayacatlán, F. Ventura 15466 (IEB); km 30, municipio Jayacatlán, F. Ventura 15473 (IEB). Distrito Ixtlán: 4 km al NE de Chicomezúchil, municipio Guelatao, H. Arroyo 76 (IEB); 3 km al NW del puente de Chicomezúchil, río abajo, municipio Guelatao, H. Arroyo 81 (IEB), 82 (IEB); 3 km al W de Tecocuilco, municipio Tecocuilco, H. Arroyo 86 (IEB, MEXU, OAX); $1 \mathrm{~km}$ al O del río Grande brecha a Amatlán, A. García et al. 1770 (IEB), 1772 (IEB, MEXU); Guelatao, municipio Guelatao, F. Ventura 16361 (ENCB), 16364 (IEB). Distrito Nochixtlán: $20 \mathrm{~km}$ al W de Anonas, H. Arroyo 133-A (ENCB, IEB, MEXU, OAX). Distrito Teotitlán: $3 \mathrm{~km}$ al norte de San Martín Toxpalan, municipio Teotitlán, H. Arroyo 23 (IEB); 3 km al N de Teotitlán, camino a Huautla, E. Martínez et al. 21746 (MEXU); 6 km al W de San Gabriel Casa Blanca, municipio San Antonio Nanahuatipam, J. Rzedowski 53875 (IEB); río Xiquila (Tierra Grande), 10 km al S de Ignacio Mejía (a su vez 2-3 km al E por la orilla del río), $18^{\circ} 03^{\prime} \mathrm{N}, 97^{\circ} 08^{\prime} \mathrm{W}$, A. Salinas et al. 
4543 (IEB, MEXU); $14 \mathrm{~km}$ al E de Santa María Ixcatlán, por la terracería a Tecomavaca, A. Salinas y $P$. Tenorio 5847 (MEXU); $12-13 \mathrm{~km}$ al SO de Tecomavaca, brecha a Ixcatlán, 1755' N, 9704' W, A. Salinas 7652 (MEXU); Santiago Viejo, municipio Tecomavaca, F. Ventura 15327 (ENCB, MEXU); 4 mi south of Tecomavaca, 1754' N, 9659' W, G. L. Webster et al. 20103 (MEXU). PUEBLA: Municipio Caltepec: $8 \mathrm{~km}$ al SEE de Acatepec, terracería a Caltepec, F. Chiang et al. F-2581 (ENCB, MEXU); $1 \mathrm{~km}$ al NO del km 6 a La Compañía, terracería a Caltepec, hacia Acatepec, O. Dorado y A. Salinas F-2953 (MEXU); camino de La Cumbre a San Luis Tultitlanapa, 18¹4' N, 97²5' W, R. Medina et al. 1195 (IEB, MEXU), 1195a (IEB, MEXU), 1195b (IEB, MEXU); cerro de Castillo, C. A. Purpus 3159 (UC); Tlacuilotepec, C. A. Purpus 4068 (UC); $3 \mathrm{~km}$ al SE de Atexcoco, sobre el camino a Caltepec, J. Rzedowski 53864 (IEB), 53865 (IEB); cerro El Coatepec, $1.7 \mathrm{~km}$ al SE de San Luis Atolotitlán, A. Salinas y O. Dorado F-2754 (MEXU); Barranca del Granizo, al W de Caltepec, P. Tenorio y C. Romero 3913 (MEXU); cerro Yeltepec, al NE de La Compañía, P. Tenorio y C. Romero 7627 (MEXU); cerro El Coatepec, al SE de Caltepec, P. Tenorio y C. Romero 7742 (IEB); Barranca Honda al NW de Caltepec, P. Tenorio et al. 17324 (MEXU); Barranca de San Lorenzo, al W de Membrillos, P. Tenorio y C. Romero 17344 (IEB, MEXU); Planes de San Miguel, F. Ventura 15390 (ENCB, IEB, MEXU). Municipio Coxcatlán: near Coxcatlan on Cerro Ajuereado and in adjacent valley, C. E. Smith Jr. et al. 3559 (MEXU); 2-3 km al NNE de San Rafael, A. Salinas 7093 (MEXU); Calipan, $1.5 \mathrm{~km}$ al N de Coxcatlán, I. Trejo 1254 (MEXU). Municipio Tehuacán: $2 \mathrm{~km}$ al W de Tehuacán, F. Chiang et al. F-8 (ENCB, MEXU); $6 \mathrm{~km}$ al SW de Tehuacán, carretera a Huajuapan, F. Chiang et al. F-326 (MEXU); $4 \mathrm{~km}$ al NE de Tehuacán, A. García et al. 3307 (IEB, MEXU); 4 mi SW of Tehuacan, H. S. Gentry 22417 (MEXU); carretera Cuacnopalan - Oaxaca, a $16 \mathrm{~km}$ antes de llegar a la caseta de Tehuacán, J. D. Hernández B-231 (IEB); 5 mi SW of Tehuacan along road to Huajuapan, C. T. Mason et al. 3027 (ENCB, UC); Tehuacán, F. Miranda 3488 (MEXU), 3494 (MEXU); El Riego - Santa Ana, F. Miranda 4405 (MEXU); 8 km al SW de Tehuacán, sobre el camino a Zapotitlán, L. S. Rodríguez y A. Patiño 1405 (ENCB, MEXU); $8 \mathrm{~km}$ al SW de Tehuacán, sobre la carretera a Huajuapan, J. Rzedowski 9018 (ENCB, MEXU); San Diego, $10 \mathrm{~km}$ al S de Tehuacán, J. Rzedowski 9023 (ENCB); 8 km al SW de Tehuacán, J. Rzedowski 19125 (ENCB, MEXU); El Riego, 3 km al W de Tehuacán, J. Rzedowski 28180 (ENCB, MEXU), 28181 (ENCB); $8 \mathrm{~km}$ al ENE de Tehuacán, sobre la carretera a Orizaba, J. Rzedowski 32187 (ENCB, MEXU); $6 \mathrm{~km}$ al NE de Tehuacán, sobre la carretera a Orizaba, J. Rzedowski 34982 (ENCB, MEXU), 35624 (ENCB); $7 \mathrm{~km}$ al NE de Tehuacán, sobre la carretera a Orizaba, J. Rzedowski 36535 (ENCB); 2 km al NE de Tehuacán, cerca de la Escuela Militar, A. Salinas y P. Solís F-3599 (MEXU); $2.5 \mathrm{~km}$ al NE de Tehuacán, A. Salinas y A. Campos F-3610 (MEXU); desviación a Santiago Miahuatlán, F. Ventura 15242 (IEB), 15245 (IEB); Santa Ana, F. Ventura 15250 (ENCB, IEB, MEXU), 15252 (ENCB, IEB, MEXU), 15253 (ENCB, MEXU); Tula, F. Ventura 15271 (IEB); San José Tochapa, F. Ventura 15272 (ENCB, IEB, MEXU, OAX, UAMIZ); minas de cantera de Santa Ana, F. Ventura 15289a (IEB), 15290 (ENCB, MEXU, UAMIZ), 15293 (IEB), 


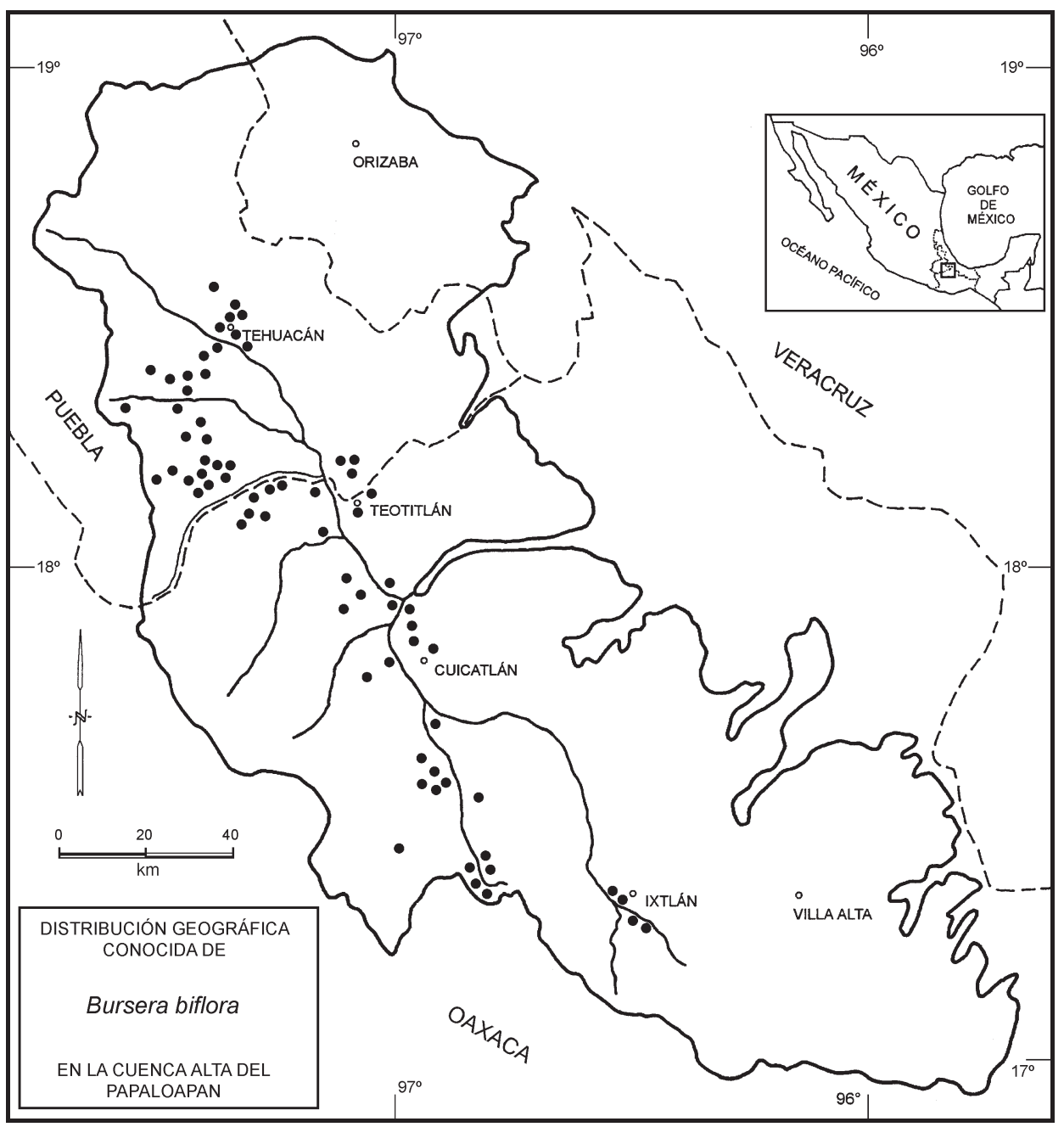

15294 (ENCB, IEB, MEXU); $5.5 \mathrm{mi}$ SW of Tehuacan, G. L. Webster et al. 17305 (MEXU). Municipio Zapotitlán: $3 \mathrm{~km}$ del poblado de San Juan Raya, por la brecha, 18¹9'21" N, 97³6'18" W, L. Alvarado et al. 149 (MEXU); 4 km al NW de Los Reyes Mezontla, H. Arroyo 138 (ENCB, IEB, MEXU, OAX); $3.7 \mathrm{~km} \mathrm{~S}$ of San Antonio Texcala, $13 \mathrm{~km}$ S of Tehuacan, G. J. Breckon 2344 (ENCB); camino Salinas San

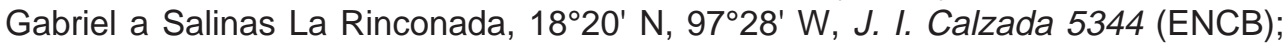
$3.5 \mathrm{~km}$ al NE de Zapotitlán Salinas, carretera a Tehuacán, F. Chiang et al. F-1986 (MEXU); $10.5 \mathrm{~km}$ desviación a Atolotitlán, carretera a Tehuacán - Huajuapan, $F$. Chiang et al. F-2393 (MEXU); $3 \mathrm{~km}$ al SW de San Antonio Texcala, A. C. Gibson 3450 (ENCB, MEXU); terracería a San Juan Raya, R. Medina et al. 1201 (MEXU); $3 \mathrm{~km}$ al SW de San Antonio Texcala, J. Rzedowski 19134 (ENCB, MEXU); $1 \mathrm{~km}$ 
al N de Zapotitlán Salinas, sobre la carretera a Tehuacán, J. Rzedowski 28176 (ENCB, MEXU); $22 \mathrm{~km}$ al SW de Tehuacán, sobre la carretera a Huajuapan, J. Rzedowski 33223 (ENCB); $17 \mathrm{~km}$ al SW de Tehuacán sobre la carretera a Huajuapan, J. Rzedowski 33227 (ENCB, MEXU); 4 km al NE de Zapotitlán Salinas, por la carretera a Tehuacán, J. Rzedowski 33233 (ENCB, MEXU); 3 km al SW de San Antonio Texcala, sobre la carretera a Zapotilán Salinas, J. Rzedowski 34962 (ENCB, MEXU), 35418 (ENCB, MEXU); $15 \mathrm{~km}$ al SW de Tehuacán, sobre la carretera a Huajuapan, J. Rzedowski 37068 (ENCB); 5 km al SW de Zapotitlán, por la carretera 125 rumbo a Santiago Chazumba, A. Salinas y O. Dorado F- 3084 (MEXU); $4 \mathrm{~km}$ al SE de Xochiltepec, brecha a San Luis Atolotitlán, P. Tenorio et al. 17363 (IEB, MEXU); $2 \mathrm{~km}$ al NW del poblado de San Juan Raya, A. Valiente et al. 347 (MEXU), 352 (MEXU); Los Reyes Mezontla, $1 \mathrm{~km}$ al NW de los Reyes Mezontla, A. Valiente et al. 413 (MEXU), 485 (MEXU); $1 \mathrm{~km}$ al SW de Zapotitlán Salinas, A. Valiente 925 (MEXU); San Antonio Texcala, F. Ventura 15262 (ENCB, IEB, MEXU), 15263 (ENCB, MEXU); minas de las canteras de San Antonio Texcala, F. Ventura 15267 (ENCB, IEB); cerro de La Colmena, F. Ventura 15279a (ENCB, MEXU, OAX), $15279 b$ (ENCB, MEXU), 15282 (ENCB, IEB, MEXU); cerro El Sanjuanero, F. Ventura 15285 (ENCB, IEB, MEXU).

B. biflora es quizás la especie de Bursera más frecuente y más ampliamente distribuida en la región de estudio. Su tolerancia ecológica es vasta, pues prospera desde los matorrales más secos hasta las áreas de transición del bosque tropical caducifolio con el encinar, en altitudes entre 550 y $2200 \mathrm{~m}$.

Es también de los taxa más variables en su morfología. La mayor parte de las poblaciones se caracteriza por tener hojas uniformemente trifolioladas, pero en algunas se presentan individuos con 3 y 5 foliolos. Existen, a su vez, poblaciones enteras de plantas con hojas unifolioladas, tanto en Oaxaca como en Puebla. Se pueden observar asimismo notables diferencias en la pubescencia del follaje, pues éste oscila de ser casi glabro a densamente pubérulo en la madurez. Igualmente variable resulta el largo del peciolo y de los foliolos, al grado de que los extremos dan la impresión de pertenecer a especies distintas. En la gran mayoría de los individuos las inflorescencias constan solamente de tres flores, pero algunas plantas masculinas presentan conjuntos paniculiformes con diversos múltiplos de este número. Otro rasgo inconstante es el que corresponde a la corteza externa del tronco, que suele ser lisa y gris en la mayoría de los árboles, pero dentro de la misma población, con cierta frecuencia se observan también individuos con corteza amarillenta y más o menos intensamente exfoliante, propiedad poco usual en las especies pertenecientes a la sección Bullockia.

No se ha logrado encontrar ninguna correlación clara que pudiera existir entre la variación de los diversos caracteres mencionados ni tampoco entre esta última y la distribución geográfica y ecológica de las poblaciones de $B$. biflora, por lo que se optó por reconocer a este conjunto de plantas como un solo taxon. 
7. Bursera bipinnata (DC.) Engl., DC. Monogr. Phaner. 4: 49. 1883. Amyris bipinnata DC., Prodr. 2: 82. 1825. Elaphrium bipinnatum (DC.) Schltdl., Linnaea 17: 631. 1843. Terebinthus bipinnata (DC.) W. F. Wight ex Rose, Contr. U.S. Nat. Herb. 10: 119. 1906. Lectotipo: lámina 0715 de la colección Torner de ilustraciones de la expedición dirigida por Sessé y Mociño, designado por R. McVaugh en Botanical results of the Sessé \& Mociño expedition (1783-1803). VII. Guide to relevant scientific names of plants. p. 104. 2000.

Bursera gracilis Engl., DC. Monogr. Phaner. 4: 50. 1883. Terebinthus gracilis (Engl.) Rose, Contr. U.S. Nat. Herb. 10: 119. 1906. Elaphrium gracile (Engl.) Rose, North Amer. Fl. 25: 249. 1911. Tipo: México: Morelos: Xochicalco, Anónimo s. n. 30.VI.1866 (holotipo P!).

Bursera elemifera (Royle) Baill., Traité Bot. Med. p. 952. 1884. Elaphrium elemiferum Royle, Man. Mat. Med. Therap. p. 344. 1847. Tipo: México: Oaxaca: cerca de Oaxaca, Anónimo s. n. (from Dr. Royle, 1846) (holotipo BM).

Bursera bipinnata var. ovalifolia J. D. Smith, Bot. Gaz. 27: 332. 1899. Tipo: Guatemala: Dept. Huehuetenango, VII. 1896, C. Seler y E. Seler 3108 (probablemente B, destruido).

Bursera verapacensis Pittier, Journ. Wash. Acad. Sci. 11: 229. 1921. Tipo: Guatemala: Baja Verapaz, between Salamá and Rabinal, 31.V.1904, O. F. Cook y C. B. Doyle 283 (holotipo US).

Nombres comunes registrados en la zona: copal, copal negro, copal virgen, copalillo.

Nombres comunes registrados fuera de la zona de estudio: copal amargo, copal amargoso, copal chino, copal chino colorado, copal santo, incienso, jaboncillo del país, tetlate, tetlatín, tetlatlán, yah yal (lengua zapoteca).

Árbol o a veces arbusto dioico, hasta de 8(12) $\mathrm{m}$ de alto, muy resinoso y con aroma agradable al estrujarse; tronco hasta de $35(50) \mathrm{cm}$ de diámetro, su corteza gris, por lo general lisa, no exfoliante, ramillas laterales cortas, agudas, a menudo semejando espinas; hojas fasciculadas en los extremos de ramillas cortas, o bien, alternas sobre ramillas vigorosas de crecimiento nuevo, precedidas en su aparición por una roseta de catafilos anchamente triangulares a lanceolados, de 2 a $4 \mathrm{~mm}$ de largo, moreno-rojizos, pubescentes en ambas caras, sobre todo en el ápice, precozmente caducos; hojas simulando las frondas de algunos helechos, en ocasiones una vez pinnadas, con más frecuencia parcialmente bipinnadas y a veces con tendencia a tripinnadas, peciolo hasta de 1.5(2) $\mathrm{cm}$ de largo, lámina ovada a oblonga en contorno general, de 2.5 a $7.5(10) \mathrm{cm}$ de largo y de 1 a $6.5 \mathrm{~cm}$ de ancho, en la base con (0)3 ó 4(8) pares de pinnas (con 1 a 5(8) pares de foliolos 


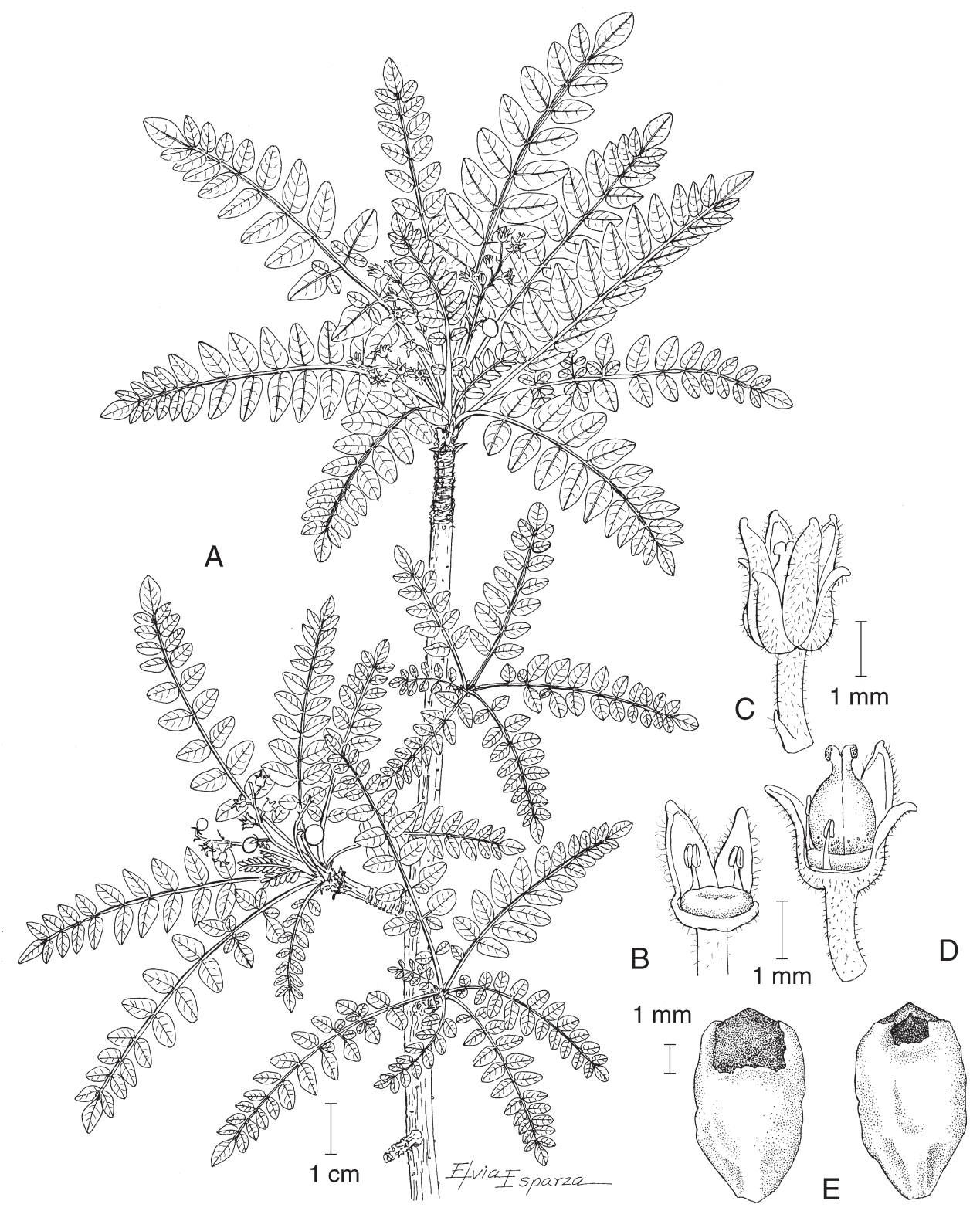

Bursera bipinnata (DC.) Engl. A. rama con hojas, flores femeninas y frutos tiernos; B. flor masculina desprovista de 3 segmentos del cáliz, de 3 pétalos y de 6 estambres; C. flor femenina en vista externa; D. flor femenina desprovista de un segmento del cáliz, de 3 pétalos y de varios estaminodios; E. hueso visto por ambas caras. Ilustrado por Elvia Esparza. 
Rzedowski et al.: Las especies de Bursera de la cuenca del río Papaloapan, México
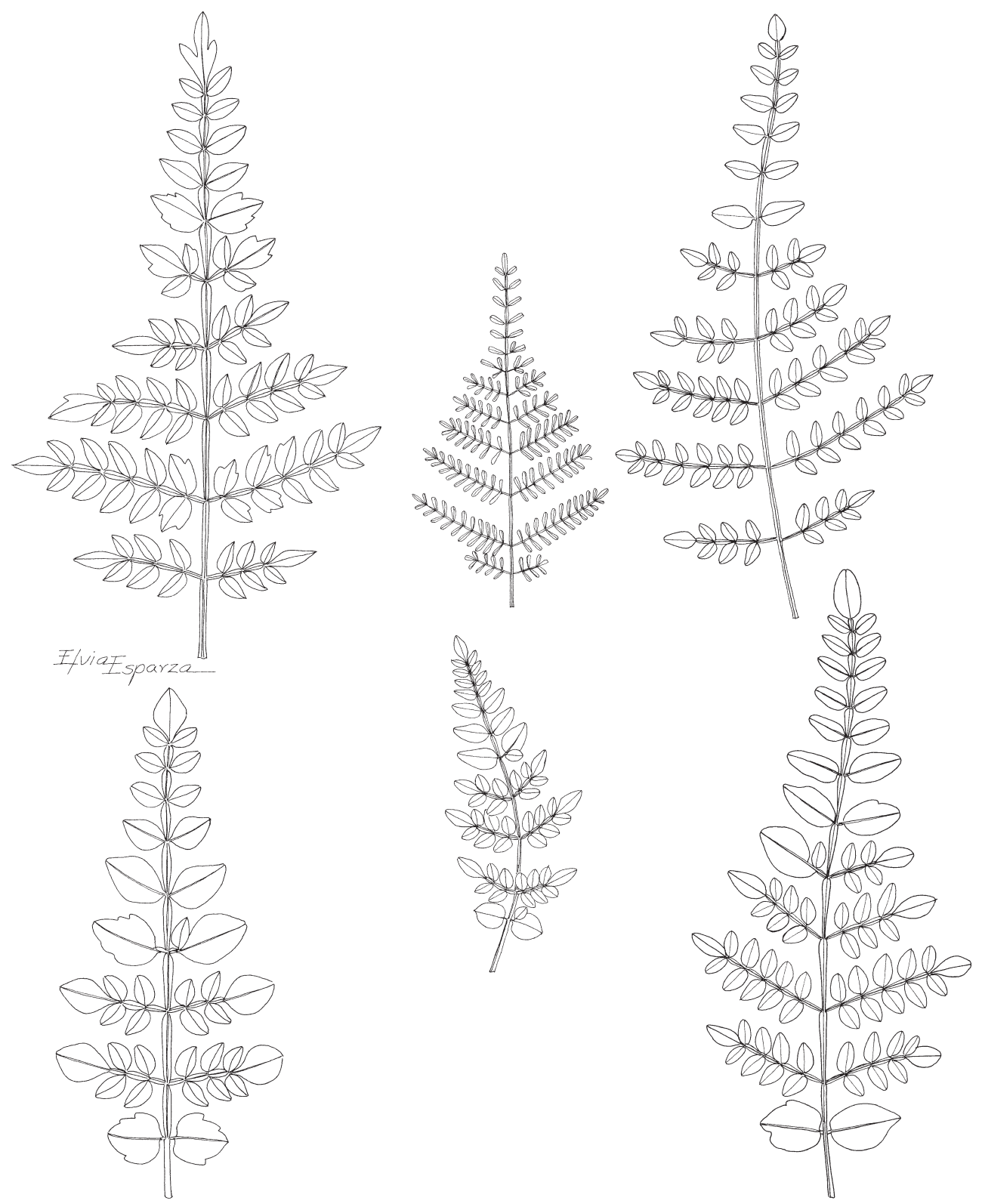

Bursera bipinnata (DC.) Engl. Diferentes variantes de hojas. Ilustrado por Elvia Esparza. 
secundarios cada una) y en la porción distal con (4)5 a 9 pares de foliolos primarios, raquis y raquillas angostamente alados, de borde entero, foliolos sésiles 0 subsésiles, de tamaño y forma muy variables a menudo en la misma hoja, lineares, oblongos, elípticos a ovados, obovados o suborbiculares, de 3 a 8(15) $\mathrm{mm}$ de largo y (1)2 a 5(11) mm de ancho, ápice agudo a redondeado, base cuneada a levemente cordada, margen entero a trilobado, lustrosas en el haz, de textura cartácea, con la venación prominente en el envés, pubérulos y más o menos glabrescentes en el haz, vilosos y a veces glabrescentes en el envés; inflorescencias racimosas 0 paniculadas, de 2 a $6 \mathrm{~cm}$ de largo, pubérulas, bracteolas subuladas, de ca. $2 \mathrm{~mm}$ de largo, pedicelos de 1 a $2 \mathrm{~mm}$ de largo; flores masculinas tetrámeras, lóbulos del cáliz angostamente triangulares, de 1.5 a $2.5 \mathrm{~mm}$ de largo, a veces excediendo en longitud a los pétalos, pubérulos en ambas caras, pétalos blanquecinos a amarillentos o verdosos, oblanceolados, de 1.8 a $2.5 \mathrm{~mm}$ de largo, más o menos cuculados e incurvados en el ápice, apenas reflejos en la madurez, pubérulos por fuera, principalmente a lo largo de la costa, estambres 8 , filamentos de 0.8 a $1 \mathrm{~mm}$ de largo, anteras ovado-oblongas, de 0.4 a $0.5 \mathrm{~mm}$ de largo; flores femeninas tetrámeras, similares en forma y tamaño a las masculinas, también a veces con los pétalos un poco más cortos que los lóbulos del cáliz, ovario bilocular, glabro, estigmas 2, anteras de los estaminodios de 0.3 a $0.4 \mathrm{~mm}$ de largo; infrutescencias hasta de $6 \mathrm{~cm}$ de largo, con uno o varios frutos bivalvados, obovoides, de 6 a 8(9) $\mathrm{mm}$ de largo y 4 a $5 \mathrm{~mm}$ de diámetro, glabros, hueso algo comprimido, de 5 a $6 \mathrm{~mm}$ de largo y 3.5 a 4(5) $\mathrm{mm}$ de ancho, recubierto casi totalmente por un pseudoarilo rojo en la madurez, la parte expuesta negra.

Elemento moderadamente frecuente de los bosques tropicales caducifolios, penetrando marginalmente a encinares y pinares adyacentes, en altitudes de 800 a $1600 \mathrm{~m}$. Florece en mayo y en junio. Por lo general permanece sin follaje de noviembre a mayo.

Esta es una de las especies más ampliamente distribuidas del género, pues su área conocida se extiende desde Durango hasta Honduras y El Salvador. No muy común en Puebla, pero vastamente repartida en varios sectores de Oaxaca.

Material examinado: OAXACA: Distrito Cuicatlán: $7 \mathrm{~km}$ al NE de Cuicatlán, camino a Concepción Pápalo, H. Arroyo 58 (ENCB, MEXU); 5 km al NW de Cuicatlán, camino a Concepción Pápalo, H. Arroyo 70 (ENCB, IEB); 4 km al W de la estación de ferrocarril El Venado, camino a Almoloyas, H. Arroyo 121 (ENCB, MEXU); $2.5 \mathrm{~km}$ al E de Santa Catarina, municipio San Pedro Jaltepetongo, H. Arroyo 127 (ENCB, MEXU); Loma del Zacatal, San José del Chilar, 1742'47" N, 9656'33" W, municipio Cuicatlán, C. A. Cruz y R. García 91 (MEXU); cerro La Copalera, a $3.2 \mathrm{~km}$ al NE de San José del Chilar, 17'41'15" N, 96 57'16" W, C. A. Cruz y E. San Pedro 1429 (IEB, MEXU); 9 km al NE de Cuicatlán, rumbo a Concepción Pápalo, F. González Medrano et al. F-1595 (MEXU), F-1683 (ENCB, 


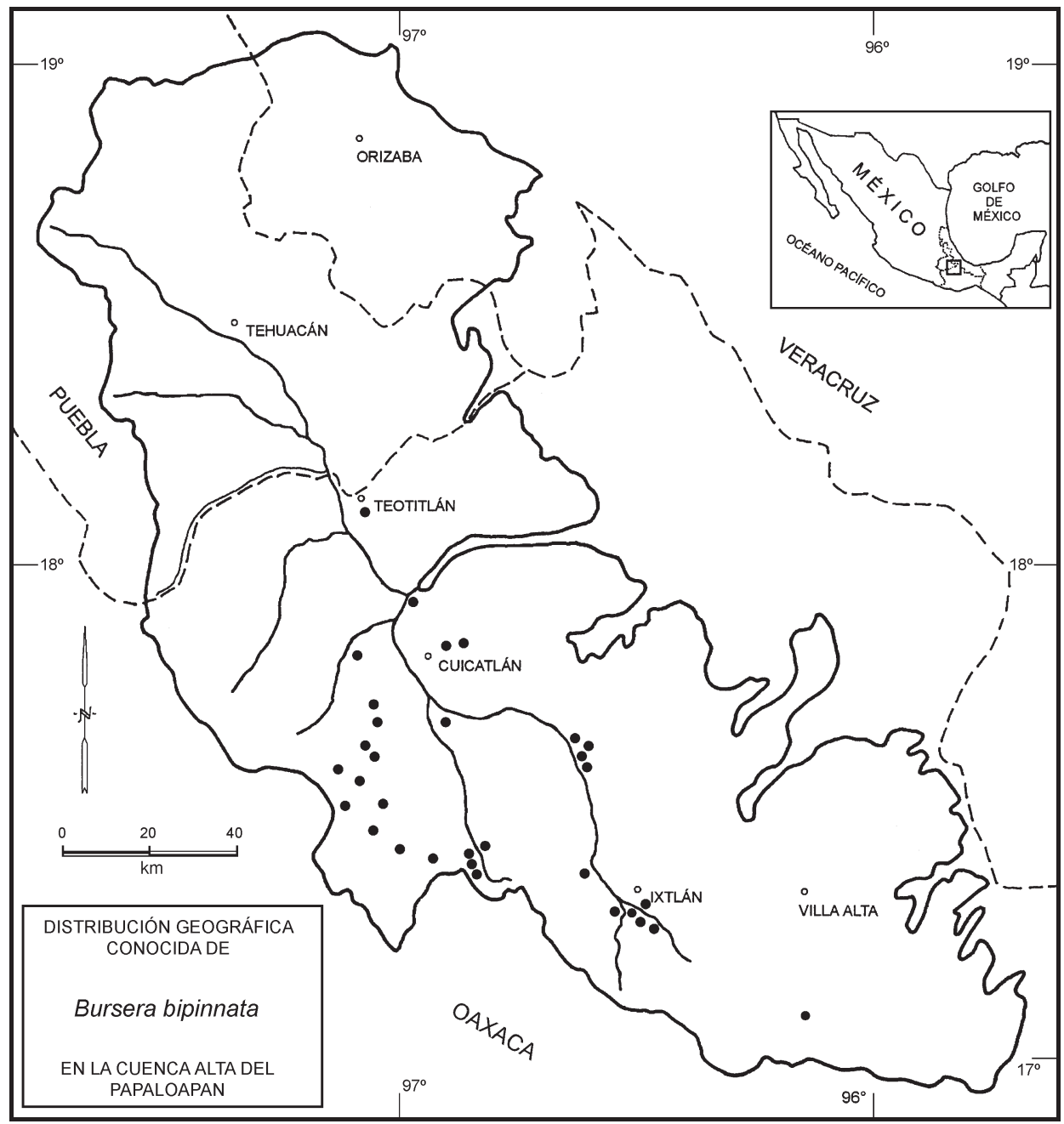

MEXU), F-1725 (MEXU); camino Cuicatlán - Concepción Pápalo, F. Miranda 4591 (MEXU); $1.8 \mathrm{~km}$ al N de Santa Catarina Tlaxila, A. Salinas 7345 (MEXU); 9-10 km al E de Cuicatlán, brecha a Concepción Pápalo, A. Salinas 7460 (MEXU); cerro El Castillo, al N de San Pedro Nodón, P. Tenorio 17753 (MEXU); 1 km al S de Jaltepetongo, E. Torres 178 (OAX); Quiotepec, municipio Cuicatlán, F. Ventura 15561 (ENCB, MEXU). Distrito Etla: $8 \mathrm{~km}$ del camino a San Juan Bautista

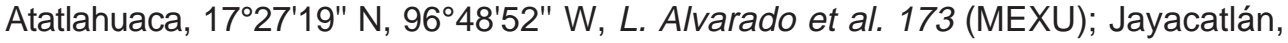
M. Ambrosio et al. 586 (IEB); La Curva, carretera a Etla, municipio Jayacatlán, $M$. Ambrosio y B. Brosi 597 (IEB); $2 \mathrm{~km}$ al $\mathrm{N}$ de El Parián, sobre el río, dirección N, H. Arroyo 114 (ENCB, MEXU); $4.5 \mathrm{~km}$ al W de Anonas, H. Arroyo 133 (ENCB); 
sin localidad precisa, municipio San Juan Jayacatlán, M. C. López 1 (IEB); cañada al SW de la estación de ferrocarril EI Venado, R. Medina et al. 1075 (MEXU); cañada $1.5 \mathrm{~km}$ al S de El Parián, adelante del panteón, R. Medina et al. 1120 (MEXU), 1122 (MEXU); 8 km por la terracería a San Juan Bautista Jayacatlán, 17²7' N, 9648' W, R. Medina et al. 1228 (MEXU); terracería a San Sebastián Sedas, municipio Telixtlahuaca, 17²0' N, 9656' W, R. Medina et al. 1252 (IEB, MEXU), 1254 (IEB, MEXU); El Parián, cerca del cementerio, municipio Telixtlahuaca, J. Rzedowski 53882 (IEB), 53883 (IEB); El Parián, F. Ventura 15460 (ENCB), km 30, municipio Jayacatlán, F. Ventura 15468 (ENCB, MEXU). Distrito Ixtlán: $2 \mathrm{~km}$ al NE de Chicomezúchil, municipio Chicomezúchil, H. Arroyo 75 (ENCB); $3 \mathrm{~km}$ al NW del puente Chicomezúchil, río abajo, municipio Guelatao de Juárez, H. Arroyo 80 (ENCB); $1 \mathrm{~km}$ al W de Tecocuilco, municipio Tecocuilco, H. Arroyo 83 (ENCB); paraje a orillas del río Mariposa y límites con Luvina, en Macuiltianguis, G. Díaz 7 (ENCB); $300 \mathrm{~m}$ del río Comal, sobre el camino a Macuiltianguis, R. Lucero L50 (ENCB); rancho Chuparrosa, Comaltepec, G. J. Martin 580 (ENCB); 4 km al SW

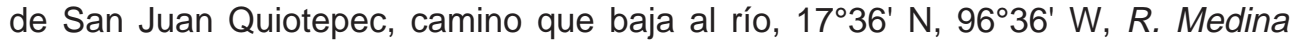
et al. 1280 (MEXU); paraje Santa Cruz Macuiltianguis, G. Pérez C205 (ENCB); 4 km al S de Guelatao, J. Rzedowski 30645 (ENCB); Loma Colorada, municipio Comaltepec, F. Ventura 15546 (ENCB); Tectitlán, municipio Comaltepec, F. Ventura 15551 (ENCB); planta de la luz, municipio San Juan Chicomezúchil, F. Ventura 16106 (ENCB, IEB, MEXU); Guelatao, municipio Guelatao, F. Ventura 16361a (ENCB); San Miguel del Río, municipio Ixtlán, F. Ventura 16365 (ENCB). Distrito Teotitlán: San Martín Toxpalan, F. Ventura 15563 (ENCB, MEXU). Distrito indefinido (Mixe o Tlacolula): vicinity of cerro Zempoaltepec, along trail from Tlahuitoltepec to Santo Domingo Albarradas, B. Hallberg 980 (ENCB).

Bullock (op. cit., p. 355) redujo a $B$. gracilis a la sinonimia de $B$. bipinnata y el examen del tipo de la primera confirma plenamente esta decisión.

La imagen del holotipo de Elaphrium elemiferum, obtenida gracias a la amabilidad de las autoridades del Museo de Historia Natural de Londres, también indica en forma clara que la planta en cuestión debe considerarse como B. bipinnata. Sin embargo, el ejemplar $H$. Finck s. n. IV.1865 (K), procedente de "Cordova, Mexico" e identificado por Bullock como B. elemifera no corresponde a B. bipinnata sino a $B$. graveolens.

La resina de este árbol se usa como aromatizante a manera de incienso y tiene empleo medicinal.

8. Bursera cinerea Engl., DC. Monogr. Phaner. 4: 43. 1883. Terebinthus cinerea (Engl.) Rose, Contr. U.S. Nat. Herb. 10: 119. 1906. Elaphrium cinereum (Engl.) Rose, North Amer. Fl. 25: 245. 1911. Tipo: México: Veracruz: Vallée de Cordova, 6.V.1966, E. Bourgeau 2326 (holotipo P!). 


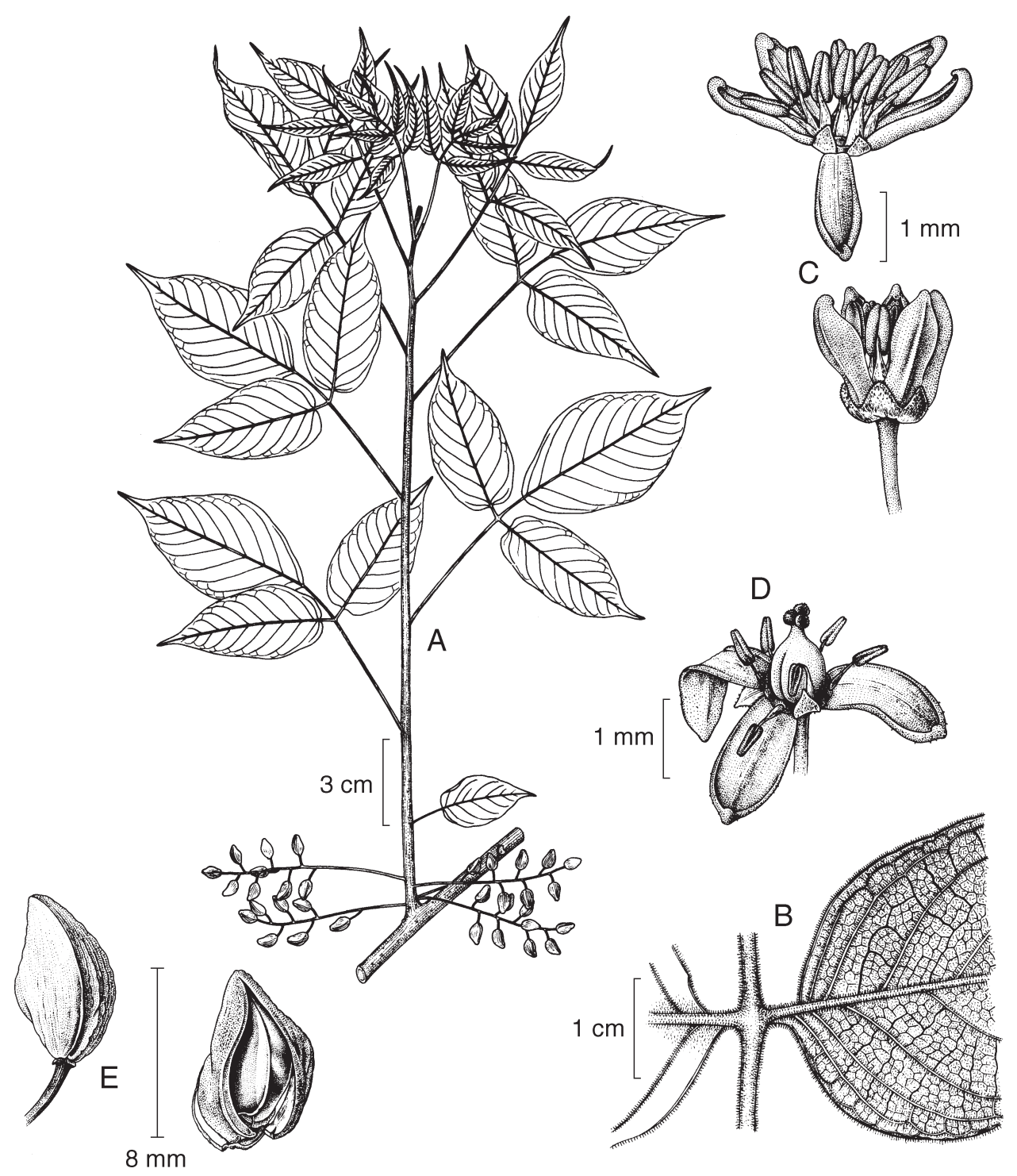

Bursera cinerea Engl. A. rama con hojas y frutos; B. detalle de la pubescencia en la hoja; C. flores masculinas; D. flor femenina; E. frutos. Ilustrado por Edmundo Saavedra y reproducido de la pág. 11 del fascículo 94 de la Flora de Veracruz. 
Bursera gummifera var. pubescens Engl., DC. Monogr. Phaner. 4: 40. 1883. Elaphrium subpubescens Rose, North Amer. Fl. 25: 247. 1911 (nombre basado en B. gummifera var. pubescens), B. subpubescens (Rose) Engl., in Engl. \& Prantl, Nat. Pflanzenfam. ed. 2, 19a: 425. 1931. Lectotipo: México: Veracruz, région d'Orizaba, 25.VIII.1866. E. Bourgeau $2899(\mathrm{P})$, designado por J. Rzedowski y Graciela Calderón de Rzedowski en Flora de Veracruz 94: 21. 1996.

Nombres comunes registrados en la zona de estudio: cuajiote rojo, mulato, palo mulato.

Nombres comunes registrados fuera de la zona de estudio: camarón, camaroncillo, copalillo.

Árbol dioico o a veces polígamo-dioico, hasta de 15(20?) m de alto, resinoso y aromático al estrujarse; tronco hasta de $30 \mathrm{~cm}$ de diámetro, su corteza externa rojiza, anaranjado-rojiza o café-rojiza, exfoliándose en láminas delgadas, corteza interna verdosa, ramillas jóvenes por lo común densamente pubérulas; hojas de 10 a $30(45) \mathrm{cm}$ de largo y 10 a $20 \mathrm{~cm}$ de ancho, peciolo hasta de $10.5 \mathrm{~cm}$ de largo, por lo general densamente pubérulo, foliolos (1)3 ó 5, excepcionalmente 7 , raquis sin alas, peciólulos laterales de 1 a $9 \mathrm{~mm}$ de largo, el terminal hasta de $3 \mathrm{~cm}$ de largo, foliolos laterales lanceolados a oblongos u ovados, el terminal por lo común obovado a anchamente elíptico u ovado, de 4 a $9(14) \mathrm{cm}$ de largo y 2 a 5(7) $\mathrm{cm}$ de ancho, caudado-acuminado en el ápice, base cuneada a subcordada, comúnmente oblicua en los foliolos laterales, margen entero, las escasas hojas simples (o unifolioladas) por lo general ovadas a cordiformes, a veces subreniformes, de textura membranácea a cartácea, brillantes en el haz o en ambas superficies en la madurez, por lo general densamente pubérulas en todas sus partes en la juventud, glabrescentes al menos en el haz en la madurez, en ocasiones casi totalmente glabras desde un principio; inflorescencias racimoso-paniculadas, hasta de $8(20) \mathrm{cm}$ de largo, más o menos densamente pubérulas a casi glabras, sus ejes rojizos oscuros, brácteas triangular-ovadas, de menos de $1 \mathrm{~mm}$ de largo, precozmente caducas, pedicelos filiformes, de 1 a $5 \mathrm{~mm}$ de largo; las masculinas por lo general ramificadas, con flores pentámeras o rara vez tetrámeras, lóbulos del cáliz anchamente triangulares, de ca. $0.5 \mathrm{~mm}$ de largo, glabros o casi glabros, pétalos de color crema o blanquecinos, elíptico-oblongos, cuculados, encorvados en el ápice, de ca. $2 \mathrm{~mm}$ de largo, glabros o casi glabros, estambres (8)10, filamentos de ca. $1 \mathrm{~mm}$ de largo, anteras oblongas, de ca. $0.8 \mathrm{~mm}$ de largo, gineceo vestigial; inflorescencias femeninas por lo general sin ramificarse, flores trímeras o rara vez tetrámeras, similares a las masculinas, anteras de los estaminodios de ca. $0.8 \mathrm{~mm}$ de largo, ovario trilocular, estigmas 3; frutos hasta más de 10 por inflorescencia, con pedúnculos y pedicelos notablemente engrosados, estos últimos hasta de $12 \mathrm{~mm}$ de largo; frutos trivalvados, globosos a ovoides, ligeramente triquetros, de 6 a $10 \mathrm{~mm}$ de largo, rojizos a cafés en la madurez, glabros, hueso plano-convexo, de 5 a $6 \mathrm{~mm}$ de diámetro, totalmente cubierto por un pseudoarilo rojo o anaranjado. 
Rzedowski et al.: Las especies de Bursera de la cuenca del río Papaloapan, México

Habitante a menudo abundante y a veces dominante en el bosque tropical caducifolio, sobre diversos sustratos geológicos, en altitudes entre 1100 y 1700 m. Florece de abril a principios de junio. Se encuentra desprovista de hojas de noviembre a mayo.

Especie formalmente sólo conocida de Oaxaca y Veracruz. Aunque existen registros visuales de su existencia en algunas localidades del municipio de Coxcatlán, Puebla, no se han visto los ejemplares de herbario correspondientes.

Material examinado: OAXACA: Distrito Cuicatlán: $3 \mathrm{~km}$ al $\mathrm{W}$ de la estación de F.F.C.C. El Venado, camino a Almoloyas, H. Arroyo 110(a) (IEB, MEXU); Barranca de las Guacamayas, municipio Cuicatlán, J. Calónico 23943 (MEXU); $16 \mathrm{~km}$ al SE de Dominguillo, carretera Tehuacán - Oaxaca, F. Chiang et al. F-1808 (MEXU); Cañada de Agua Amarilla, San José del Chilar, 1740'38.6" N, 9657'57.6" W, C. A. Cruz y R. García 320 (MEXU); Barranca del Balconcito, San José del Chilar,

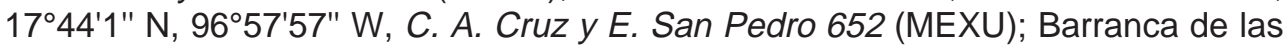
Guacamayas, San José del Chilar, 17040'40.1 N, 9657'56.9 W, C. A. Cruz y E. San Pedro 823 (MEXU), 1094 (MEXU); Barranca de las Guacamayas, San José del Chilar, municipio Cuicatlán, R. García 138 (MEXU); $0.5 \mathrm{~km}$ al E de San José Aragón, municipio Nacaltepec, R. García 233 (OAX); 16 km al SE de Dominguillo, $11 \mathrm{~km}$ al NW de Tonaltepec, entre Cuicatlán y Telixtlahuaca, F. González Medrano et al. F-1101 (MEXU); $7 \mathrm{~km}$ de Santa María Almoloyas, a la estación de ferrocarril El Venado, por la terracería, $17^{\circ} 32^{\prime} 31^{\prime \prime} \mathrm{N}, 97^{\circ} 3^{\prime} 13^{\prime \prime} \mathrm{W}$, municipio San Pedro Jaltepetongo, R. Medina et al. 1031 (IEB, MEXU), 1035 (IEB, MEXU); estación de ferrocarril El Venado, arriba de la cañada, $17^{\circ} 35^{\prime} 4^{\prime \prime} \mathrm{N}, 97^{\circ} 0^{\prime} 5^{\prime \prime} \mathrm{W}$, municipio San Pedro Jaltepetongo, R. Medina et al. 1037 (IEB, MEXU); $6 \mathrm{~km}$ después de Santa María Almoloyas, camino a la estación El Venado, R. Medina et al. 1067 (MEXU);

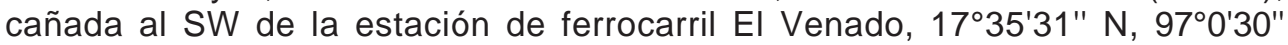
W, R. Medina et al. 1073 (MEXU), 1076 (MEXU); $14 \mathrm{~km}$ al S de Santiago Dominguillo - Santiago Nacaltepec, R. Medina et al. 1276b (IEB, MEXU); $15 \mathrm{~km}$ al S de Dominguillo, J. Rzedowski 34115 (ENCB, MEXU); Almoloyas - Santa Catarina,

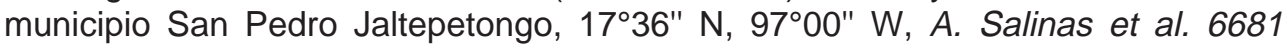
(MEXU); cerro El Castillo, al N de San Pedro Nodón, municipio Cuicatlán, P. Tenorio 17766 (MEXU); El Puente Viejo, cerca de Tonaltepec, municipio Nacaltepec, F. Ventura 15305 (IEB, MEXU). Distrito Etla: $6 \mathrm{~km}$ al N de Jayacatlán, H. Arroyo 73 (IEB, MEXU); $8 \mathrm{~km}$ por la terracería a San Juan Bautista Jayacatlán 17²7' N, 96 $48^{\prime}$ R. Medina et al. 1225 (IEB, MEXU), 1226 (IEB, MEXU); 3 km al N de El Parián, por la vía férrea El Parián - Tlaxila, A. Salinas 6253 (MEXU); El Progreso, Jayacatlán, F. Ventura 15467 (IEB, MEXU). Distrito Ixtlán: pueblo de Teococuilco, H. Arroyo 84 (IEB); 8 km de San Juan Atepec - Abejones, por la terracería en el puente de río Grande, municipio San Juan Atepec, R. Medina et al. 1041 (IEB, MEXU); $4 \mathrm{~km}$ al SW de San Juan Quiotepec, camino que baja al río, 17³6' N, 96 $36^{\prime}$ W, R. Medina et al. 1281 (IEB, MEXU); zona caliente, Macuiltianguis, R. Ortega 972 (MEXU); paraje río Mariposas, Macuiltianguis, G. Pérez C-200 (IEB, MEXU); 


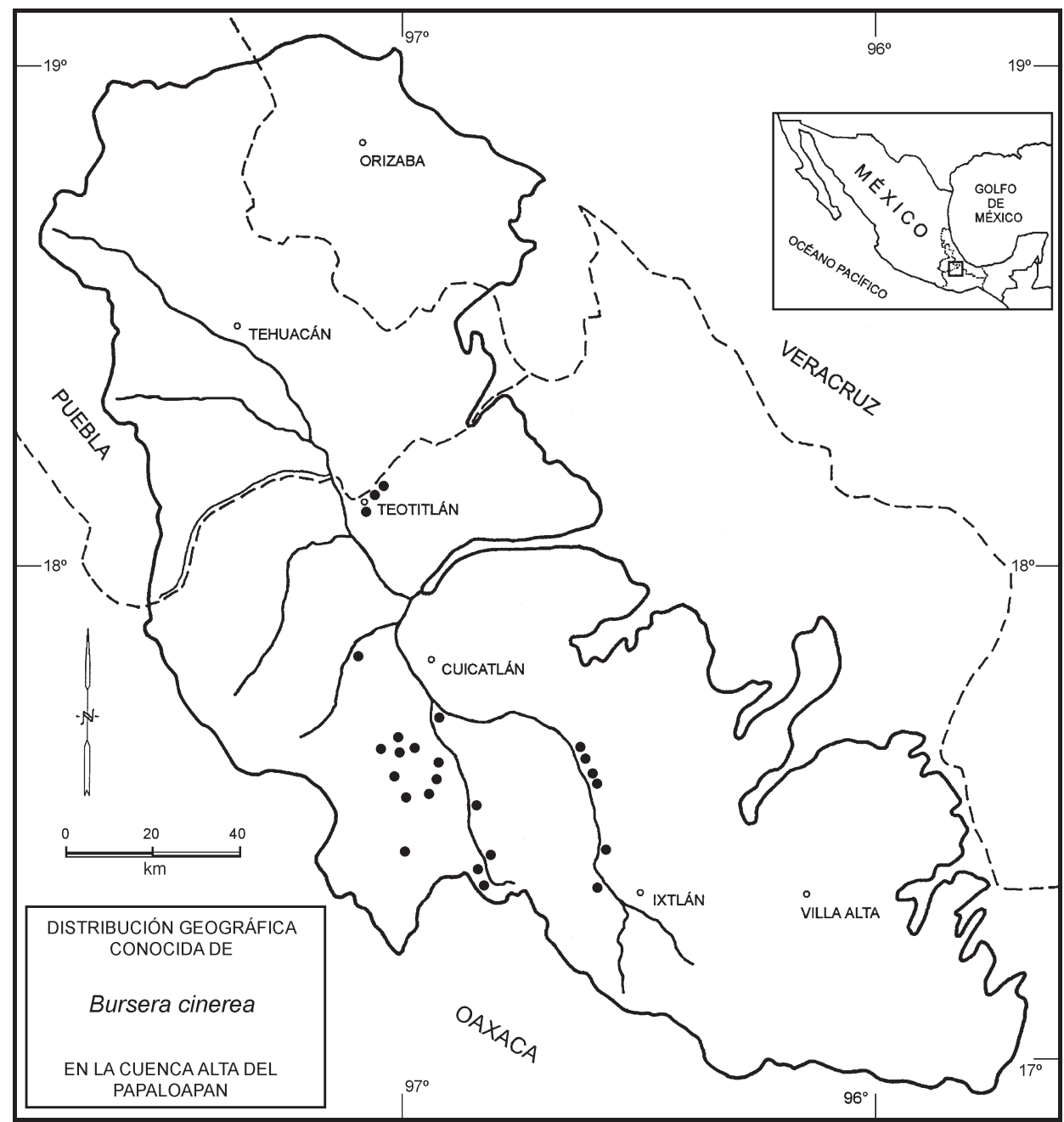

en la zona del río Culebra, Macuiltianguis, G. Pérez C-244 (MEXU); en la ribera del "Yesi-yoo", Macuiltianguis, N. Romero N36 (IEB, MEXU); en la desembocadura del río Carrizal, orilla del río Grande, $17^{\circ} 32^{\prime} 49^{\prime \prime}$ N, 96³6'55.6" W, S. H. Salas et al. 4342 (IEB). Distrito Teotitlán: Barranca de Tomazalco, municipio Teotitlán de Flores Magón, L. M. Cervantes 2192 (MEXU); Teotitlan to Huautla, km 6, C. A. Pendry y A. Reyes 969 (MEXU); $10 \mathrm{~km}$ al E de Teotitlán del Camino, sobre el camino a Huautla, L. S. Rodríguez y A. Patiño 1401 (ENCB, MEXU); 8 km al E de Teotitlán del Camino, sobre la carretera a Huautla, J. Rzedowski 32849 (IEB); $1 \mathrm{~km}$ al S de Teotitlán del Camino, J. Rzedowski 32853 (IEB, MEXU); 7 km al E de Teotitlán del Camino, sobre la carretera a Huautla, J. Rzedowski 35668 (IEB); 35669 (IEB, 
MEXU); $5 \mathrm{~km}$ al E de Teotitlán del Camino, sobre la carretera a Huautla, J. Rzedowski 37070 (ENCB, MEXU); Barranca Cruztitla, 6 km al NE de Teotitlán, carretera a Huautla, P. Tenorio y E. Martínez Correa 17389 (MEXU); $10 \mathrm{~km}$ al NW de Teotitlán, carretera a Huautla, P. Tenorio y E. Martínez Correa 17392 (MEXU).

Especie a menudo confundida en los herbarios y en la literatura con $B$. simaruba y con B. grandifolia (Schltdl.) Engl. De hecho, B. cinerea difiere de ambas en sus hojas con foliolos menos numerosos; de la primera se diferencia además en sus frutos más chicos y de la segunda en sus frutos glabros.

Engler (op. cit.) describió B. gummifera var. pubescens citando en el protólogo dos ejemplares: E. Bourgeau 2899 y E. Bourgeau 3131, ambos procedentes del estado de Veracruz. Rose (1911) la elevó a nivel de especie, misma que denominó Elaphrium subpubescens. Bullock (op. cit.) sumergió este taxon a la sinonimia de B. ovalifolia.

A su vez, Rzedowski y Calderón de Rzedowski (1996) lo consideraron como sinónimo de B. simaruba y designaron como lectotipo al espécimen Bourgeau 2899. Un examen más minucioso de las fotografías de los sintipos de $B$. gummifera var. pubescens revela, sin embargo, que los dos no pertenecen a la misma especie. Mientras el ejemplar 3131 representa sin mayor duda a una planta del tipo de $B$. simaruba, el del número 2899 tiene hojas con 3 ó 5 foliolos y frutos de tamaño relativamente pequeño, por lo que debe identificarse como $B$. cinerea. De lo anterior se deduce que la colocación de $B$. gummifera var. pubescens en la sinonimia de $B$. simaruba resulta incorrecta y dada la lectotipificación mencionada, es necesario ubicar el nombre como sinónimo de $B$. cinerea.

No están aún del todo claras las relaciones de la especie con algunas plantas de esta misma afinidad de hojas con 3 ó 5 foliolos, que prosperan en la vertiente pacífica de México, en Chiapas y en Centroamérica.

En la región de Teotitlán del Camino se han observado numerosos individuos de $B$. cinerea plantados para formar cercas vivas.

9. Bursera esparzae Rzedowski, Calderón \& Medina sp. nov. Tipo: México: Oaxaca: distrito Etla: El Parián, municipio Telixtlahuaca, cerca del cementerio, alt. $1500 \mathrm{~m}$, 13.VI.2002, J. Rzedowski 53888 (holotipo IEB, isotipos por distribuirse).

Nombres comunes registrados fuera de la zona de estudio: copal, yàg-yàal (lengua zapoteca).

Arbor vel saepe frutex usque $7 \mathrm{~m}$ altus ut videtur dioecius; truncus cortice griseo non exfolianti, ramuli juniores dense villosi vel velutini; foliorum rosulae juventute cataphyllis exterioribus potius tarde deciduis cinctae, folia plerumque imparipinnata rhachidi exalata, foliola (3)5-11 oblonga ad elliptica vel oblanceolata, (1.5)2-6(8) cm longa, 1-2.7(4) cm lata, apice acuta vel breviter acuminata, basi cuneata usque truncata, marginibus serratis, saepe duplo serratis, supra puberula, subtus dense tomentosa, maturitate cartacea vel coriacea; inflorescentiae paniculatae 


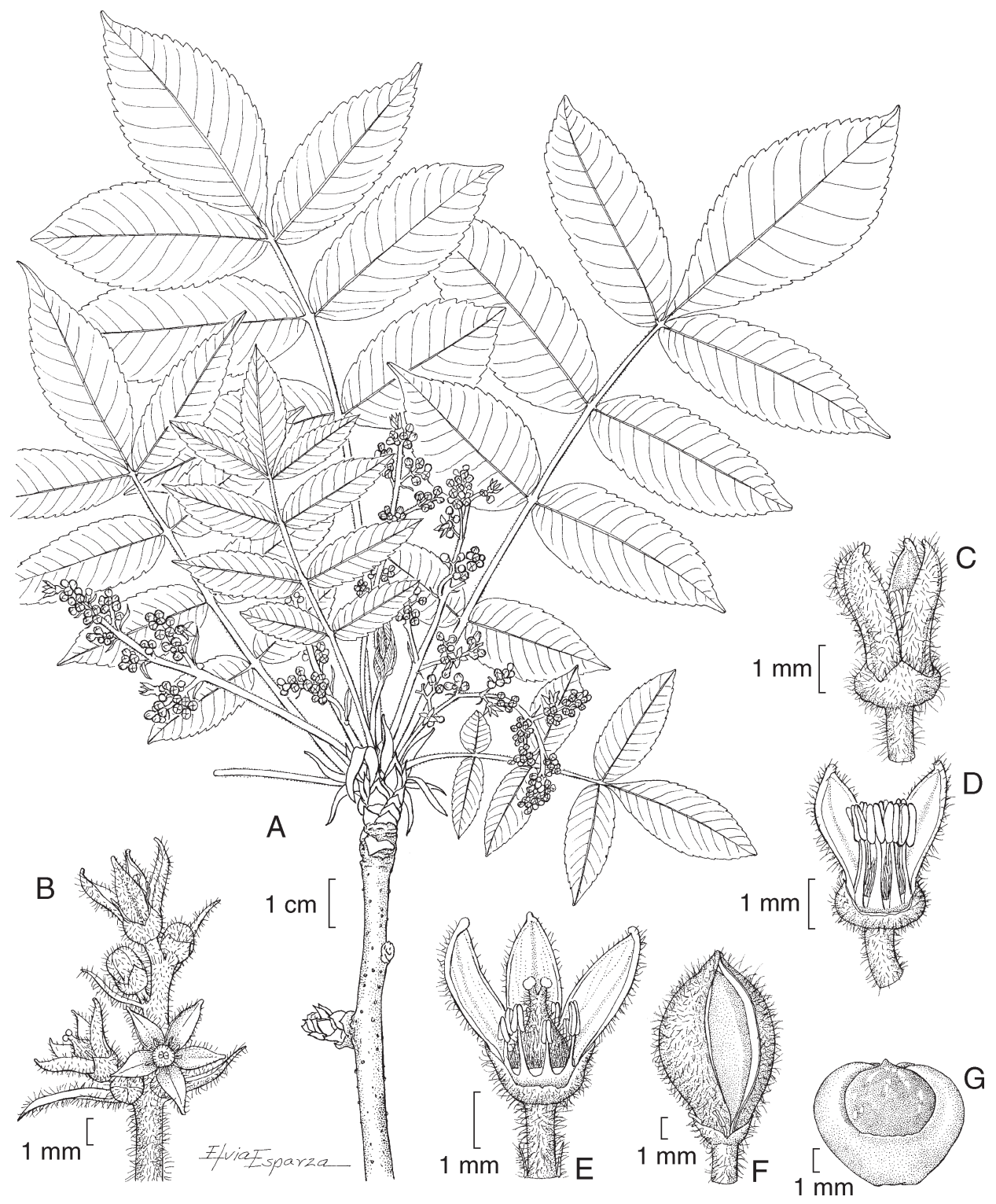

Bursera esparzae Rzed., Calderón \& Medina. A. rama con hojas e inflorescencias masculinas; B. ramilla de la inflorescencia femenina; C. flor masculina en vista externa; D. flor masculina desprovista de un segmento del cáliz y de 2 pétalos; E. flor femenina desprovista de un pétalo; F. fruto; G. hueso. Ilustrado por Elvia Esparza. 
vel racemosae usque ad $7 \mathrm{~cm}$ longae; flores masculi tetrameri vel interdum pentameri, calycis lobi triangulares ca. $0.5 \mathrm{~mm}$ longi, petala albida oblonga vel oblanceolata 2.5-3 mm longa, stamina 8 vel 10; flores feminei masculinorum similes, ovarium biloculare, stigmata 2; fructus ellipsoidei vel obovoidei, dense villosopuberuli, 8-9 mm longi, 5-6 mm diametro, pyrenae late lenticulares, 4-5 mm longae, pseudoarillo aurantiaco per 1/3-2/3 partibus inferis indutae.

Árbol o a menudo arbusto, aparentemente dioico, hasta de $7 \mathrm{~m}$ de alto, resinoso y aromático al estrujarse; tronco hasta de $30 \mathrm{~cm}$ de diámetro, corteza externa gris, lisa, no exfoliante, ramas rojizas oscuras a grises, las jóvenes densamente vilosas o velutinas; hojas con frecuencia aglomeradas en los ápices de las ramillas, otras veces alternas en ramillas de crecimiento nuevo, precedidas en su aparición por un conjunto de catafilos triangulares a angostamente triangulares, de 3 a $15 \mathrm{~mm}$ de largo, rojizos, densamente cubiertos en ambas caras por glándulas sésiles o cortamente estipitadas y a menudo también seríceos, sobre todo hacia el ápice, por lo general más bien no muy precozmente caedizos, peciolo hasta de $6 \mathrm{~cm}$ de largo, densamente velutino o viloso, lámina foliar elíptica a oblanceolada en contorno general, de (6)10 a $25 \mathrm{~cm}$ de largo, por lo general imparipinnada, foliolos (3)5 a 11, raquis sin alas, peciólulo del foliolo terminal hasta de $5 \mathrm{~mm}$ de largo, los de los laterales de 0 a $1 \mathrm{~mm}$ de largo, foliolos oblongos a elípticos, ovados u oblanceolados, el terminal a veces romboide, de (1.5)2 a 6(8) cm de largo, de 1 a $2.7(4) \mathrm{cm}$ de ancho, ápice agudo a cortamente acuminado, base cuneada a truncada, a menudo oblicua, margen más o menos regularmente serrado casi hasta la base del foliolo y con frecuencia en parte doblemente serrado (los dientes provistos de escotadura), de textura cartácea o coriácea en la madurez, hasta con 17 pares de nervaduras secundarias, más o menos paralelas, pero no muy prominentes, verdes oscuros en el haz, mucho más pálidos en el envés, pubérulos en el haz con pelos de base ampulosa y vilosos a lo largo de la costa, provistos además de un gran número de glándulas sésiles o casi sésiles, densamente tomentosos en el envés; inflorescencia paniculada o racimosa, hasta de $7 \mathrm{~cm}$ de largo, moderadamente laxa, vilosa y con numerosas glándulas sésiles o casi sésiles, bracteolas lineares, hasta de $6 \mathrm{~mm}$ de largo, pedicelos filiformes, hasta de $3 \mathrm{~mm}$ de largo; flores masculinas tetrámeras o a veces pentámeras, lóbulos del cáliz triangulares, de ca. $0.5 \mathrm{~mm}$ de largo, esparcidamente vilosos por fuera, ciliados, pétalos blanquecinos, oblongos a oblanceolados, de 2.5 a $3 \mathrm{~mm}$ de largo, vilosos por fuera, estambres 8 ó 10, filamentos de ca. $1 \mathrm{~mm}$ de largo, anteras oblongas, de ca. $0.8 \mathrm{~mm}$ de largo, gineceo vestigial; flores femeninas similares a las masculinas, estaminodios con anteras de 0.5 a $0.7 \mathrm{~mm}$ de largo, ovario bilocular, densamente velutino, estigmas 2; pedúnculos fructíferos hasta de $5 \mathrm{~cm}$ de largo, llevando por lo general varios frutos, éstos bivalvados, elipsoides u obovoides, de 8 a $10 \mathrm{~mm}$ de largo, de 5 a $6 \mathrm{~mm}$ de diámetro, densamente viloso-pubérulos, rojizos en la madurez, hueso gruesamente lenticular, de 4 a $5 \mathrm{~mm}$ de largo, cubierto de un lado hasta sus $2 / 3$ inferiores y del otro sólo hasta $1 / 3$ de su longitud por un pseudoarilo anaranjado, la porción expuesta café oscura. 


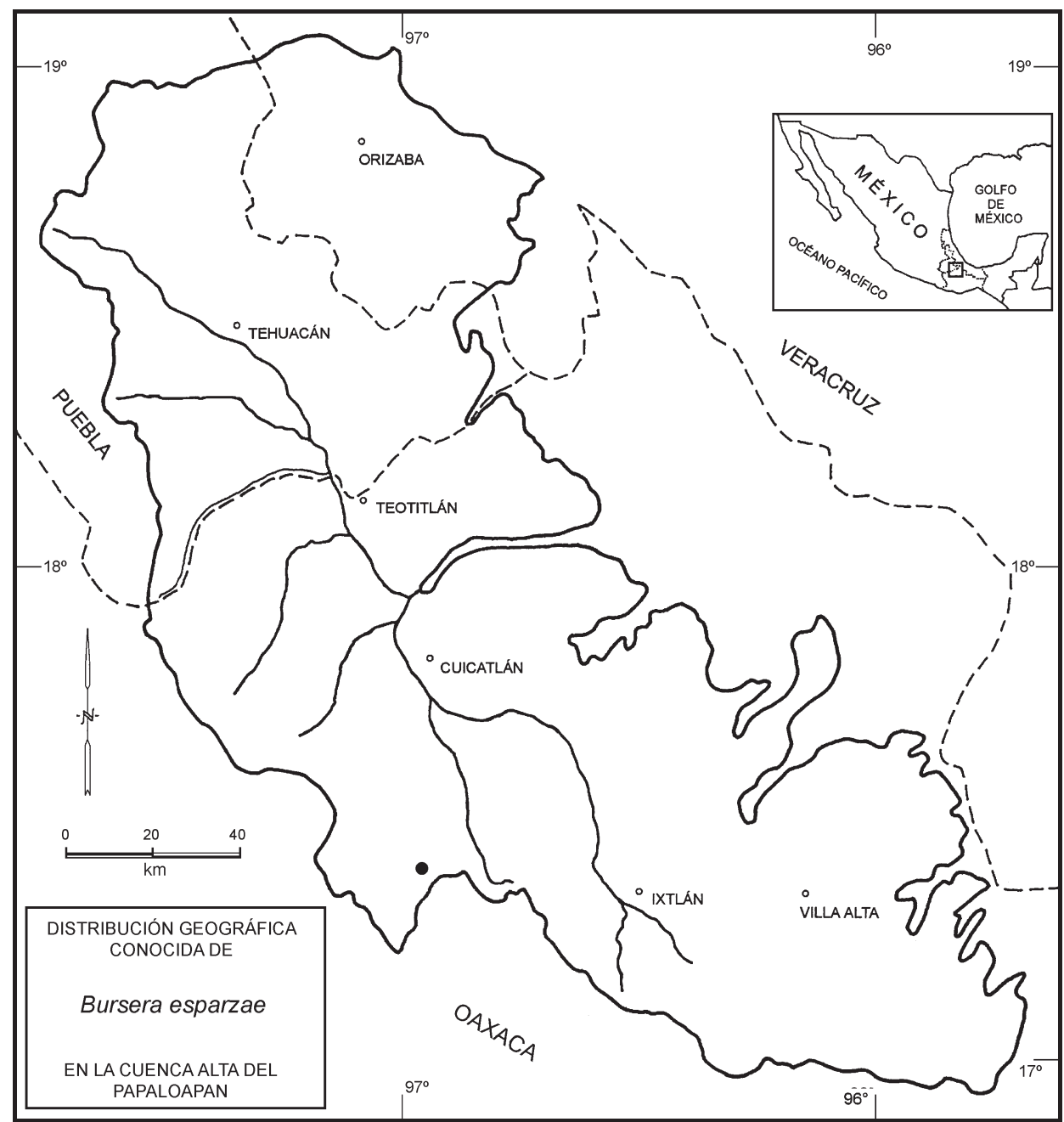

Elemento más bien escaso del bosque tropical caducifolio, en la región de estudio solamente encontrado en los alrededores de la estación de ferrocarril El Parián, con altitud de1500 m. Florece en mayo y junio, se encuentra sin follaje de noviembre a mayo.

Se ha colectado también en el sur del estado de Oaxaca, en bosques tropicales caducifolios, en matorrales esclerófilos y en bosques de encino, en altitudes entre 1550 y 1950 m.

Material adicional examinado de la región de estudio: OAXACA: Distrito Etla: El Parián, municipio Telixtlahuaca, cerca del cementerio: J. Rzedowski 53885 (IEB), 
53886 (IEB), 53887 (IEB); Parián - Las Sedas, colecta del km 309-314 de la vía férrea, municipio Telixtlahuaca, $17^{\circ} 23^{\prime \prime}$ N, 9700' W, A. Salinas et al. 6836 (MEXU); Parián, municipio Telixtlahuaca, F. Ventura 15459 (IEB, MEXU).

Material extraterritorial examinado: OAXACA: Distrito Ejutla: San Vicente Coatlán, municipio San Vicente Coatlán, C. Robles 59 (IEB, MEXU, OAX). Distrito Miahuatlán: on old road just off hwy 175, 7 miles S of Miahuatlán, G. J. Breckon y M. Breckon 712 (MEXU); $5 \mathrm{~km}$ al SO de Miahuatlán, camino a Quixtla, A. García y R. Torres 1598 (MEXU); ca. 6 miles SE of Miahuatlán, H. S. Gentry 22376 (MEXU); municipio San Juan Mixtepec, $1.0 \mathrm{~km}$ NNE, N of Río Calabazas, $16^{\circ} 18^{\prime} 00^{\prime \prime} \mathrm{N}$, 96¹7'08" W, E. Hunn OAX-326 (MEXU); $5 \mathrm{~km}$ al SW de Miahuatlán, cerca de Cuixtla, $R$. Torres y A. García 6796 (IEB, MEXU). Distrito Sola de Vega: 1 km al NW de San Sebastián de las Grutas, municipio Sola de Vega, R. López 951 (IEB, MEXU, OAX).

En virtud del raquis foliar carente de alas y de sus frutos pubescentes, algunos ejemplares de esta especie fueron inicialmente identificados como Bursera aff. vejarvazquezii Miranda. Sin embargo, esta última difiere notablemente de Bursera esparzae en sus foliolos más largos y angostos, en sus frutos más grandes, así como en sus flores más grandes con lóbulos del cáliz lineares y de 3 a $5 \mathrm{~mm}$ de largo.

Por sus flores predominantemente tetrámeras, ovario bicarpelar y fruto bivalvado, $B$. esparzae sin duda pertenece a la sección Bullockia, pero no están claros sus vínculos con otros miembros de la misma.

Sus foliolos muestran gran semejanza en forma, nerviación, ápice, margen, color y pubescencia con la planta que Toledo Manzur (1982, p. 87) distinguió como $B$. aff. palmeri, originalmente sólo conocida de la parte central de Guerrero, pero en tiempos más recientes también colectada en el distrito de Juxtlahuaca en Oaxaca. De este árbol, que con toda probabilidad representa una especie aun no descrita del grupo de B. excelsa (H.B.K.) Engl., no se han visto las flores. Sin embargo, sus frutos son glabros, las divisiones del cáliz, que tienen forma linearlanceolada, miden unos $3 \mathrm{~mm}$ de largo y el raquis foliar presenta alas incipientes de $0.5 \mathrm{~mm}$ a $1 \mathrm{~mm}$ de ancho.

El nombre de la especie se dedica como homenaje a Elvia Esparza Alvarado, muy destacada y ameritada ilustradora biológica mexicana.

10. Bursera fagaroides (H.B.K.) Engl., Bot. Jahrb. 1: 41. 1881. Elaphrium fagaroides H.B.K., Nov. Gen. \& Sp. 7: 27. t. 611. 1824. Amyris fagaroides (H.B.K.) Spreng., Syst. Veg. 4: 148. 1827. Terebinthus fagaroides (H.B.K.) Rose, Contr. U.S. Nat. Herb. 10: 1906. Tipo: México: Querétaro: Querétaro, A. Humboldt y A. Bonpland 4200 (holotipo P).

Amiris ventricosa La Llave, Reg. Trim. 1: 355. 1832. Tipo: México, Distrito Federal, Santa Fe (sin haberse localizado). 


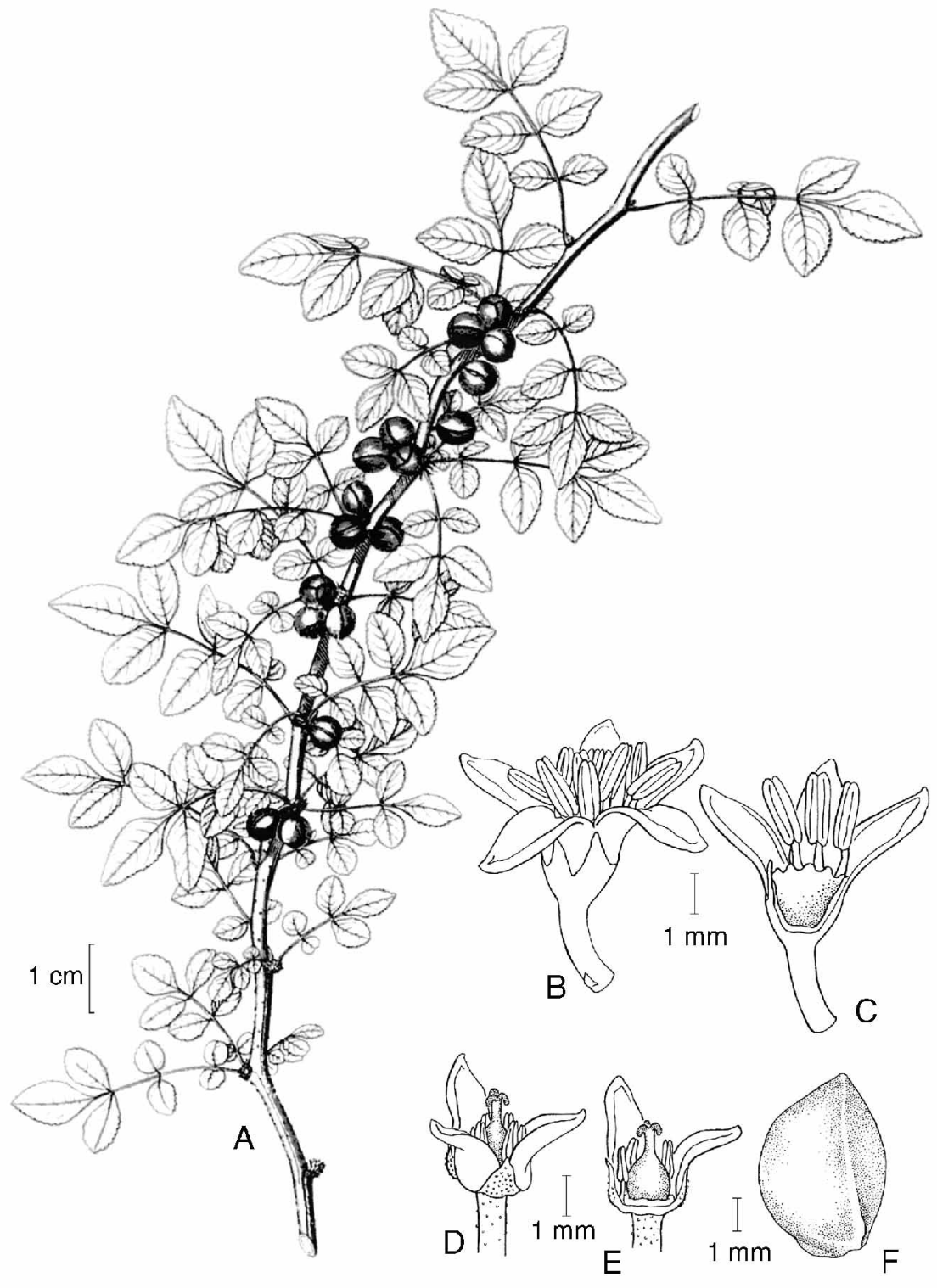

Bursera fagaroides (H.B.K.) Engl. A. rama con hojas y frutos; B. flor masculina; C. flor masculina desprovista de 2 segmentos del cáliz, de 2 pétalos y de 7 estambres; D. flor femenina; E. flor femenina desprovista de un segmento del cáliz, de un pétalo y de varios estaminodios; F. hueso. Ilustrado: A. por Pierre-Jean-François Turpin y reproducido de la lámina 611 de Nova genera et species plantarum de A. Humboldt, A. Bonpland y S. Kunth; B-F. Ilustrado por Elvia Esparza. 
Bursera obovata Turcz., Bull. Soc. Nat. Mosc. 36: 614. 1863. Elaphrium obovatum (Turcz.) Rose, North Amer. Fl. 25: 245. 1911. Tipo: México: Veracruz: Orizaba, M. Botteri 912 (holotipo probablemente en KW).

Bursera schaffneri S. Watson, Proc. Amer. Acad. Arts 22: 469. 1887. Terebinthus schaffneri (S. Watson) Rose, Contr. U.S. Nat. Herb. 10: 122. 1906. Elaphrium schaffneri (S. Watson) Rose, North Amer. Fl. 25: 245. 1911. Tipo: México: San Luis Potosí: in montibus Morales, J. G. Schaffner 90, en 1876 (holotipo GH, isotipo K).

Schinus occidentalis Sessé \& Moc., PI. Nov. Hisp. p. 173. 1890. Tipo: Ic. FI. Mex. 406, identificado como lámina 117 del Catálogo de láminas del Real Jardín Botánico, publicado como apéndice del libro La Real Expedición Científica a Nueva España, Madrid 1987.

Nombres comunes registrados en la zona: aceitillo, copal, sarzafrás, xixote. Nombres comunes registrados fuera de la zona de estudio: cuajiote, cuajiote amarillo, cuajiote blanco, cuajiote colorado, jiote, palo del diablo, papelillo.

Arbusto o árbol dioico (ocasionalmente hermafrodita), de 0.5 a 8(10) $\mathrm{m}$ de alto, glabro, ramillas jóvenes con abundante resina transparente, ligeramente aromática; tronco hasta de $30 \mathrm{~cm}$ de diámetro, corteza interna verde, con látex blanquecino o de color crema, la externa exfoliante, amarilla a amarillo-grisácea; catafilos inconspicuos, pronto caducos, hojas por lo general imparipinnadas, menos frecuentemente trifolioladas o unifolioladas, peciolo de 0.5 a 2(3) $\mathrm{cm}$ de largo, raquis con alas inconspicuas, foliolos (1)5 a 11(13), en las plantas de la región de estudio 5 ó 7, los laterales sésiles a subsésiles, el terminal con peciólulo hasta de $1 \mathrm{~cm}$ de largo, elípticos, oblongos, obovados a suborbiculares, de 0.5 a 2(4) $\mathrm{cm}$ de largo y de 0.3 a $1(2) \mathrm{cm}$ de ancho, aumentando de tamaño hacia la porción distal de la hoja, ápice agudo a obtuso, base cuneada, obtusa o redondeada, margen entero a crenado o serrado, de textura membranácea algo rígida, nervadura central evidente en ambas caras, amarillenta, las secundarias hasta 6 pares, poco conspicuas en el haz; flores solitarias o agrupadas por pocas en inflorescencias cortas, a menudo densamente aglomeradas en los ápices de ramillas cortas; las masculinas por lo general pentámeras, ocasionalmente trímeras o tetrámeras, lóbulos del cáliz angostamente triangulares, agudos, glandular-dentados, verdes con tintes rojizos, de 1 a $2 \mathrm{~mm}$ de largo, pétalos verdosos a blanquecino-amarillentos, oblongos a oblongo-lanceolados, de 3 a $6 \mathrm{~mm}$ de largo, cuculados, encorvados en el ápice, reflexos en la madurez, filamentos de ca. $1 \mathrm{~mm}$ de largo, anteras oblongas, de ca. $1.5 \mathrm{~mm}$ de largo, disco verde, glutinoso; las flores femeninas semejantes en tamaño y forma, aunque generalmente trímeras, estaminodios de ca. $1 \mathrm{~mm}$ de largo, ovario trilocular, estigmas 3; pedúnculos del fruto de $(0.2) 0.5$ a 2(5) $\mathrm{mm}$ de largo, ligeramente incurvados y engrosados, fruto trivalvado, obovoide a subesférico, cortamente apiculado, rojizo, glabro, de 0.5 a $0.8 \mathrm{~cm}$ de largo, hueso cubierto totalmente por el pseudoarilo rojizo o amarillento en la madurez. 
Habita en el matorral xerófilo y en el bosque tropical caducifolio, en suelos diversos, en altitudes de 700 a 2200 m. Florece de abril a junio. Permanece sin follaje de noviembre a mayo.

Se distribuye desde el suroeste de Estados Unidos hasta Oaxaca en México.

Material examinado: OAXACA: Distrito Coixtlahuaca: km 76 Tehuacán Oaxaca (cuota), G. D. Furth 97-2 (MEXU); $1 \mathrm{~km}$ al $\mathrm{S}$ de Magdalena Jicotlán, $A$. García y D. H. Lorence 1924 (IEB, MEXU); km 92 del corte de la carretera Cuacnopalan - Oaxaca, municipio Tepelmeme, A. Salinas 7728 (MEXU); subida de Cacalosúchil, cerro Verde, P. Tenorio et al. 6933 (MEXU). Distrito Cuicatlán: km 100 carretera Tecomavaca - Cuicatlán, municipio Cuicatlán, H. Arroyo 42 (IEB, MEXU); $2.5 \mathrm{~km}$ al noreste de la desviación a Quiotepec, $H$. Arroyo 45 (IEB, MEXU); $7 \mathrm{~km}$ al NW de Cuicatlán, municipio Cuicatlán, H. Arroyo 66 (IEB, MEXU); barranca de las Guacamayas, 1740'36" N, 9657'55" W, J. Calónico et al. 23978 (IEB, MEXU); km 125 carretera Teotitlán - Cuicatlán, Santiago Quiotepec, L. M. Cervantes 2275 (MEXU); Plan de beis, San José del Chilar, C. A. Cruz et al. 157 (MEXU); barranca del Casiquito, San José del Chilar, 17²41'43.2" N, 9657'16.2" W, C. A. Cruz y E. San Pedro 704 (MEXU); cerro El Zacatal, San José del Chilar, C. A. Cruz et al. 820 (MEXU), 923 (MEXU); barranca Agua Amarilla, San José del Chilar, $C$. A. Cruz y E. San Pedro 1058 (MEXU); barranca de las Tinajas, San José del Chilar, 17²1'17" N, 9657'40" W, C. A. Cruz et al. 1128 (MEXU); 9 km al NE de Cuicatlán, rumbo a Concepción Pápalo, F. González Medrano et al. F-1634 (ENCB); cerca de la bifurcación San Pedro Jaltepetongo - Santa María Texcatitlán, R. Medina et al. 1011 (MEXU); terracería de Tomellín a Santa María Texcatitlán, 1744'46" N, 9658'52" W, municipio Valerio Trujano, R. Medina et al. 1058 (MEXU); 5 km de San Pedro Jaltepetongo, cañada W, municipio San Pedro Jaltepetongo, R. Medina et al. 1107 (MEXU), 1108 (MEXU); terracería de Santiago Quiotepec a Cuicatlán, $17^{\circ} 47^{\prime} \mathrm{N}, 9^{\circ} 57^{\prime} \mathrm{W}$, R. Medina et al. 1262 (MEXU), 1266 (IEB, MEXU); $1 \mathrm{~km}$ al E de Cuicatlán, camino a Pápalo, L. S. Rodríguez y A. Patiño 1396 (ENCB, MEXU); $9 \mathrm{~km}$ al SE de Dominguillo, sobre la carretera a Oaxaca J. Rzedowski 35656 (ENCB); $2 \mathrm{~km}$ al NE de Dominguillo, sobre la carretera a Cuicatlán, J. Rzedowski 35659 (ENCB); $6 \mathrm{~km}$ al $\mathrm{N}$ de Cuicatlán por la carret. 131 y $2.5 \mathrm{~km}$ al W por la terracería que va rumbo a San Pedro Jocotipac, A. Salinas et al. 4261 (IEB, MEXU); $3 \mathrm{~km}$ al NE de Cuicatlán, I. Trejo 1655 (MEXU); San Pedro, municipio Cuicatlán, F. Ventura 15298 (MEXU); Dominguillo, municipio Cuicatlán, F. Ventura 15318 (IEB, MEXU); Quiotepec, cerca de la estación de ferrocarril, antes de pasar el río, $F$. Ventura 15349 (IEB, MEXU); camino de Pápalo, cerca de la desviación de Quiotepec, municipio Cuicatlán, F. Ventura 16425 (ENCB, MEXU); San José del Chilar, municipio Cuicatlán, F. Ventura 16437 (ENCB, MEXU). Distrito Etla: ca. 6 mi NE of Telixtlahuaca, H. S. Gentry 22370 (MEXU), 22371 (MEXU); kilómetro 30, municipio Jayacatlán, F. Ventura 15471 (IEB, MEXU). Distrito Ixtlán: Guelatao, municipio Guelatao, F. Ventura 16362 (ENCB, MEXU). Distrito Teotitlán: 2 km al N de Santa María Tecomavaca, municipio Santa María Tecomavaca, H. Arroyo 


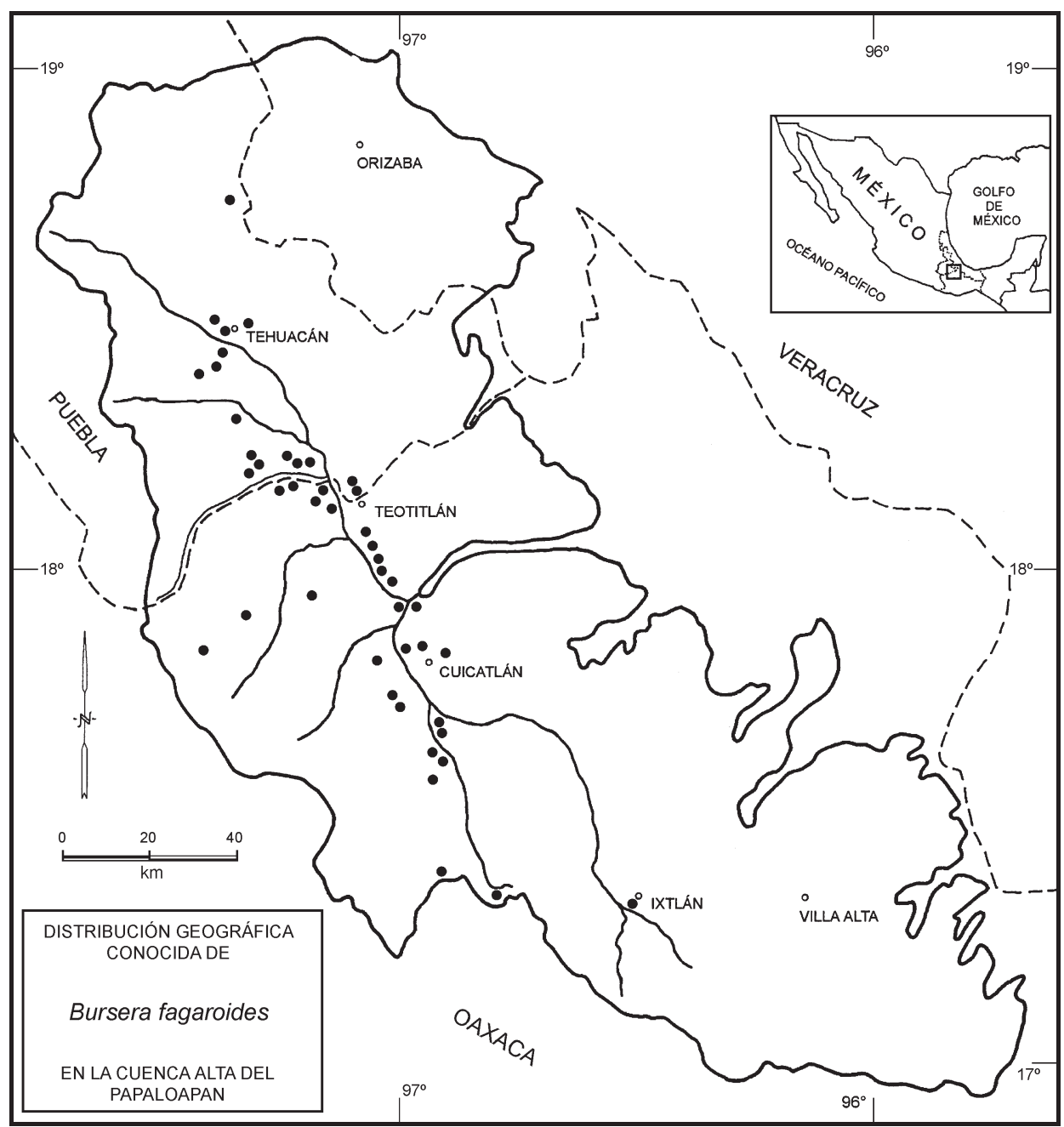

27 (IEB, MEXU); al NW de Sn. Juan de los Cues, municipio San Juan de Los Cues, H. Arroyo 38a (IEB, MEXU), 38b (IEB, MEXU); cerro Nahualtepec, $8 \mathrm{~km}$ al NW de San Gabriel Casa Blanca, A. García et al. 3479 (IEB, MEXU); 3-8 mi W of San Antonio, H. S. Gentry 22421 (MEXU); $5 \mathrm{~km}$ al N de Tecomavaca, sobre la carretera a Teotitlán del Camino, J. Rzedowski 28168 (ENCB), 32854 (IEB, MEXU); 6 km al W de San Gabriel Casa Blanca, municipio San Antonio Nanahuatipan, J. Rzedowski 53876 (IEB); $19 \mathrm{~km}$ al S de Tecomavaca, por la carretera a Oaxaca, A. Salinas y O. Dorado F-2668 (MEXU); km 80 de la carretera 135 rumbo a Oaxaca, A. Salinas y A. Reyes 4837 (MEXU); $5 \mathrm{~km}$ al S de Tecomavaca y $23 \mathrm{~km}$ al W, rumbo a Santa María Ixcatlán, A. Salinas y E. Martínez Correa 6142 (MEXU); cerro La Mina al SE de San Antonio Nanahuatipam, P. Tenorio et al. 20474 (MEXU); 
puente del río Salado, municipio de Tecomavaca, F. Ventura 15321 (MEXU); camino a Telixtlahuaca, municipio San Martín Toxpalan, F. Ventura 15335 (MEXU). PUEBLA: Municipio Caltepec: La Cumbre, frente al cerro El Gavilán, a 2 km de Caltepec hacia San Luis Atolotitlán, E. M. Lira et al. 1572 (MEXU), 1581 (MEXU); La Cumbre, meseta, adelante del cerro El Gavilán, 18¹0' N, 97²7' W, R. Medina et al. 1186 (IEB, MEXU), 1193 (IEB, MEXU); lindero de Peña Flor, al N de Caltepec, P. Tenorio y C. Romero 8933 (IEB, MEXU); Planes de San Miguel, F. Ventura 15394 (IEB, MEXU), 15396 (IEB, MEXU). Municipio Chapulco: $25 \mathrm{~km}$ al $\mathrm{S}$ de Esperanza, por la carretera a Azumbilla, A. Salinas y G. Flores 4210 (MEXU). Municipio Coxcatlán: San Rafael, F. Ventura 15365 (IEB, MEXU); $6.5 \mathrm{mi}$ NW of Teotitlan (near border of Oaxaca), $18^{\circ} 09^{\prime}$ N, 9706' W, G. L. Webster y S. Lynch 17244 (MEXU). Municipio

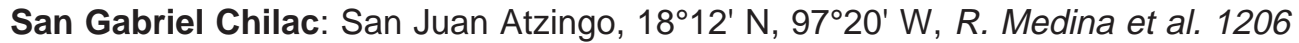
(IEB, MEXU). Municipio San José Miahuatlán: cerro Petlanco, aproximadamente $9 \mathrm{~km}$ al SE de Axusco, F. Chiang et al. F-2232 (MEXU); cerro Tepetroje, $6 \mathrm{~km}$ al $\mathrm{O}$ de Axusco, A. García et al. 3325 (IEB, MEXU), 3337 (MEXU); cerro Tepetroje, $13 \mathrm{~km}$ al SW de Axusco, E. Martínez y A. García 21729 (MEXU); cerro Tepetroje,

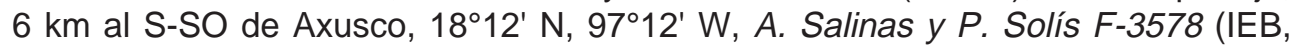
MEXU); cerro Tepetroje, aproximadamente $6.5 \mathrm{~km}$ al SW de Axusco, A. Salinas et al. 4072 (MEXU); 6-7 km al SW de Axusco, A. Salinas y J. Sánchez Ken 5550 (MEXU); Cañada del Cosahuico, $\mathrm{N}$ del cerro Tepetroje, $\mathrm{S}$ de Axusco, P. Tenorio y E. Martínez Correa 17929 (MEXU). Municipio Tehuacán: $1.5 \mathrm{~km}$ al este de Tehuacán, H. Arroyo 1 (IEB, MEXU); Meseta de San Lorenzo, $8 \mathrm{~km}$ al W de Tehuacán, A. García et al. 3299 (IEB, MEXU); SW de El Riego, F. Miranda 4381 (MEXU); W de El Riego, F. Miranda 4443 (MEXU); cerros al W de Tehuacán, J. Rzedowski 9013 (ENCB); 8 km al SW de Tehuacán, sobre la carretera a Huajuapan, J. Rzedowski 9017 (MEXU); minas de cantera de Santa Ana, F. Ventura 15291 (ENCB). Municipio Zapotitlán: Cerro Viejo, A. Valiente et al. 812 (MEXU); San Antonio Texcala, F. Ventura 15259 (ENCB, MEXU).

Como se menciona al inicio de este trabajo, en el género Bursera existen varios conjuntos de taxonomía aún poco esclarecida y uno de ellos se centra en B. fagaroides.

La especie en cuestión es de amplia repartición, frecuencia y abundancia en México. Presenta un mosaico de variantes morfológicas, que no ha resultado fácil entender, definir ni correlacionar con patrones de distribución ecológica o geográfica.

Las poblaciones de la región de estudio no escapan de este complejo comportamiento y así, mientras algunas constan de plantas arbustivas, a menudo de menos de $50 \mathrm{~cm}$ de alto, similares a un bonsai, en otras predominan árboles vigorosos y robustos con tallas de 5 o hasta $8 \mathrm{~m}$. A su vez, las hojas son diversas en forma y tamaño de los foliolos, cuyo margen puede ser uniformemente crenado, escasamente crenado-ondulado o completamente entero.

La variación de los caracteres foliares es tan continua y carente de correlación, que no ha sido posible ubicar una importante proporción de los ejemplares en alguna de las variedades propuestas para esta parte del país por 
McVaugh y Rzedowski (op. cit.). Concretamente se ha encontrado un solapamiento notable de rasgos que se están usando para distinguir $B$. fagaroides var. fagaroides de B. fagaroides var. purpusii (Brandegee) McVaugh \& Rzed.

Queda pendiente de definir la correcta e integral interpetación taxonómica del grupo.

11. Bursera galeottiana Engl., Bot. Jahrb. 1: 43. 1881. Terebinthus galeottiana (Engl.) Rose, Contr. U.S. Nat. Herb. 10: 119. 1906. Elaphrium galeottianum (Engl.) Rose, North Amer. Fl. 25: 249. 1911. Tipo: México: Puebla: Tehuacán, VIII-XI.1840, H. Galeotti 4004 (holotipo G, isotipos K, P).

Schinus angustifolius Sessé \& Moc., PI. Nov. Hisp. p. 173. 1890. Tipo: México: Guanajuato: in aridis montibus Ixtlae haereditatis prope Queretarum; M. Sessé y J. M. Mociño; aparentemente perdido.

Nombres comunes registrados en la zona: copal, cuajiote colorado.

Nombres comunes registrados fuera de la zona de estudio: breo, copal mulato, cuajiote rojo, xiote colorado, xixote, xixote colorado.

Árbol o arbusto, dioico u ocasionalmente polígamo-dioico, de 2 a $8 \mathrm{~m}$ de alto, resinoso, aromático; tronco hasta de $30(50) \mathrm{cm}$ de diámetro, con corteza de color rojo oscuro, exfoliante en pequeñas láminas, ramillas jóvenes pubescentes, ramas maduras glabras, catafilos inconspicuos; hojas imparipinnadas, oblongas en contorno general, de 4 a $7 \mathrm{~cm}$ de largo y de 1 a $4 \mathrm{~cm}$ de ancho, peciolo acanalado, hasta de $7 \mathrm{~mm}$ de largo, densamente pubérulo, raquis acanalado, con alas inconspicuas, espaciadamente pubérulo, lámina con (5)13 a 19(29) foliolos, sésiles o subsésiles, lineares, de (0.4)8 a $20 \mathrm{~mm}$ de largo y de ca. $1 \mathrm{~mm}$ de ancho, disminuyendo de tamaño hacia los extremos de la hoja, ápice obtuso a agudo, base atenuada, margen entero, nervadura principal evidente, nervaduras secundarias inconspicuas, glabros; flores solitarias o a veces dispuestas en pares, con frecuencia densamente agrupadas en el ápice de las ramillas cortas, sobre pedúnculos hasta de $5 \mathrm{~mm}$ de largo, finamente pubescentes, bracteolas subuladas, rojizas, de ca. $1 \mathrm{~mm}$ de largo, resinosas; flores masculinas pentámeras o rara vez tetrámeras, lóbulos del cáliz linear-triangulares, de 1.5 a $2 \mathrm{~mm}$ de largo, finamente pubérulos en la parte externa, pétalos amarillos pálidos, triangular-lanceolados, cuculado-encorvados, de 2.5 a $3 \mathrm{~mm}$ de largo, glabros o casi glabros, estambres (8) 10 , filamentos de 0.5 a $1 \mathrm{~mm}$ de largo, anteras oblongas, de 1 a $1.5 \mathrm{~mm}$ de largo; flores femeninas trímeras, similares a las masculinas, pero con los lóbulos del cáliz y los pétalos más anchos, anteras de los estaminodios de menos de $1 \mathrm{~mm}$ de largo, ovario trilocular, glabro, estigmas 3; pedúnculos fructíferos hasta de $1 \mathrm{~cm}$ de largo, engrosados, marcadamente encorvados y pubérulos; fruto oblicuamente ovoide, de 6 a $8 \mathrm{~mm}$ de largo, glabro, rojizo, trivalvado, apiculado, el hueso cubierto totalmente por un pseudoarilo anaranjado o amarillo pálido antes de llegar a la madurez. 


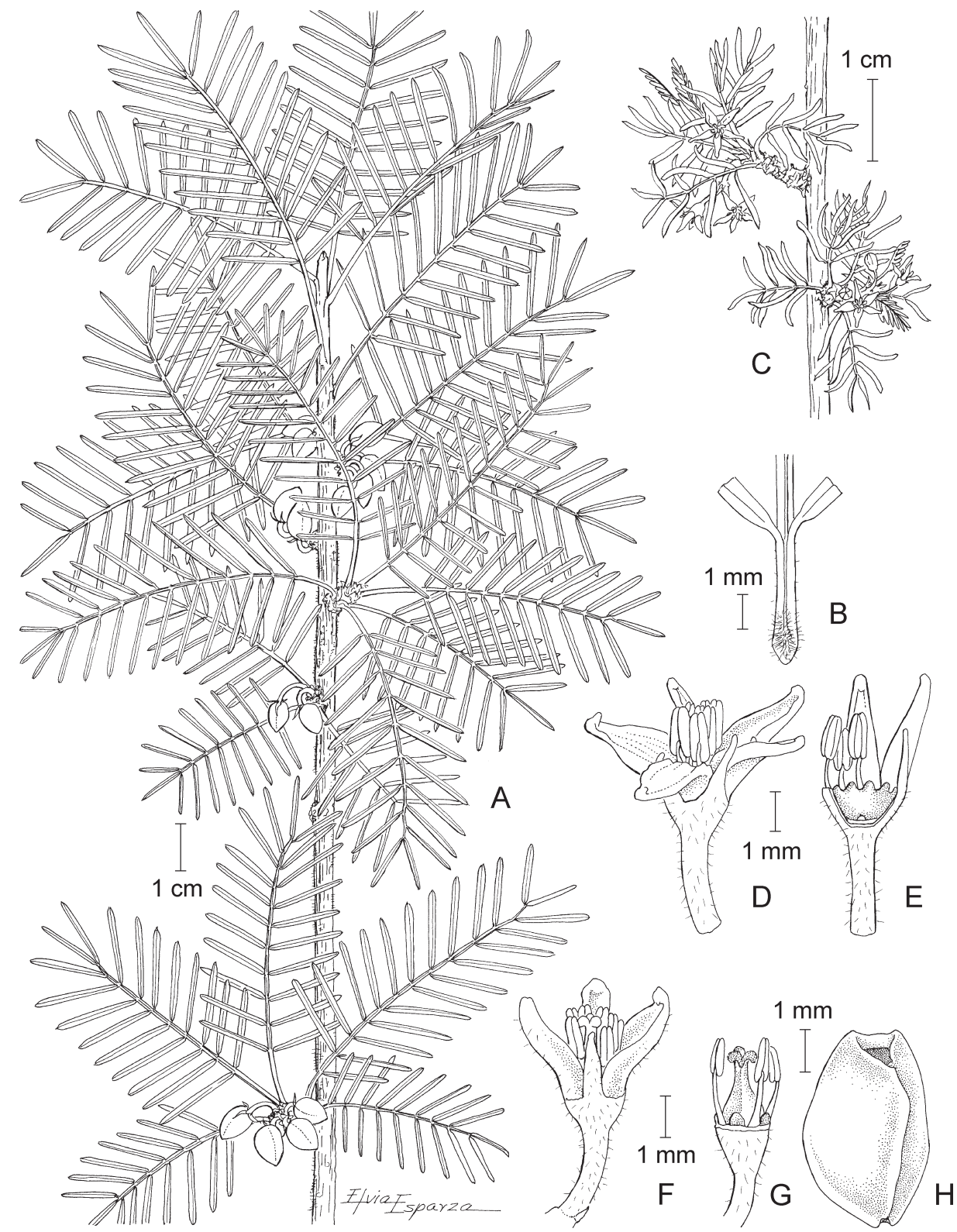

Bursera galeottiana Engl. A. rama con hojas y frutos; B. detalle de la pubescencia del peciolo; C. ramilla con flores masculinas; D. flor masculina; E. flor masculina desprovista de 2 segmentos del cáliz, de 3 pétalos y de 7 estambres; F. flor femenina; G. flor femenina desprovista de cáliz, de corola y de 7 estaminodios; H. fruto. Ilustrado por Elvia Esparza. 
Habita principalmente en el bosque tropical caducifolio y en la ecotonía de éste con el bosque de Quercus, así como también en matorral xerófilo, en suelos someros derivados de rocas ígneas y de calizas, en altitudes de 550 a $2200 \mathrm{~m}$. Florece durante los meses de abril y mayo. Permanece sin follaje de noviembre a mayo.

B. galeottiana tiene una área disyunta, se distribuye principalmente en los estados de Oaxaca y Puebla con poblaciones al parecer relictuales en Guanajuato y Querétaro. Recientemente se ha registrado también para el estado de Guerrero.

Material examinado: OAXACA: Distrito Coixtlahuaca: cerro Conejo, W de San Antonio Abad, camino a La Mexicana, P. Tenorio 17551 (MEXU); cerro entre el pueblo de El Rodeo y el cerro de La Mesa de Coscomate, P. Tenorio 21292 (MEXU). Distrito Cuicatlán: $4 \mathrm{~km}$ al W de la estación de ferrocarril El Venado, camino a Santa María Almoloyas, H. Arroyo 123 (ENCB, MEXU); $2 \mathrm{~km}$ al E de Santa Catarina, H. Arroyo 125 (ENCB); $43 \mathrm{~km} \mathrm{~N}$ of Telixtlahuaca on road to Tehuacán, D. E. Breedlove 59823 (MEXU); 6 km después de Santa María Almoloyas, camino a la estación de ferrocarril EI Venado, R. Medina et al. 1033 (MEXU), 1066 (MEXU); $24 \mathrm{~km}$ al $\mathrm{N}$ de San Sebastián Sedas a Cuicatlán, municipio Santiago Nacaltepec, $17^{\circ} 19^{\prime} \mathrm{N}, 96^{\circ} 55^{\prime} \mathrm{W}$, R. Medina 1256 (IEB, MEXU), 1258 (IEB, MEXU). Distrito Etla: $2 \mathrm{~km}$ al $\mathrm{N}$ de El Parián, sobre el río, dirección $\mathrm{N}$, municipio San Francisco Telixtlahuaca, H. Arroyo 116 (ENCB, IEB, MEXU); $1.5 \mathrm{~km}$ al W de Anona, H. Arroyo 132 (ENCB, IEB, MEXU, UAMIZ); El Parián, C. Conzatti s. n. 31.X.1909 (MEXU); $6 \mathrm{mi} \mathrm{NE}$ of San Francisco Telixtlahuaca, H. S. Gentry 22372 (MEXU); 1-2 km de Anona, al N de El Parián, A. Salinas y E. Martínez Correa 6265 (MEXU); Faustino G. Olivera, municipio Telixtlahuaca, F. Ventura 15461 (MEXU). Distrito Nochixtlán: cerro Cuchetaya, $310 \mathrm{~m}$ al W-SW de San Juan Tlalixtlahuaca, sobre brecha a Huauclilla, 17³0'55.7" N, 97¹'57.9" W, S. H. Salas et al. 4362 (IEB); 4 km al E de Huauclilla, brecha a El Parián, 17²4' N, 9703' W, P. Tenorio 17042 (IEB, MEXU). Distrito Teotitlán: barranca Cruztitla, $6 \mathrm{~km}$ al NE de Teotitlán, carretera a Huautla, P. Tenorio y E. Martínez Correa 17391 (MEXU); $7 \mathrm{~km}$ al SE de Santa María Ixcatlán, P. Tenorio 20601 (MEXU). PUEBLA: Municipio Caltepec: La Cumbre, cerca del cerro El Gavilán, de Caltepec a San Luis Tultitlanapa, 18 ${ }^{\circ} 10^{\prime}$ N, 97 $27^{\prime}$ W, L. Alvarado et al. 128 (MEXU); La Cumbre, meseta, adelante del cerro El Gavilán 1810' N, 97²7' W, R. Medina et al. 1173 (IEB, MEXU); cerro El Gavilán, al SE de Caltepec, P. Tenorio et al. 3719bis (MEXU), 5759 (MEXU); cerro El Carpintero, al NW de San Simón Tlacuilotepec, P. Tenorio 20065 (MEXU). Municipio Coxcatlán: $9 \mathrm{~km}$ al NE de Teotitlán, rumbo a Huautla de Jiménez, $F$. González Medrano et al. F-1470 (ENCB, MEXU); km 9 on hwy 182 Teotitlan to Huautla de Jiménez, C. A. Pendry y A. Reyes 987 (MEXU). Municipio Santiago Miahuatlán: Santa Ana, F. Ventura 15248 (ENCB, MEXU), 15251 (ENCB, MEXU), 15254 (ENCB, IEB, MEXU); minas de cantera de Santa Ana, F. Ventura 15292 (ENCB, MEXU). Municipio Tehuacán: $4.4 \mathrm{~km}$ al E de San Pablo Tepetzingo, $F$. Chiang et al. F-117 bis (MEXU); 3 km al NW de Tehuacán, E. Martínez 21724 


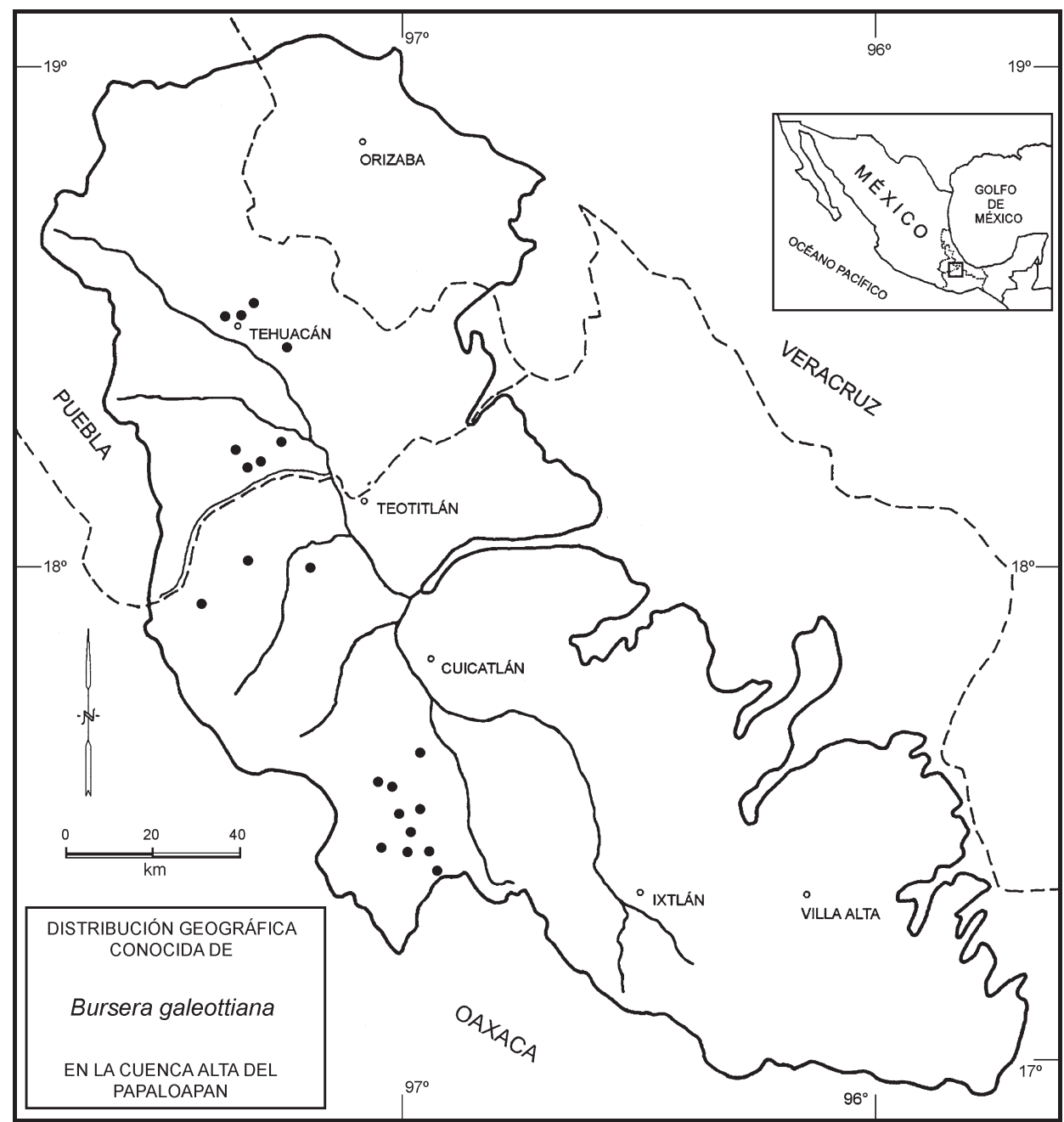

(MEXU); 6 km al NE de Tehuacán, carretera a Orizaba, J. Rzedowski 35625 (ENCB, MEXU); $2 \mathrm{~km}$ al $\mathrm{N}$ de Tehuacán, cerca de la Escuela Militar, $A$. Salinas y $P$. Solís F-3602 (MEXU). Municipio Zapotitlán: Los Reyes, H. Arroyo 137 (ENCB); 1 km del poblado de Los Reyes Mezontla, A. Valiente et al. 428 (MEXU).

Esta especie llega a confundirse con B. morelensis; sin embargo en $B$. galeottiana los foliolos son más angostos y con peciolos finamente pubérulos, al igual que las ramillas tiernas, los pedúnculos y los lóbulos del cáliz.

Como lo discutieron McVaugh y Rzedowski (op. cit., pp. 362-364), la descripción de Schinus angustifolius corresponde sin mayor duda a B. galeottiana. 
Sin embargo, en el herbario de Sessé y Mociño en Madrid no se han encontrado ejemplares pertenecientes a esta planta.

12. Bursera glabrifolia (H.B.K.) Engl., in Engl. \& Prantl, Nat. Pflanzenfam. III. 4: 251. 1896. Elaphrium glabrifolium H.B.K., Nov. Gen. \& Sp. 7: 28. 1824. Tipo: México: Michoacán: inter Patzcuaro et montem ignivosum Jorullo, prope Ario, A. Humboldt y A. Bonpland 4328 (holotipo P!, isotipo B-WILLD).

Bursera schiedeana Engl., DC. Monogr. Phaner. 4: 57. 1883. Terebinthus schiedeana (Engl.) Rose, Contr. U.S. Nat. Herb. 10: 122. 1906. Elaphrium schiedeanum (Engl.) Rose, North Amer. Fl. 25: 256. 1911. Tipo: México: Morelos: Huautla, C. J. W. Schiede s. n., XI.1836 (holotipo B, probablemente destruido).

Bursera nelsonii Rose, Contr. U.S. Nat. Herb. 3: 314. 1895. Terebinthus nelsonii (Rose) Rose, Contr. U.S. Nat. Herb. 12: 279. 1909. Elaphrium nelsonii (Rose) Rose, North Amer. FI. 25: 251. 1911. Tipo: México: Puebla, Atlixco, 25.VII1.VIII.1893, E. W. Nelson s. n. (holotipo US).

Nombres comunes registrados en la zona: copal, copalillo.

Nombres comunes registrados fuera de la zona de estudio: copal blanco, copal hembra.

Árbol o a veces arbusto dioico, hasta de $12 \mathrm{~m}$ de alto, resinoso y aromático al estrujarse; tronco hasta de $35 \mathrm{~cm}$ de diámetro, corteza gris, por lo general lisa, no exfoliante, ramillas rojizas, las tiernas tomentoso-lanosas, pronto glabrescentes; hojas mayormente agrupadas en fascículos sobre ápices de ramillas cortas, en ocasiones alternas sobre ramillas de nuevo crecimiento, precedidas en su aparición por una roseta de catafilos oblongos a triangulares, hasta de $8 \mathrm{~mm}$ de largo, con frecuencia densamente tomentoso-pubérulos en ambas caras, otras veces con la pubescencia restringida a la parte apical y a la superficie interna, hojas imparipinnadas, oblongas en contorno general, hasta de $12.5 \mathrm{~cm}$ de largo y $6 \mathrm{~cm}$ de ancho, peciolo hasta de $2.5 \mathrm{~cm}$ de largo, raquis por lo común angostamente alado, las alas de 0.4 a 1(2) $\mathrm{mm}$ de ancho de cada lado, foliolos (5)7 ó 9(11), sésiles o casi sésiles, elípticos a ovado-elípticos, el terminal a menudo subrómbico a suborbicular, de 0.8 a $2.5(3) \mathrm{cm}$ de largo, de 0.5 a $1.5(2) \mathrm{cm}$ de ancho, agudos a redondeados en el ápice, truncados a cuneados en la base, toscamente crenadoserrados en la mitad superior del margen, enteros en la inferior, inicialmente membranáceos, coriáceos en la madurez y a menudo brillantes en el haz, el envés más claro y con las nervaduras prominentes, densamente lanoso-tomentosas en la juventud, con particular énfasis en los nudos del raquis, más o menos glabrescentes en la madurez, sobre todo en el haz; inflorescencias racimosas o paniculadas, las masculinas por lo general ramificadas, hasta de $5(8) \mathrm{cm}$ de largo, sus ejes viloso-tomentosos, sin pelos glandulares, pedicelos de 2 a $5 \mathrm{~mm}$ de largo, bracteolas filiformes, hasta de $2 \mathrm{~mm}$ de largo, flores tetrámeras, cáliz con los lóbulos 


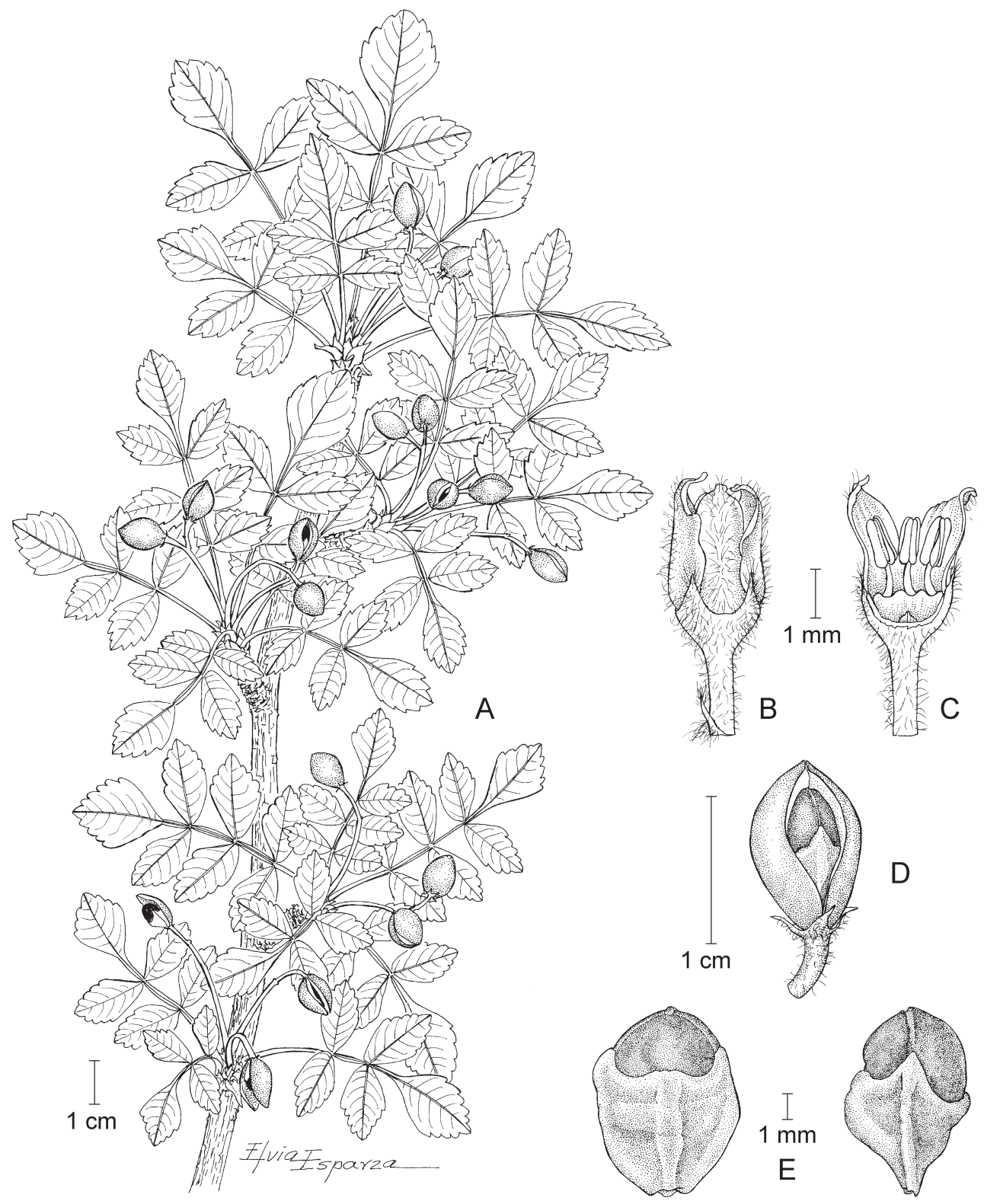

Bursera glabrifolia (H.B.K.) Engl. A. rama con hojas y frutos; B. flor masculina en vista externa; C. flor masculina desprovista de 2 segmentos del cáliz, de 3 pétalos y de 5 estambres; D. fruto; E. hueso visto de frente y de perfil. Ilustrado por Elvia Esparza. 
subulados a angostamente triangulares, de $1 \mathrm{a} 1.5 \mathrm{~mm}$ de largo, vilosos por fuera, pétalos blanquecinos o amarillentos, oblongos, de 3 a $4 \mathrm{~mm}$ de largo, agudos en el ápice, pubérulo-vilosos por fuera, filamentos de 0.7 a $1 \mathrm{~mm}$ de largo, anteras oblongas, de ca. $1 \mathrm{~mm}$ de largo, gineceo vestigial o ausente; inflorescencias femeninas por lo general sin ramificar, hasta de $4(5) \mathrm{cm}$ de largo, flores similares a las masculinas, pero más pequeñas, pétalos de 2 a $2.5 \mathrm{~mm}$ de largo, anteras de los estaminodios de ca. $0.5 \mathrm{~mm}$ de largo, ovario bilocular, estigmas 2; fruto bivalvado, elipsoide a orbicular u obovoide, de 9 a $13 \mathrm{~mm}$ de largo, por lo general apiculado, glabro, rojizo en la madurez, hueso subesférico a sublenticular, de 5 a $7 \mathrm{~mm}$ de largo y de ancho, con la mitad o las 2/3 partes inferiores cubiertas por un pseudoarilo amarillo o rojo-anaranjado, la porción expuesta negra.

Componente frecuente y más o menos abundante del bosque tropical caducifolio, así como de áreas transicionales con el encinar. En la región de estudio se ha registrado de altitudes entre 1400 y $2200 \mathrm{~m}$. Florece en mayo y junio. Permanece sin follaje entre noviembre y mayo.

Especie endémica de México, conocida de los estados de México, Michoacán, Morelos, Guerrero, Oaxaca y Puebla.

Material examinado: OAXACA: Distrito Coixtlahuaca: cerro Conejo al W de San Antonio Abad, camino a La Mexicana, P. Tenorio 17552 (MEXU). Distrito Cuicatlán: $4 \mathrm{~km}$ de la estación de F.F.C.C. El Venado, camino a Almoloyas, $H$. Arroyo 124 (ENCB, IEB, MEXU); $2.5 \mathrm{~km}$ al E de Santa Catarina, H. Arroyo 126 (ENCB); 6 km después de Santa María Almoloyas a la estación El Venado, $R$. Medina et al. 1068 (MEXU); $24 \mathrm{~km}$ al N de San Sebastián Sedas a Cuicatlán, 17¹9' N, 9655' W, R. Medina et al. 1255 (IEB, MEXU). Distrito Etla: Telixtlahuaca, km 215 de la autopista Oaxaca - Tehuacán, S. Acosta 2439 (MEXU); barranca de los Horcones, municipio Jayacatlán, M. Ambrosio y B. Brassi 601 (IEB), 610 (IEB); 2 $\mathrm{km}$ al N de El Parián, sobre el río dirección norte, H. Arroyo 115 (ENCB, IEB);1.5 km al W de Anona, H. Arroyo 131 (ENCB, MEXU); El Parián, C. Conzatti 1924 (F, MEXU); cañada $1.5 \mathrm{~km}$ S de El Parián, adelante del panteón Faustino G. Olivera, municipio San Francisco Telixtlahuaca, R. Medina et al. 1121 (MEXU); $8 \mathrm{~km}$ por la terracería a San Juan Bautista Jayacatlán, $17^{\circ} 27^{\prime} \mathrm{N}, 96^{\circ} 48^{\prime} \mathrm{W}, \mathrm{R}$. Medina et al. 1227 (IEB, MEXU); El Parián, cerca del cementerio, municipio Telixtlahuaca, J. Rzedowski 53884 (IEB); $1-2 \mathrm{~km}$ al N de Anona, A. Salinas y E. Martínez 6263 (MEXU); El Parián, F. Ventura 15458 (ENCB, MEXU); Faustino G. Olivera, F. Ventura 15462 (ENCB, MEXU, UC). Distrito Ixtlán: 2 km al NE de Chicomezúchil, municipio Chicomezúchil, H. Arroyo 74 (ENCB, MEXU). Distrito Nochixtlán: 4 km al E de Huauclilla, brecha al Parián, $17^{\circ} 24^{\prime} \mathrm{N}, 97^{\circ} 03^{\prime} \mathrm{W}$, municipio Huauclilla, $P$. Tenorio 17039 (IEB, MEXU). PUEBLA: Municipio Caltepec: La Cumbre, cerca de

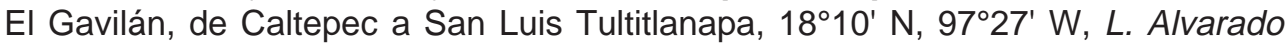
134 (MEXU); La Cumbre, frente al cerro El Gavilán, a 2 km de Caltepec, hacia San Luis Atolotitlán, E. M. Lira 1607 (MEXU); entrada a Caltepec, ladera W, parte baja, 


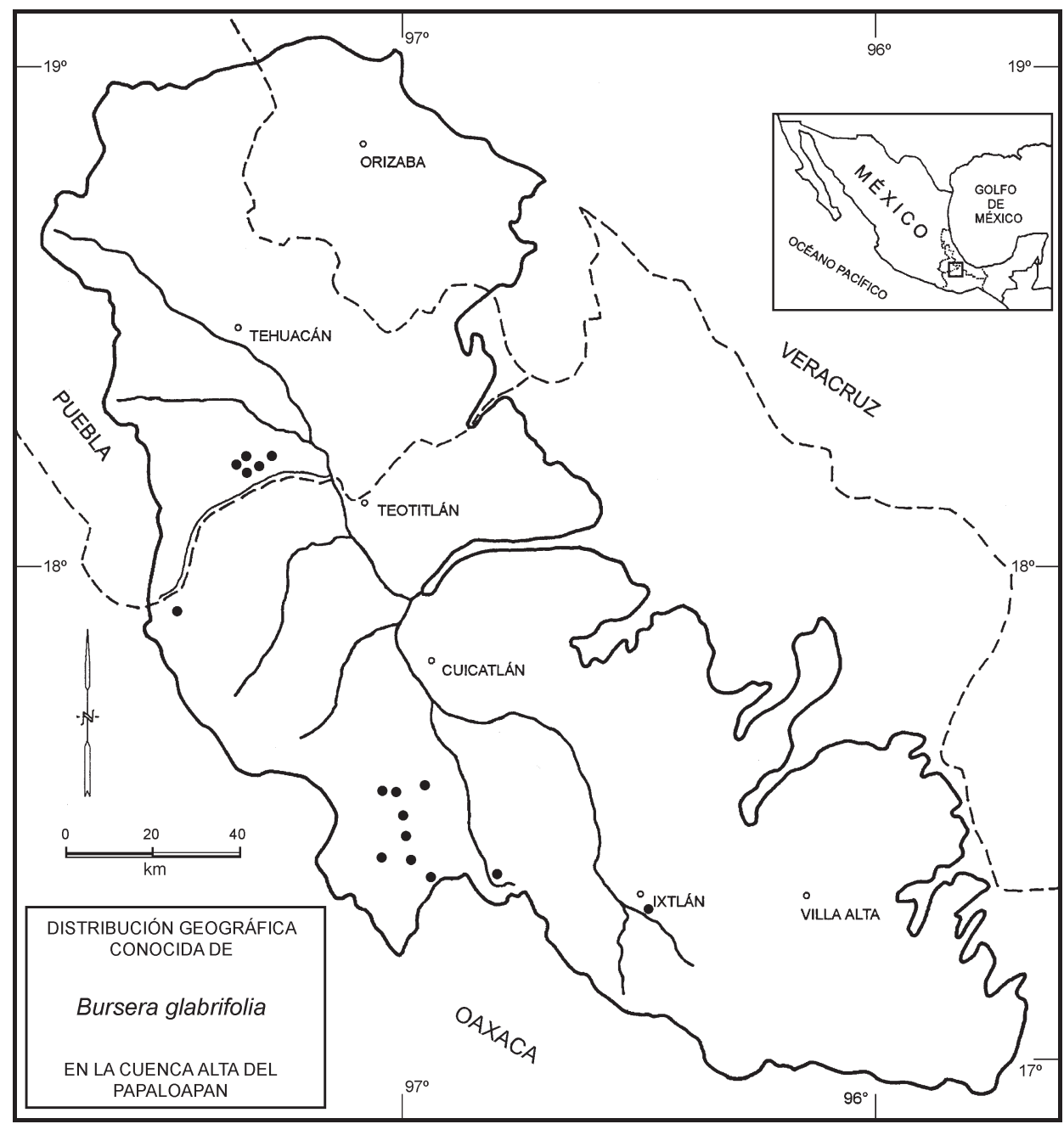

cerca del río, R. Medina et al. 1170 (IEB, MEXU); La Cumbre, meseta, adelante

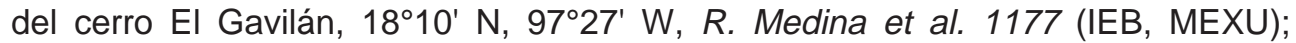
Tlacuiloltepec, C. A. Purpus 4069 (UC); Callejón del Cosahuico, al S de Caltepec, $P$. Tenorio y C. Romero 6823 (IEB, MEXU).

Engler (op. cit.) consideró a B. glabrifolia como sinónimo de B. penicillata (DC.) Engl. Rose (1911) la reivindicó como especie independiente y Bullock (op.cit.) amplió su circunscripción para incluir a $B$. aloexylon, $B$. nelsonii y $B$. schiedeana. Sin embargo, Miranda (1947) pudo distinguir a $B$. aloexylon como un taxon distinto y así se le acepta en este trabajo bajo el nombre de $B$. linanoe. 
B. glabrifolia y $B$. linanoe en efecto se parecen mucho en la morfología de sus hojas y de sus flores y en los ejemplares de herbario no siempre es fácil distinguirlas. En el campo en general se les puede reconocer por sus perfumes discrepantes. Sus principales rasgos diferenciales pueden resumirse de la siguiente manera:

\begin{tabular}{lll}
\hline \multicolumn{1}{c}{ Carácter } & \multicolumn{1}{c}{ B. glabrifolia } & \multicolumn{1}{c}{ B. linanoe } \\
\hline Hojas tiernas & $\begin{array}{l}\text { con pubescencia } \\
\text { conspicuamente } \\
\text { concentrada en los } \\
\text { nudos del raquis }\end{array}$ & $\begin{array}{l}\text { sin pubescencia } \\
\text { conspicuamente } \\
\text { concentrada en los } \\
\text { nudos del raquis }\end{array}$ \\
$\begin{array}{l}\text { Textura de hojas maduras } \\
\begin{array}{l}\text { Pubescencia de la } \\
\text { inflorescencia }\end{array}\end{array}$ & sin pelos glandulosos & membranácea \\
$\begin{array}{l}\text { Forma del fruto } \\
\text { elipsoide a orbicular u }\end{array}$ & $\begin{array}{l}\text { con pelos glandulosos, } \\
\text { diminutos y espaciados }\end{array}$ \\
$\begin{array}{l}\text { Intervalo altitudinal } \\
\text { conocido en la región } \\
\text { de estudio }\end{array}$ & comoide, pero algo \\
\hline
\end{tabular}

En este contexto no deja de resultar sorprendente el hecho de que, de acuerdo con el estudio de ADN ribosomal llevado a cabo por Becerra y Venable (1999), las dos especies en cuestión no están cercanamente relacionadas entre sí y por consiguiente su similitud morfológica debe interpretarse más bien como resultado de procesos de convergencia.

Los árboles de B. glabrifolia se emplean para conformar cercas vivas y su resina aromática se quema a manera de incienso. La madera se utiliza (sobre todo en el distrito de Etla) para la elaboración de artesanías.

13. Bursera graveolens (H.B.K.) Tr. \& Planch., Ann. Sci. Nat. 5 sér. 14: 303. 1872. var. graveolens. Elaphrium? graveolens H.B.K., Nov. Gen. Sp. 7: 31. 1825. Terebinthus graveolens (H.B.K.) Rose, Contr. U.S. Nat. Herb. 10: 119. 1906. Tipo: Colombia: Antioquia: S. Bartholomé, Río Magdalena, A. Humboldt y A. Bonpland 1626 (holotipo P!, isotipo B-WILLD).

Elaphrium? pubescens Schltdl., Linnaea 16: 517. 1842. Terebinthus pubescens (Schltdl.) Rose, Contr. U.S. Nat. Herb. 12: 279. 1909. non Bursera pubescens S. Wats. Tipo: México: Campeche: Campeche, A. Humboldt y A. Bonpland s. $n$. (holotipo B-WILLD). 


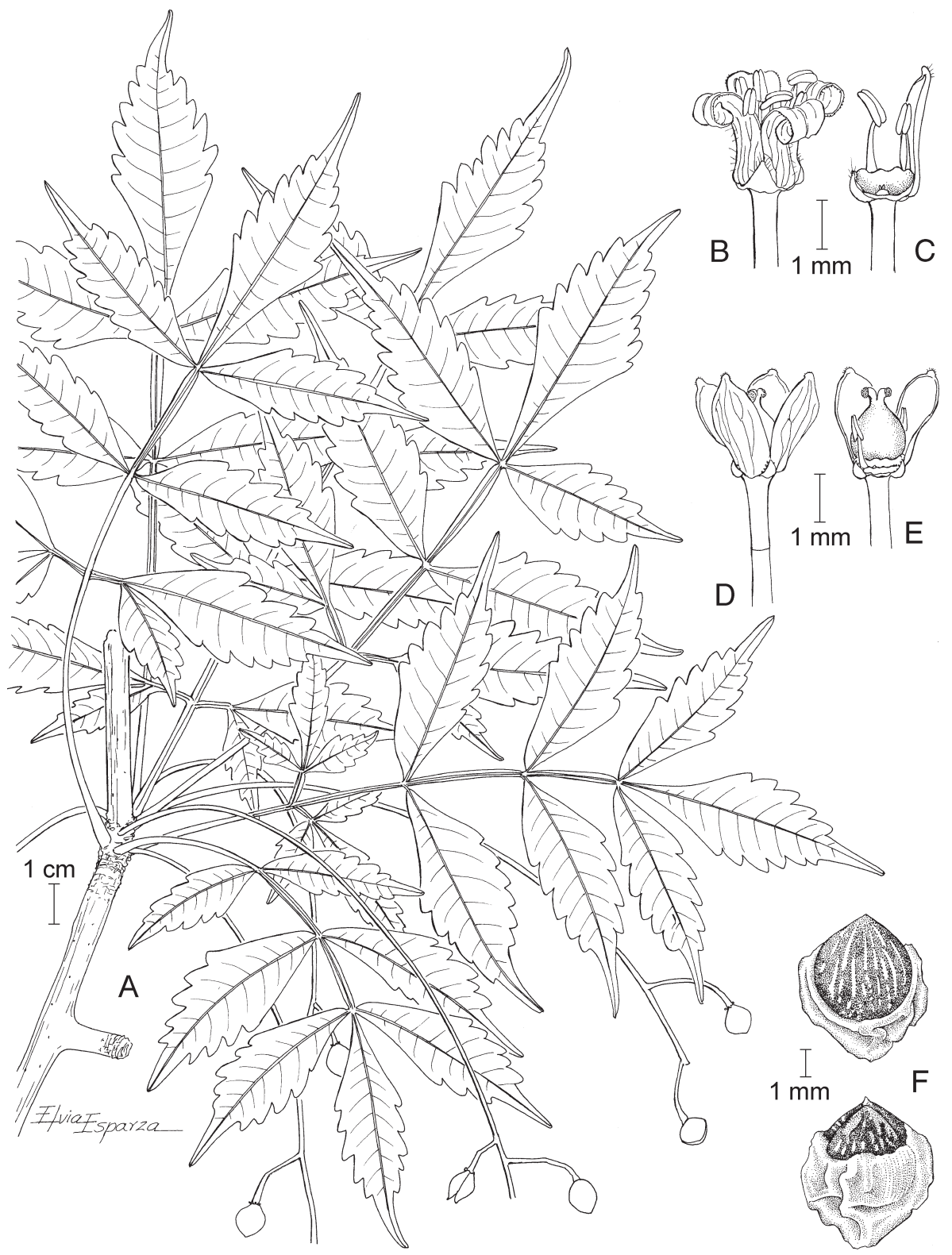

Bursera graveolens (H.B.K.) Triana \& Planch. var. graveolens. A. rama con hojas y frutos; B. flor masculina; C. flor masculina desprovista de cáliz, de 3 pétalos y de 6 estambres; D. flor femenina; E. flor femenina desprovista de un segmento del cáliz, de 2 pétalos y de varios estaminodios; F. hueso visto por ambas caras. Ilustrado por Elvia Esparza. 
Bursera tatamaco (Tul.) Tr. \& Planch., Ann. Sci. Nat. 5 sér. 14: 303. 1872. Elaphrium tatamaco Tul., Ann. Sci. Nat. 3 sér. 6: 368. 1846. Tipo: Colombia: Santa Martha, Nlle. Granade, J. Goudot s. n. (holotipo P).

Spondias edmonstonei Hook. f., Trans. Linn. Soc. 20: 230. 1847. Sintipos: Ecuador: Albermarle Island, Galápagos, F. B. Macrae s. n. (K); Charles Island, Galápagos, T. Edmonstone s. n. (K). (Los dos ejemplares están montados sobre la misma cartulina y no resulta fácil decidir qué parte corresponde al espécimen de Macrae y qué otra al de Edmonstone; razón por la cual no se designa el lectotipo correspondiente). hediondo.

Nombres comunes registrados en la zona: aceitillo, coyoluche, coyoluxi, palo

Nombres comunes registrados fuera de la zona: aceitilla, azafrán, gomilla, mizquixochicopalli, nabanché, palo de brujo, sasafrás.

Árbol o a veces arbusto, hasta de 12(15) m de alto, por lo general muy resinoso y aromático al estrujarse en casi todas sus partes, con el olor persistente por muchos meses en los ejemplares de herbario; tronco hasta de $40 \mathrm{~cm}$ de diámetro, su corteza gris, lisa, no exfoliante, ramillas rojizas, glabras o casi glabras; hojas fasciculadas en los extremos de ramillas cortas, o bien, esparcidas sobre ramillas vigorosas tiernas, precedidas en su aparición por una roseta de catafilos oblongos a ovados, de 4 a $8(12) \mathrm{mm}$ de largo, agudos u obtusos en el ápice, densamente pubérulos en ambas caras, precozmente caducos, hojas imparipinnadas o parcialmente bipinnadas, oblongas a obovadas en contorno general, hasta de $30 \mathrm{~cm}$ de largo y $18 \mathrm{~cm}$ de ancho, peciolo hasta de $9 \mathrm{~cm}$ de largo, raquis angostamente alado, salvo el entrenudo proximal que por lo general carece de alas, foliolos comúnmente 7 ó 9(11), aunque en las primeras hojas pueden ser sólo 3 ó 5 y en algunos casos los foliolos proximales están sustituidos por pinnas trifolioladas, sésiles o casi sésiles, lanceolados a ovados, variando a elípticos, oblongos o romboides, de 3 a 7(9) $\mathrm{cm}$ de largo, de 1 a 2.5(4) $\mathrm{cm}$ de ancho, acuminados a largamente acuminados en el ápice, cuneados a obtusos y a menudo inequiláteros en la base, margen toscamente ( $y$ a veces doblemente) crenado-serrado, nervaduras por lo general conspicuas en las hojas maduras, las secundarias por lo común 8 a 12 pares, de textura membranácea, inicialmente pubérulos, con la edad glabrescentes; inflorescencia en forma de panícula laxa, por lo común pilósula y en ocasiones también con diminutos pelos glandulosos, otras veces casi totalmente glabra, con frecuencia tan larga como las hojas, pedicelos filiformes, hasta de $5 \mathrm{~mm}$ (20 mm en fruto) de largo; flores masculinas tetrámeras, cáliz turbinado, sus lóbulos triangulares, diminutos, de menos de $0.5 \mathrm{~mm}$ de largo, pétalos blanquecinos, amarillentos o verdosos, oblongos a elípticos, de 3 a $4 \mathrm{~mm}$ de largo, encorvados en el ápice, pilósulos o glabros por fuera, estambres 8, filamentos de 1 a $1.5 \mathrm{~mm}$ de largo, anteras oblongas, de ca. $0.8 \mathrm{~mm}$ de largo, gineceo vestigial por lo común presente; flores femeninas similares a las masculinas, estaminodios 


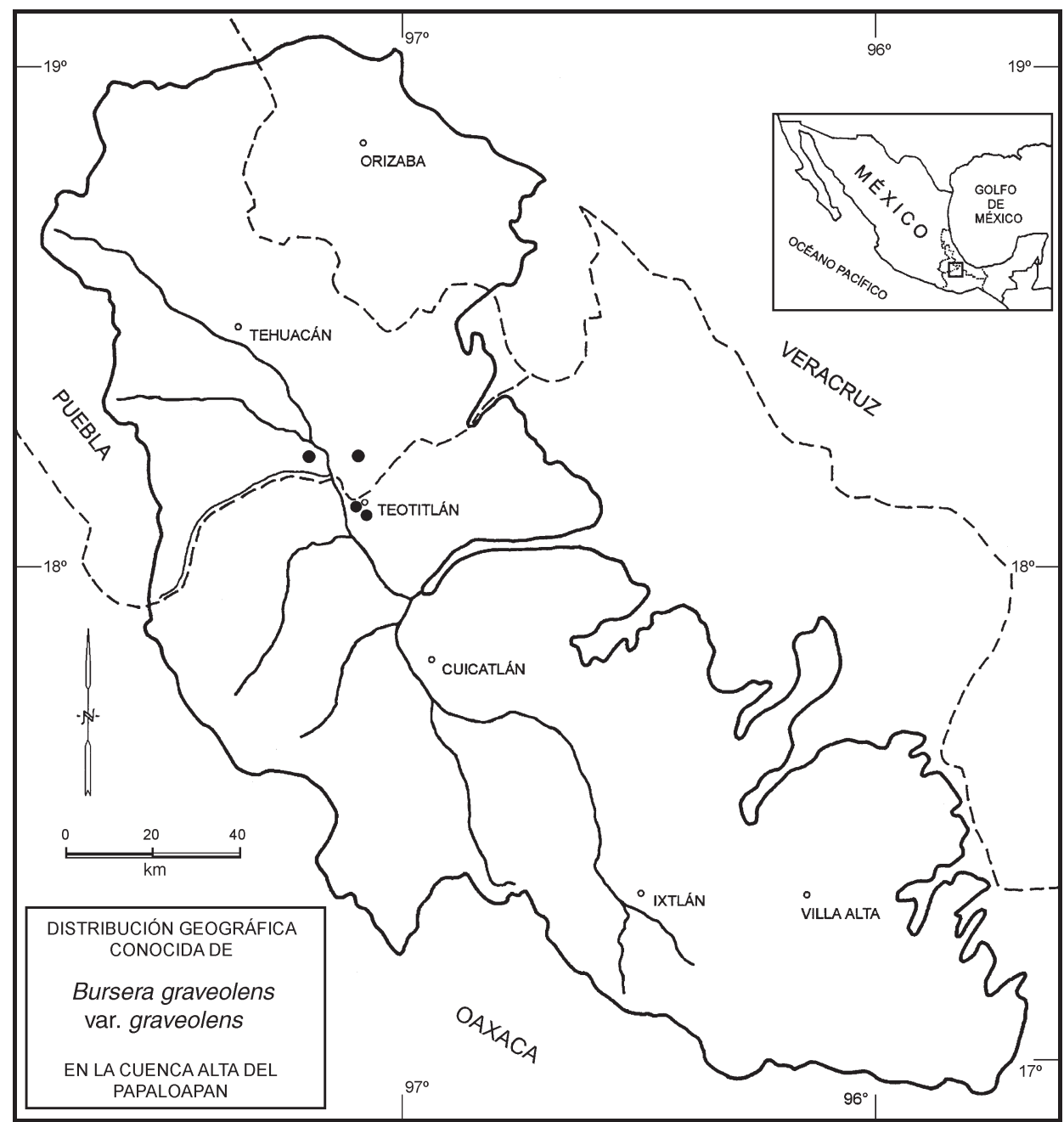

con anteras de menos de $0.6 \mathrm{~mm}$ de largo, ovario bilocular, estilo brevísimo, estigmas 2; fruto bivalvado, subesférico a obovoide, de 6 a $10 \mathrm{~mm}$ de largo, conspicuamente apiculado, glabro, rojizo en la madurez, longitudinalmente estriado en seco, hueso sublenticular, de 4 a $6 \mathrm{~mm}$ de largo y ancho, cubierto en sus 2/3 inferiores por un pseudoarilo anaranjado o rojizo, la parte expuesta negra.

En la región de estudio sólo se ha observado en cultivo, mayormente formando cercas vivas, también en las calles y las plazas de algunos poblados, en altitudes de 950 a $1650 \mathrm{~m}$. Florece de abril a junio. Permanece sin follaje de noviembre a mayo. 
La variedad se distribuye del este y sureste de México a Colombia, Venezuela, Ecuador y Perú, incluyendo las islas Galápagos. También se registra como naturalizada en Cuba. De nuestro país existen colectas de Puebla, Oaxaca, Veracruz, Tabasco, Chiapas, Campeche y Yucatán, pero al parecer principalmente procedentes de plantas cultivadas, salvo algunas de las del centro de Veracruz y posiblemente del centro de Chiapas.

Material examinado: OAXACA: Distrito Teotitlán: $1 \mathrm{~km}$ de San Martín Toxpalan, sobre la carretera a Teotitlán, municipio San Martín Toxpalan, H. Arroyo 19 (IEB); Teotitlán, C. Conzatti s. n., 26.V. 1921 (MEXU); en las afueras de Teotitlán

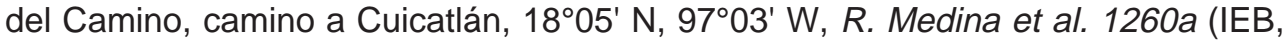
MEXU); Teotitlán del Camino, J. Rzedowski 28163 (IEB), 34116 (IEB), 35661 (IEB); $1 \mathrm{~km}$ al S de Teotitlán del Camino, J. Rzedowski 32852 (IEB), camino a Huautla de Jiménez, municipio Teotitlán del Camino, F. Ventura 15360 (IEB, MEXU). PUEBLA: Municipio Coxcatlán: dentro de la población de Coxcatlán, J. Rzedowski 38118 (ENCB). Municipio San José Miahuatlán: San Pedro Tetitlán, poblado a $1 \mathrm{~km}$ de la autopista Puebla - Oaxaca, 18¹5'4" N, 97²0'5" W, R. Medina et al. 1212 (IEB, MEXU).

Bullock (op.cit.) no ha reconocido la existencia de esta planta en México, pues sólo menciona Elaphrium pubescens entre las especies dudosas y no vistas. Standley (op. cit.) sugiere para E. pubescens que puede tratarse de una especie introducida a México y no es imposible que tal sea el caso.

Por otro lado, sin embargo, es interesante hacer constar que en algunos sectores de la región costera de Oaxaca prosperan plantas aparentemente silvestres pertenecientes a $B$. graveolens, aunque tal vez separables en otra variedad, pues presentan con mucha frecuencia hojas parcialmente bipinnadas y sus flores son más pequeñas.

En el mismo contexto cabe agregar que $B$. graveolens está íntimamente relacionada con $B$. penicillata (DC.) Engl., especie distribuida en el occidente de México, conocida de Sonora a Colima y norte de Michoacán, pero al parecer ausente en Guerrero.

Además de su empleo como componente de cercas vivas, la planta se aprecia también en la medicina tradicional. Todos los individuos observados en la región de Teotitlán del Camino son masculinos, resultado indudable de la propagación vegetativa por medio de estacas.

14. Bursera hintonii Bullock, Kew Bull. 1936: 366. 1936. Tipo: México: Estado de México: distrito Temascaltepec: Cañitas, XI.1934. G. B. Hinton 6991 (holotipo $\mathrm{K}$, isotipo NY).

Nombres comunes registrados fuera de la zona de estudio: copal, copal manso. 


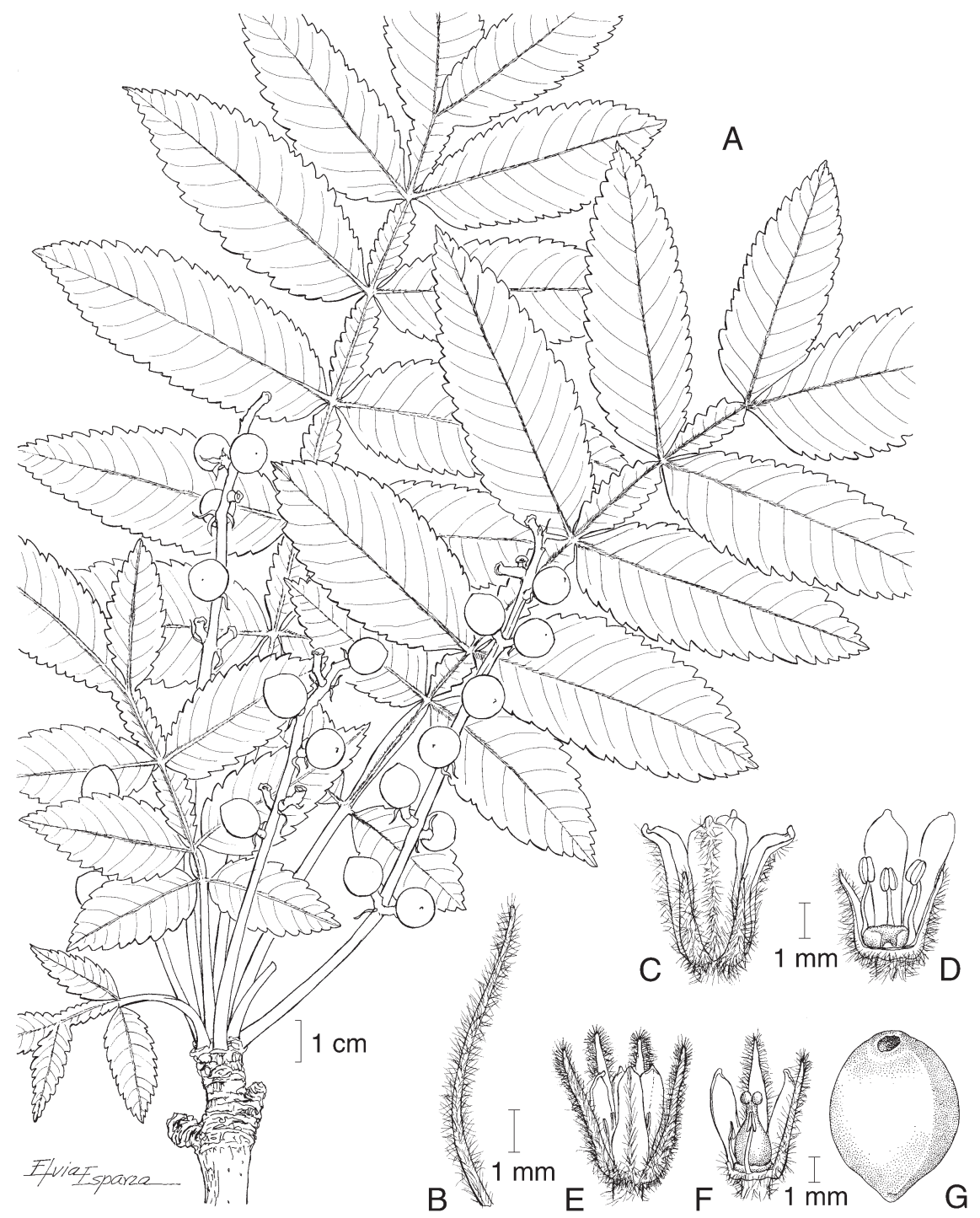

Bursera hintonii Bullock. A. rama con hojas y frutos; B. bracteola; C. flor masculina en vista externa; D. flor masculina desprovista de un segmento del cáliz, de 2 pétalos y de 5 estambres; E. flor femenina en vista externa; F. flor femenina desprovista de 2 segmentos del cáliz, de 2 pétalos y de varios estaminodios; G. hueso. llustrado por Elvia Esparza. 
Arbusto o más frecuentemente árbol dioico o a veces polígamo-dioico, de 3 a $12 \mathrm{~m}$ de alto, resinoso y aromático al estrujarse; tronco hasta de $30 \mathrm{~cm}$ de diámetro, de corteza gris no exfoliante, ramillas jóvenes densamente hirsuto-pilosas, las lignificadas de color rojizo oscuro, glabras o casi glabras; hojas aglomeradas en rosetas dispuestas en el ápice de las ramillas, o bien, alternas en ramillas vigorosas de crecimiento nuevo, precedidas en su aparición por un conjunto de catafilos oblongos o largamente triangulares de hasta $1.5 \mathrm{~cm}$ de largo y alrededor de $8 \mathrm{~mm}$ de ancho en su base, blanquecinos los más jóvenes, los maduros de color café-rojizo y glabros por dentro, densamente lanoso-tomentosos por fuera, precozmente caedizos, peciolo de 4 a $8(14) \mathrm{cm}$ de largo, densamente tomentoso, lámina de (20)25 a 30(35) cm de largo y de 12 a 17(20) cm de ancho, imparipinnada, con 11 a 17(21) foliolos sésiles o subsésiles, raquis manifiestamente alado con las alas más angostas y enteras en la parte proximal, en la distal hasta de 4(5) $\mathrm{mm}$ de ancho y a menudo con el margen crenado o serrado, los foliolos laterales por lo común lanceolados a elípticos, hasta de $10(16) \mathrm{cm}$ de largo y $3.5(7) \mathrm{cm}$ de ancho, el terminal con frecuencia algo romboide y en las hojas maduras un poco más grande que los laterales, ápice agudo a acuminado, base redondeada a cuneada, por lo común algo oblicua, margen doble e irregularmente crenado-serrado, de textura cartácea a coriácea, con nervaduras manifiestas, más prominentes en el envés, los jóvenes de apariencia aterciopelada, densamente velutinos en el haz, velutino-tomentosos en el envés, donde se presentan además diminutas glándulas sésiles o casi sésiles, los maduros velutinos y más o menos brillantes en el haz, con pubescencia velutina, especialmente densa en las nervaduras por el envés; inflorescencia hasta de $20 \mathrm{~cm}$ de largo, pedúnculo de 4 a $8 \mathrm{~cm}$ de largo, flores de ambos sexos tetrámeras y pilosas; inflorescencia masculina en forma de tirso o panícula muy densa, brácteas lineares, hasta de $8 \mathrm{~mm}$ de largo, tomentosas, pedicelos de ca. $0.8 \mathrm{~mm}$ de largo, lóbulos del cáliz lanceolados a linear-lanceolados, de 2.5 a 3.5(5) $\mathrm{mm}$ de largo, densamente tomentosos por fuera, por lo general más cortos que los pétalos, éstos blanquecinos, estrechamente oblongos, de (3)3.5 a $5 \mathrm{~mm}$ de largo, tomentosos por fuera a lo largo de una amplia línea media, estambres 8 , filamentos de $1 \mathrm{a} 2 \mathrm{~mm}$ de largo, anteras oblongas, de 0.7 a $1 \mathrm{~mm}$ de largo, pistilodio diminuto; inflorescencia femenina mucho más laxa, bracteolas finas, lineares a filiformes, de 2 a $7 \mathrm{~mm}$ de largo, pedicelos de 1 a $2 \mathrm{~mm}$ de largo, flores femeninas similares a las masculinas, estaminodios 8 , con anteras de ca. $0.5 \mathrm{~mm}$ de largo, ovario bilocular, estigmas 2; fruto bivalvado, elipsoide, de ca. $13 \mathrm{~mm}$ de largo y $8 \mathrm{~mm}$ de diámetro, glabro, hueso obovoide, de 8 a $9 \mathrm{~mm}$ de largo y ca. $6 \mathrm{~mm}$ de diámetro, cubierto total o casi totalmente por un pseudoarilo anaranjado, con la parte expuesta negra.

Habitante más bien escaso en ladera gnéisica con vegetación de bosque tropical caducifolio en transición con encinar, a una altitud de $1450 \mathrm{~m}$. Se ha colectado con flor en mayo y junio. Permance sin hojas de noviembre a mayo.

Especie registrada de los estados de Michoacán, México, Guerrero y Oaxaca. 


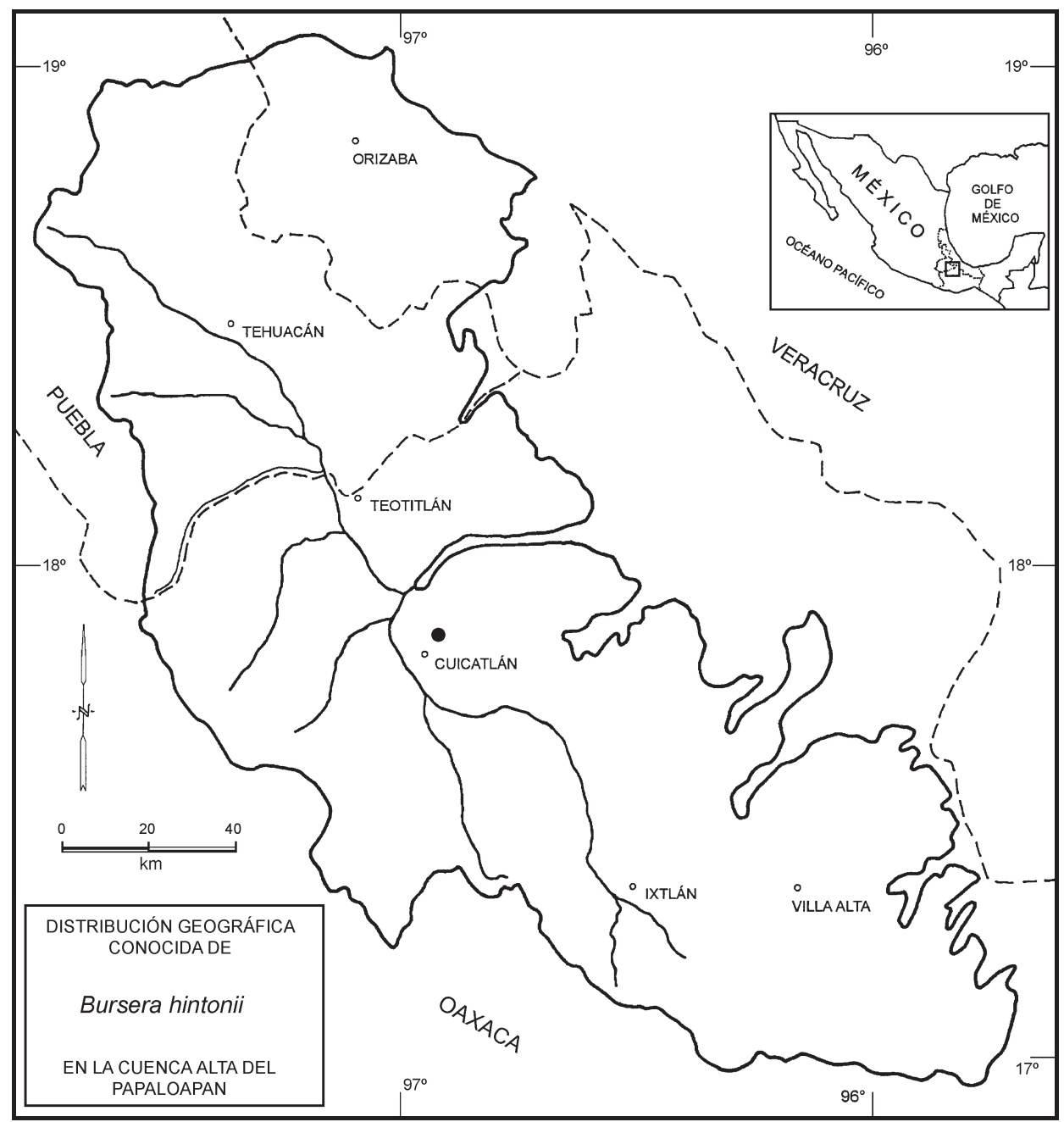

Material examinado: OAXACA: Distrito Cuicatlán: camino Cuicatlán - Reyes Pápalo, F. Miranda 4633 (MEXU); 13 km al NE de Cuicatlán sobre el camino a Pápalo, municipio Cuicatlán, J. Rzedowski 53878 (IEB, MEXU), 53879 (IEB).

Esta especie puede confundirse con B. vejar-vazquezii Miranda, conocida de Guerrero, Morelos, Puebla y Oaxaca, pues ambas destacan por sus grandes hojas de múltiples foliolos densamente pubescentes en la juventud. La última se distingue, sin embargo, por carecer de alas en el raquis interfoliar, sus frutos son pubescentes y al caer éstos en la madurez, se conserva un cáliz algo persistente, de 4 segmentos rígidos, divergentes, ligeramente desiguales, de 3 a $5 \mathrm{~mm}$ de largo. 
15. Bursera linanoe (La Llave) Rzedowski, Calderón \& Medina, comb. nova. Amiris linanoé La Llave, Reg. Trim. 1: 356. 1832. A. linaloé La Llave, La Naturaleza 7, apénd. p. 73. 1884. Tipo: México: La Misteca (sin haberse localizado). Neotipo que aquí se designa: México: Oaxaca: distrito Teotitlán: camino a Huautla de Jiménez, 12.VIII.1978, F. Ventura 15356 (holoneotipo IEB, isoneotipos por distribuirse).

Elaphrium aloëxylon Schiede ex Schltdl., Linnaea 17: 252. 1843. Bursera aloexylon (Schiede ex Schltdl.) Engl., Bot. Jahrb. 1: 44. 1881. Terebinthus aloexylon (Schiede ex Schltdl.) W. F. Wight ex Rose, Contr. U.S. Nat. Herb. 10: 118. 1906. Tipo: México: Morelos: Real de Huautla, VII.1835, C. J. W. Schiede 1003 (holotipo HAL).

Bursera delpechiana Poisson ex Engl., DC. Monogr. Phaner. 4: 53. 1883. Terebinthus delpechiana (Poisson ex Engl.) Rose, Contr. U.S. Nat. Herb. 10: 119. 1906. Elaphrium delpechianum (Poisson ex Engl.) Rose, North Amer. Fl. 25 : 253. 1911. Tipo: México: Morelos: Cuautla, N. Delpech s. n., 1879 (holotipo P!).

Elaphrium longipedunculatum Rose, North Amer. FI. 25: 254. 1911. Bursera longipedunculata (Rose) Standl., Publ. Field Mus. Nat. Hist. Bot. Ser. 4: 217. 1929. Tipo: México: Oaxaca: distrito Cuicatlán: near Almoloyas, 2.IX.1906, J. N. Rose y J. S. Rose 11282 (holotipo US).

Nombres comunes registrados en la zona: copalillo, linaloé, linanoé, ulinoé. Nombres comunes registrados fuera de la zona de estudio; inanué, linaloe, linalué, ulinalué, xochicopal.

Árbol dioico o a veces polígamo-dioico, hasta de $8(10) \mathrm{m}$ de alto, muy resinoso, con aroma agradable y penetrante al estrujarse; tronco hasta de $60 \mathrm{~cm}$ de diámetro, con corteza gris-rojiza, no exfoliante, ramillas lignificadas francamente rojizas oscuras, glabras o las más jóvenes a veces densamente pubérulas 0 esparcidamente vilosas; hojas con frecuencia aglomeradas en los ápices de ramillas cortas, otras veces alternas en ramillas de crecimiento nuevo, precedidas en su aparición por un conjunto de catafilos lanceolados a angostamente ovados, de 6 a $10 \mathrm{~mm}$ de largo, agudos a redondeados en el ápice, densa y muy finamente glanduloso-pubérulos en ambas caras, con frecuencia ciliados en el margen, precozmente caducos, hojas por lo general imparipinnadas, de 6 a $12(15) \mathrm{cm}$ de largo y 3 a $8(10) \mathrm{cm}$ de ancho, peciolo de 1 a $3 \mathrm{~cm}$ de largo, viloso o esparcidamente glanduloso-pubérulo, foliolos (3)5 ó 7(11?), raquis con alas de margen entero, hasta de 2(2.5) $\mathrm{mm}$ de ancho de cada lado, notablemente más anchas hacia el extremo distal del entrenudo, peciólulos de 0.3 a $1 \mathrm{~mm}$ de largo, foliolos ovados a elípticos, lanceolados u oblongos, el terminal a menudo subrómbico, de 1.2 a $3(4) \mathrm{cm}$ de largo, de 0.8 a $1.8(2) \mathrm{cm}$ de ancho, agudos a redondeados en el ápice, cuneados a redondeados en la base, toscamente serrados a crenados en el margen y a veces 


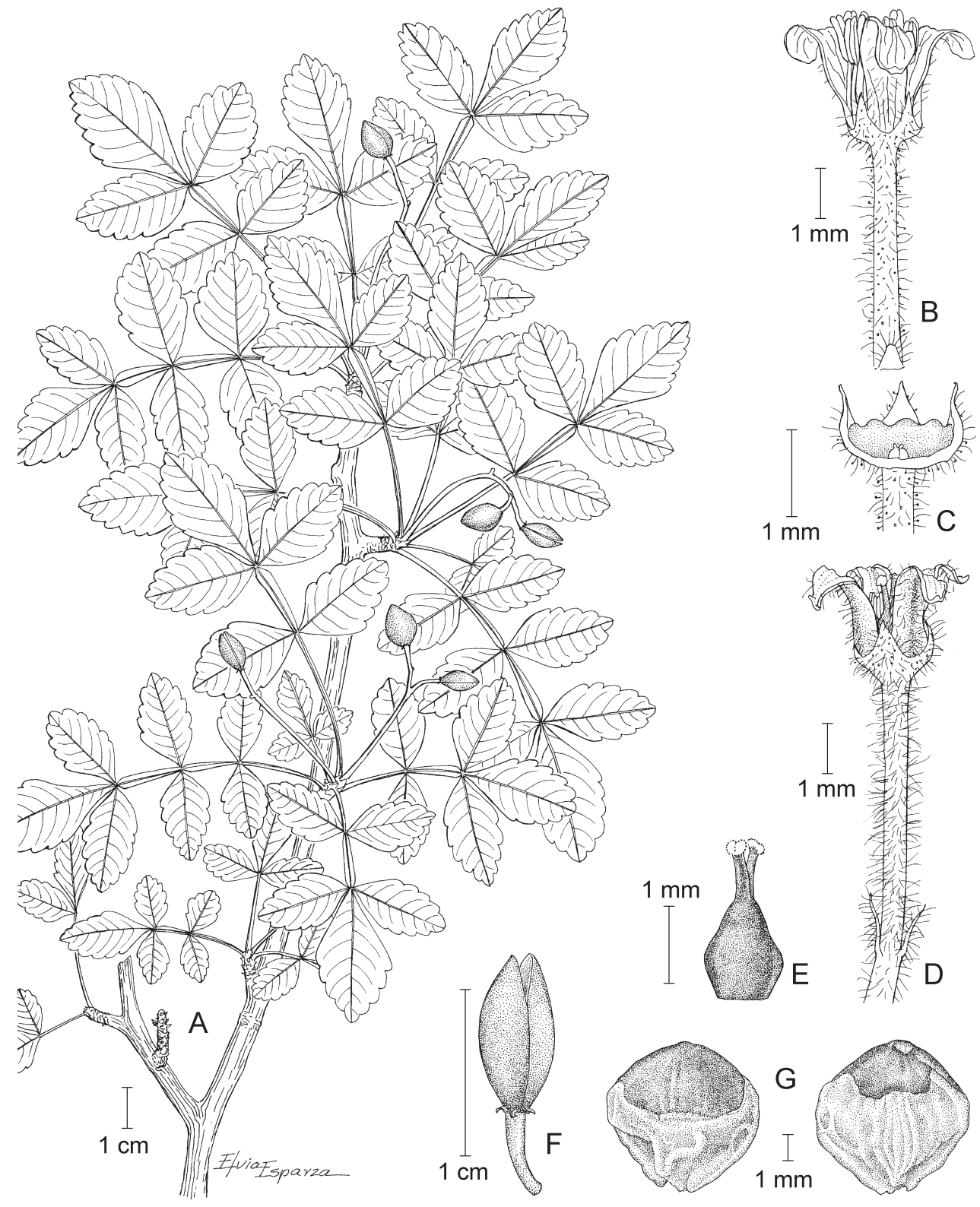

Bursera linanoe (La Llave) Rzed., Calderón \& Medina. A. rama con hojas y frutos; B. flor masculina; C. flor masculina desprovista de un segmento del cáliz, de los 4 pétalos y del androceo; D. flor femenina; E. pistilo; F. fruto; G. hueso visto por ambas caras. Ilustrado por Elvia Esparza. 
con tendencia a doblemente serrados (con escotadura en al ápice de los dientes), de textura membranácea, algo brillantes en el haz, con venación prominente en el envés, con pelos de ca. $0.6 \mathrm{~mm}$ de largo y a menudo también acompañados de diminutos pelos glandulosos espaciados; inflorescencias racimoso-paniculadas, hasta de 6(8) $\mathrm{cm}$ de largo y hasta con 35 flores, aunque por lo general mucho más modestas, vilosas y glanduloso-pubérulas, bracteolas linear-subuladas, de ca. $2 \mathrm{~mm}$ de largo, pedicelos de 3 a $8 \mathrm{~mm}$ de largo; flores masculinas tetrámeras, lóbulos del cáliz triangulares, de 0.6 a $0.8 \mathrm{~mm}$ de largo, glanduloso-pubérulos y esparcidamente vilosos, pétalos blanquecinos, oblongos a oblanceolados, de 3 a $4 \mathrm{~mm}$ de largo, glanduloso-pubérulos y vilosos por fuera, estambres 8 , filamentos de 1.5 a $2 \mathrm{~mm}$ de largo, anteras oblongas, de 0.9 a $1.2 \mathrm{~mm}$ de largo, gineceo vestigial; flores femeninas semejantes a las masculinas, pero con los pétalos de ca. $2 \mathrm{~mm}$ de largo, estaminodios con anteras de 0.7 a $0.8 \mathrm{~mm}$ de largo, ovario bilocular, estilo evidente, a veces con dos ramas libres casi hasta la base, estigmas 2; pedúnculos fructíferos hasta de $4 \mathrm{~cm}$ de largo, pedicelos ligeramente engrosados, hasta de 9(12) $\mathrm{mm}$ de largo, frutos hasta 8 por infrutescencia, pero no pocas veces solitarios, bivalvados, obovoides y a menudo atenuados en el ápice, pero algo comprimidos, de 9 a $11 \mathrm{~mm}$ de largo, de ca. $8 \mathrm{~mm}$ de ancho, glabros, rojizos en la madurez, hueso sublenticular o plano-convexo, de 5 a $6 \mathrm{~mm}$ de diámetro, a menudo más ancho que largo, cubierto en la mitad o en los 2/3 inferiores por un pseudoarilo anaranjado, la porción expuesta negra.

Habitante relativamente frecuente del bosque tropical caducifolio y de algunos matorrales xerófilos, sobre diversos sustratos geológicos, en altitudes de 650 a $1500 \mathrm{~m}$. Florece de mayo a principios de julio. Se encuentra desprovisto de follaje de noviembre a mayo.

Especie endémica del sur de México, conocida de Morelos, Puebla, Guerrero y Oaxaca.

Material examinado: OAXACA: Distrito Cuicatlán: Dominguillo, El Tetechal, M. Ambrosio 567 (IEB), 571 (IEB); Dominguillo, carretera Cuicatlán - Oaxaca, km 141, M. Ambrosio et al. 592 (IEB), 593 (IEB, MEXU); 1 km al sur de San Juan Bautista Cuicatlán, H. Arroyo 31 (IEB); 3 km al N de Cuicatlán, camino a Concepción Pápalo, H. Arroyo 50 (IEB); $15 \mathrm{~km}$ al S de Dominguillo, carretera a Oaxaca, H. Arroyo 63 (IEB); $3 \mathrm{~km}$ al W de la estación de ferrocarril El Venado, camino a Santa María Almoloyas, H. Arroyo 117 (ENCB, MEXU); $2.2 \mathrm{~km}$ al SW de San José del Chilar, 17²41'56" N, 9657'1" W, J. Calónico et al. 24078 (IEB, MEXU); 12 km al SE de Dominguillo, carretera Tehuacán - Oaxaca, F. Chiang et al. F-162 (MEXU); $2.5 \mathrm{~km}$ al NE de San Juan Bautista Cuicatlán, camino a Concepción Pápalo, F. Chiang et al. F-2434 (OAX), F-2435 (MEXU); cuesta de Quiotepec, C. Conzatti 4027 (MEXU); cerro de enfrente de la Peña Cerrada, San José del Chilar, 17²4'47" N, 9656'33" W, municipio Cuicatlán, C. A. Cruz y R. García 17 (MEXU); Plan de beis, San José del Chilar, $17^{\circ} 41^{\prime} 0.337$ N, 9656'0.139 W, municipio Cuicatlán, C. A. Cruz 


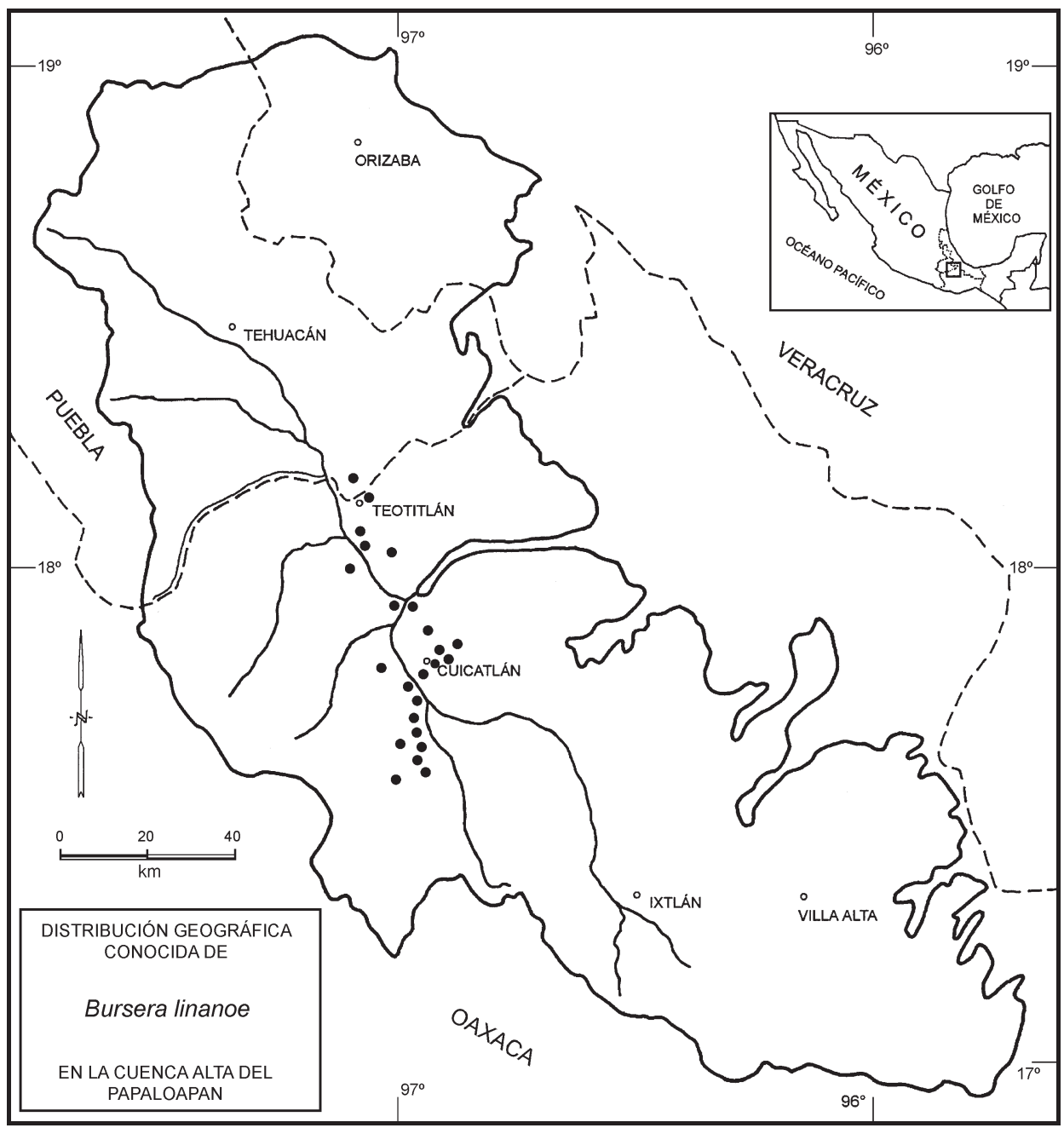

et al. 154 (MEXU); barranca El Ciruelo, San José del Chilar, 1742'26.9" N, 9656'27.1 W. C. A. Cruz y E. San Pedro 695 (MEXU); cerro Copalillo, a 2.6 km al SW de San José del Chilar, $17^{\circ} 42^{\prime} 8^{\prime \prime}$ N, 9657'32" W, C. A. Cruz y E. San Pedro 1361 (IEB, MEXU); $9 \mathrm{~km}$ al NE de San Juan Bautista Cuicatlán, camino a Concepción Pápalo, F. González Medrano et al. F-1699 (MEXU); cañada al SW

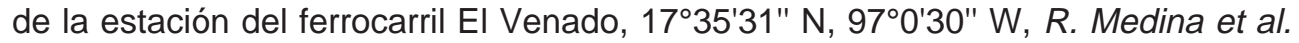
1074 (MEXU); terracería de Santiago Quiotepec a Cuicatlán, 17²4' N, 9657' W, R. Medina et al. 1269 (IEB, MEXU), 1270 (IEB, MEXU); Dominguillo, F. Miranda 1005 (MEXU); laderas al SE de Cuicatlán, F. Miranda 4564 (MEXU); 4 km al NE de Cuicatlán, camino a Concepción Pápalo, L. S. Rodríguez y A. Patiño 1399 (MEXU); near Tomellin, J. N. Rose et al. 10092 (MEXU); 15 km al N de Dominguillo, 
sobre la carretera a Cuicatlán, J. Rzedowski 35658 (IEB); $1.5 \mathrm{~km}$ al W de Dominguillo, A. Salinas et al. 4153 (MEXU, OAX); El Organal, Cañón de Tomellín, A. Salinas et al. 6930 (MEXU); 4 km al E de Cuicatlán, brecha a Concepción Pápalo, municipio Cuicatlán, $17^{\circ} 49^{\prime} \mathrm{N}, 96^{\circ} 57^{\prime} \mathrm{W}$, A. Salinas 7470 (MEXU); $1 \mathrm{~km}$ de Quiotepec, hacia la estación de ferrocarril, L. Schibli 120 (OAX); 8 km al NE de Cuicatlán hacia Santos Reyes Pápalo, R. Torres y J. L. Villaseñor 5057 (IEB, MEXU); 3 km NE de Cuicatlán I. Trejo 1664 (MEXU), 1668 (MEXU); San Pedro, F. Ventura 15296 (IEB); Dominguillo, F. Ventura 15320 (IEB); camino de Pápalo, cerca de la desviación de Quiotepec, F. Ventura 16426 (IEB); Dominguillo, F. Ventura 16431 (IEB, MEXU); $6 \mathrm{~km}$ al $\mathrm{S}$ de Santiago Dominguillo, municipio Cuicatlán, S. Zamudio y E. Pérez 9167 (IEB, MEXU, XAL). Distrito Teotitlán: $1.5 \mathrm{~km}$ al NE de Teotitlán del Camino, H. Arroyo 14 (IEB); $3 \mathrm{~km}$ al oeste de Tecomavaca, H. Arroyo 26 (IEB); $5 \mathrm{~km}$ al N de Tecomavaca, sobre la carretera a Teotitlán del Camino, J. Rzedowski 28170 (IEB), 28171 (IEB), 32855 (IEB), 32861 (IEB); 4 km al E de Teotitlán del Camino, sobre la carretera a Huautla, J. Rzedowski 37081 (ENCB); Santiago Viejo, F. Ventura 15330 (IEB); cerro a la entrada del sol de San Juan de Los Cues, F. Ventura 15340 (IEB). PUEBLA: Municipio Coxcatlán: alrededores de San Rafael, J. Rzedowski 53874 (IEB).

Durante años a esta especie se le conoció con el nombre de $B$. aloexylon, pero el epiteto de La Llave tiene prioridad cronológica y no hay duda acerca de la identidad de este último, pues el mismo Schiede, quien en aquellos años vivía en la ciudad de México, lo menciona en su protólogo. Infortunadamente no se conoce el paradero del material original en que se basó La Llave para su descripción y es muy factible que tales ejemplares ya no existan. En el herbario histórico de la Benemérita Universidad Autónoma de Puebla, que puede consultarse en la biblioteca José María Lafragua, se encuentra un espécimen estéril de la planta en cuestión procedente de "La Mixteca", que esta identificado como Amiris linaloe, sin datos de colector, ni fecha. La Llave a este respecto indica en la misma página 356: "Empeñado en ver las flores de este vegetal, se las encargué a un residente de la Misteca, y de cuya eficacia estaba seguro, y su diligencia fué tal, que me puso un propio inmediatamente, con un saco en que había ramas y hojas frescas, con una gran porción de frutos, pero desgraciadamente sin una flor siquiera, que era lo que más interesaba. Lo mismo le sucedió al Sr. D. Antonio Cal, que como yo, sólo obtuvo hojas y semillas, de todo lo que mandó ejemplares". Probablemente el espécimen depositado en Puebla es el que ha identificado y herborizado el propio Antonio Cal, pero no hay indicio claro de que lo hubiera examinado directamente Pablo de La Llave. En tal circunstancia se estimó apropiado designar un neotipo para el binomio Amiris linanoe.

Con cierta frecuencia se ha estado usando asimismo para la especie en cuestión el nombre de $B$. delpechiana, basado en un ejemplar con flores masculinas y hojas muy tiernas. La comparación del tipo correspondiente con materiales modernos de $B$. linanoe, muestreados en similar estado fenológico, claramente indican que se trata del mismo taxon. 
El tipo de Elaphrium longipedunculatum fue colectado en la región de estudio y discrepa un poco en sus hojas ligeramente más grandes que las que más comúnmente se observan, pero coincide en los demás caracteres de hojas y frutos. Bullock (op. cit., p. 374) consideró a B. delpechiana como sinónimo de B. penicillata (DC.) Engl., pero ya Rzedowski y McVaugh (op. cit., p. 335) rectificaron esta incorrecta interpretación.

Bursera linanoe se asemeja en muchos aspectos y con frecuencia se confunde en los herbarios con $B$. glabrifolia. Un comentario más detallado sobre este particular se incluye al final de la discusión de esta última especie.

El linaloé se conoce mundialmente por el fino aroma de su aceite esencial, que se ha estado explotando en forma intensiva y exportando a Europa en el siglo XIX y en las primeras décadas del XX.

Tan atractivo resultó este producto que unos ingleses se llevaron propágulos de plantas mexicanas a la India, país que en la actualidad abastece de tal sustancia a las industrias especializadas en diferentes partes del mundo.

En el estado de Guerrero la madera perfumada de linaloé se utiliza para la elaboración de artesanías. En la región de estudio la especie se emplea con propósitos medicinales.

16. Bursera mirandae C. A. Toledo, Biotica 9: 441. 1984. Tipo: México: Guerrero: $5 \mathrm{~km}$ al E de Xochipala, municipio Zumpango del Río, sobre el camino a Milpillas, 8.XI.1979, J. Rzedowski 36377 (holotipo ENCB!).

Nombres comunes registrados fuera de la zona de estudio: copal, copal santo.

Árbol o a veces arbusto dioico, hasta de $8 \mathrm{~m}$ de alto, resinoso y aromático al estrujarse; tronco hasta de $20 \mathrm{~cm}$ de diámetro, su corteza externa por lo general café-rojiza y exfoliante en tiras gruesas y cartáceas, a veces gris y no exfoliante, ramillas con frecuencia rojizas oscuras y glabras, salvo las de crecimiento nuevo que son densamente pubérulas; hojas fasciculadas en los extremos de ramillas cortas, o bien, alternas sobre ramillas vigorosas tiernas, precedidas en su aparición por una roseta de catafilos triangulares a linear-triangulares, hasta de $8 \mathrm{~mm}$ de largo, café-rojizos a negruzcos, glabros o algo pubérulos, precozmente caducos, peciolo filiforme, hasta de $2(2.5) \mathrm{cm}$ de largo, pubérulo o cortamente piloso y con escasos pelos glandulares, lámina oblonga en contorno general, de 5 a $11 \mathrm{~cm}$ de largo, de 2.5 a $4 \mathrm{~cm}$ de ancho, imparipinnada, raquis filiforme y sin alas, o bien, con alas hasta de $0.2 \mathrm{~mm}$ de ancho en los segmentos distales, foliolos 7 a 13(17), sésiles o casi sésiles, ovados a lanceolados, el terminal a menudo romboide, de (6)9 a 17(21) $\mathrm{mm}$ de largo, de (3)4 a 10(12) $\mathrm{mm}$ de ancho, agudos a cortamente acuminados $\mathrm{o}$ a veces redondeados en el ápice, cuneados a redondeados y con frecuencia oblicuos en la base, a menudo tosca y más bien irregularmente serrados en el margen, algo lustrosos en el haz, de textura cartácea en la madurez, con la venación prominente en el envés, pubérulos o con más frecuencia glabros o casi glabros en el haz, aunque en las principales nervaduras se observan numerosas 
Rzedowski et al.: Las especies de Bursera de la cuenca del río Papaloapan, México

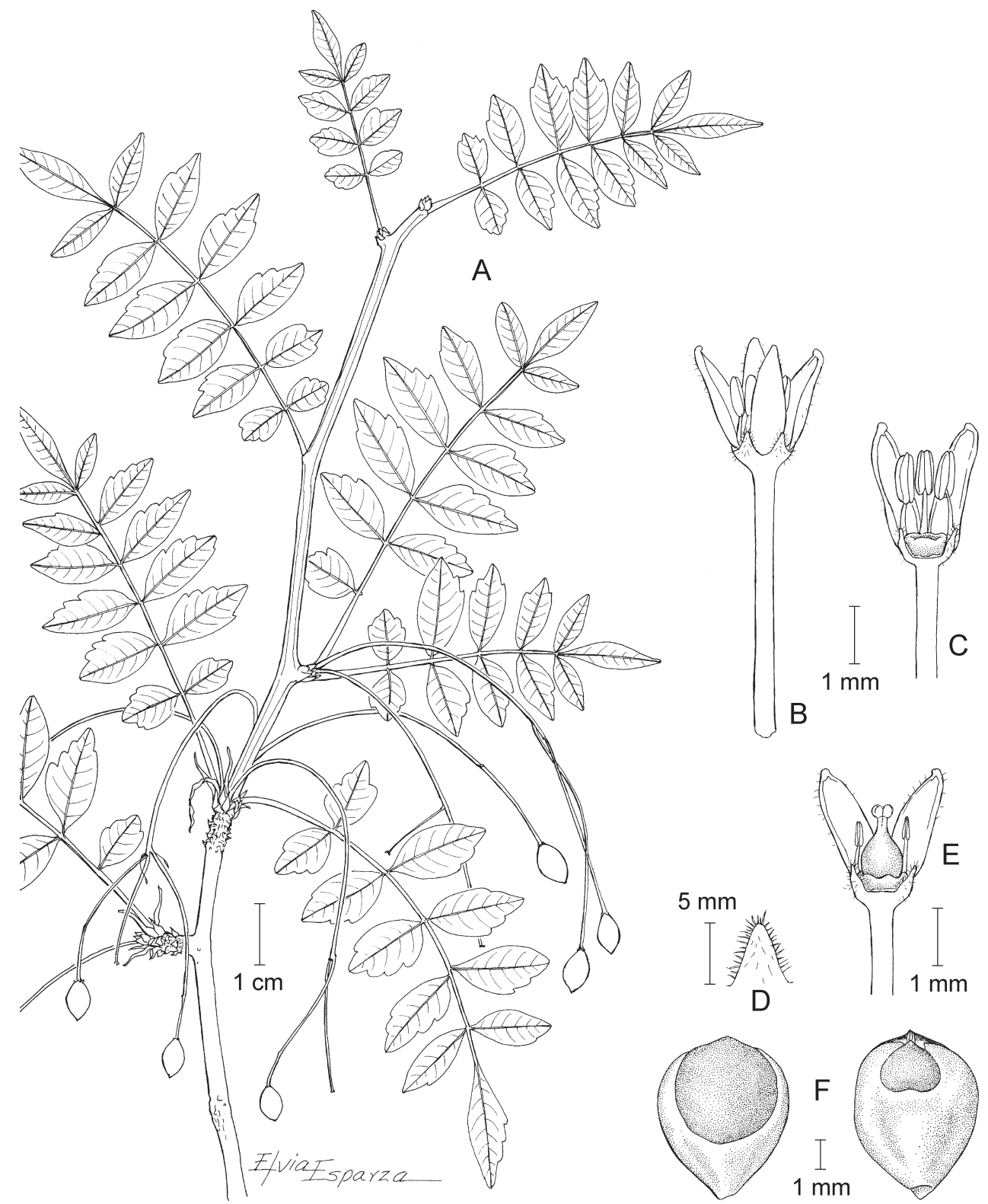

Bursera mirandae C. A. Toledo. A. rama con hojas y frutos; B. flor masculina; C. flor masculina desprovista de 2 segmentos del cáliz, de 2 pétalos y de 5 estambres; D. segmento del cáliz; E. flor femenina desprovista de 2 segmentos del cáliz, de 2 pétalos y de varios estaminodios; F. hueso visto por ambas caras. Ilustrado por Elvia Esparza. 


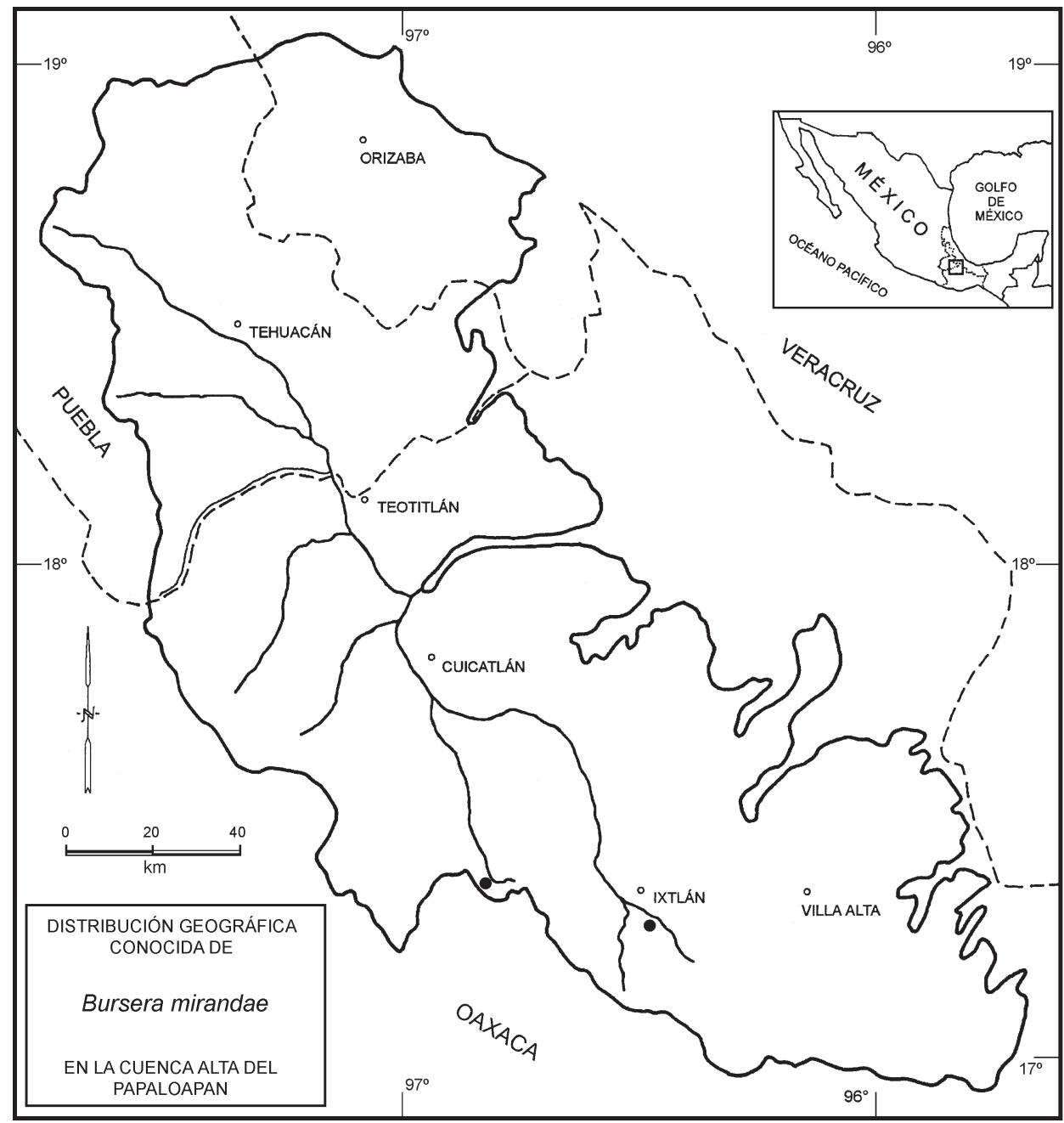

glándulas sésiles o cortamente estipitadas, el envés más a menudo pubérulo a lo largo de las nervaduras y también glandular; inflorescencia en forma de panícula laxa, hasta de $20 \mathrm{~cm}$ de largo y $8 \mathrm{~cm}$ de ancho, bracteolas lineares o subuladas, hasta de $3 \mathrm{~mm}$ de largo, pedicelos capilares, hasta de 8(10) $\mathrm{mm}$ de largo; flores masculinas tetrámeras, lóbulos del cáliz triangulares, de 0.4 a $0.5(0.8) \mathrm{mm}$ de largo, glabros o algo pubérulos, ciliados, pétalos blanquecinos o verdosos, oblongos a oblanceolados, de 1.7 a $2.3 \mathrm{~mm}$ de largo, glabros o algo pilosos por fuera, estambres 8 , filamentos de ca. $1 \mathrm{~mm}$ de largo, anteras oblongas, de ca. $1 \mathrm{~mm}$ de largo, ovario vestigial; flores femeninas similares a las masculinas, estaminodios con anteras de ca. $0.4 \mathrm{~mm}$ de largo, ovario bilocular, estigmas 2; fruto obovoide, bivalvado, de 7 a $8 \mathrm{~mm}$ de largo, de 5 a $7 \mathrm{~mm}$ de diámetro, apiculado en el ápice, glabro, rojizo en 
la madurez, hueso lenticular, de 5 a $6 \mathrm{~mm}$ de largo, cubierto hasta la mitad de su longitud por un pseudoarilo rojo o anaranjado, la parte expuesta negra.

Habitante poco frecuente del bosque tropical caducifolio, en altitudes de 1450 a $1650 \mathrm{~m}$. Florece de mayo a principios de julio. Permanece sin follaje de noviembre a mayo.

Especie endémica de la cuenca del Balsas y del Papaloapan, conocida de Guerrero, Puebla y Oaxaca.

Material examinado: OAXACA: Distrito Etla: $\mathrm{km} 30$, municipio Jayacatlán, $F$. Ventura 15472 (IEB, UAMIZ). Distrito Ixtlán: 1 km al W de Río Grande, brecha a Amatlán, A. García et al. 1771 (IEB, MEXU).

17. Bursera morelensis Ramírez, An. Inst. Méd. Nac. Méx. 2: 17. 1896. Terebinthus morelensis (Ramírez) Rose, Contr. U.S. Nat. Herb. 10: 120. 1906. Elaphrium morelense (Ramírez) Rose, North Amer. Fl. 25: 250. 1911. Tipo: lámina que acompaña la descripción original, basada en planta procedente de Jojutla, Morelos, México.

Nombres comunes registrados en la zona: copalillo, cuajiote rojo.

Nombres comunes registrados fuera de la zona de estudio: cuajiote, palo colorado, palo mulato, xixote.

Árbol dioico, de 3 a 10(13) m de alto, con resina aceitosa abundante, aromática; tronco hasta de $40 \mathrm{~cm}$ de diámetro, corteza exfoliante rojiza en láminas delgadas, ramas jóvenes y maduras glabras; catafilos inconspicuos, pronto deciduos, hojas imparipinnadas, de 5 a $11 \mathrm{~cm}$ de largo y 1.5 a $4.5 \mathrm{~cm}$ de ancho, peciolo acanalado, de 1 a $2 \mathrm{~cm}$ de largo, foliolos 15 a 45(51), raquis inconspicuamente alado, foliolos sésiles o subsésiles, linear-oblongos a linearlanceolados, de 7 a $22 \mathrm{~mm}$ de largo y 1.4 a $2.5 \mathrm{~mm}$ de ancho, ápice agudo, base aguda a cuneada, margen entero, nervadura central evidente, las secundarias inconspicuas; flores masculinas dispuestas en inflorescencias racimosas o paniculadas, hasta de $5 \mathrm{~cm}$ de largo, con bracteolas filiformes a subuladas, deciduas, flores generalmente pentámeras o con menos frecuencia trímeras o tetrámeras, cáliz con lóbulos angostamente triangulares, de 0.7 a $2.3 \mathrm{~mm}$ de largo, ápice agudo, glabros; pétalos amarillentos, verdosos o blanquecinos, de 3 a $6 \mathrm{~mm}$ de largo, oblongos a lanceolados, cuculados, estambres (6)10, filamentos de ca. $1 \mathrm{~mm}$ de largo, anteras oblongas, de $1.5 \mathrm{~m} 2 \mathrm{~mm}$ de largo; flores femeninas usualmente solitarias, rara vez en pares o en panículas cortas, por lo general trímeras, menos frecuentemente tetrámeras o pentámeras, semejantes en forma y tamaño a las masculinas, anteras de los estaminodios de 1 a $1.5 \mathrm{~mm}$ de largo, ovario trilocular, estigmas 3; pedúnculos en el fruto marcadamente engrosados, encorvados y glabros, de 1.3 a $2.2 \mathrm{~cm}$ de largo, fruto trivalvado, oblicuamente 


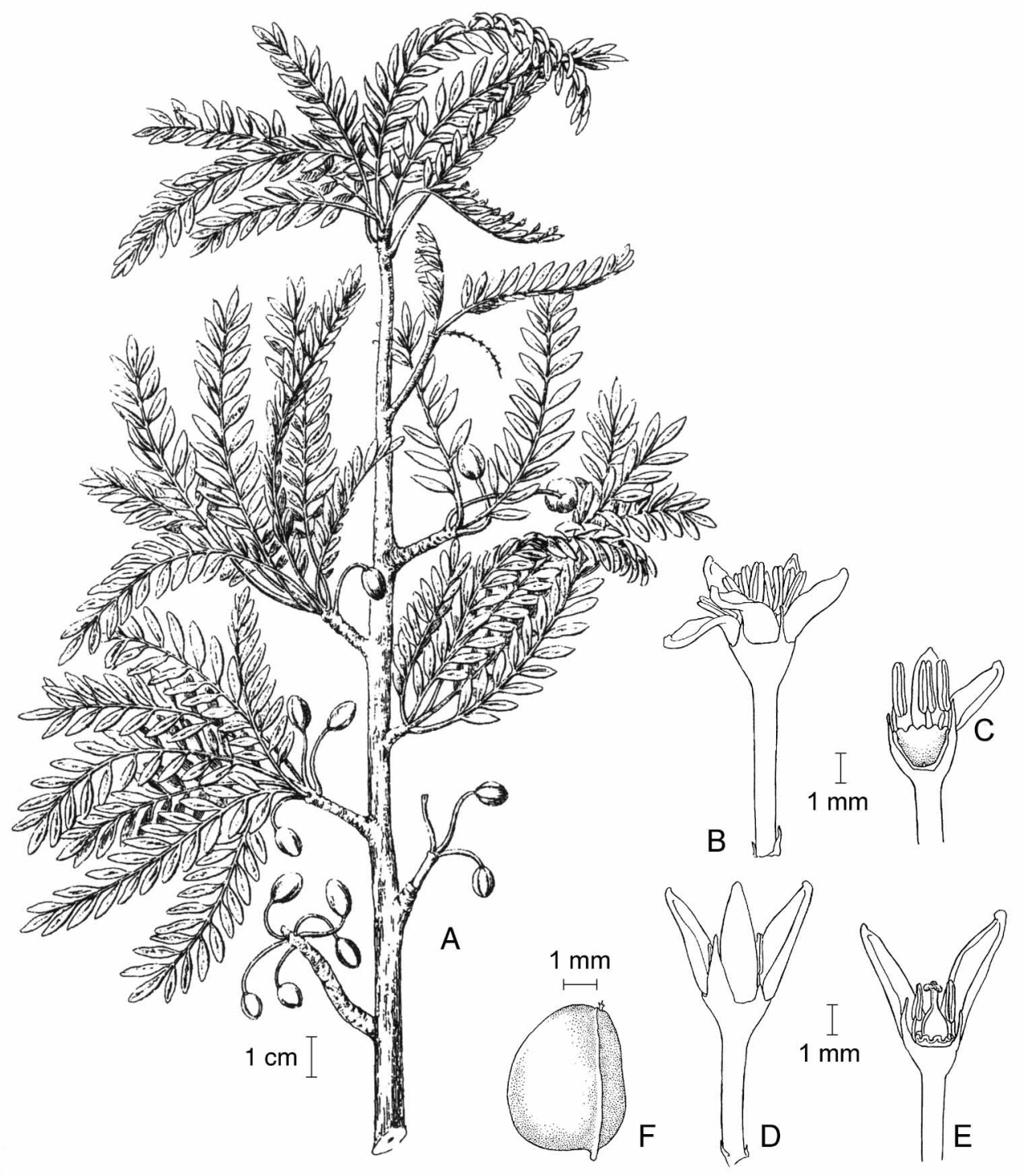

Bursera morelensis Ramírez. A. rama con hojas y frutos; B. flor masculina; C. flor masculina desprovista de 2 pétalos y de 5 estambres; D. flor femenina en vista externa; E. flor femenina desprovista de un pétalo y de varios estaminodios; F. hueso. llustrado: A. por Adolfo Tenorio y reproducido de la lámina III del vol. 2 de los Anales del Instituto Médico Nacional. 1896; B-F. por Elvia Esparza. 
ovoide, de 5 a 8(10) $\mathrm{mm}$ de largo y de 4 a $6 \mathrm{~mm}$ de ancho, ligeramente apiculado, glabro, el hueso recubierto totalmente por un pseudoarilo amarillo pálido.

Habitante muy vistoso por su corteza de color rojizo intenso, frecuente y algunas veces dominante en el bosque tropical caducifolio, sobre diferentes tipos de sustrato, en altitudes entre 500 y 1500 m. Permanece sin hojas entre noviembre y mayo.

La especie es muy abundante en muchos parajes de la porción oriental de la cuenca del Balsas, sobre todo en los estados de Guerrero, Morelos y Puebla. En Oaxaca se extiende también hacia las cuencas de los ríos Tehuantepec y Papaloapan, y además prospera en forma dispersa en los cañones labrados por los afluentes del río Pánuco en San Luis Potosí, Guanajuato, Querétaro e Hidalgo.

Material examinado: OAXACA: Distrito Coixtlahuaca: La Huerta, $20 \mathrm{~km}$ al NE de Tepelmeme de Morelos, R. Cruz 2617 (ENCB). Distrito Cuicatlán: 3.8 km al S de San José del Chilar, 1741'11" N, 9657'31" W, J. P. Abascal et al. 151 (MEXU); 2.5 km al NW de la desviación a Quiotepec, municipio Cuicatlán, H. Arroyo 47 (ENCB); 3 km al N de Cuicatlán, camino a Concepción Pápalo, municipio Cuicatlán, H. Arroyo 51 (ENCB); 3 km al N de Cuicatlán camino a Concepción Pápalo, municipio Cuicatlán, H. Arroyo 54 (ENCB); $15 \mathrm{~km}$ al S de Dominguillo, carretera a Oaxaca, municipio Cuicatlán, H. Arroyo 62 (ENCB); $3 \mathrm{~km}$ al W de la estación de F.F.C.C. El Venado, H. Arroyo 119 (ENCB, IEB); $4 \mathrm{~km}$ al W de la estación de F.F.C.C. El Venado, camino Almoloyas, H. Arroyo 120 (ENCB, MEXU); San José del Chilar, C. A. Cruz y R. García 7 (MEXU); Plan de beis, San José del Chilar, C. A. Cruz et al. 152 (MEXU), 160 (MEXU); barranca del Casiquito, San José del Chilar, C. A. Cruz et al. 703 (MEXU); camino a la barranca de Agua Amarilla, C. A. Cruz et al. 814 (MEXU); cerro El Ciruelo, San José del Chilar, $C$. A. Cruz et al. 906 (MEXU); cerro La Copalera, a 32 km al NE de San José del Chilar, 1741'15" N, 9657'16" W, C. A. Cruz y E. San Pedro 1446 (IEB, MEXU); $7 \mathrm{~km}$ al NE de Quiotepec, por el camino a Chiquihuitlán, F. González Medrano et al. F-1121 (MEXU); $13 \mathrm{~km}$ de Cuicatlán, rumbo a Quiotepec, P. Guerrero 493 (IEB); 10 km de Santiago Quiotepec a Cuicatlán, por la brecha, E. M. Lira et al. 1697 (MEXU); 5 km de San Pedro Jaltepetongo, cañada W, R. Medina et al. 1098 (MEXU), 1099 (MEXU); terracería de Santiago Quiotepec a Cuicatlán, 1747' N, 9657' W, R. Medina et al. 1260 (IEB, MEXU); 4 km al E de Cuicatlán, sobre el camino a Pápalo, municipio Cuicatlán, L. S. Rodríguez y A. Patiño 1397 (ENCB); $15 \mathrm{~km}$ al $\mathrm{S}$ de Dominguillo, municipio Cuicatlán, sobre el camino a Oaxaca, J. Rzedowski 34111 (ENCB); 12 km al SE de Dominguillo, municipio Cuicatlán, sobre la carretera a Oaxaca, J. Rzedowski 35462 (ENCB); 9 km al SE de Dominguillo, sobre la carretera a Oaxaca, J. Rzedowski 35654 (ENCB); 2 km al NW de Dominguillo, sobre la carretera a Cuicatlán, J. Rzedowski 35660 (ENCB); 9 km al S de Dominguillo, municipio Cuicatlán, sobre la carretera a Oaxaca, J. Rzedowski 36525 (ENCB); $6 \mathrm{~km}$ al $\mathrm{N}$ de Cuicatlán por la carretera 131, $2.5 \mathrm{~km}$ al W por la 
terracería que va rumbo a San Pedro Jocotipac, A. Salinas et al. 4259 (IEB, MEXU); $3 \mathrm{~km}$ al SW de la estación de tren Tomellín, brecha a San Pedro Jaltepetongo, $A$. Salinas y E. Martínez Correa 8083 (MEXU); 6.2 km de Cuicatlán hacia Jocotipac, L. Schibli 111 (OAX); $4 \mathrm{~km}$ al NE de Cuicatlán, P. Tenorio y E. Martínez Correa 17416 (MEXU); $0.3 \mathrm{~km}$ al E de Santa Catalina Tlaxila, E. Torres 103 (OAX); $3 \mathrm{~km}$ al NE de Cuicatlán, I. Trejo 1585 (MEXU); Tomellín, municipio Cuicatlán, F. Ventura 15300 (ENCB, MEXU); El Puente Viejo, municipio Nacaltepec, F. Ventura 15308 (ENCB); Quiotepec, cerca de la estación de F.F.C.C., antes de pasar el río, F. Ventura 15345 (ENCB, MEXU); camino de Pápalo, cerca de la desviación de Quiotepec, municipio Cuicatlán, F. Ventura 16428 (ENCB, MEXU); Dominguillo, municipio Cuicatlán, F. Ventura 16433 (ENCB); San José del Chilar, municipio Cuicatlán, F. Ventura 16439 (ENCB, MEXU). Distrito Etla: 4 km al N de Jayacatlán, municipio Jayacatlán, $H$. Arroyo 72 (ENCB, MEXU); terracería a San Juan Bautista Jayacatlán, R. Medina et al. 1222 (IEB, MEXU); km 30, municipio Jayacatlán, $F$. Ventura 15470 (ENCB, MEXU). Distrito Ixtlán: camino a El Carrizal, Macuiltianguis, Oaxaca, R. Lucero L70 (MEXU). Distrito Teotitlán: $1.5 \mathrm{~km}$ al NE de Teotitlán del Camino, municipio Teotitlán del Camino, H. Arroyo 13 (ENCB, IEB, MEXU); 3 km al N de San Martín Toxpalan, H. Arroyo 24 (ENCB, IEB, MEXU); cerro Nahualtepec, $8 \mathrm{~km}$ al NW de San Gabriel Casa Blanca, A. García et al. 3453 (IEB, MEXU); 1 km después de San Martín Toxpalan, rumbo a Cuicatlán, F. González Medrano et al. F-1161 (MEXU); $2 \mathrm{~km}$ al SE de San Martín Toxpalan, municipio Teotitlán, $F$. González Medrano et al. 11682 (MEXU); 3 mi north of Teotitlan, C. T. Mason et al. 3018 (ENCB); $5 \mathrm{~km}$ al SW de Tecomavaca, S. Ramírez 352 (OAX); $5 \mathrm{~km}$ al $\mathrm{N}$ de Tecomavaca, carretera a Teotitlán del Camino, J. Rzedowski 32862 (ENCB, MEXU); $5.5 \mathrm{~km}$ de Tecomavaca hacia Ixcatlán, L. Schibli 84 (OAX); $6 \mathrm{~km}$ SE of Teotitlan on hwy between Tehuacan and Telixtlahuaca, $W$. D. Stevens y E. Martínez 25199 (IEB); Río Seco, $10 \mathrm{~km}$ al W de Tecomavaca, camino a Ixcatlán, municipio Ixcatlán, P. Tenorio y E. Martínez Correa 17403 (MEXU); cerro La Mina, al SE de San Antonio Nanahuatipam, 186' N 97'9' W, P. Tenorio et al. 20468 (MEXU); puente del Río Salado, municipio Tecomavaca, F. Ventura 15322 (ENCB, MEXU); cerro al oriente de San Juan de Los Cues, municipio San Juan de Los Cues, F. Ventura 15343 (ENCB, MEXU); camino a Huautla de Jiménez, municipio Teotitlán del Camino, F. Ventura 15358 (ENCB); Ignacio Mejía, municipio Teotitlán del Camino, F. Ventura 15370 (ENCB, MEXU). PUEBLA: Municipio Coxcatlán: $5 \mathrm{~km}$ al SE de San Rafael, carretera Coxcatlán, H. Arroyo 34 (ENCB, IEB, MEXU); km 56 SE of Tehuacan on the road to Teotitlan del Camino and ca. $2 \mathrm{~km} \mathrm{NW}$ of the Oaxaca border, B. Bartholomew et al. 3139 (MEXU); $45 \mathrm{~km}$ al SE de Tehuacán, $3.5 \mathrm{~km}$ al SE de Coxcatlán, A. Gibson 3444 (ENCB); $2 \mathrm{~km}$ al S de San Rafael, sobre la carretera a Oaxaca, J. Rzedowski 36527 (ENCB); 3 km al SE de San Rafael, J. Rzedowski 53872 (IEB), 53873 (IEB); 2-3 km al NE de San Rafael, A. Salinas 7099 (MEXU); rancho El Aguaje, aproximadamente $4 \mathrm{~km}$ al $S$ de la cabecera municipal de Coxcatlán, A. Valiente et al. 115 (MEXU), 144 (MEXU); $5 \mathrm{~km}$ adelante de Coxcatlán, V. Vázquez y M. Cházaro 685 (ENCB, MEXU, XAL); Tilapa, F. Ventura 15351 (ENCB, IEB); San Rafael, F. Ventura 15362 (ENCB), 15366 (IEB); Pueblo 


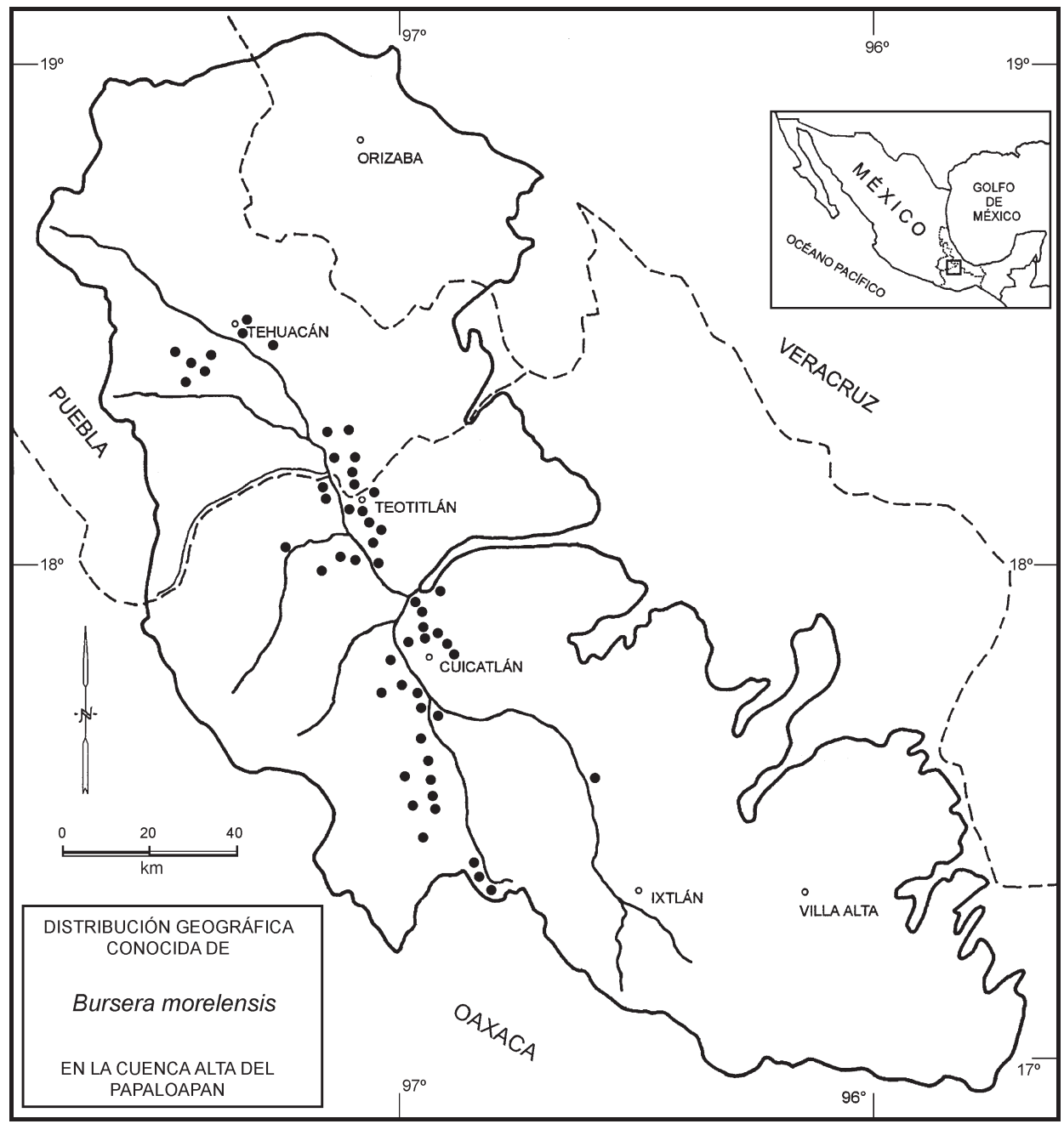

Nuevo, F. Ventura 15378 (ENCB, MEXU). Municipio San José Miahuatlán: cerro Tepetroje, en la Cañada Corral de Burros, $9 \mathrm{~km}$ al SE de Pueblo Nuevo, $18^{\circ} 12^{\prime} \mathrm{N}$, 97¹3' W, J. Sánchez Ken et al. 37 (MEXU). Municipio Tehuacán: carretera Tehuacán - Teotitlán, Valle de Tehuacán, L. Abundiz 813 (MEXU); 4.4 km al E de San Pablo Tepetzingo, municipio Tehuacán, F. Chiang et al. F-51 (ENCB, MEXU); hills E of Tehuacan, J. N. Rose et al. 9973 (MEXU); San Diego, $10 \mathrm{~km}$ al S de Tehuacán, J. Rzedowski 9021a (ENCB, MEXU), 9021b (MEXU); Tula, F. Ventura 15269 (IEB), 15270 (IEB); San José Tochapa, municipio Tehuacán, F. Ventura 15274 (ENCB, MEXU, UC), 15275 (ENCB, MEXU). Municipio Zapotitlán: a 3 km

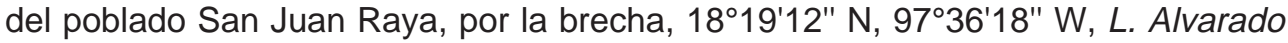
et al. 146 (MEXU); $3 \mathrm{~km}$ al SW de San Antonio Texcala, A. C. Gibson 3449 (ENCB, 
MEXU); $4 \mathrm{~km}$ al NE de Zapotitlán Salinas, sobre la carretera a Tehuacán, J. Rzedowski 33232 (ENCB, MEXU); 5 km al SW de Zapotitlán, por la carretera 125, rumbo a Chazumba, $A$. Salinas y O. Dorado F- 3083 (MEXU); minas de las canteras de San Antonio Texcala, F. Ventura 15265 (ENCB); cerro de La Colmena, F. Ventura 15284 (ENCB, MEXU, UC); 2 mi NW of San Antonio Texcala, G. L. Webster et al. 17201 (MEXU). Municipio Zinacatepec: $7 \mathrm{~km}$ al N de Calipan, A. Salinas y C. H. Ramos F-3822 (MEXU); 4 km al NW de Calipan, sobre la carretera a Tehuacán, J. Rzedowski 28160 (ENCB).

Los ejemplares J. Rzedowski 53873 y F. Ventura 15366 difieren de la generalidad del material en sus hojas con menor número de foliolos (11 a 21) y a menudo con algo de pubescencia fina, en sus flores siempre solitarias y con pétalos rojizos. Inicialmente se pensó que estas plantas podrían pertenecer a $B$. suntui C. A. Toledo, pero una visita a los alrededores del poblado de San Rafael reveló que en medio de una amplia población de $B$. morelensis que prospera allí sobre suelos yesosos, existen contados individuos con las características arriba mencionadas, pero que en su aspecto general y en la abundante producción de frutos no discrepan de los árboles de $B$. morelensis. Es muy probable que estos árboles diferentes lleven la influencia genética de $B$. arida, que también se ha observado en la misma zona.

18. Bursera pontiveteris Rzedowski, Calderón \& Medina sp. nov. Tipo: México: Oaxaca: distrito Cuicatlán, arriba del río Las Ventas, de regreso a Puente Viejo, municipio de Santiago Nacaltepec, 22.X.2002, R. Medina et al. 1279 (holotipo IEB, isotipos por distribuirse).

Nombres comunes registrados en la zona: copal, copalillo.

Arbor vel frutex usque $7 \mathrm{~m}$ altus dioecius vel polygamo-dioecius; truncus cortice griseo non exfolianti, ramuli juniores dense puberuli; foliorum rosulae juventute cataphyllis exterioribus cito deciduis cinctae, folia imparipinnata vel trifoliolata rhachide exalata, foliola 3 vel 5 ovata vel oblonga, lanceolata, triangularia nunc rhombica, (1)2-8 cm longa, (0.5)1-4(5) cm lata, foliolum terminale plerumque lateralibus valde majus, apice rotundata usque acuta et interdum acuminata, basi rotundata usque cuneata, marginibus profunde et irregulariter serratis, supra puberula, subtus juventute tomentosa, maturitate sericea; inflorescentia racemosopaniculata ad 6(8) cm longa; flores masculi tetrameri, calycis lobi lineares usque anguste lanceolati vel anguste triangulares, $1.5-3 \mathrm{~mm}$ longi, petala albida oblonga 2.5-3.5 mm longa, stamina 8; flores feminei masculinorum similes, calyces lobi 1.5$2 \mathrm{~mm}$ longi, petala 1.8-2.5 mm longa, ovarium biloculare, stigmata 2; fructus globosi usque late obovoidei 8-9 mm longi, pyrenae biconvexae 5-6 mm longae pseudoarillo aurantiaco per 2/3 partibus inferis indutae.

Árbol o arbusto dioico o polígamo-dioico, hasta de $7 \mathrm{~m}$ de alto; tronco hasta de $30 \mathrm{~cm}$ de diámetro, corteza gris, no exfoliante, con abundante oleoresina 
Rzedowski et al.: Las especies de Bursera de la cuenca del río Papaloapan, México

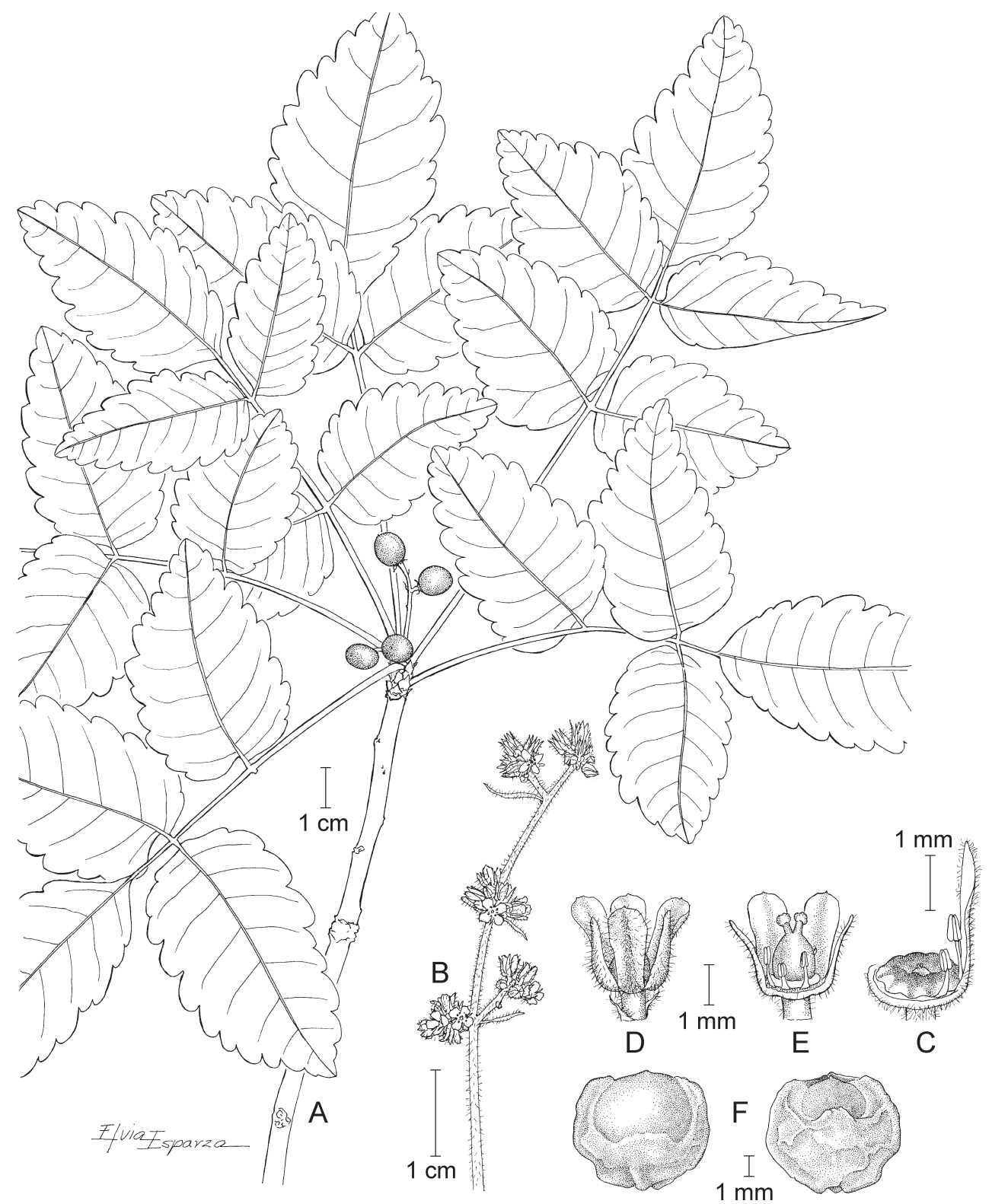

Bursera pontiveteris Rzed., Calderón \& Medina. A. rama con hojas y frutos; B. porción de inflorescencia masculina; C. flor masculina desprovista de cáliz, de 3 pétalos y de 6 estambres; D. flor femenina en vista externa; E. flor femenina desprovista de un segmento del cáliz, de 2 pétalos y de varios estaminodios; F. hueso visto por ambas caras. Ilustrado por Elvia Esparza. 
aromática, ramas cafés a rojizas oscuras, ramillas jóvenes densamente pubérulas; hojas con frecuencia agrupadas en rosetas en los extremos de ramillas cortas originadas en años pasados, otras veces alternas en ramillas de crecimiento nuevo, todas precedidas en su aparición por un conjunto de catafilos triangulares, de unos $5 \mathrm{~mm}$ de largo y de 2 a $3 \mathrm{~mm}$ de ancho, variando a deltoides y hasta de $3 \mathrm{~mm}$ de largo y de $2 \mathrm{~mm}$ de ancho, densamente pubérulos a canescentes por fuera y a veces también por dentro, precozmente caducos, los interiores a menudo de forma intermedia entre el catafilo y la hoja, hojas imparipinnadas o trifolioladas, hasta de $20 \mathrm{~cm}$ de largo y $13 \mathrm{~cm}$ de ancho, peciolo hasta de $8 \mathrm{~cm}$ de largo, densamente pubérulo, raquis sin alas o prácticamente sin alas, foliolos laterales subsésisles 0 sobre peciólulos de 1 a $4 \mathrm{~mm}$ de largo, el del foliolo terminal de 0.3 a 1 (2) $\mathrm{cm}$ de largo, foliolos 3 o más comúnmente 5 , de forma y tamaño variables, ovados u oblongos a lanceolados, triangulares o rómbicos, de (1)2 a $8 \mathrm{~cm}$ de largo y de

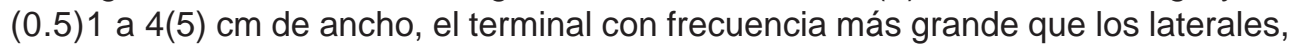
redondeados a agudos, en ocasiones acuminados en el ápice, redondeados o cuneados, a veces truncados en la base, margen profunda e irregularmente serrado, a menudo con cierta tendencia a ser doblemente serrado, de textura membranácea, haz pubérulo, envés tomentoso en las hojas jóvenes, en las maduras seríceo, sobre todo a lo largo de las nervaduras, además a menudo provisto de numerosas glándulas diminutas; inflorescencia en forma de racimo simple o algo ramificado, con frecuencia desarrollándose al mismo tiempo que las hojas tiernas, sus ejes densamente vilosos; flores de ambos sexos tetrámeras; inflorescencias masculinas de (1)3 a 6(8) cm de largo, incluyendo el pedúnculo, rara vez subsésiles, bracteolas lineares a lanceoladas o espatuladas, de 5 a $10 \mathrm{~mm}$ de largo, de 0.2 a $1 \mathrm{~mm}$ de ancho, vilosas y glandulosas, pedicelos de 0.5 a $1.5 \mathrm{~mm}$ de largo, lóbulos del cáliz lineares a estrechamente lanceolados o estrechamente triangulares, con frecuencia algo desiguales, más cortos a ocasionalmente más largos que los pétalos, de 1.5 a $3 \mathrm{~mm}$ de largo, viloso-pubérulos en ambas superficies, pétalos blanquecinos, oblongos, de 2.5 a $3.5 \mathrm{~mm}$ de largo, ápice agudo y apiculado, con frecuencia doblado hacia dentro, viloso-pubérulos por fuera, especialmente hacia la línea media, con pelos escasos por dentro, filamentos de 0.7 a $1.2 \mathrm{~mm}$ de largo, anteras oblongas, de ca. $0.5 \mathrm{~mm}$ de largo, gineceo diminuto, prácticamente ausente; inflorescencias femeninas más laxas que las masculinas, escasamente ramificadas y con pocas flores, pedicelos de 1 a $2 \mathrm{~mm}$ de largo, segmentos del cáliz lanceolados a estrechamente triangulares, de 1.5 a $2 \mathrm{~mm}$ de largo, pétalos de 1.8 a $2.5 \mathrm{~mm}$ de largo, estaminodios con anteras de 0.2 a $0.5 \mathrm{~mm}$ de largo, ovario bilocular, estigmas 2; frutos 1 a 8 por pedúnculo, bivalvados, esféricos a ampliamente obovoides, de 7 a $9 \mathrm{~mm}$ de largo, rojizos en la madurez, glabros, hueso biconvexo, de 5 a $6 \mathrm{~mm}$ de largo, pseudoarilo anaranjado, cubriendo sus 2/3 inferiores, la superficie descubierta negra o negruzca.

Habitante poco común e infrecuente en el bosque tropical caducifolio en altitudes entre 800 y $1800 \mathrm{~m}$. Florece en junio y julio. Permanece sin follaje de noviembre a mayo. 
Esta especie sólo se conoce de la región de estudio, donde se ha colectado tanto en el estado de Oaxaca, como en el de Puebla.

Material adicional examinado: OAXACA: Distrito Coixtlahuaca: La Huerta, $20 \mathrm{~km}$ al NE de Tepelmeme de Morelos, R. Cruz 2613 (IEB, MEXU). Distrito Cuicatlán: $16 \mathrm{~km}$ al SE de Dominguillo, por la carretera Tehuacán - Oaxaca, $F$. González Medrano et al. F-1807 (MEXU); arriba del río Las Ventas, cerca de Puente Viejo, municipio Santiago Nacaltepec, R. Medina et al. 1278 (IEB, MEXU); Buenavista, Coyula, Cuicatlán 1755.2'61" N, 9657.1'57" W, J. Pérez 436 (IEB, MEXU); $15 \mathrm{~km}$ al S de Dominguillo, sobre la carretera a Oaxaca, J. Rzedowski 34926 (IEB, MEXU); cerro Virgen de Guadalupe, al NW de Cuicatlán, $6 \mathrm{~km}$ al N de Cuicatlán por la carretera 131 y $10 \mathrm{~km}$ al W por la terracería rumbo a San Pedro Jocotipac, $17^{\circ} 47^{\prime}$ N, 97 $92^{\circ}$ W, A. Salinas et al. 4587 (IEB, MEXU); El Puente Viejo, cerca de Tonaltepec, municipio Nacaltepec, F. Ventura 15306 (IEB, MEXU). Distrito Teotitlán: $14 \mathrm{~km}$ al E de Santa María Ixcatlán, por la terracería a Tecomavaca, A. Salinas y P. Tenorio 5851 (MEXU). PUEBLA: Municipio San Gabriel Chilac:

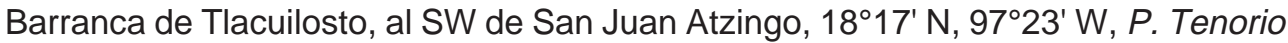
y D. Frame 12132 (IEB, MEXU). Municipio San José Miahuatlán: Cañada Agua Los Granados, al W de San Pedro Tetitlán, 18¹3'20" N, 97¹9'11" W, R. Medina et al. 1211 (IEB, MEXU), 1211a (IEB, MEXU).

B. pontiveteris es una entidad variable, que requiere todavía de estudios más profundos y detallados. En primera instancia destacan las diferencias en el tamaño de los foliolos, pues mientras en algunas poblaciones éstos miden sólo $1 \mathrm{a} 2.5 \mathrm{~cm}$ de largo, en otras alcanzan tallas de 6 a $8 \mathrm{~cm}$. Aún más significativas son las divergencias en los segmentos del cáliz de las flores masculinas que en las plantas provenientes de localidades ubicadas al sur de Cuicatlán son aproximadamente de la longitud de los pétalos, sin embargo en las de otros sitios apenas sobrepasan la mitad de su largo.

Este último carácter es de particular consideración, pues en la mayor parte de las especies de Bursera la proporción entre el tamaño del cáliz y de la corola suele ser bastante constante. No obstante, en los ejemplares estudiados no se ha visto clara correlación entre estas discrepancias y ningún otro rasgo morfológico, por lo que optamos por reconocer todo el material como perteneciente a una especie.

En virtud de sus flores tetrámeras, ovario bilocular y fruto bivalvado, $B$. pontiveteris se ubica en la sección Bullockia y sus características distintivas principales consisten en los foliolos profundamente serrados en el margen y el raquis foliar carente o prácticamente carente de alas. Este último rasgo no es frecuente en los representantes de la sección mencionada, pero debe haberse originado de manera independiente y convergente en varios linajes evolutivos, pues $B$. pontiveteris no parece estar relacionada con $B$. mirandae, $B$. esparzae, $B$. vejarvazquezii Miranda, $B$. fragrantissima Bullock, ni con $B$. bonetii Rzed. Sus vínculos 


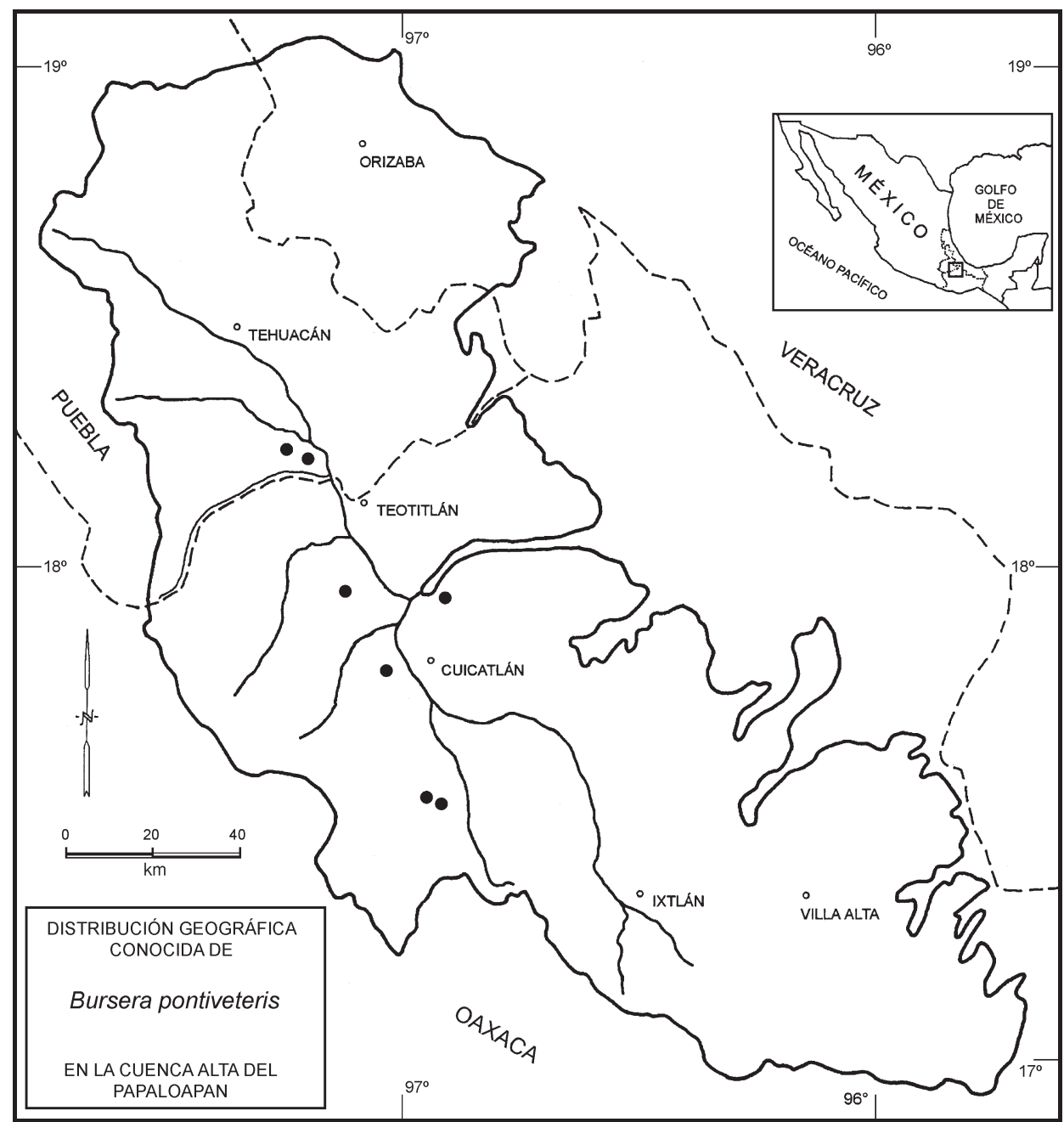

más estrechos posiblemente se dirigen hacia $B$. altijuga, especie aproximadamente simpátrica, pero de afinidad ecológica diferente. Esta última se distingue de $B$. pontiveteris en sus hojas con el raquis alado, con foliolos de textura más rígida en la madurez y de margen menos profundamente serrado.

El nombre del taxon hace referencia a su localidad tipo, Puente Viejo, lugar en el que lo encontró en 1978 Francisco Ventura. Se trata de las ruinas de un puente del antiguo camino real que unía a Oaxaca con Tehuacán, ubicadas cerca de la población de Tonaltepec, en el municipio de Nacaltepec. 
19. Bursera schlechtendalii Engl., DC. Monogr. Phaner. 4: 41. 1883. (nombre basado en Elaphrium simplicifolium Schltdl.). Elaphrium simplicifolium Schltdl., Linnaea 16: 352. 1842. (non Bursera simplicifolia DC., 1825). Terebinthus schlechtendalii (Engl.) Rose, Contr. U.S. Nat. Herb. 10: 119. 1906. Tipo: México: in regione calida, localidad indefinida, XI.1835, C. J. W. Schiede 1022 (holotipo $\mathrm{HAL})$.

Bursera jonesii Rose, Contr. U.S. Nat. Herb. 3: 314. 1895. Terebinthus jonesii (Rose) Rose, Contr. U.S. Nat. Herb. 10: 119. 1906. Elaphrium jonesii (Rose) Rose, North Amer. FI. 25: 244. 1911. Tipo: México: Colima: Colima, 2.VII.1892, M. E. Jones 73 (holotipo US!).

Nombres comunes registrados fuera de la zona de estudio: aceitillo, copal, copal negro, mulato rojo.

Arbusto o a veces árbol dioico (¿o en ocasiones hermafrodita?), de (0.5)1 a $3(10) \mathrm{m}$ de alto, con abundante resina aceitosa de olor fuerte en la corteza y en las partes verdes, glabro, aunque algunas porciones tiernas presentan papilas blanquecinas diminutas; tronco de hasta $20(30) \mathrm{cm}$ de diámetro, corteza externa roja, exfoliante en láminas grandes y delgadas; hojas simples (unifolioladas), peciolo de 3 a 10 (14) mm de largo, lámina elíptica a oblanceolada u obovada, de 1 a 6(15) cm de largo y 0.5 a $2.5(5) \mathrm{cm}$ de ancho, por lo general redondeada u obtusa en el ápice, pero a veces mucronada o apiculada, la base cuneada a obtusa, margen entero, nervaduras secundarias (2)3 a 9(11) pares, prominentes en el envés, por lo general distalmente bifurcadas, de textura cartácea; flores por lo común solitarias o a veces en racimos cortos, sobre pedúnculos hasta de $5 \mathrm{~mm}$ de largo, las masculinas por lo general pentámeras o en ocasiones tetrámeras, lóbulos del cáliz triangulares o triangular-oblongos, de 0.4 a $0.7(1) \mathrm{mm}$ de largo, pétalos triangularlanceolados, de (2)2.5 a 3(3.5) mm de largo, cuculados y con el ápice encorvado, amarillentos o rojizos, estambres (8)10, filamentos de poco menos de $1 \mathrm{~mm}$ de largo, anteras oblongas, de 1.2 a $1.5 \mathrm{~mm}$ de largo; las flores femeninas similares a las masculinas, generalmente trímeras, estaminodios de ca. $1 \mathrm{~mm}$ de largo, ovario trilocular, estigmas 3; pedúnculos fructíferos hasta de $5 \mathrm{~mm}$ de largo, notablemente engrosados, frutos trivalvados, oblicuamente ovoides, de 4 a $8 \mathrm{~mm}$ de largo, frecuentemente apiculados, glabros, el hueso recubierto totalmente por un pseudoarilo amarillo o rojo.

Habita en el matorral xerófilo y en el bosque tropical caducifolio, llegando a ser muy abundante; en altitudes de 600 a 1600 m. Florece de marzo a junio, con follaje de junio a diciembre.

De entre las especies del género, ésta es una de las de más amplia distribución, pues su área se extiende de Zacatecas, Coahuila y Tamaulipas a la península de Yucatán y Guatemala. Frecuente y abundante en algunas porciones de la cuenca del Balsas y sobre todo en Oaxaca. 


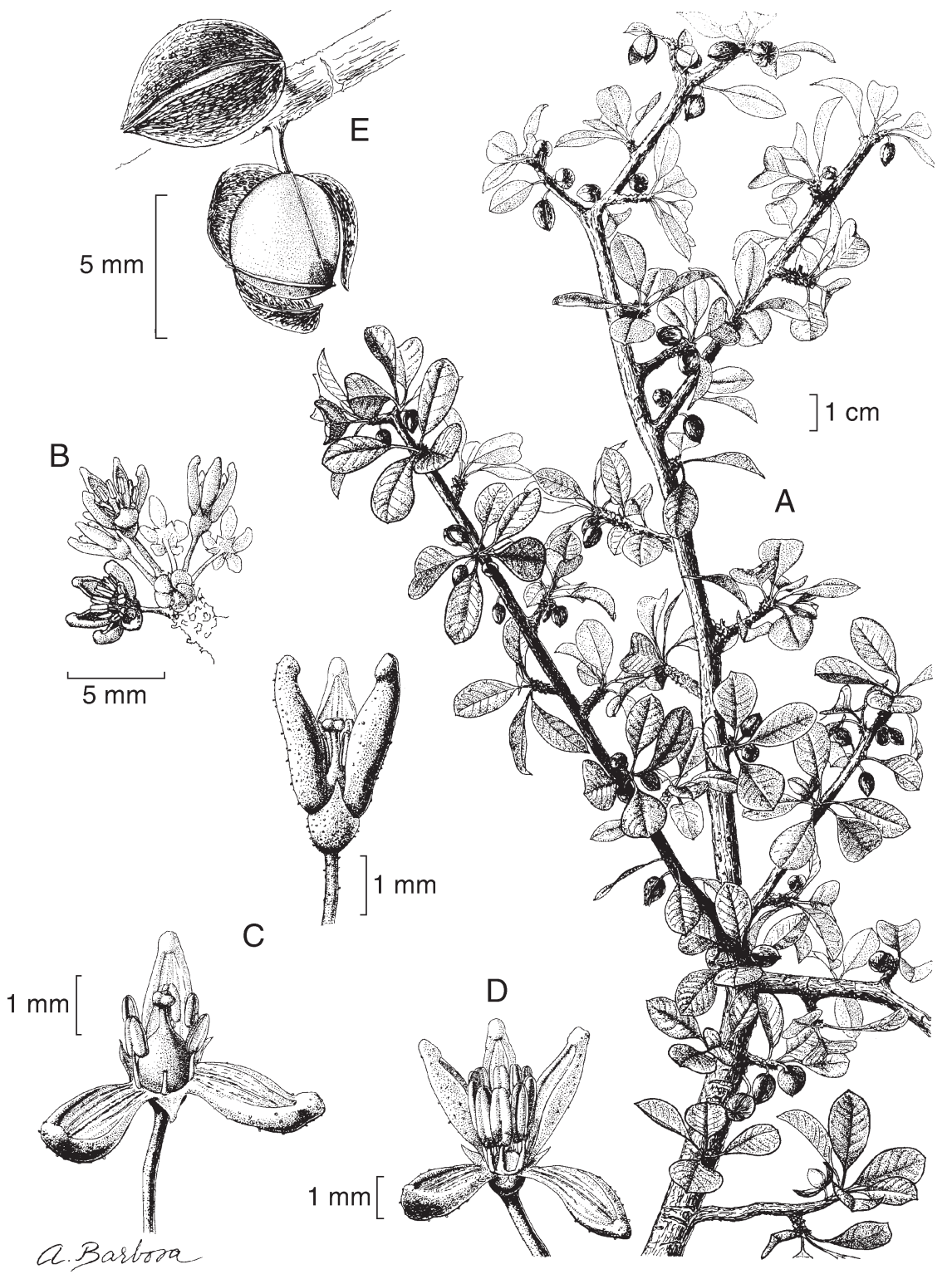

Bursera schlechtendalii Engl. A. rama con hojas y frutos; B. conjunto de flores masculinas en el extremo de una ramilla corta; C. flores femeninas; D. flor masculina; E. frutos. llustrado por Alfonso Barbosa y reproducido del fascículo 3 de la Flora del Bajío y de Regiones Adyacentes. 
Material examinado: OAXACA: Distrito Coixtlahuaca: La Huerta, $20 \mathrm{~km}$ al NE de Tepelmeme de Morelos, R. Cruz 2616 (ENCB); Concepción Buenavista, base del cerro Pluma, base del cañón del puente Santa Lucía, km 99-100 de la carrretera Tehuacán - Oaxaca (cuota), J. L. Panero y J .I. Calzada 4035 (IEB, MEXU, TEX); puente Calapa, municipio Tepelmeme de Morelos, A. Salinas 7710 (MEXU); faldas del cerro Pluma, km 100 del corte de la carretera Cuacnopalan - Oaxaca, A. Salinas 7720 (MEXU); subida del Cacalosúchil, cerro Verde, municipio Tepelmeme de Morelos, P. Tenorio et al. 6936 (MEXU, OAX); Agua El Tule, ladera E de cerro Verde, municipio Tepelmeme de Morelos, P. Tenorio et al. 8872 (MEXU); El Paraje, cerro Verde, municipio Tepelmeme de Morelos, P. Tenorio y L. Kelly 20154 (MEXU). Distrito Cuicatlán: brecha de Santiago Quiotepec a Cuicatlán, L. Alvarado et al. 1196 (MEXU); 5 km al NE de Cuicatlán, camino a Concepción Pápalo, municipio Cuicatlán, H. Arroyo 56 (ENCB), 68 (ENCB); 8 km al NE de Cuicatlán, camino a Concepción Pápalo, municipio Cuicatlán, H. Arroyo 59 (ENCB); $15 \mathrm{~km}$ al S de Dominguillo, carretera a Oaxaca, municipio Cuicatlán, H. Arroyo 61 (ENCB); $5 \mathrm{~km}$ al NW de Cuicatlán, camino a Cuicatlán, municipio Cuicatlán, H. Arroyo 65 (ENCB); $4 \mathrm{~km}$ al NE de la estación de F.F.C.C. El Venado, camino a Almoloyas, municipio San Pedro Jaltepetongo, H. Arroyo 122 (IEB, MEXU); 3 km al NE de Santa Catarina, municipio San Pedro Jaltepetongo, H. Arroyo 129 (ENCB); San José del Chilar, C. A. Cruz y R. García 2 (MEXU); loma del Zacatal, San José del Chilar, C. A. Cruz y R. García 84 (MEXU); Plan de beis, San José del Chilar, C. A. Cruz et al. 153 (MEXU), 156 (MEXU); barranca El Ciruelo, San José del Chilar, C. A. Cruz y E. San Pedro 690 (MEXU), 693 (MEXU), 891 (MEXU); barranca de las Tinajas, San

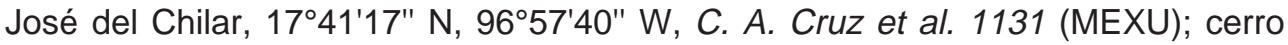

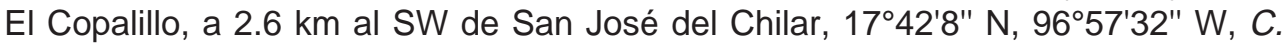
A. Cruz y E. San Pedro 1362 (MEXU); $12 \mathrm{~km}$ al SE de Dominguillo, por la carretera a Oaxaca, F. Chiang et al. F-163 (MEXU); $13 \mathrm{~km}$ al N de Cuicatlán, R. García 277 (OAX); $0.5 \mathrm{~km}$ al E de San José Aragón, R. García 232 (OAX); $5 \mathrm{~km}$ al SE de Cuicatlán, por la desviación a San Pedro Jocotipac, F. González Medrano et al. F-1562 (MEXU); $10 \mathrm{~km}$ de Santiago Quiotepec, por la brecha a Cuicatlán, E. M. Lira et al. 1698 (MEXU); terracería de Tomellín, hacia Santa María Texcatitlán, municipio Valerio Trujano, R. Medina et al. 1057 (MEXU); 5 km de San Pedro Jaltepetongo, cañada W, municipio San Pedro Jaltepeteongo, R. Medina et al. 1102 (MEXU); terracería de Santiago Quiotepec a Cuicatlán, $17^{\circ} 47^{\prime} \mathrm{N}, 96^{\circ} 57^{\prime} \mathrm{W}, R$. Medina et al. 1264 (IEB, MEXU); camino Cuicatlán - Reyes Pápalo, F. Miranda 4639 (MEXU); Tomellín Cañón, C. G. Pringle 5781 (MEXU); 4 km al E de Cuicatlán, sobre el camino al Pápalo, L. S. Rodríguez y A. Patiño 1398 (MEXU, ENCB); $15 \mathrm{~km}$ al $S$ de Dominguillo, municipio Cuicatlán, sobre el camino a Oaxaca, J. Rzedowski 34110 (ENCB, IEB); 12 km al SE de Dominguillo, municipio Cuicatlán, sobre la carretera a Oaxaca, J. Rzedowski 35463 (ENCB); $9 \mathrm{~km}$ al S de Dominguillo, municipio Cuicatlán, sobre la carretera a Oaxaca, J. Rzedowski 35655 (ENCB), 35657 (ENCB), 36523 (ENCB); $19 \mathrm{~km}$ al S de Tecomavaca, por la carretera rumbo a Oaxaca $A$. Salinas y O. Dorado F-2666 (MEXU); $6 \mathrm{~km}$ al $\mathrm{N}$ de Cuicatlán, por la carretera 131 y $2.5 \mathrm{~km}$ al W por la terracería que va a San Pedro Jocotipac, 
A. Salinas et al. 4252 (IEB, MEXU), 5720 (MEXU); barranca Matamba, $8 \mathrm{~km}$ al S de San Pedro Chicozapotes, brecha a Tutepetongo, A. Salinas et al. 6780 (MEXU); cerro Virgen de Guadalupe, al NW de Cuicatlán, por la brecha a San Pedro Jocotipac, A. Salinas et al. 7253 (MEXU); $6.2 \mathrm{~km}$ de Cuicatlán hacia Jocotipac, $L$. Schibli 112 (OAX); cerro El Castillo, al N de San Pedro Nodón, P. Tenorio y E. Martínez Correa 17774 (MEXU); 3 km al SW de Dominguillo, E. Torres 167 (OAX); $3 \mathrm{~km}$ al NE de Cuicatlán, I. Trejo 1601 (MEXU); San Pedro, municipio Cuicatlán, F. Ventura 15297 (ENCB); Tomellín, municipio Cuicatlán, F. Ventura 15299 (ENCB); El Puente Viejo, municipio Nacaltepec, F. Ventura 15304 (ENCB, IEB); El Mirador, cerca de San Juan Tonaltepec, municipio Santiago Nacaltepec, F. Ventura 15312 (ENCB, XAL); Quiotepec, cerca de F.F.C.C., antes de pasar el río, municipio Cuicatlán, F. Ventura 15347 (ENCB, IEB); camino de Pápalo, cerca de la desviación a Quiotepec, municipio Cuicatlán, F. Ventura 16429 (ENCB, MEXU); Dominguillo, municipio Cuicatlán, F. Ventura 16432 (ENCB); San José del Chilar, municipio Cuicatlán, F. Ventura 16440 (ENCB, MEXU); 6 km al S de Santiago Dominguillo, municipio Cuicatlán, S. Zamudio y E. Pérez 9168 (IEB, MEXU). Distrito Etla: al NW de San Juan Bautista Jayacatlán, $9 \mathrm{~km}$ después del poblado, L. Alvarado et al. 181 (MEXU); $2 \mathrm{~km}$ al $\mathrm{N}$ de El Parián, sobre el río, dirección $\mathrm{N}$, municipio Telixtlahuaca, H. Arroyo 113 (ENCB, IEB, MEXU); $1-2 \mathrm{~km}$ al $\mathrm{N}$ de Anona, al N de El Parián, A. Salinas y E. Martínez Correa 6275 (MEXU); El Parián, municipio Telixtlahuaca, F. Ventura 15457 (ENCB, MEXU, UC); Faustino G. Olivera, municipio Telixtlahuaca, F. Ventura 15463 (ENCB, MEXU); km 30, municipio Jayacatlán, $F$. Ventura 15469 (ENCB, MEXU, OAX, UAMIZ). Distrito Ixtlán: camino a El Carrizal, Macuiltianguis, Oaxaca, R. Lucero L75 (ENCB). Distrito Teotitlán: $1 \mathrm{~km}$ al W de San Martín Toxpalan, municipio Teotitlán del Camino, H. Arroyo 18 (ENCB, MEXU); $2 \mathrm{~km}$ al $\mathrm{N}$ de San Martín Toxpalan, municipio Teotitlán del Camino, H. Arroyo 20 (ENCB); $3 \mathrm{~km}$ al $\mathrm{N}$ de San Martín Toxpalan, municipio Teotitlán del Camino, $H$. Arroyo 25 (ENCB); $1 / 2 \mathrm{~km}$ al $\mathrm{S}$ de la desviación a Santiago Quiotepec, municipio Santa María Ixcatlán, $H$. Arroyo 41 (ENCB, MEXU); Cerro Nahualtepec, $8 \mathrm{~km}$ al NW de San Gabriel Casa Blanca, A. García et al. 3480 (IEB, MEXU); 3-8 mi W of San Antonio, Teotitlán, H. S. Gentry 22420 (MEXU); 1 km después de San Martín Toxpalan, rumbo a Cuicatlán, F. González Medrano et al. F-1160 (MEXU); 5 km al SW de Tecomavaca, S. Ramírez 353 (OAX); $5 \mathrm{~km}$ al N de Tecomavaca, sobre la carretera a Teotitlán del Camino, J. Rzedowski 32860 (ENCB, MEXU), 32865 (ENCB, MEXU); $2 \mathrm{~km}$ al W de San Gabriel Casa Blanca, A. Salinas et al. 4172 (IEB, MEXU); río Xiquila, Tierra Grande, $10 \mathrm{~km}$ al S de San Ignacio Mejía, 2 ó $3 \mathrm{~km}$ al E por el río, A. Salinas et al. 4529 (IEB, MEXU); $3 \mathrm{~km}$ adelante de Santiago Quiotepec, carretera rumbo a Tehuacán, A. Salinas 4873 (MEXU); $5.5 \mathrm{~km}$ de Tecomavaca hacia Ixcatlán, L. Schibli 88 (OAX); $6 \mathrm{~km}$ SE of Teotitlán on hwy, between Tehuacán and Telixtlahuaca, W. D. Stevens y E. Martínez 25205 (IEB, MEXU); Las Salinas, barranca Paso Bandera, brecha de San Antonio Nanahuatipam a Calapa, P. Tenorio et al. 20448 (MEXU); 11.2 km de Teotitlán, E. Torres 13 (OAX); puente del Río Salado, municipio de Tecomavaca, F. Ventura 15324 (ENCB, MEXU); Santiago Viejo, municipio Tecomavaca, F. Ventura 15331 (ENCB, IEB); 
camino a Telixtlahuaca, municipio San Martín Toxpalan, F. Ventura 15332 (ENCB); cerro al W de San Juan de Los Cues, municipio San Juan de Los Cues, F. Ventura 15342 (ENCB, MEXU); 4 mi S of Tecomavaca, G. L. Webster et al. 20098 (MEXU). PUEBLA: Municipio Ajalpan: Ajalpan, L. W. Boege 2188 (MEXU). Municipio Caltepec: Tlacuilotepec, C. A. Purpus 4052 (UC); Planes de San Miguel, F. Ventura 15392 (ENCB). Municipio Coxcatlán: $4 \mathrm{~km}$ al $\mathrm{S}$ de Coxcatlán, F. Chiang et al. F-2373 (MEXU); $45 \mathrm{~km}$ al SE de Tehuacán, $3.5 \mathrm{~km}$ al SE de Coxcatlán, camino a Teotitlán del Camino, A. C. Gibson 3445 (ENCB); $4 \mathrm{~km}$ al S de Coxcatlán, G. Gómez et al. 14 (MEXU); 3 mi N of Teotitlán, C. T. Mason et al. 3019 (ENCB, UC); cerca de Tilapa, J. Rzedowski 28162 (ENCB); 2 km al S de San Rafael, J. Rzedowski 36528 (ENCB); 3 km al SE de San Rafael, J. Rzedowski 53869 (IEB); Tilapa, F. Ventura 15354 (ENCB); San Rafael, F. Ventura 15361 (ENCB, MEXU); Pueblo Nuevo, F. Ventura 15381 (ENCB, MEXU), 15383 (ENCB, MEXU); $6.5 \mathrm{mi}$ NW of Teotitlán, near of border of Oaxaca, G. L. Webster y S. Lynch 17242 (MEXU). Municipio San José Miahuatlán: cerro Petlanco, $9 \mathrm{~km}$ al SE de Axusco, F. Chiang et al. F-2233 (MEXU); $10 \mathrm{~km}$ adelante de Axusco, por la terracería rumbo a cerro Petlanco, F. Chiang et al. F-2476 (MEXU); cerro Tepetroje, $6 \mathrm{~km}$ al W de Axusco, A. García et al. 3345 (MEXU); en la carretera Cuacnopalan - Oaxaca, antes del puente Calapa, en el límite de los estados de Puebla y Oaxaca, J. D. Hernández $B$-236 (IEB); 9 km al NW de Axusco, por la terracería rumbo a San José Miahuatlán, A. Salinas et al. 4561 (MEXU); 6-7 km al SW de San José Axusco, A. Salinas et al. 4803 (MEXU); cerro Petlanco, 9-10 km al S de Axusco, A. Salinas y V. Juárez 6962 (MEXU); W of the Rio Salado on and around Petlanco, C. E. Smith Jr. et al. 3659 (MEXU); cerro Xancantitla, al W de Axusco, P. Tenorio y E. Martínez Correa 17374 (MEXU). Municipio Tehuacán: $1.5 \mathrm{~km}$ al este de Tehuacán, $H$. Arroyo 6 (IEB); $4.4 \mathrm{~km}$ al E de San Pablo Tepetzingo, F. Chiang et al. F-58 (ENCB, MEXU); $6 \mathrm{~km}$ al SW de Tehuacán, por la carretera a Huajuapam de León, F. Chiang et al. F-333 (ENCB, MEXU); al W de El Riego, Tehuacán, F. Miranda 4442 (MEXU); hills E of Tehuacan, J. N. Rose et al. 9974 (MEXU); cerros al W de Tehuacán, J. Rzedowski 9014 (ENCB); 2 km al SW de Tehuacán, carretera a Coxcatlán, J. Rzedowski 28156 (ENCB), 28157 (ENCB); 8 km al SW de Tehuacán, sobre la carretera a Huajuapan de León, J. Rzedowski 35630 (ENCB), 35631 (ENCB); San José Tochapa, F. Ventura 15276 (ENCB); cerro Colorado, cerca de San Pablo, F. Ventura 15384 (ENCB, MEXU); $5.5 \mathrm{mi}$ SW of Tehuacán, G. L. Webster et al. 17306 (MEXU). Municipio Zapotitlán: camino a Los Reyes Mezontla, $3 \mathrm{~km}$ al E de la carretera Zapotitlán - Huajuapan, H. Arroyo 136 (ENCB); SE slope on S side of hwy 125, 2/10 mi by road $\mathrm{E}$ of $\mathrm{km} 16$ marker between San Antonio Texcala and

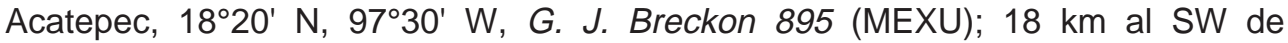
Tehuacán, cerca de Zapotitlán Salinas, carretera que va a Huajuapan de León, F. González Medrano et al. F-1365 (MEXU); sur del desierto del Valle de Tehuacán, Zapotitlán Salinas, J. Meléndez 16 (ENCB); 4 km al NW de Los Reyes Mezontla, $P$. Tenorio et al. 17364 (MEXU); ranchería El Tablón, 2 km al SW de Zapotitlán Salinas, A. Valiente et al. 553 (MEXU); Jardín Botánico de Cactáceas y Suculentas de Zapotitlán Salinas, A. Valiente y P. Díaz-Maeda 714 (MEXU); San Antonio 


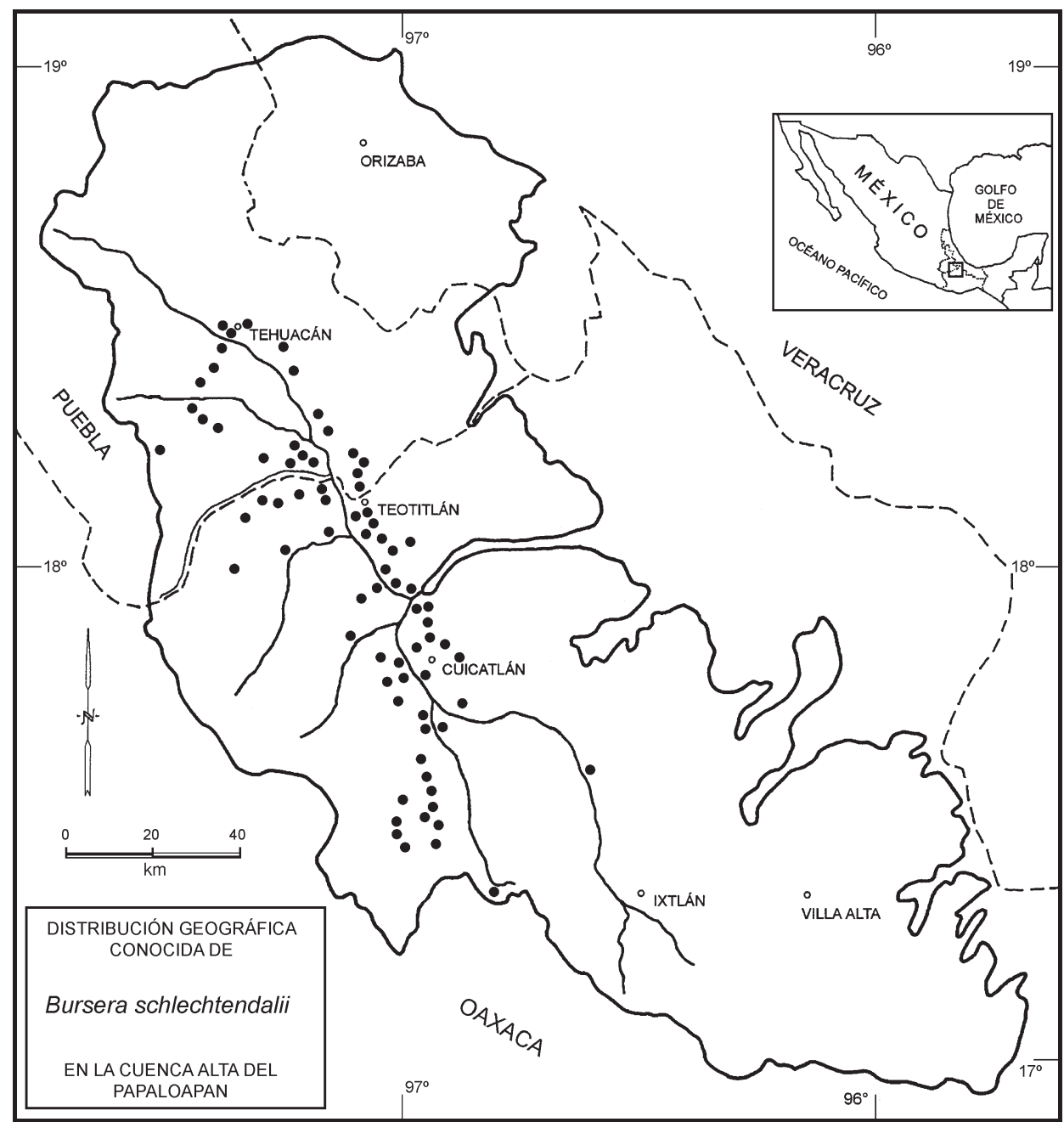

Texcala, F. Ventura 15260 (ENCB, MEXU). Municipio Zinacatapec: $7 \mathrm{~km}$ al S de Zinacatepec, carretera a Oaxaca, O. Dorado y A. Salinas F-2967 (MEXU); Mazatepec, F. Ventura 15375 (ENCB).

20. Bursera simaruba (L.) Sarg., Gard. \& For. 3: 260. 1890. Pistacia simaruba L., Sp. Pl. p. 1026. 1753. B. gummifera L., Sp. Pl. ed. 2 p. 471. 1762. (nombre basado en Pistacia simaruba). Terebinthus simaruba (L.) W. F. Wight in Rose, Contr. U.S. Nat. Herb. 10: 122. 1906. Elaphrium simaruba (L.) Rose, North Amer. Fl. 25: 246. 1911. Lectotipo: lámina No. 199 del Catalogus Plantarum de H. Sloane, ilustrando una planta procedente de Jamaica, designado por R. H. Howard en Flora of the Lesser Antilles 4: 577. 1988. 
Rzedowski et al.: Las especies de Bursera de la cuenca del río Papaloapan, México

Terebinthus brownii Jacq., Enum. Pl. Carib. p. 18. 1760. Tipo por definirse.

Burseria gummifera Jacq., Select. Stirp. Amer. Hist. p. 94. t. 65.1763 (variante ortográfica de Bursera gummifera).

Bursera integerrima (Tul.) Tr. \& Planch., Ann. Sci. Nat. 5. sér. 14: 303. 1872. Elaphrium integerrimum Tul., Ann. Sci. Nat. 3. sér. 6: 368. 1846. Tipo: Colombia: Quindio, Nlle. Granade, J. Goudot s. n. (holotipo P).

Nombres comunes registrados en la zona: chaca, mulato, palo mulato, thiun (lengua chinanteca).

Nombres comunes registrados fuera de la zona de estudio: chakaj, jiote, tzaca.

Árbol dioico o a veces polígamo-dioico, de 4 a 30(35)m de alto, resinoso y aromático al estrujarse; tronco hasta de $1 \mathrm{~m}$ de diámetro, su corteza externa rojiza, café-rojiza o verdosa, exfoliante en tiras delgadas, ramillas jóvenes glabras o pubescentes; hojas elípticas a oblongas en contorno general, hasta de $45 \mathrm{~cm}$ de largo y $30 \mathrm{~cm}$ de ancho, imparipinnadas, peciolo acojinado en la base, hasta de $10 \mathrm{~cm}$ de largo, raquis sin alas, sus segmentos de 2 a $5 \mathrm{~cm}$ de largo, peciólulos de (2)3 a 13(30) $\mathrm{mm}$ de largo, con (3)5 a 9(13) foliolos mayormente lanceolados u oblongos, variando a ovados, obovados o elípticos, los laterales por lo común notablemente asimétricos, de 4 a $9(15) \mathrm{cm}$ de largo y 1.8 a $3.5(8) \mathrm{cm}$ de ancho, por lo general acuminados a caudado-acuminados en el ápice, base cuneada a truncada, comúnmente oblicua, margen entero, con (6)8 a 15 nervaduras secundarias arqueadas hacia el extremo distal y conformando una nervadura marginal más o menos bien definida de cada lado, prominentes en el envés, las nervaduras terciarias anastomosándose, firmemente membranáceos a cartáceos, de color verde oscuro y a menudo brillantes en el haz, más pálidos y opacos en el envés, totalmente glabros a pubescentes en ambas caras; flores masculinas agrupadas en panículas tirsiformes o racimos hasta de $20(28) \mathrm{cm}$ de largo, pedicelos filiformes, de 2 a $5 \mathrm{~mm}$ de largo, flores pentámeras o rara vez tetrámeras, lóbulos del cáliz triangular-ovados, de ca. $0.6 \mathrm{~mm}$ de largo, pétalos elípticos, de color crema, blanquecino o verdoso, de 2 a $3 \mathrm{~m}$ de largo, cuculados, encorvados en el ápice, filamentos de 1.5 a $2 \mathrm{~mm}$ de largo, anteras oblongas, de ca. $1 \mathrm{~mm}$ de largo, ovario vestigial o ausente; inflorescencias femeninas hasta de $14 \mathrm{~cm}$ de largo, con frecuencia racemiformes, las flores trímeras, rara vez tetrámeras o pentámeras, similares a las masculinas, pétalos anchamente elípticos, estaminodios con filamentos de menos de $1 \mathrm{~mm}$ de largo, anteras también de menos de $1 \mathrm{~mm}$ de largo, ovario trilocular, glabro, estigmas 3; flores hermafroditas a veces presentes, similares a las masculinas, pero con el pistilo funcional; infrutescencia hasta de $15 \mathrm{~cm}$ de largo, con pedúnculos y pedicelos notablemente engrosados, estos últimos hasta de $15 \mathrm{~mm}$ de largo, fruto trivalvado, globoso u ovoide y ligeramente 


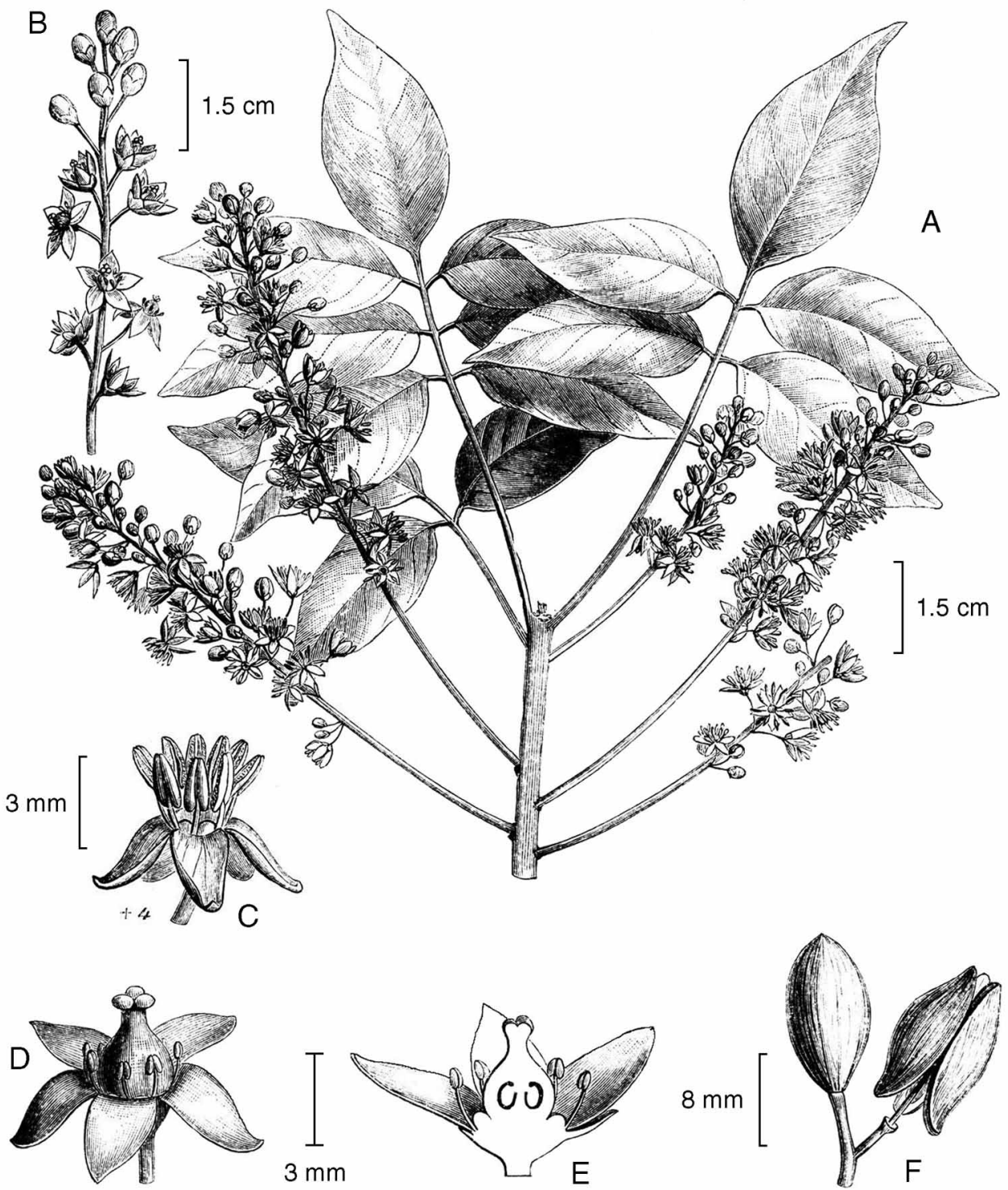

Bursera simaruba (L.) Sarg. A. rama con hojas e inflorescencias masculinas; B. ramilla de inflorescencia femenina; C. flor masculina; D. flor femenina; E. corte longitudinal de la flor femenina; F. 2 frutos. Reproducido con algunas modificaciones de Die natürlichen

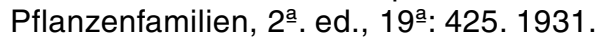


triquetro, glabro, de 10 a $15 \mathrm{~mm}$ de largo, rojizo o café-rojizo en la madurez, el hueso totalmente cubierto por un pseudoarilo rojo o anaranjado.

Elemento frecuente del bosque tropical perennifolio y subcaducifolio, penetrando marginalmente al bosque mesófilo de montaña y a algunos encinares; participa asimismo de ciertas comunidades secundarias y se le ve a menudo en cercas vivas en las porciones cálido-húmedas de la región de estudio, en altitudes entre 400 y 1200 (en cultivo hasta 1750) m. El reducido número de colectas de esta especie es el reflejo del relativamente pobre nivel de exploración de las porciones más húmedas de la cuenca superior del Papaloapan. Florece de febrero a mayo (agosto). Se encuentra sin follaje de (diciembre) enero a febrero (abril); el largo de este período varía mucho con el clima.

Especie distribuida desde el norte de México y extremo sureste de Estados Unidos, a través de Centroamérica y las Antillas, hasta el norte de Brasil. En México conocida de Sonora y Tamaulipas a Chiapas y Yucatán.

Material examinado: OAXACA: Distrito Choapan: al S del poblado Santiago Jalahui, senda para la parcela de Beto Morales, carretera a Latani, municipio San Juan Lalana, J. I. Calzada y S. Anta 15569 (MEXU). Distrito Tuxtepec: adelante de Jalapa de Díaz, camino a San Bartolo Ayautla, entre arroyo Guaje y loma Naranjo, 1803' N, 96³8' W, R. Medina et al. 1282 (IEB, MEXU); 16 km delante de Jalapa de Díaz, camino a San Bartolomé Ayautla, cerca de la hacienda cafetalera La Carlota, $18^{\circ} 02^{\prime} \mathrm{N}, 96^{\circ} 41^{\prime} \mathrm{W}$, R. Medina et al. 1283 (IEB, MEXU); $13 \mathrm{~km}$ adelante de Jalapa de Díaz, camino a San Bartolomé, $18^{\circ} 05^{\prime} \mathrm{N}, 96^{\circ} 12^{\prime} \mathrm{W}, \mathrm{R}$. Medina et al. 1284 (IEB, MEXU); $15 \mathrm{~km}$ de Jalapa de Díaz, 1802' N, 96³4' W, R. Medina et al. 1285 (IEB, MEXU). VERACRUZ: Municipio Acultzingo, camino vecinal del poblado, por la carretera principal entrando por la parada El Mezquite, $H$. Oliva $y$ F. Ramón HOR-1269 (IEB). Municipio Coetzala, Coetzala, V. Vázquez 394 (ENCB, IEB, XAL).

A lo largo de toda su área de distribución, las poblaciones de este taxon varían notablemente en cuanto a la pubescencia de sus ramas, hojas e inflorescencias, sin que se comprenda el significado de tales diferencias.

Bursera simaruba es el elemento central de un grupo de especies, de las que muchas carecen todavía de una circunscripción conocida y entendida. Bullock (op. cit.) excluyó este binomio de la flora de nuestro país y usó el nombre de $B$. ovalifolia (Schltdl.) Engl. para un gran conjunto de plantas mexicanas, que seguramente está integrado por varios taxa. El tipo de Elaphrium ovalifolium Schltdl. es un espécimen estéril procedente de localidad indefinida y aunque su identidad es difícil de establecer, no es conespecífico con los árboles de Veracruz y del norte de Oaxaca, que son más afines a las plantas de las Antillas, de donde fue descrita B. simaruba. 


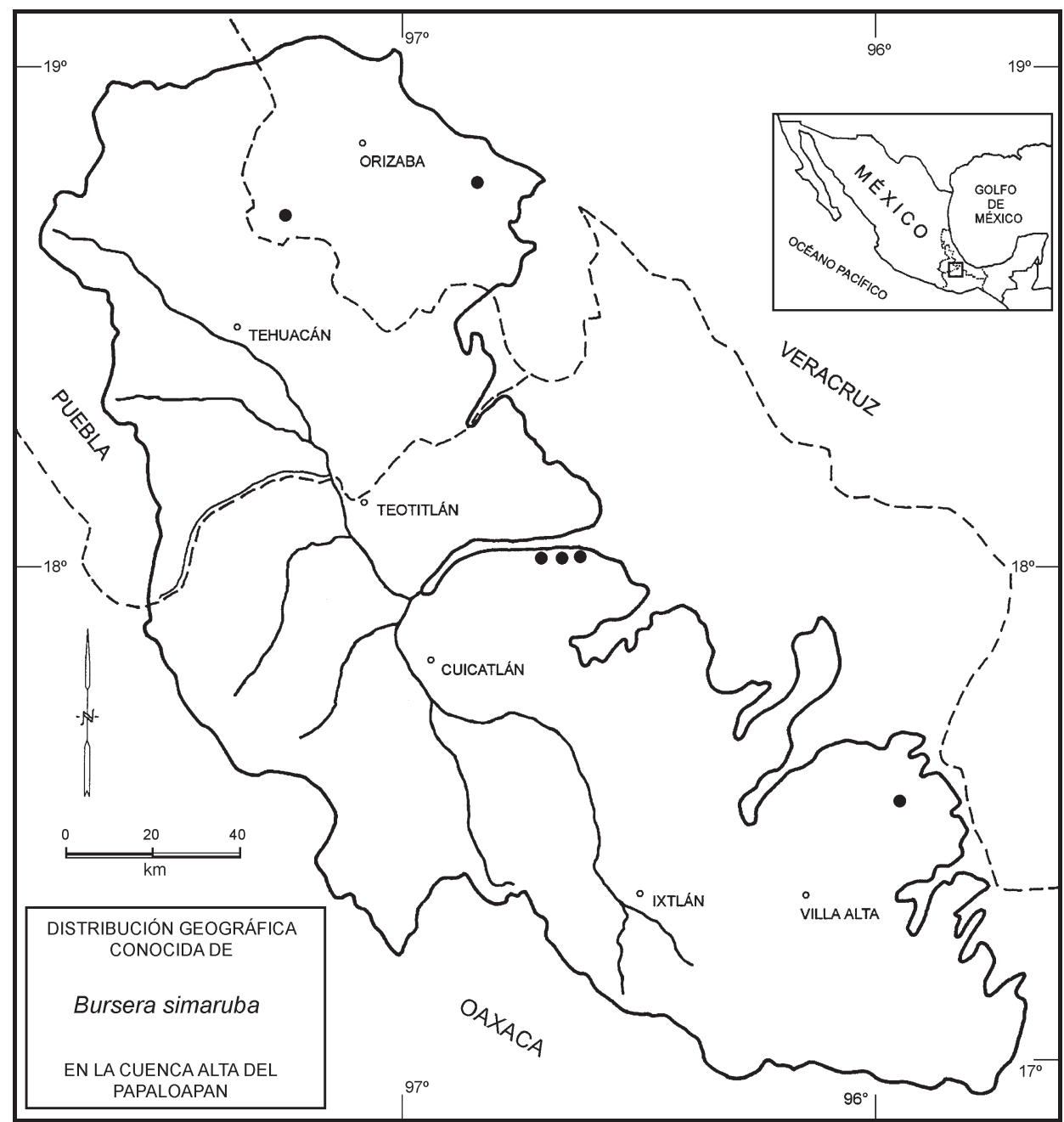

La especie se usa con mucha frecuencia en el establecimiento de cercas vivas. También es común su empleo en la medicina tradicional, incluyendo la veterinaria. La madera no es muy apreciada, pues si bien es ligera y fácil de trabajar, tiende a mancharse y no es durable. En la literatura se indica que se emplea para la fabricación de chapas, de madera terciada y comprimida, de cajas, cerillos, palillos para dientes y para la construcción ligera.

21. Bursera submoniliformis Engl., DC. Monogr. Phaner. 4: 55. 1883. Terebinthus submoniliformis Rose, Contr. U.S. Nat. Herb. 10: 122. 1906. Elaphrium submoniliforme (Engl.) L. Marchand ex Rose, North Amer. FI. 25: 255. 1911. 
Tipo: México: Oaxaca: río Vueltas, V. 1842, F. M. Liebmann 76 (C), lectotipo que aquí se designa; isolectotipo $(P)$.

Nombres comunes registrados en la zona: copal, copalillo, copalillo blanco. Nombres comunes registrados fuera de la zona de estudio: copalcahuic, tecomaca.

Árbol dioico de (2.5) 4 a 9(12) $\mathrm{m}$ de alto, resinoso pero de aroma desagradable al estrujarse; tronco hasta de $40 \mathrm{~cm}$ de diámetro, su corteza gris a gris-rojiza, lisa, no exfoliante, ramillas rojizas, las lignificadas glabras, las jóvenes densamente vilosas y con abundantes glándulas sésiles o casi sésiles; hojas fasciculadas en los extremos de ramillas cortas, o bien, esparcidas sobre ramillas vigorosas tiernas, precedidas en su aparición por una roseta de catafilos triangulares de 2.5 a $8(13) \mathrm{mm}$ de largo, pubérulos en ambas caras, precozmente caducos, hojas imparipinnadas, oblongas a elípticas en contorno general, hasta de $15(20) \mathrm{cm}$ de largo y 6(7) $\mathrm{cm}$ de ancho, peciolo hasta de 4(5) $\mathrm{cm}$ de largo, foliolos 9 a 13(17), raquis por lo general angostamente alado, las alas de 0.5 a $2(3.5) \mathrm{mm}$ de ancho, enteras, peciólulos de 0 a $1 \mathrm{~mm}$ de largo, foliolos por lo común oblongos, a veces elípticos o lanceolados, el terminal subrómbico, de (1.3)2 a 3.5(5) cm de largo y (5)6 a 14(20) mm de ancho, ápice generalmente agudo u obtuso, a veces variando a redondeado o acuminado, base truncada a cuneada, margen serrado a crenado, en ocasiones subentero, de textura membranácea a cartácea, de color verde olivo y densamente velutinos en el haz, muchos más claros, a menudo grisáceos y densamente tomentosos en el envés; inflorescencias en forma de panículas laxas, tirsiformes, hasta de 10(12) cm de largo, las femeninas más cortas y menos ramificadas, densamente vilosas, bracteolas lineares a filiformes, hasta de $5 \mathrm{~mm}$ de largo, pedicelos de 1 a $3 \mathrm{~mm}$ de largo; flores masculinas tetrámeras, segmentos del cáliz prácticamente libres desde la base, lineares a angostamente lanceolados, de 2 a $4 \mathrm{~mm}$ de largo, pilosos en ambas caras, pétalos oblanceolados o elípticos, de 3 a $4 \mathrm{~mm}$ de largo, amarillentos con el centro más oscuro, pilosos por fuera, glabros por dentro, estambres 8, filamentos de 1 a $1.5 \mathrm{~mm}$ de largo, anteras oblongas, de ca. $1 \mathrm{~mm}$ de largo, gineceo vestigial; flores femeninas similares a las masculinas, pero con los pétalos angostamente oblongos, más cortos que los segmentos del cáliz, anteras de los estaminodios de ca. $0.5 \mathrm{~mm}$ de largo, ovario bilocular, rojizo, densamente velutino, estigmas 2; fruto bivalvado, ovoide a obovoide, de 7.5 a $12 \mathrm{~mm}$ de largo y 6 a $7 \mathrm{~mm}$ de ancho, a menudo apiculado, densamente velutino, hueso elipsoide, de 6 a $9 \mathrm{~mm}$ de largo y 4 a $6 \mathrm{~mm}$ de diámetro, total o casi totalmente cubierto por el pseudoarilo amarillo o anaranjado.

Habitante común y no pocas veces codominante del bosque tropical caducifolio entre 500 y 1400 (1600) m. Florece de mayo a julio. Se encuentra desprovisto de follaje de noviembre a mayo. 


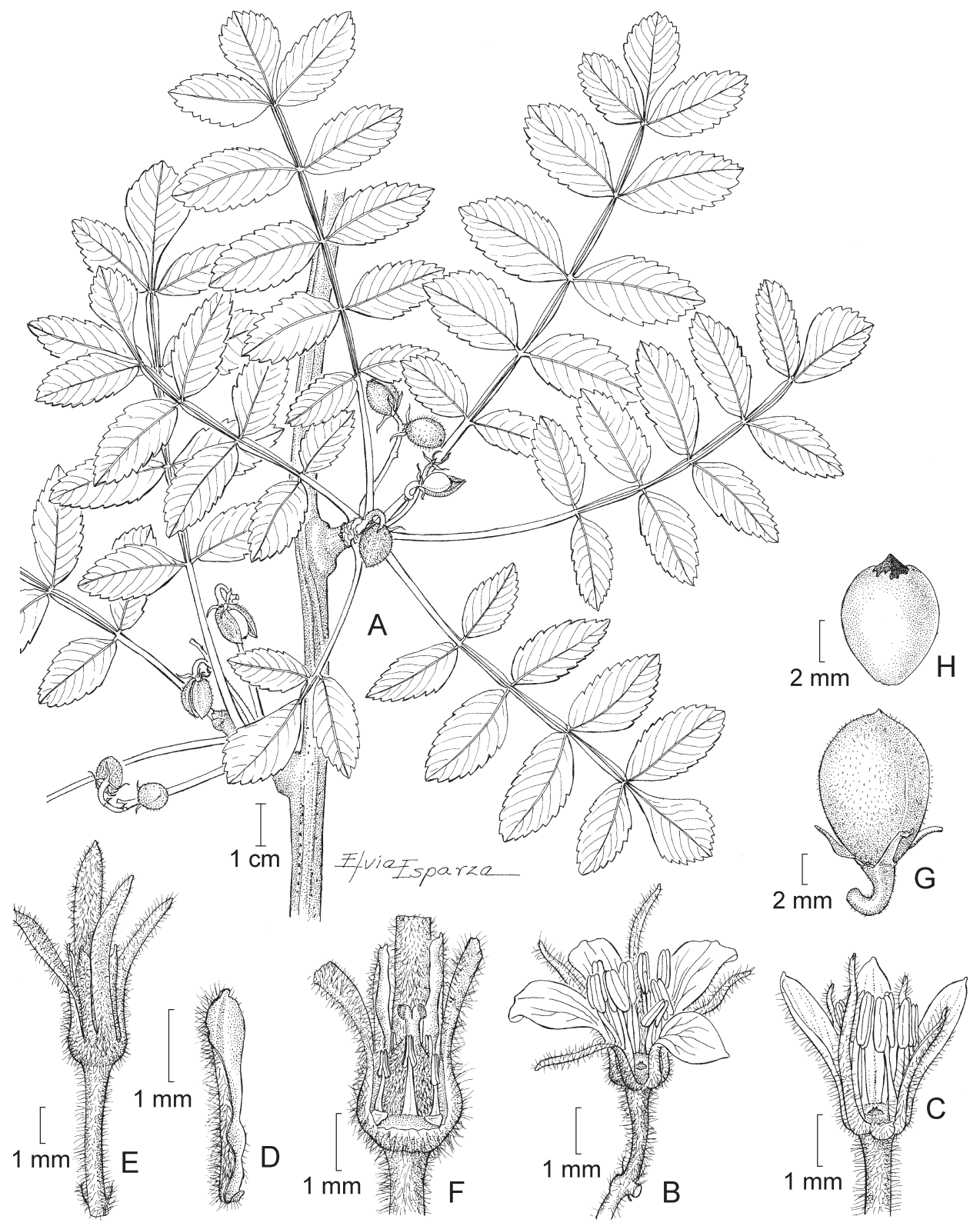

Bursera submoniliformis Engl. A. rama con hojas y frutos; B. flor masculina; C. flor masculina desprovista de un pétalo; D. pétalo de la flor femenina; E. flor femenina en vista externa; F. flor femenina desprovista de un segmento del cáliz, de 2 pétalos y de varios estaminodios; G. fruto; H. hueso. Ilustrado por Elvia Esparza. 
Especie endémica de México, conocida de Michoacán, Estado de México, Guerrero, Morelos, Puebla y Oaxaca, aparentemente restringida en su distribución a las cuencas del Balsas y del Papaloapan.

Material examinado: OAXACA: Distrito Coixtlahuaca: km 78.5 carretera Cuacnopalan - Oaxaca, M. Ambrosio et al. 594 (IEB, MEXU); La Huerta, 20 km al NE de Tepelmeme de Morelos, R. Cruz 2620 (ENCB); Agua El Tule, ladera E de cerro Verde, municipio Tepelmeme de Morelos, P. Tenorio et al. 8878 (MEXU); El Paraje, cerro Verde, P. Tenorio y L. Kelly 20163 (MEXU). Distrito Cuicatlán: brecha de Santiago Quiotepec a Cuicatlán, L. Alvarado et al. 193 (MEXU); Dominguillo, El Tetechal, M. Ambrosio 568 (IEB); 2 km al NW de la desviación a Quiotepec, municipio Cuicatlán, H. Arroyo 46 (ENCB, MEXU); $2 \mathrm{~km}$ al S de San Pedro, municipio Cuicatlán, H. Arroyo 48 (ENCB, IEB, MEXU); $3 \mathrm{~km}$ al $\mathrm{N}$ de Cuicatlán, camino a Concepción Pápalo, municipio Cuicatlán, H. Arroyo 53 (ENCB, IEB); $5 \mathrm{~km}$ al NW de Cuicatlán, camino a Quiotepec, municipio Cuicatlán, $H$. Arroyo 67 (ENCB); $3 \mathrm{~km}$ al W de la estación de F.F.C.C. El Venado, camino a Almoloyas, municipio Nacaltepec, H. Arroyo 118 (ENCB, IEB, MEXU); barranca de las Guacamayas, 17²0'36" N, 9657'55" W, J. Calónico et al. 23906 (MEXU); estación de Almoloyas, Cañón de Tomellín, C. Conzatti 2020a (MEXU), 2020b (MEXU); Plan de beis, San José del Chilar, C. A. Cruz et al. 150 (MEXU), 164 (MEXU); El Campanario, San José del Chilar, C. A. Cruz et al. 205 (MEXU); $5 \mathrm{~km}$ al SE de Cuicatlán, por la desviación a San Pedro Jocotipac, F. Chiang et al. F-1526 (MEXU); río Grande, a 5 km de Cuicatlán, Cañón de Tomellín, A. Delgado et al. 561 (ENCB, MEXU); km 20 Cuicatlán - Telixtlahuaca, P. Guerrero 180 (IEB); Río Chiquito, a $16 \mathrm{~km}$ de Santiago Quiotepec, brecha a Cuicatlán, E. M. Lira et al. 1701 (MEXU); $6 \mathrm{~km}$ después de Santa María Almoloyas, camino a la estación El Venado, $17^{\circ} 32^{\prime} 31^{\prime \prime} \mathrm{N}, 9^{\circ} 03^{\prime} 13^{\prime \prime} \mathrm{W}$, R. Medina et al. 1069a (MEXU); $5 \mathrm{~km}$ de San Pedro Jaltepetongo, cañada W, R. Medina et al. 1097 (MEXU); terracería de Santiago Quiotepec a Cuicatlán, $17^{\circ} 47^{\prime} \mathrm{N}, 96^{\circ} 57^{\prime}$ W, R. Medina et al. 1265 (IEB, MEXU), 1271 (IEB, MEXU); $14 \mathrm{~km}$ al S de Santiago Dominguillo - Santiago Nacaltepec, R. Medina et al. 1276a (MEXU); laderas al SE de Cuicatlán, F. Miranda 4554 (MEXU); $1 \mathrm{~km}$ al E de Cuicatlán, sobre el camino a Pápalo, L. S. Rodríguez y A. Patiño 1394 (ENCB), 1395 (ENCB); 15 km al S de Dominguillo, municipio Cuicatlán, sobre la carretera a Oaxaca, J. Rzedowski 34939 (ENCB, IEB, MEXU); $12 \mathrm{~km}$ al SE de Dominguillo, sobre la carretera a Oaxaca, J. Rzedowski 35464 (ENCB); 9 $\mathrm{km}$ al S de Dominguillo, sobre la carretera a Oaxaca, J. Rzedowski 36524 (ENCB); $6 \mathrm{~km}$ al $\mathrm{N}$ de Cuicatlán, carretera 131 y $2.5 \mathrm{~km}$ al W por la terracería rumbo a San Pedro Jocotipac, A. Salinas et al. 4250 (IEB, MEXU, OAX); $6.2 \mathrm{~km}$ de Cuicatlán hacia Jocotipac, L. Schibli 110 (OAX); $3.2 \mathrm{~km}$ al S de Valerio Trujano, E. Torres 77 (OAX); $11 \mathrm{~km}$ al $\mathrm{N}$ de Tonaltepec, carretera Telixtlahuaca - Teotitlán, municipio Santiago Nacaltepec, R. Torres et al. 9974 (MEXU); Tomellín, municipio Cuicatlán, F. Ventura 15301 (ENCB, MEXU); El Mirador, F. Ventura 15316 (ENCB); Dominguillo, municipio Cuicatlán, F. Ventura 15319 (ENCB, MEXU); Quiotepec, cerca de F.F.C.C. antes de pasar el río, F. Ventura 15346 (ENCB, MEXU, UC); 
camino de Pápalo, cerca de la desviación a Quiotepec, municipio Cuicatlán, $F$. Ventura 16427 (ENCB, MEXU); Dominguillo, F. Ventura 16436 (ENCB, MEXU); San José del Chilar, F. Ventura 16441 (ENCB, MEXU). Distrito Etla: Jayacatlán, M. Ambrosio et al. 585 (IEB, MEXU); barranca de los Horcones, municipio Jayacatlán, M. Ambrosio y B. Brosi 595 (IEB), 596 (IEB), 603 (IEB), 604 (IEB), 609 (IEB); ibid., M. Ambrosio et al. 608 (IEB), 612 (IEB); La Curva, carretera a Etla, municipio Jayacatlán, M. Ambrosio y B. Brosi 598 (IEB); desviación carretera Atatlahuaca, municipio S.J.B. Jayacatlán, M. Ambrosio et al. 607 (IEB, MEXU); 8 km por la terracería a San Juan Bautista Jayacatlán, R. Medina et al. 1223 (IEB, MEXU), 1224 (IEB, MEXU); El Progreso, municipio Jayacatlán, F. Ventura 15465 (ENCB, IEB, MEXU). Distrito Teotitlán: $1 \mathrm{~km}$ al SW de Teotitlán del Camino, $H$. Arroyo 16 (ENCB); $2 \mathrm{~km}$ al $\mathrm{N}$ de San Martín Toxpalan, municipio Teotitlán del Camino, $H$. Arroyo 21 (ENCB); $3 \mathrm{~km}$ al W de Tecomavaca, H. Arroyo 30 (ENCB); $2 \mathrm{~km}$ al NW de San Juan de Los Cues, municipio San Juan de Los Cues, H. Arroyo 40 (ENCB, MEXU); $5 \mathrm{~km}$ al S de Teotitlán, por la carretera a San Juan de Los Cues, F. Chiang et al. F-2495 (MEXU); cerro Nahualtepec, $8 \mathrm{~km}$ al NW de San Gabriel Casa Blanca, A. García et al. 3462 (IEB, MEXU); 9 mi W of San Antonio, H. S. Gentry 22427 (MEXU); $3 \mathrm{~km}$ E of Teotitlán on hwy 182 to Huautla, C. A. Pendry y A. Reyes 960 (MEXU); $10 \mathrm{~km}$ al E de Teotitlán del Camino, camino a Huautla, L. S. Rodríguez y A. Patiño 1400 (ENCB, MEXU); $5 \mathrm{~km}$ al N de Tecomavaca, sobre la carretera a Teotitlán del Camino, J. Rzedowski 28166 (ENCB), 28167 (ENCB), 32858 (ENCB); $3 \mathrm{~km}$ al E de Teotitlán del Camino, sobre la carretera a Huautla, J. Rzedowski 35664 (ENCB, MEXU); río Seco - río Santiago, al SW de Tecomavaca, municipio de Santa María Ixcatlán, A. Salinas et al. 7206 (MEXU); 5.5 km de Tecomavaca hacia Ixcatlán, L. Schibli 88a (OAX); $6 \mathrm{~km}$ SE of Teotitlan on hwy, between Tehuacan Telixtlahuaca, W. D. Stevens y E. Martínez 25202 (MEXU); río Seco, $10 \mathrm{~km}$ al W de Tecomavaca, camino a Ixcatlán, P. Tenorio y E. Martínez Correa 17404 (MEXU); cerro La Mina, al SE de San Antonio Nanahuatipam, P. Tenorio et al. 20466 (MEXU); puente del Río Salado, municipio Tecomavaca, F. Ventura 15325 (ENCB); camino a Telixtlahuaca, cerca de San Martín Toxpalan, F. Ventura 15333 (ENCB, MEXU); cerro al oriente de San Juan de Los Cues, municipio San Juan de Los Cues, F. Ventura 15339 (ENCB, MEXU); camino a Huautla de Jiménez, municipio Teotitlán del Camino, F. Ventura 15355 (ENCB, MEXU); Ignacio Mejía, municipio Teotitlán, F. Ventura 15371 (ENCB, MEXU). PUEBLA: Municipio Ajalpan: $6 \mathrm{~km}$ al E de Ajalpan, F. Chiang et al. F-2198 (MEXU). Municipio Altepeji: $5 \mathrm{~km}$ al NW de Ajalpan, F. González Medrano et al. F-1448 (MEXU). Municipio Coxcatlán: $5 \mathrm{~km}$ al SE de San Rafael, carretera Coxcatlán Tilapa, H. Arroyo 35 (ENCB, MEXU); km 56 SE of Tehuacan on the road to Teotitlan del Camino and ca. $2 \mathrm{~km} \mathrm{NW}$ of the Oaxaca border, B. Bartholomew et al. 3132 (MEXU); brecha de Coxcatlán a Coyomeapan, M. Cházaro y B. L. Mostul 7690 (IEB); 3 km al W de San José Tilapa, F. Chiang et al. F-130 (MEXU); Calipan, poblado próximo a Tehuacán, camino a la Sierra, F. Cruz s. n. (MEXU); $3 \mathrm{~km}$ al NE de Teotitlán, P. Dávila 64 (ENCB, UAMIZ); cerca de Tilapa, J. Rzedowski 28161 (ENCB); $3 \mathrm{~km}$ al S de Coxcatlán, J. Rzedowski 53868 (IEB, MEXU); 3 km al SE de San Rafael, J. Rzedowski 53870 


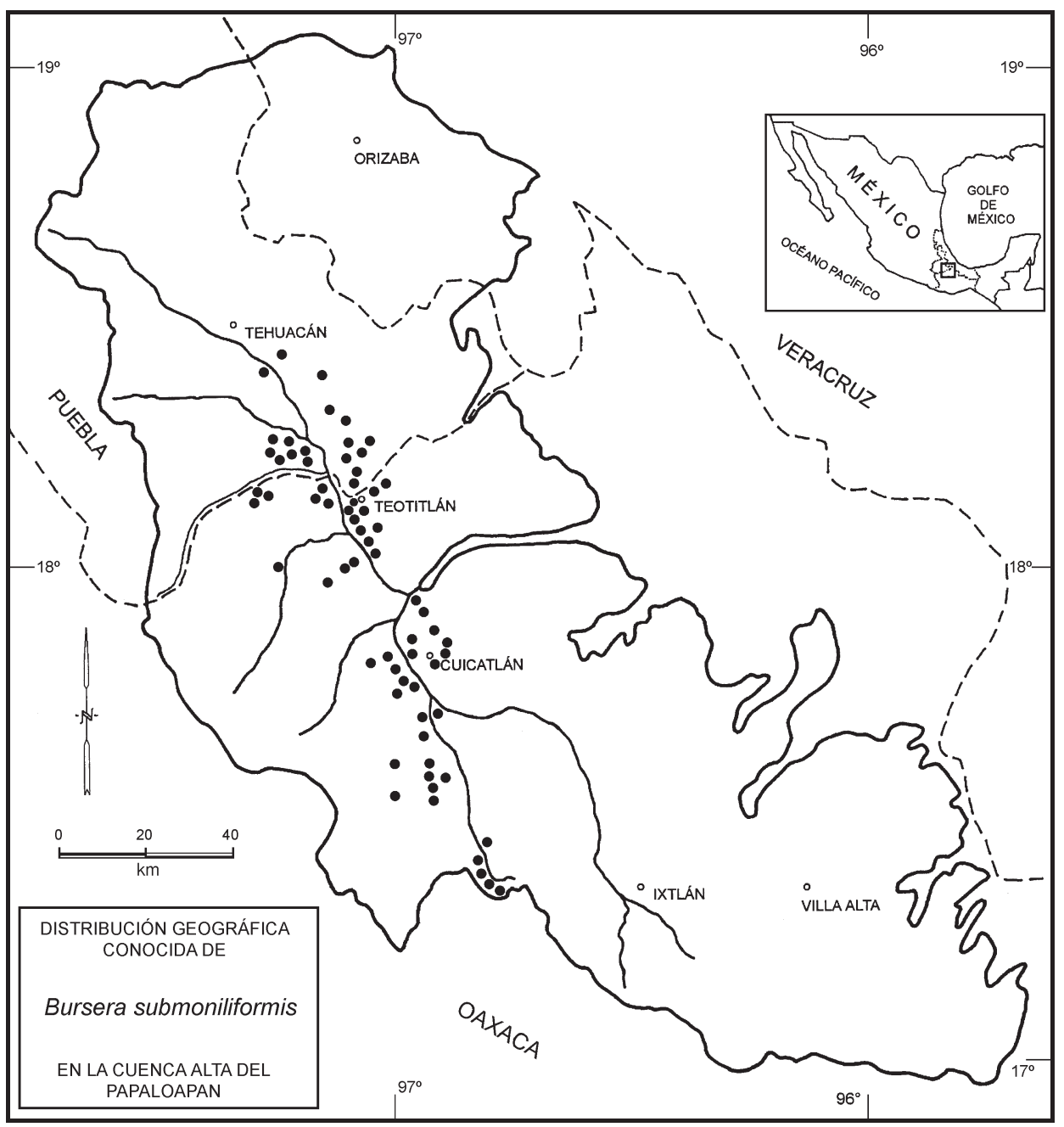

(IEB); near Coxcatlán on Cerro Ajuereado and in the adjacent valley, C. E. Smith Jr. et al. 3615 (MEXU); rancho El Aguaje, $4 \mathrm{~km}$ al $\mathrm{S}$ de la cabecera municipal de Coxcatlán, A. Valiente et al. 6 (MEXU), 130 (MEXU); Tilapa, F. Ventura 15352 (ENCB); Pueblo Nuevo, F. Ventura 15382 (ENCB). Municipio San Gabriel Chilac: terracería a San Juan Atzingo, 18 $19^{\prime} \mathrm{N}, 97^{\circ} 22^{\prime} \mathrm{W}$, R. Medina et al. 1204 (IEB,

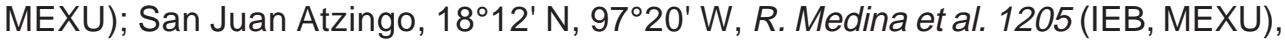
$1207 a$ (MEXU). Municipio San José Miahuatlán: carretera Cuacnopalan - Oaxaca, a $23 \mathrm{~km}$ después de la caseta de Tehuacán - Tetitlán, y entre San Gabriel Chilac y Miahuatlán, J. D. Hernández B-234 (IEB); cerro Tepetroje, $6 \mathrm{~km}$ al SW de Axusco, A. Salinas y P. Solís F-3590 (MEXU); Barranca Seca, al SW de San José Axusco, A. Salinas 7787 (MEXU); Barranca Seca, al SW de Axusco, P. Tenorio y C. Romero 
6906 (IEB, MEXU); cerro Xancantitla, al W de Axusco, P. Tenorio y E. Martínez Correa 17371 (MEXU), 17377 (MEXU). Municipio Tehuacán: cerro Colorado, cerca de San Pablo, F. Ventura 15387 (ENCB). Municipio Zinacatepec: $7 \mathrm{~km}$ al N de Calipan, A. Salinas y C. H. Ramos F-3829 (MEXU); Mazatepec, F. Ventura 15377 (ENCB).

En su protólogo Engler (op. cit., p. 55) hace referencia a los ejemplares de Liebmann procedentes de Rio Vuellas (o más bien Río Vueltas, de acuerdo con la etiqueta), depositados en los herbarios de Copenhague y de París. Los especímenes fueron colectados en mayo, por lo que llevan hojas y flores de desarrollo incipiente, hecho que dificulta un tanto su apropiada ubicación taxonómica. Sin embargo, varios detalles de la pubescencia, de la morfología foliar y floral apuntados por Engler, así como la comparación con plantas colectadas recientemente en estado fenológico similar en los alrededores de la población de Jayacatlán (ubicada en el distrito de Etla, Oaxaca, y en el valle del río de las Vueltas), no dejan duda acerca de la correcta aplicación del nombre a árboles con las características que se señalan en el dibujo y en la descripción que antecede. Es uno de los elementos más comunes del bosque tropical caducifolio de las porciones inferiores del valle de Cuicatlán.

De los dos ejemplares citados por Engler se escoge como lectotipo al depositado en el herbario de Copenhague, en vista de su carácter más completo y mejor estado de conservación, como lo muestra la fotografía correspondiente.

En la región de Jayacatlán la madera de $B$. submoniliformis se extrae para la elaboración de artesanías.

\section{ASPECTOS FITOGEOGRÁFICOS}

En los siguientes cuatro cuadros se resume la información cuantitativa relativa a la diversidad, amplitud de distribución geográfica de las especies y similitud en términos de elementos comunes, definidas para las especies de Bursera de la cuenca del Papaloapan y a nivel comparativo para otras 10 regiones en las que se concentran representantes de este género.

Cabe enfatizar el hecho de que los valores numéricos asignados corresponden al estado actual de conocimiento del grupo y que los futuros avances con seguridad los irán modificando en función de hallazgos de especies adicionales y de algunos cambios en la circunscripción de otras. Aun así, seguirán siendo válidos los principales lineamientos que se esbozan y por consiguiente las bases de las deducciones y conclusiones que a continuación se exponen.

\section{a. Diversidad}

En este apartado, así como en todo el resto de la discusión fitogeográfica, se excluye a $B$. graveolens, pues sólo se ha comprobado la presencia de individuos cultivados de esta planta en el área de estudio. 
Las restantes 20 especies son, al menos mayoritariamente silvestres y el cuadro siguiente compara este guarismo con valores similares conocidos para algunas otras comarcas de México y de América tropical.

\begin{tabular}{lc}
\hline Región & $\begin{array}{c}\text { No. de especies } \\
\text { conocidas }\end{array}$ \\
\hline Cuenca del Balsas & 49 \\
Occidente de México (Jalisco, Colima y Nayarit) & 27 \\
Cuenca del río Tehuantepec y la región istmeña adyacente & 21 \\
Cuenca del Papaloapan & 20 \\
Antillas & 13 \\
Centroamérica & 10 \\
Sonora & 10 \\
Cuenca del Pánuco & 9 \\
Sudamérica & 7 \\
Baja California & 6 \\
Planicie costera de Veracruz & 5 \\
\hline
\end{tabular}

Esta relación revela que, si bien la concentración de especies de Bursera en el área de estudio es significativamente inferior a la de la cuenca del Balsas, compite favorablemente con la de muchas otras comarcas.

b. Amplitud geográfica de las especies

De acuerdo con su distribución global, las 20 entidades reconocidas para la cuenca superior del Papaloapan pueden agruparse en seis categorías, como se señala a continuación.

Tipo de distribución

No. de especies

De repartición geográfica amplia, alcanzando 4 áreas fuera del territorio de México

De repartición que abarca 6 ó 7 estados de la República

De repartición que abarca 3 ó 4 estados de la República

Restringida al estado de Oaxaca

Casi restringidas a la región de estudio

Sólo conocida de la región de estudio

A su vez, a continuación se comparan los números de especies de Bursera de distribución restringida en diferentes comarcas de América tropical. 
Región

No. de especies de distribución restringida

Cuenca del Balsas $\quad 20$

Antillas

Jalisco, Colima y Nayarit

6

Cuenca del río Tehuantepec y región istmeña adyacente

5

Cuenca del Papaloapan

5

Baja California

3

Sudamérica

3

Centroamérica

Cuenca del Pánuco

2

Sonora

1

Planicie costera de Veracruz

0

0

c. Similitud con otras regiones en términos de componentes comunes

Los números de especies de Bursera compartidas con algunas regiones vecinas y otras más lejanas revelan las proporciones ilustradas en el cuadro esbozado en seguida.

Región

No. de especies compartidas con la cuenca del Papaloapan

Cuenca del Balsas

Cuenca del río Tehuantepec y

región istmeña adyacente

Valle de Oaxaca

Cuenca del Pánuco

Planicie costera de Veracruz

Jalisco, Colima y Nayarit

Centroamérica

Sonora

Baja California

Sudamérica

Antillas
16 (del total de 49)

9 (del total de 21)

6 (del total de 6)

5 (del total de 9)

4 (del total de 5)

5 (del total de 28)

3 (del total de 10)

2 (del total de 10)

1 (del total de 6)

1 (del total de 7)

1 (del total de 13)

De los datos arriba presentados pueden definirse varias inferencias de mayor significación.

1. La región de estudio puede considerarse como uno de los principales núcleos de concentración de las especies de Bursera.

2. En términos de abundancia de endemismos la situación es análoga, ya que sólo 
la cuenca del Balsas y las Antillas superan sensiblemente el valor encontrado para la zona es objeto del presente trabajo.

3. De las 20 especies de Bursera propias de la región, 16 (80\%) se comparten con la flora de la cuenca del Balsas, hecho que apoya la hipótesis de que en épocas geológicamente no muy remotas el área formaba parte de esta última.

Al respecto de todo lo anterior, es preciso comentar que ninguna de estas conclusiones es fundamentalmente novedosa y se trata más bien de la confirmación de conocimientos ya existentes 0 al menos insinuados a raíz de las contribuciones de Bullock (op. cit.), de Miranda (1948), de Toledo-Manzur (op. cit.), así como de Kohlmann y Sánchez-Colón (1984).

Bursera tiene una larga historia evolutiva, pues se han encontrado restos fósiles atribuibles a plantas de este género desde el Eoceno (MacGinitie, 1969). De tal suerte, la impresionante diversificación del grupo debe haber tenido lugar a lo largo de la mayor parte del Cenozoico.

En su incisivo análisis de la distribución geográfica de Bursera en el estado de Guerrero, Toledo Manzur (op. cit.) plantea la idea de que las comarcas de particular concentración de las especies y sobre todo de los endemismos, deben haber actuado como áreas de supervivencia en épocas geológicas climáticamente desfavorables para el grueso de las plantas de este género.

Es muy verosímil que la cuenca superior del Papaloapan funcionó como este tipo de refugio. En favor de tal hipótesis cabe agregar la singular ubicación y diversidad ecológicas de la zona. En el mismo sentido se pronuncia también la distribución geográfica disyunta y la vinculación vicariante de varias de las especies, como es el caso de B. cinerea, B. galeottiana, B. hintonii, B. mirandae y B. morelensis.

\section{AGRADECIMIENTOS}

Los autores agradecen a la Maestra Elvia Esparza la elaboración de la mayor parte de los dibujos que ilustran el presente trabajo, al Sr. Juan Sandoval su apoyo en el trabajo de campo y a la Biól. Mirna Ambrosio los datos proporcionados acerca de los usos de las especies de Bursera en la región de estudio. Se dan las gracias asimismo al Bibl. Armando Butanda, al Dr. Douglas Daly y a la Dra. Victoria Noble por su ayuda en la obtención de la información bibliográfica. El Sr. Manuel E. de Santiago, director de la biblioteca "José Ma. Lafragua" de la ciudad de Puebla, facilitó la consulta del herbario histórico bajo su cuidado. Al Dr. Uwe Braun, de la Universidad Martin-Luther de Halle, y a la Dra Victoria Noble, del Museo de Historia Natural de Londres, se les debe reconocimiento por haber puesto a nuestra disposición imágenes de materiales de herbario depositados en sus respectivas colecciones. El M. en C. Emmanuel Pérez Calix preparó el mapa de la cuenca del Papaloapan y el Sr. Felipe Villegas dibujó el que sirvió de base para señalar la distribución geográfica de cada una de las especies reconocidas. El Dr. Victor W. Steinmann tuvo la amabilidad de revisar substancialmente el resumen en inglés. 


\section{LITERATURA CITADA}

Andrés-Hernández, A. R. 2001. Análisis y descripción de estructuras foliares de especies del género Bursera Jacq. ex L. que se distribuyen en la cuenca del río Balsas. Tesis. Facultad de Ciencias. Universidad Nacional Autónoma de México. México, D.F. 86 pp.

Andrés-Hernández, A. R. y D. Espinosa-Organista. 2002. Morfología de plántulas de Bursera Jacq. ex L. (Burseraceae) y sus implicaciones filogenéticas. Bol. Soc. Bot. Méx. 70: $5-12$.

Becerra, J. X. 2003. Evolution of Mexican Bursera (Burseraceae) inferred from ITS, ETS and 5S nuclear ribosomal DNA sequences. Molec. Phylog. Evol. 26: 300-309.

Becerra, J. X. y D. L. Venable. 1999. Nuclear ribosomal DNA phylogeny and its implications for evolutionary trends in Mexican Bursera (Burseraceae). Amer. Journ. Bot. 86: 1047-1057.

Browne, P. 1756. The civil and natural history of Jamaica in three parts. Londres. 503 pp. + 49 láms.

Bullock, A. A. 1936. Notes on the Mexican species of the genus Bursera. Bull. Misc. Inf. Kew 1936: 346-387.

Daly, D. C. 1993. Studies in neotropical Burseraceae. VII. Notes on Bursera in South America. Brittonia 45: 240-246.

De la Cruz, M. 1552. Libellus de medicinalibus indorum herbis. Manuscrito azteca traducido del náhuatl por J. Badiano. 70 pp. 185 figs.

Engler, A. 1883. Burseraceae. DC. Monogr. Phaner. 4: 1-169.

Gillett, J. B. 1979. Commiphora (Burseraceae) in South America and its relationships to Bursera. Kew Bull. 34: 569-589.

Gómez-Vázquez, B. G. y E. M. Engleman. 1984. Bark anatomy of Bursera longipes and Bursera copallifera. IAWA Bull. 5: 325-340.

Hernández, F. 1651. Nova plantarum animalium et mineralium Mexicanorum historia. Roma. $950+90 \mathrm{pp}$.

Hooker, J. D. 1862. Bursera. In: Bentham, G. y J. D. Hooker. Genera plantarum. Londres. vol. 1. p. 324.

Jacquin, N. J. 1760. Enumeratio systematica plantarum. T. Haak. Leiden. 41 pp.

Jacquin, N. J. 1763. Selectarum stirpium americanarum historia. Viena. 284 pp. + 183 láms.

Johnson, M. B. 1992. The genus Bursera in Sonora, Mexico and Arizona, U.S.A. Desert Plants 10: 126-144.

Kohlmann, B. y S. Sánchez-Colón. 1984. Estudio areográfico del género Bursera Jacq. ex L. (Burseraceae) en México: una síntesis de métodos. In: Ezcurra, E. et al. Métodos cuantitativos en la biogeografía. Publicación No. 12. Instituto de Ecología, A.C. México, D.F. pp. 41-120.

Kunth, C. S. 1825. Burseraceae. In: Humboldt, A., A. Bonpland y C. S. Kunth. Nova genera et species plantarum. París. vol. 7. pp. 23-35.

Linnaeus (Linné), C. 1753. Species plantarum. Estocolmo. 2 vols.

Linnaeus (Linné), C. 1762-1763. Species plantarum. 2a. ed. Estocolmo. 2 vols.

Loefling, P. 1758. Iter hispanicum. Estocolmo. $316 \mathrm{pp}$.

Lomas, B. T. C. 1998. Un estudio de la lluvia y la dinámica de la vegetación en el Valle de Tehuacán - Cuicatlán, a través del uso del índice de vegetación NDVI (Normalized difference vegetation index). Tesis. Facultad de Ciencias. Universidad Nacional Autónoma de México. México, D.F. 75 pp.

Ludwig, C. G. 1760. Definitiones generum plantarum. 3a. ed. Leipzig. 516 pp. 
MacGinitie, H. D. 1969. Fossil plants of the Florissant beds, Colorado. Univ. Calif. Publ. Geol. Sci. 83: 1-140.

McVaugh, R. y J. Rzedowski. 1965. Synopsis of the genus Bursera L. in western Mexico, with notes on the material of Bursera collected by Sessé \& Mociño. Kew Bull. 18: 317-382.

Miller, P. 1754. The gardener's dictionary. 4a. ed. abreviada. Londres. vol. 3. p. 435.

Miranda, F. 1947. Estudios sobre la vegetación de México. Rasgos de la vegetación en la cuenca del Río de las Balsas. Rev. Soc. Mex. Hist. Nat. 8: 95-114.

Miranda, F. 1948. Datos sobre la vegetación de la cuenca alta del Papaloapan. An. Inst. Biol. Méx. 19: 333-364.

Ochoa, T. V. 2001. Geomorfología, clima y vegetación del Valle de Tehuacán - Cuicatlán, Pue. - Oax., México. Tesis. Facultad de Ciencias. Universidad Nacional Autónoma de México. México, D.F. 88 pp.

Palacios Chávez, R. 1984. La morfología de los granos de polen de las especies mexicanas de Bursera (Burseraceae). Biotica 9: 153-182.

Rose, J. N. 1906. Restoration of Terebinthus with its species. Contr. U.S. Nat. Herb. 10: 117-123.

Rose, J. N. 1911. Burseraceae. North Amer. FI. 25: 241-261.

Rzedowski, J. y H. Kruse. 1979. Algunas tendencias evolutivas en Bursera (Burseraceae). Taxon 28: 103-116.

Rzedowski, J. y G. Calderón de Rzedowski. 1996. Burseraceae. Flora de Veracruz 94: 137.

Rzedowski, J. y R. Palacios-Chávez. 1984. La presencia de Commiphora (Burseraceae) en México. Taxon 34: 207-210.

Schlechtendal, D. F. L. 1842-1843. Burseraceae. In: De plantis Mexicanis a G. Schiede, M. Dr., Car. Ehrenbergio aliisque, collectis. Linnaea 16: 523-532; 17: 245-253, 625634.

Sloane, H. 1696. Catalogus plantarum quae in insula Jamaica sponte proseniunt. D. Brown. Londres. 232 pp.

Standley, P. C. 1923. Burseraceae. In: Trees and shrubs of Mexico. Contr. U.S. Nat. Herb. 23: $542-552$.

Suárez Ramos, G. y E. M. Engleman. 1982. Resin canals in the bark of Bursera copallifera and Bursera grandifolia. Bol. Soc. Bot. Méx. 42: 41-54.

Toledo Manzur, C. A. 1982. El género Bursera (Burseraceae) en el estado de Guerrero (México). Tesis. Facultad de Ciencias. Universidad Nacional Autónoma de México. México, D.F. 182 pp.

Triana, J. y J. E. Planchon. 1872. Bursera. In: Prodromus florae Novo-Granatensis. Ann. Sci. Nat. 5 sér. 14: 302-304.

Weeks, A. y B. B. Simpson. 2001. The presence of Commiphora (Burseraceae) in the New World confirmed. Botany 2001. Annual meeting. Albuquerque, New Mexico. Abstracts.

Weeks, A. y B. B. Simpson. 2002. Whence the Bursereae (Burseraceae)?: new insights on Burseraceae phylogeny and biogeography based on nuclear and chloroplast sequence data. Botany 2002. Annual meeting. Madison, Wisconsin. Abstracts. p. 157. 


\section{LISTA DE EXSICCATA}

Abascal, J. P. et al. 151(17), 186(2).

Abundiz, L. 810(5), 813(17).

Acosta, S. 2439(12), 2440(4).

Alvarado, L. et al. 128(11), 129(1), 134(12), 146(17), 148(2), 149(6), 173(7), 181(19), 193(21), 196(19), 873(2).

Ambrosio, M. 567(15), 568(21), 571(15).

Ambrosio, M. y B. Brosi 595(21), 596(21), 597(7), 598(21), 601(12), 604(21), 609(21), 610(12), 613(21).

Ambrosio, M. y M. C. León 613(6), 614(6).

Ambrosio, M. et al. 585(21), 586(7), 592(15), 593(15), 594(21), 595(21), 607(21), 608(21), 612(21).

Anderson, W. R. y C. Anderson 5402(2).

Anónimo s. n.(7).

Arroyo, H. 1(10), 2(3), 3(3), 4(3), 6(19), 7(2), 10(2), 13(17), 14(15), 15(2), 16(21), 17(2), 18(19), 19(13), 20(19), 21(21), 22(2), 23(6), 24(17), 25(19), 26(15), 27(10), 30(21), 31(15), 34(17), 35(21), 38a(10), 38b(10), 39(2), 40(21), 41(19), 42(10), 43(6), 44(6), 45(10), 46(21), 47(17), 48(21), 49(2), 50(15), 51(17), 52(2), 53(21), 54(17), 55(2), 56(19), 57(2), 58(7), 59(19), 60(2), 61(19), 62(17), 63(15), 64(2), 65(19), 66(10), 67(21), 68(19), 69(2), 70(7), 71(6), 72(17), 73(8), 74(12), 75(7), 76(6), 80(7), 81(6), 82(6), 83(7), 84(8), 86(6), 110(a)(8), 113(19), 114(7), 115(12), 116(11), 117(15), 118(21), 119(17), 120(17), 121(7), 122(19), 123(11), 124(12), 125(11), 126(12), 127(7), 129(19), 131(12), 132(11), 133(7), 133a(6), 134(2), 135(3), 136(19), 137(11), 138(6), 139(5), 140(3).

Bartholomew, B. et al. 3132(21), 3139(17).

Boege, L. W. 2188(19).

Botteri, M. 912(10), s. n.(3).

Bourgeau, E. 2326(8), 2899(8).

Breckon, G. J. 895(19), 2344(6).

Breckon, G. J. y M. Breckon 712(9).

Breedlove, D. E. y F. Almeda 59822(6), 59823(11).

Calónico, J. 23943(8).

Calónico J. et al. 23906(21), 23978(10), 24078(15).

Calzada, J. I. 5344(6).

Calzada, J. I. y S. Anta 15569(20).

Chavelas, J. y C. Zamora ES-4840(2).

Cházaro, M. y B. L. Mostul 7688(5), 7689(2), 7690(21).

Cházaro, M. et al. 653(2), 686(2), 687(2).

Chiang, F. y M. A. Martínez F-2322(3).

Chiang, F. et al. F-8(6), F-9a(3), F-9b(3), F-51(17), F-54(3), F-58(19), F-76(3), F108(2), F-114(3), F-116(2), F-117bis(11), F-122(2), F-130(21), F-154(2), F162(15), F-163(19), F-326(6), F-333(19), F- 347(3), F-366(3), F-1808(8), F- 
1910(2), F-1916(3), F-1923(3), F- 1986(6), F-2198(21), F-2232(10), F2233(19), F-2373(19), F-2393(6), F-2434(15), F-2435(15), 2476(19), F2483(2), F-2485(2), F-2486(2), F-2495(21), F-2581(6), F-2595(1).

Cochrane, T. S. et al. 8512(2).

Conzatti, C. 1924(12), 2020a(21), 2020b(21), 4027(15), s. n.(11), s. n.(13).

Cook, O. F. y C. B. Doyle 283(7).

Cruz, C. A. y R. García 2(19), 7(17), 17(15), 84(19), 91(7), 320(8).

Cruz, C. A. y E. San Pedro 652(8), 690(19), 693(19), 695(15), 704(10), 820(10), 823(8), 891(19), 904(2), 963(2), 1041(2), 1058(10), 1094(8), 1361(15), 1362(19), 1429(7), 1446(17).

Cruz, C. A. et al. 150(21), 152(17), 153(19), 154(15), 156(19),157(10), 160(17), 164(21), 205(21), 703(17), 814(17), 906(17), 923(10), 1128(10), 1131(19), 1157(2), 1446bis(2).

Cruz, F. s. n.(21).

Cruz, R. 2166(1), 2362(1), 2613(18), 2616(19), 2617(17), 2620(21), 2621(2).

Dávila, P. 62(2), 64(21).

Delgado, A. et al. 62(2), 561(21).

Delpech, N. s. n.(15).

Díaz, G. 7(7).

Dorado, O. y A. Salinas F-2953(6), F-2967(19).

Edmonstone, T. s. n.(13).

Furth, G. D. 97-2(10).

Galeotti, H. 4004(11).

García, A. y D. H. Lorence 1924(10).

García, A. y F. Mérida 2529(1).

García, A. y R. Torres 1598(9).

García, A. et al. 1770(6), 1771(16), 1772(6), 3299(10), 3301(3), 3307(6), 3325(10), $3337(10), 3345(19), 3355(5), 3372(2), 3453(17), 3462(21), 3479(10)$, $3480(19)$.

García, R. 138(8), 232(19), 233(8), 277(19).

Gentry, H. S. 22370(10), 22371(10), 22372(11), 22376(9), 22417(6), 22419(2), 22420(19), 22421(10), 22427(21).

Gentry, H. S. et al. 20237(2).

Gibson, A. C. 3443(2), 3444(17), 3445(19), 3447(3), 3449(17), 3450(6), 3452(2).

Gómez, G. et al. 14(19).

González Medrano, F. et al. F-1101(8), F-1121(17), F-1157(3), F-1160(19), F1161(17), F-1365(19), F-1369(3), F-1448(21), F-1463(2), F-1470(11), F1525(6), F- 1526(21), F-1562(19), F-1595(7), F-1620(2), F-1634(10), F1683(7), F-1699(15), F-1725(7), F-1807(18), 11682(17).

Goudot, J. s. n.(13), s. n.(20).

Guerrero, P. 180(21), 493(17).

Hallberg, B. 980(7), 981(4).

Hernández, J. D. B-231(6), B-232(5), B-234(21), B-236(19). 
Hinton, G. B. et al. 6991(14), 9052(4).

Humboldt, A. y A. Bonpland 1626(13), 4200(10), 4327(4), 4328(12), s. n.(13).

Hunn, E. OAX-326(9).

Jones, M. E. 73(19).

Karwinski, F. W. s. n.(4).

Liebmann, F. M. 76(21), 78(4).

Lira, E. M. et al. 1572(10), 1607(12), 1697(17), 1698(19), 1701(21).

López, M. C. 1(7).

López, R. 951(9).

Lorence, D. H. y A. García 4782(1).

Lucero, R. L-50(7), L-70(17), L-75(19).

Macrae, F. B. s. n.(13).

Martin, G. J. 580(7).

Martínez, E. 21724(11).

Martínez, E. y A. García 21729(10).

Martínez, E. et al. 21746(6).

Mason, C. T. et al. 2964(3), 3018(17), 3019(19), 3020(2), 3022(2), 3024(2), 3026(3), 3027(6).

Medellín, R. et al. 26(3).

Medina, R. et al. 1011(10), 1031(8), 1033(11), 1035(8), 1037(8), 1041(8), 1057(19), 1058(10), 1059(2),1066(11),1067(8), 1068(12), 1069a(21), 1073(8), 1074(15), 1075(7), 1076(8), 1097(21), 1098(17), 1099(17), 1100(2), 1101(2), 1102(19), 1107(10), 1108(10), 1120(7), 1121(12), 1122(7), 1164(1), 1169(5), 1170(12), 1173(11), 1174(1), 1175(1), 1176(1), 1177(12), 1184(1), 1186(10), 1193(10), 1195(6), 1195a(6), 1195b(6), 1197(3), 1199(3), 1200(2), 1201(6), 1202(3), 1204(21), 1204a(5), 1205(21), 1206(10), 1207a(21), 1207b(5), 1211(18), $1211 \mathrm{a}(18), 1212(13), 1221(6), 1222(17), 1223(21), 1224(21), 1225(8)$, 1226(8), 1227(12), 1228(7), 1252(7), 1254(7), 1255(12), 1256(11), 1258(11), $1260(17), 1260 \mathrm{a}(13), 1261(2), 1262(10), 1263(6), 1264(19), 1265(21)$, 1266(10), 1267(6), 1269(15), 1270(15), 1271(21), 1272(2), 1276a(21), $1276 b(8), 1278(18), 1279(18), 1280(7), 1281(8), 1282(20), 1283(20)$, 1284(20), 1285(20).

Meléndez, J. 16(19).

Miranda, F. 1005(15), 3488(6), 3493(3), 3494(6), 4375(3), 4381(10), 4405(6), $4442(19), \quad 4443(10), 4548(2), \quad 4554(21), 4564(15)$ 4591(7), 4633(14), 4639(19).

Nelson, E. W. s. n.(12).

Oliva, H. y F. Ramón HOR-1269(20).

Ortega, R. 972(8).

Panero, J. L. y J. I. Calzada 4035(19), 4046(6).

Pendry, C. A. y A. Reyes 960(21), 969(8), 987(11).

Pérez, G. C-200(8), C-205(7), C-244(8).

Pérez, J. 436(18). 
Pérez, L. A. et al. 1421(3).

Pringle, C. G. 5781(19), 6686(6).

Purpus, C. A. 1293(3), 3159(6), 3161(1), 3162(5), 4052(19), 4065(5), 4066(1), 4068(6), 4069(12), 5708(3).

Ramírez, S. 352(17), 353(19), 366(2).

Rauh, W. 24758(3).

Robles, C. 59(9).

Robles, D. 16(2).

Rodríguez, L. S. y A. Patiño 1394(21), 1395(21), 1396(10), 1397(17), 1398(19), 1399(15), 1400(21), 1401(8), 1402(5), 1404(3), 1405(6).

Romero, N. N 36(8).

Rose, J. N. y J. H. Painter 7534(4).

Rose, J. N. y J. S. Rose 11282(15).

Rose, J. N. et al. 9973(17), 9974(19), 9985(3), 10092(15).

Rzedowski, J. 9013(10), 9014(19), 9016(3), 9017(10), 9018(6), 9021a(17), 9021b(17), 9023(6), 19123(3), 19124(2), 19125(6), 19134(6), 28156(19), 28157(19), 28160(17), 28161(21), 28162(19), 28163(13), 28166(21), 28167(21), 28168(10), 28169(2), 28170(15), 28171(15), 28175(5), 28176(6), 28177(3), 28178(3), 28179(3), 28180(6), 28181(6), 30645(7), 32187(6), 32849(8), 32852(13), 32853(8), 32854(10), 32855(15), 32858(21), 32860(19), 32861(15), 32862(17), 32865(19), 32866(2), 33232(17), 33233(6), 33234(2), 33235(3), 33237(6), 34110(19), 34111(17), 34115(8), 34116(13), 34926(18), 34939(21), 34942(6), 34962(6), 34964(3), 34982(6), 35419(3), 35462(17), 34463(19), 35464(21), 35465(2), 35468(6), 35624(6), 35625(11), 35628(2), 35630(19), 35631(19), 35654(17), 35655(19), 35656(10), 35657(19), 35658(15), 35659(10), 35660(17), 35661(13), 35664(21), 35666(5), 35668(8), 35669(8), 36377(16), 36522(2), 36523(19), 36524(21), 36525(17), 36527(17), 36528(19), 36535(6), 37067(3), 37068(6), 37070(8), 37081(15), 37082a(5), 37082b(5), 38118(13), 53864(6), 53865(6), 53866(5), 53867(2), 53868(21), 53869(19), 53870(21), 53871(3), 53872(17), 53873(17), 53874(15), 53875(6), 53876(10), 53878(14), 53879(14), 53882(7), 53883(7), 53884(12), 53885(9), 53886(9), 53887(9), 53888(9), 53891(6), 53892(6), 53893(6), 53894(6).

Salas, S. H. et. al. 4342(8), 4362(11).

Salinas, A. 4872(2), 6253(8), 7093(6), 7099(17), 7345(7), 7460(7), 7470(15), 7652(6), 7728(10), 7787(21).

Salinas, A. y A. Campos F-3610(6).

Salinas, A. y O. Dorado F-2660(2), F-2266(19), F-2668(10), F-2754(6), F-3083(17), $\mathrm{F}-3084(6)$.

Salinas, A. y G. Flores 4210(10).

Salinas, A. y V. Juárez 6962(19).

Salinas, A. y E. Martínez Correa 6142(10), 6263(12), 6265(11), 6275(19), 7878(6), 8083(17).

Salinas, A. y C. H. Ramos F-3822(17), F-3829(21), F-3844(2). 
Salinas, A. y A. Reyes 4837(10), 4892(3).

Salinas, A. y J. Sánchez Ken 5550(10).

Salinas, A. y P. Solís F-3290(2), F-3578(10), F-3589(3), F-3590(21), F-3599(6), F3602(11).

Salinas, A. y P. Tenorio 5847(6), 5851(18).

Salinas, A. et al. F-3341(6), 4072(10), 4091(2), 4098(5), 4153(15), 4172(19), 4227(2), 4231(5), 4250(21), 4251(2), 4252(19), 4259(17), 4261(10), 4293(6), $4529(19), 4543(6), 4561(19), 4587(18), 4790(2), 4803(19), 4873(19)$, 5720(19), 6591(6), 6681(8), 6749(2), 6780(19), 6836(9), 6930(15), 7206(21), 7253(19), 7710(19), 7720(19), 7831(6).

Salee, E. H. ES-72(2), ES-97(2).

Sánchez Ken, J. et al. 37(17).

Santana, J. et al. 331(1).

Schaffner, J. G. 90(10).

Schibli, L. 84(17), 85(2), 88(19), 88a(21), 109(2), 110(21), 111(17), 112(19), 120(15).

Schiede, C. J. W. 1003(15), 1022(19), s. n.(12).

Seler, C. y E. Seler 3108(7).

Smith, C. E. jr. et al. 3555(3), 3559(6), 3615(21), 3622(5), 3659(19).

Sousa, M. 4648(5).

Spetzman, L. y M. Zapien 1389(3).

Stevens, W. D. y E. Martínez 25199(17), 25202(21), 25205(19), 25209(3).

Tenorio, P. 7269(3), 12048(2), 17039(12), 17042(11), 17365(2), 17526(3), 17551(11), 17552(12), 17753(7), 17766(8), 17908(2), 19158(1), 20065(11), 20448(19), 20601(11), 21292(11).

Tenorio, P. y D. Frame 12076(5), 12132(18).

Tenorio P. y L. Kelly 20154(19), 20163(21), 21294(6).

Tenorio P. y E. Martínez Correa 17371(21), 17374(19), 17377(21), 17389(8), 17390(5), 17391(11), 17392(8), 17403(17), 17404(21), 17416(17), 17774(19), 17929(10).

Tenorio, P. y C. Romero de T. 3913(6), 5006(3), 5937(5), 6818(5), 6823(12), 6906(21), 7627(6), 7742(6), 8933(10), 17344(6).

Tenorio, P. et al. 3719bis(11), 3723(1), 3840(5), 3866(1), 5759(11), 6933(10), 6936(19), 7803(5), 8872(19), 8876(3), 8878(21), 17190(3), 17279(5), 17324(6), 17353(1), 17363(6), 17364(19), 20466(21), 20468(17), 20474(10).

Torres, E. 13(19), 77(21), 103(17), 167(19), 178(7).

Torres, R. y A. García 6796(9).

Torres, R. y M. L. Torres 6931(6).

Torres, R. y J. L. Villaseñor 5057(15).

Torres, R. et al. 9974(21).

Trejo, I. 1254(6), 1585(17), 1586(2), 1601(19), 1655(10), 1660(2), 1664(15), $1668(15)$.

Valiente, A. 154(2), 925(6).

Valiente, A. y P. Díaz-Maeda 714(19). 
Valiente, A. et al. 6(21), 115(17), 130(21), 144(17), 313(3), 347(6), 352(6), 371(2), 410(5), 413(6), 428(11), 430(5), 485(6), 492(3), 500(2), 553(19), 812(10), $892(3)$.

Vázquez, V. 394(20).

Vázquez, V. y M. Cházaro 685(17).

Ventura, F. 15242(6), 15245(6), 15248(11), 15250(6), 15251(11), 15252(6), 15253(6), 15254(11), 15257(2), 15259(10), 15260(19), 15261(2), 15262(6), 15263(6), 15265(17), 15266(2), 15267(6), 15268(2), 15269(17), 15270(17), 15271(6), 15272(6), 15273(2), 15274(17), 15275(17), 15276(19), 15277(2), 15278(2), 15279a(6), 15279b(6), 15280(2), 15282(6), 15283(3), 15284(17), 15285(6), 15286(2), 15287(3), 15288(2), 15289(2), 15289a(6), 15290(6), 15291(10), 15292(11), 15293(6), 15294(6), 15295(2), 15296(15), 15297(19), 15298(10), 15299(19), 15300(17), 15301(21), 15303(6), 15304(19), 15305(8), 15306(18), 15307(6), 15308(17), 15309(6), 15310(6), 15311(2), 15312(19), 15314(2), 15316(21), 15317(2), 15318(10), 15319(21), 15320(15), 15321(10), 15322(17), 15323(2), 15324(19), 15325(21), 15326(2), 15327(6), 15330(15), 15331(19), 15332(19), 15333(21), 15335(10), 15336(2), 15337(3), 15338(3), 15339(21), 15340(15), 15341(2), 15342(19), 15343(17), 15344(2), 15345(17), 15346(21), 15347(19), 15348(6), 15349(10), 15350(2), 15351(17), 15352(21), 15353(2), 15354(19), 15355(21), 15356(15), 15357(2), 15358(17), 15359(2), 15360(13), 15361(19), 15362(17), 15363(2), 15364(2), 15365(10), 15366(17), 15367(3), 15369(2), 15270(17), 15371(21), 15372(2), 15375(19), 15376(2), 15377(21), 15378(17), 15379(2), 15380(2), 15381(19), 15382(21), 15383(19), 15384(19), 15385(2), 15387(21), 15388(2), 15389(3), 15390(6), 15392(19), 15394(10), 15395(1), 15396(10), 15402(1), 15457(19), 15458(12), 15459(9), 15460(7), 15461(11), 15462(12), 15463(19), 15465(21), 15466(6), 15467(8), 15468(7), 15469(19), 15470(17), 15471(10), 15472(16), 15473(6), 15546(7), 15551(7), 15561(7), 15563(7), 16106(7), 16361(6), 16361a(7), 16362(10), 16364(6), 16365(7), 16425(10), 16426(15), 16427(21), 16428(17), 16429(19), 16431(15), 16432(19), 16433(17), 16434(2), 16435(2), 16436(21), 16437(10), 16438(2), 16439(17), 16440(19), 16441(21).

Webster, G. L. et al. 17201(17), 17305(6), 17306(19), 20098(19), 20103(6).

Webster, G. L. y S. Lynch 17242(19), 17244(10).

Zamudio, S. y E. Pérez 9167(15), 9168(19). 


\section{ÍNDICE ALFABÉTICO DE NOMBRES DE PLANTAS}

aceitilla, 97

aceitillo, 83, 97, 121

Amiris linaloe, 107

A. linaloé, 103

A. linanoe, 107

A. linanoé, 103

A. ventricosa, 81

Amyris, 30

A. bipinnata, 67

A. fagaroides, 81

azafrán, 97

Boswellia, 31

breo, 87

Bursera, 23, 24, 25, 28, 29, 30, $31,32,33,34,35,43,52$, $60,66,86,119,136,137$, 138,139

B. aloexylon, 94, 103, 107

B. altijuga, 35, 36, 38, 39, 41, $42,43,119$

B. aptera, 35, 36, 43, 44, 47, 48

B. arida, 36, 49, 50, 52, 53, 116

B. ariensis, 35, 36, 53, 54, 55, 56

B. aspleniifolia, $36,38,56,57$, 59,60

B. biflora, 35, 36, 37, 42, 43, $60,61,65,66$

B. bipinnata, 37, 67, 68, 69, 71, 72

B. bipinnata var. ovalifolia, 67

B. bonetii, 119

B. brachypoda, 53

B. cinerea, $36,72,73,76,77$,
139

B. copallifera, $31,36,60$

B. delpechiana, 103, 107, 108

B. elemifera, 67,72

B. esparzae, 35, 37, 77, 78, 80, 81, 119

B. excelsa, 29, 81

B. fagaroides, 29, 35, 36, 45, $48,55,81,82,85,86$,

B. fagaroides var. fagaroides, 87

B. fagaroides var. purpusii, 87

B. fragrantissima, 119

B. galeottiana, 36, 53, 87, 88, 89, 90, 139

B. glabrifolia, 38, 42, 91, 92, 94, 95, 108

B. gracilis, 67,72

B. grandifolia, 31, 36, 77

B. graveolens, 35, 37, 72, 99, 136

B. graveolens var. graveolens, 95, 96, 98

B. gummifera, 33, 35, 126, 127

B. gummifera var. pubescens, 74,77

B. heliae, 42

B. hindsiana, 36

B. hintonii, 35, 38, 99, 100, 102, 139

B. integerrima, 127

B. jonesii, 121

B. laxiflora, 36

B. leptophloeos, 31

B. linanoe, 35, 37, 38, 94, 95, 103, 104, 106, 107, 108 
Rzedowski et al.: Las especies de Bursera de la cuenca del río Papaloapan, México

B. longipedunculata, 103

B. longipes, 31

B. microphylla, 36

B. mirandae, 35, 37, 108, 109, $110,119,139$

B. morelensis, 35, 36, 45, 53, $90,111,112,115,116,139$

B. nelsonii, 91,94

B. obovata, 83

B. odorata, 36

B. ovalifolia, 77, 129

B. aff. palmeri, 81

B. pannosa, 53

B. penicillata, 94, 99, 108

B. pontiveteris, $35,36,37,43$, 116, 117, 119, 120

B. pubescens, 95

B. sarcopoda, 31, 32

B. schaffneri, 83

B. schiedeana, 91,94

B. schlechtendalii, 35, 36, 45, 121, 122, 126

B. Secc. Bullockia, 31, 32, 42, 66, 81, 119

B. Secc. Bursera, 31, 32

B. sessiliflora, 53, 55

B. sessiliflora var. pubivalvis, 53

B. simaruba, 28, 29, 32, 33, 35, $36,77,126,128,129,130$

B. simplicifolia, 121

B. Subgén. Bursera, 30

B. Subgén. Elaphrium, 30

B. Subgén. Icica, 30

B. Subgén. Marignia, 30

B. submoniliformis, 35, 37, 130, 132, 135, 136

B. subpubescens, 74

B. suntui, 36,116
B. tatamaco, 97

B. tecomaca, 31, 32

B. vejar-vazquezii, 81, 102, 119

B. verapacensis, 67

Burseraceae, 23, 30, 32, 33

Burseria, 33, 34

B. gummifera, 33, 127

cabrestillo, 49

camarón, 74

camaroncillo, 74

chaca, 127

chakaj, 127

Commiphora, 31, 32

copal, 31, 38, 53, 56, 60, 67, 77, $83,87,91,99,108,116$, 121,131

copal amargo, 67

copal amargoso, 67

copal amarillo, 53

copal blanco, 53, 91

copal chino, 67

copal chino colorado, 67

copal grande, 53

copal hembra, 91

copal manso, 99

copal mulato, 87

copal negro, 67, 121

copal santo, 67, 108

copal virgen, 67

copalcahuic, 131

copali, 60

copalillo, 38, 43, 53, 56, 67, 74, $91,103,111,116,131$

copalillo blanco, 131

coxinyotl iztac, 43

coyoluche, 97

coyoluxi, 97 
cuachital, 43

cuajiote, 31, 32, 43, 53, 83, 111

cuajiote amarillo, 43, 83

cuajiote blanco, 43, 53, 83

cuajiote colorado, 83, 87

cuajiote rojo, $74,87,111$

cuajiote verde, 43

Elaphrium, 30, 31, 33, 34

E. aloëxylon, 103

E. apterum, 43

E. aridum, 49

E. ariense, 53, 55

E. aspleniifolium, 56

E. biflorum, 60

E. bipinnatum, 67

E. brachypodum, 53

E. cinereum, 72

E. delpechianum, 103

E. elemiferum, 67, 72

E. fagaroides, 81

E. galeottianum, 87

E. glabrum, 33

E. glabrifolium, 91

E. gracile, 67

E. graveolens, 95

E. integerrimum, 127

E. jonesii, 121

E. longipedunculatum, 103, 108

E. morelense, 111

E. nelsonii, 91

E. obovatum, 83

E. ovalifolium, 129

E. pannosum, 53

E. pubescens, 95, 99

E. schaffneri, 83

E. schiedeanum, 91
E. sessiliflorum, 53

E. simaruba, 126

E. simplicifolium, 121

E. submoniliforme, 130

E. subpubescens, 74, 77

E. tatamaco, 97

E. tomentosum, 33

Fagara, 30

gomilla, 97

guande, 53

guande blanco, 53

Icica, 30

inanué, 103

incienso, 67

jaboncillo del país, 67

jiote, 83, 127

linaloe, 103

linaloé, 103, 108

linalué, 103

linanoé, 103

mata perro, 53

mizquixochicopalli, 97

mulatillo amarillo, 60

mulato, 32, 74, 127

mulato rojo, 121

nabanché, 97

palo colorado, 111

palo de brujo, 97

palo del diablo, 83

palo hediondo, 97

palo mulato, 74, 111, 127

papelillo, 53, 83

Pistacia, 30, 34

P. simaruba, 32, 33, 34, 126

Quercus, 89

sarzafrás, 83 
sasafrás, 97

Schinus, 30

S. angustifolius, 87,90

S. occidentalis, 83

Simarouba, 32, 34

Simaruba, 32, 34

Spondias, 30

S. edmonstonei, 97 tecomaca, 131

Terebinthus, 30, 32, 33, 34

T. aloexylon, 103

T. aptera, 43

T. arida, 49

T. biflora, 60

T. bipinnata, 67

T. brownii, 33, 127

T. cinerea, 72

T. delpechiana, 103

T. fagaroides, 81

T. galeottiana, 87

T. gracilis, 67

T. graveolens, 95

T. jonesii, 121

T. morelensis, 111
T. nelsonii, 91

T. pannosa, 53

T. pubescens, 95

T. schaffneri, 83

T. schiedeana, 91

T. schlechtendalii, 121

T. sessiliflora, 53

T. simaruba, 126

T. submoniliformis, 130

tetlate, 67

tetlatín, 67

tetlatlán, 67

thi-un, 127

tzaca, 127

tzihuaccopalli, 29

ulinalué, 103

ulinoé, 103

xiote colorado, 87

xixote, 83, 87, 111

xixote colorado, 87

xochicopal, 103

yàg-yàal, 77

yah yal, 67

zapotillo, 49 